\title{
Funktionelle Analyse des Transkriptionsfaktors TGA2.1 aus Nicotiana tabacum: Identifikation von Interaktionspartnern und Charakterisierung transgener Pflanzen mit reduzierter TGA2.1-Menge
}

\author{
Dissertation \\ Zur Erlangung des Doktorgrades \\ der Mathematisch-Naturwissenschaftlichen Fakultäten \\ der Georg-August-Universität zu Göttingen
}

vorgelegt von

Stefanie Ursula Krawczyk

aus Bielefeld

Göttingen 2003 
D7

Referent: $\quad$ Prof. Dr. C. Gatz

Korreferent: PD Dr. G. Hinz

Tag der mündlichen Prüfung: 05. November 2003 


\section{Inhaltsverzeichnis}

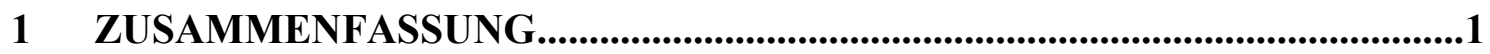

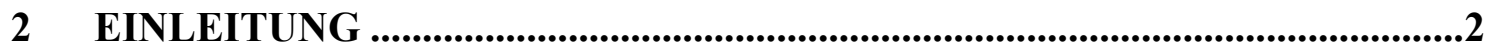

2.1 AbweHrmechanismen von PfLANZEN GEgenÜBer Pathogenen...................2

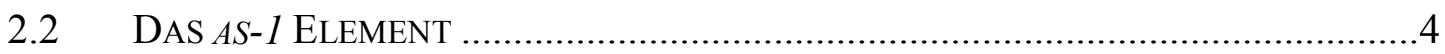

2.3 DIE FAMILIE DER TGA-FAKTOREN …......................................................

2.4 FrageStELLUNG UND EXPERIMENTELLE ANSÄTZE DIESER ARBEIT .................13

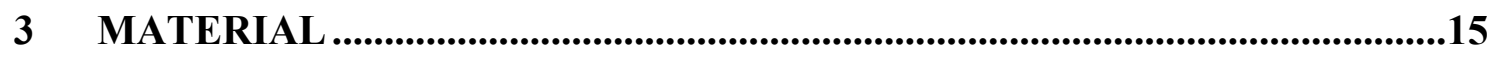

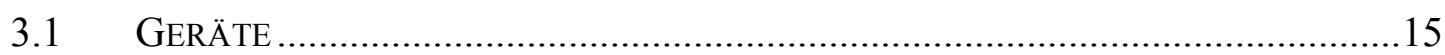

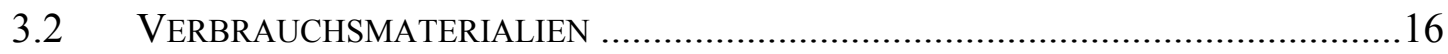

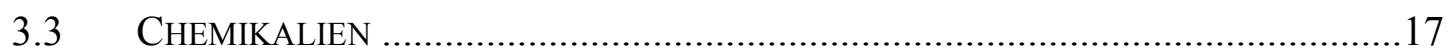

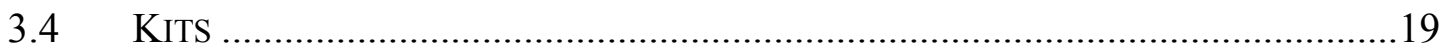

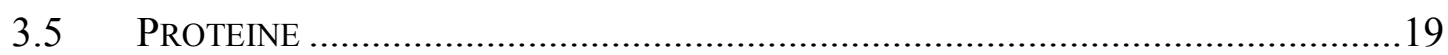

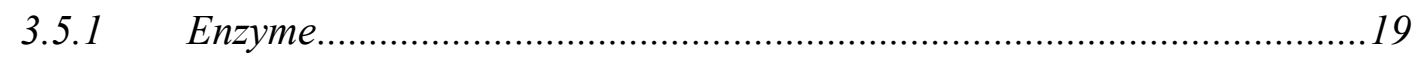

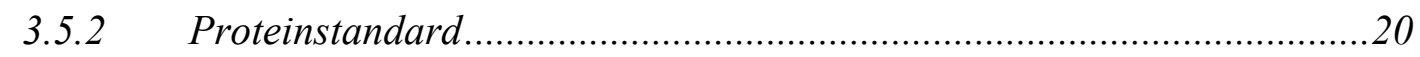

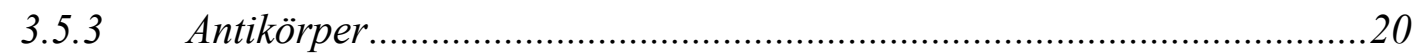

3.5.4 E. coli-Extrakte mit rekombinant exprimiertem TGA-Faktor .................20

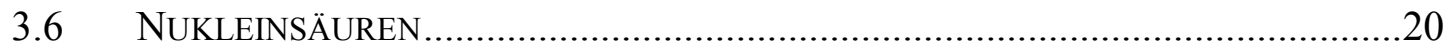

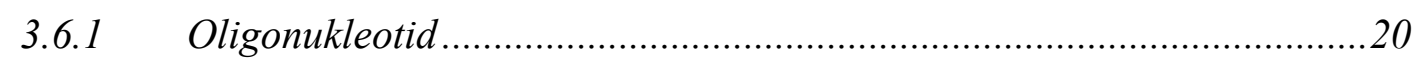

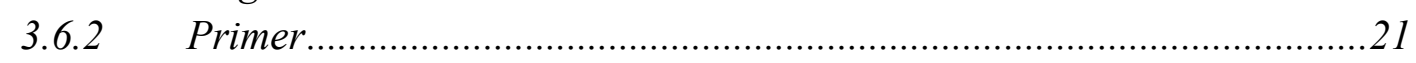

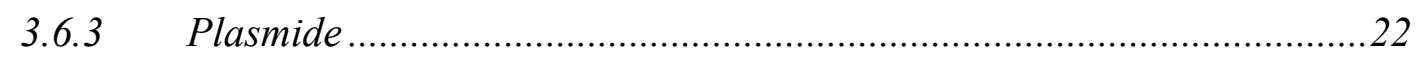

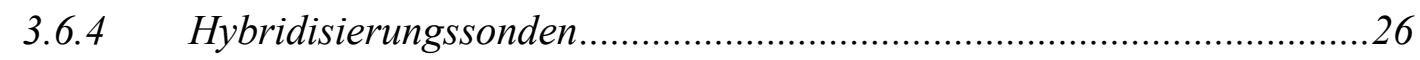

3.6.5 DNA-Fragmente für Gelretardationsanalysen......................................26

3.6.6 DNA-Fragmentlängenstandard .........................................................27

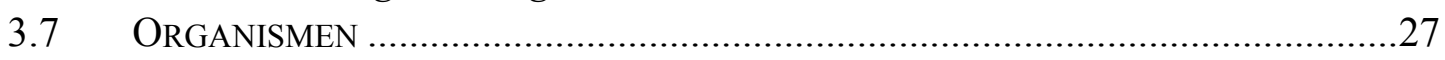

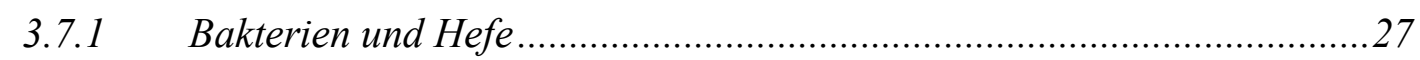

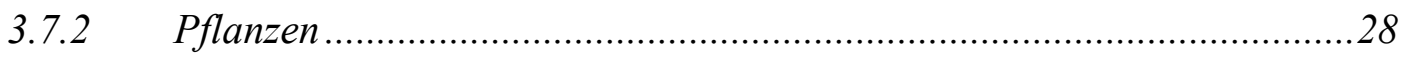

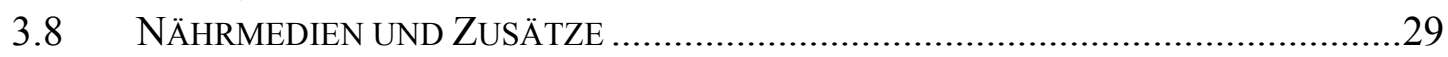

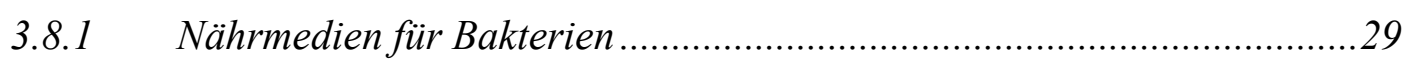

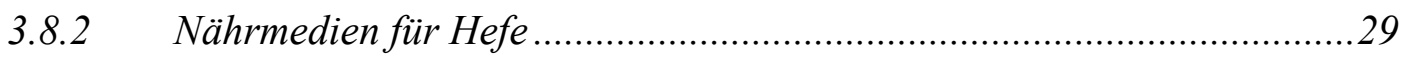

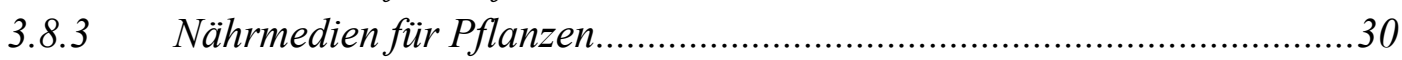

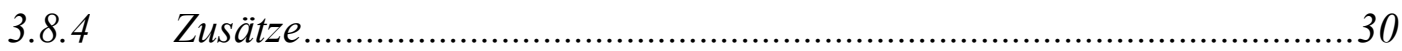

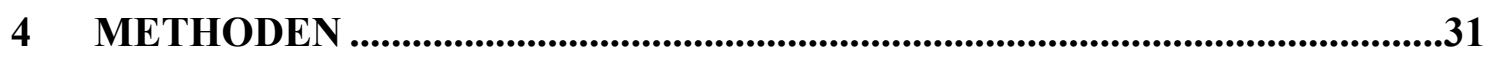

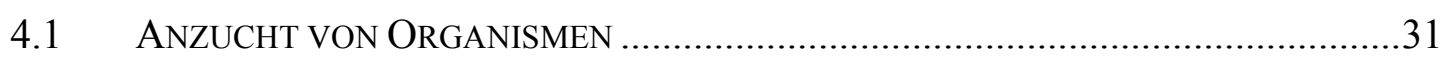

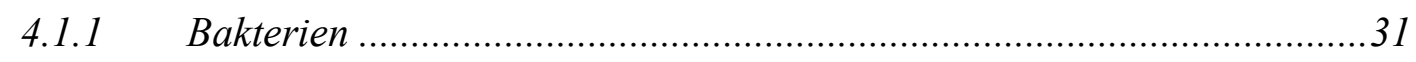

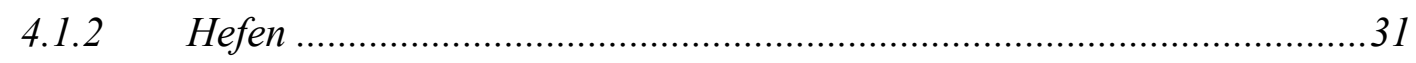




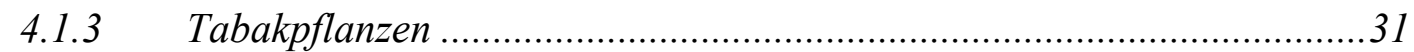

4.2 INDUKTION DER GENEXPRESSION IN TABAKPFLANZEN …................................. 31

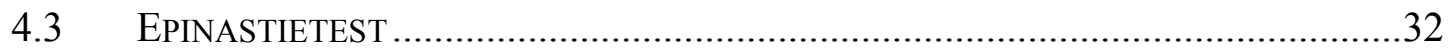

4.4 INFEKTION VON TABAKPFLANZEN MIT DEM TABAK-MOSAIK-VIRUS (TMV) ...32

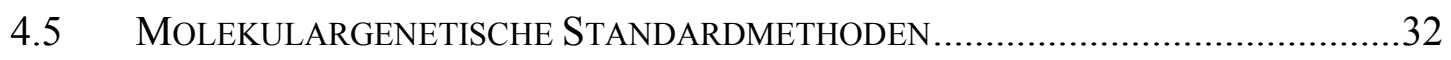

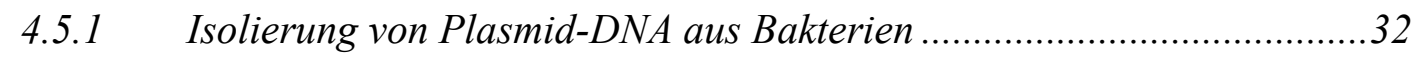

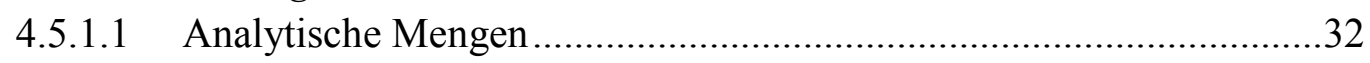

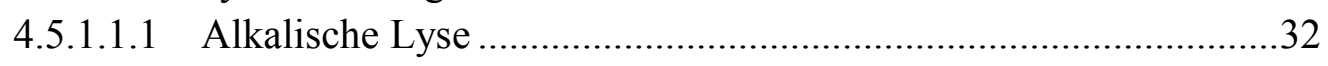

4.5.1.1.2 Plasmidisolation mit dem QIAprep Spin Miniprep-Kit .................33

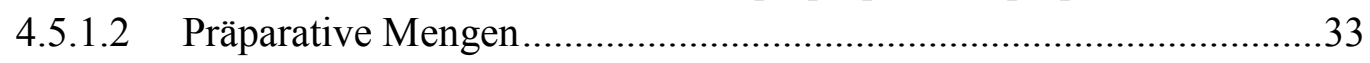

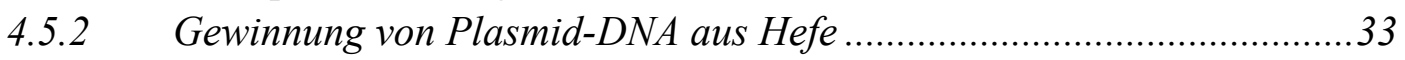

4.5.3 Ethanolfällung von Nukleinsäuren aus wässrigen Lösungen...................33

4.5.4 Isolierung von RNA aus Nicotiana tabacum ..........................................33

4.5.5 Konzentration- und Reinheitsbestimmung von Nukleinsäuren .................34

4.5.6 Gelelektrophorese von Nukleinsäuren ...................................................... 34

4.5.6.1 Auftrennung von DNA in Agarosegelen...............................................34

4.5.6.2 Auftrennung von DNA in Polyacrylamidgelen .................................34

4.5.6.3 Auftrennung von RNA in denaturierenden Agarosegelen ....................35

4.5.7 Elution von DNA-Fragmenten aus Elektrophoresegelen .........................35

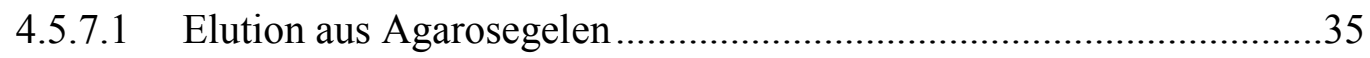

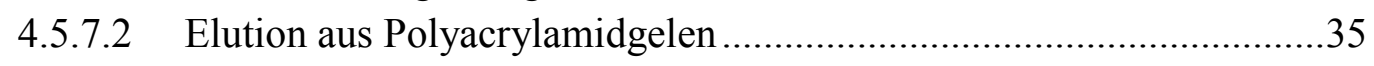

4.5.8 Hybridisierung von einzelsträngigen Oligonukleotiden zu Doppelsträngen 35

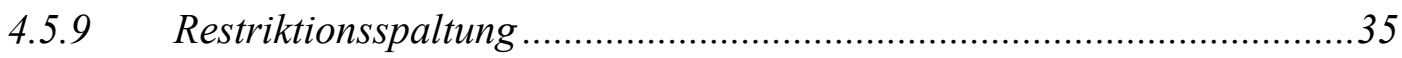

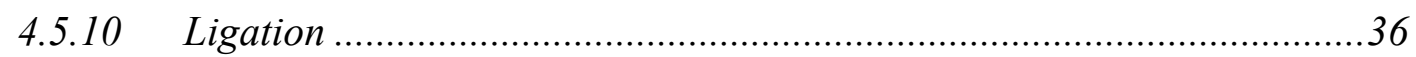

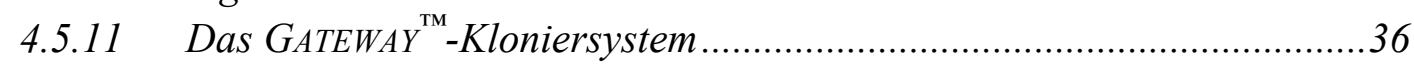

4.5.11.1 Die Aufreinigung von GATEWAYTM_PCR-Produkten........................37

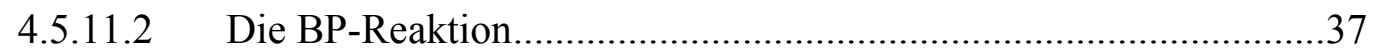

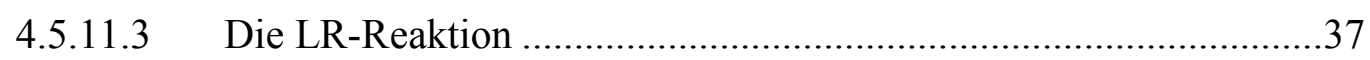

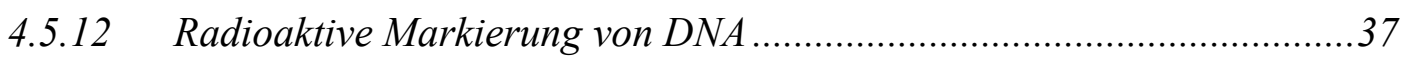

4.5.12.1 DNA-Fragmente für Gelretardationsanalysen.................................37

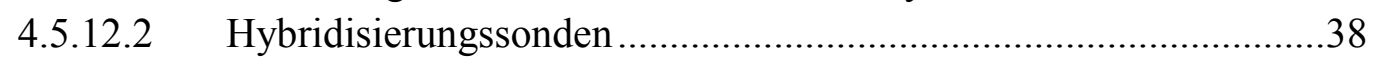

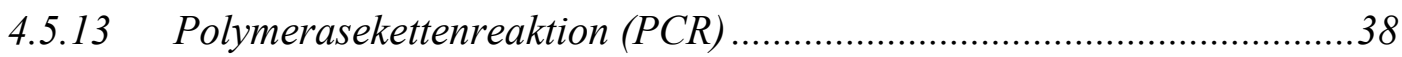

4.5.13.1 PCR zu Charakterisierung rekombinanter Klone............................39

4.5.13.2 Klonierung von PCR-Produkten ......................................................39

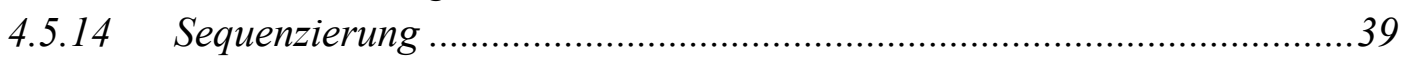

4.5.15 Transformation kompetenter Bakterienzellen ........................................40

4.5.15.1 Herstellung kompetenter E. coli-Zellen ........................................40

4.5.15.2 Transformation von $E$. coli .........................................................40

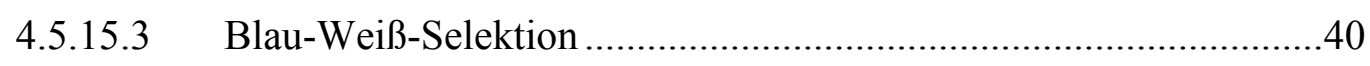

4.5.15.4 Herstellung kompetenter Agrobakterien .........................................4

4.5.15.5 Transformation von Agrobacterium tumefaciens ............................41

4.5.16 Gentransfer in Saccharomyces cerevisiae ............................................41 
4.5.16.1 Herstellung kompetenter Hefezellen ...............................................41

4.5.16.2 Transformation von Hefezellen.......................................................4

4.5.17 Stabile Transformation von Nicotiana tabacum .....................................42

4.5.18 Northern-Blot-Analyse ....................................................................42

4.5.18.1 Transfer der RNA auf Nylonmembranen .......................................42

4.5.18.2 Hybridisierung der Northern-Blot-Membran .................................42

4.5.18.3 Waschen der Northern-Blot-Membran.........................................4

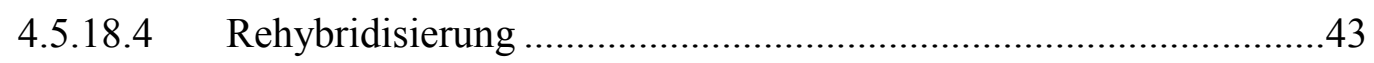

4.6 KONSTRUKTION DER VERWENDETEN PLASMIDE...............................................43

4.6.1 Plasmide für die Expression von Proteinen in Hefe.................................43

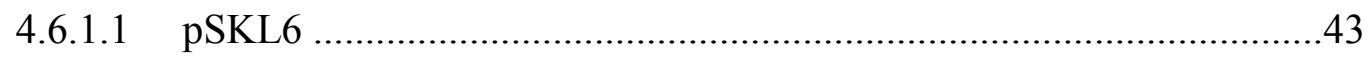

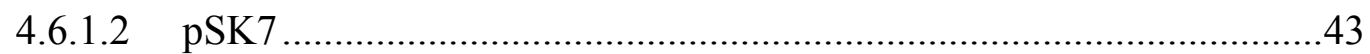

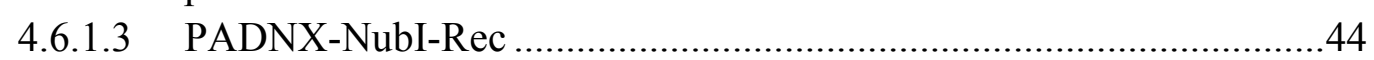

4.6.1.4 PADNX-NubI-117, PADNX-NubI-175, PADNX-NubI-184 .............44

4.6.1.5 pGAD117 und pGBT117 ................................................................44

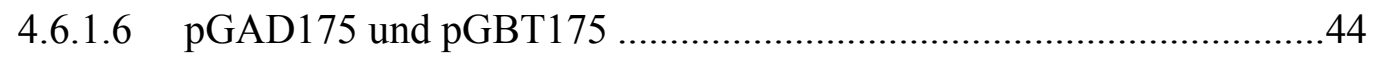

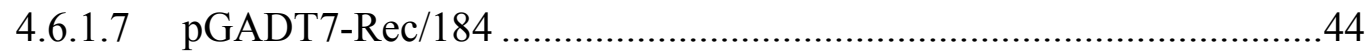

4.6.1.8 pGAD184 und pGBT184 ................................................................44

4.6.2 Binäre Plasmide für die stabile Pflanzentransformation von Nicotiana

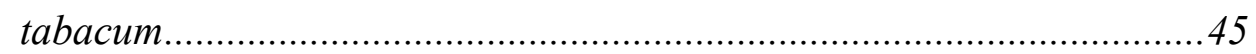

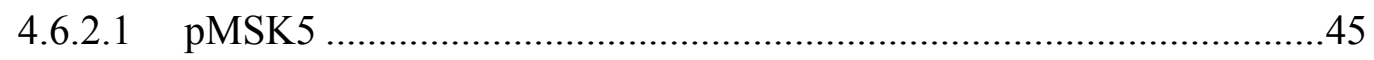

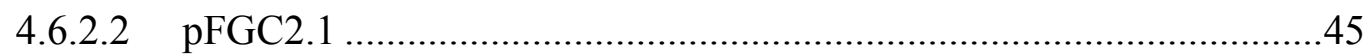

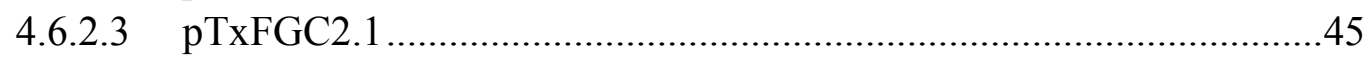

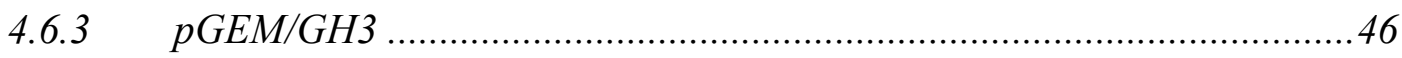

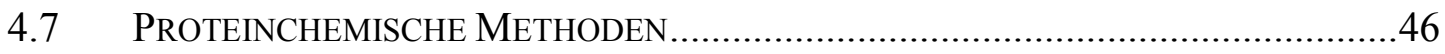

4.7.1 Proteinextraktion aus Hefezellen .............................................................46

4.7.2 Denaturierte Gesamtzellextrakte aus Tabakblättern .............................46

4.7.3 Native Gesamtzellextrakte aus Tabakblättern.........................................46

4.7.4 Kernproteinextrakte.........................................................................4 47

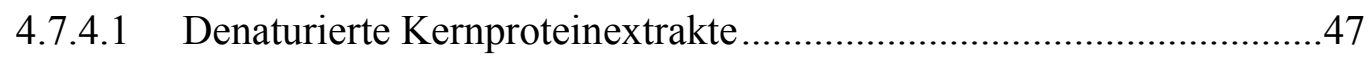

4.7.4.2 Native Kernproteinextrakte ..............................................................4

4.7.5 Konzentrationsbestimmung von Proteinextrakten...................................48

4.7.6 Affinitätsaufreinigung des Antiserums ...................................................48

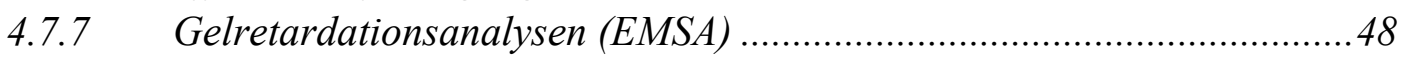

4.7.8 Diskontinuierliche SDS-Polyacrylamid-Gelelektrophorese.....................49

4.7.9 Färbung von Proteinen in SDS-Polyacrylamidgelen ..............................50

4.7.10 Immunoblotting (Western-Blot-Analyse)................................................50

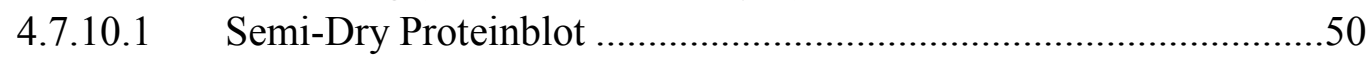

4.7.10.2 Immunologische Detektion geblotteter Proteine ...........................50

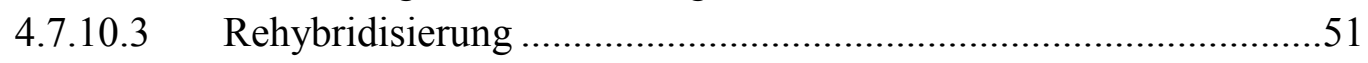

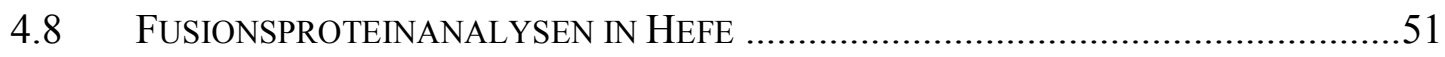

4.8.1 Herstellung einer cDNA-Bank mittels SMART-Technologie ...................52

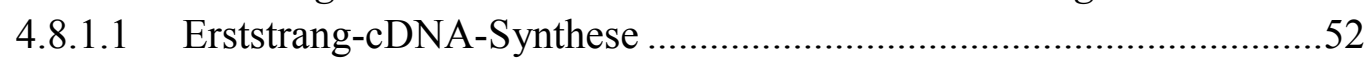


4.8.1.2 Amplifikation der ds cDNA über long distance PCR .........................53

4.8.1.3 Aufreinigung der ds cDNA ...............................................................53

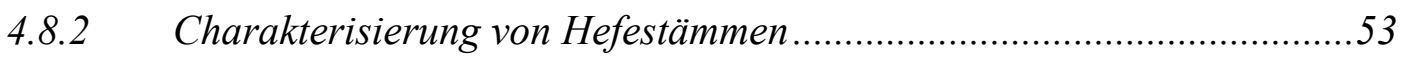

4.8.3 Toxizitätstest des verwendeten Köderproteins ........................................54

4.8.4 Präparation ultrakompetenter Hefezellen ...............................................54

4.8.5 Herstellung und Screening einer Nub-Fusionsbank ...............................54

4.8.5.1 Bestimmung der Transformationseffizienz .........................................55

4.8.6 Qualitativer Test einer Protein-Protein-Interaktion ...............................55

4.8.6.1 USPS-System („Ubiquitin-based split-protein sensor system“) .........55

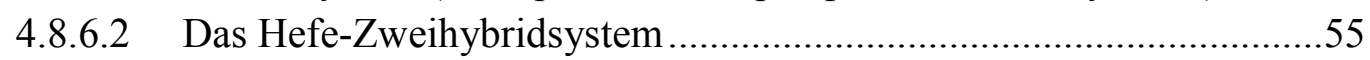

4.8.6.3 Das modifizierte „One-Hybrid“-System ............................................56

4.8.7 Verwendete Computerprogramme zur Suche nach homologen DNA-

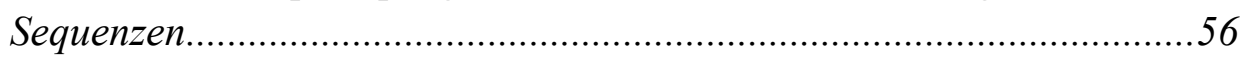

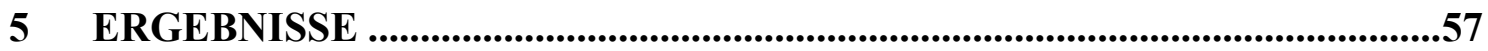

5.1 IDENTIFIKATION VON PROTEIN-INTERAKTIONSPARTNERN DES BZIP-

TRANSKRIPTIONSFAKTORS TGA2.1 MIT HILFE DES „UBIQUITIN-BASED SPLIT-

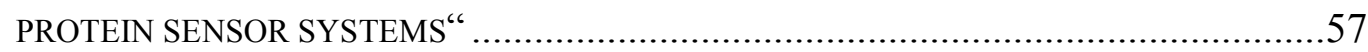

5.1.1 Das ,,Ubiquitin-based split-protein sensor system “.............................57

5.1.1.1 Charakteristika des „Ubiquitin-based split-protein sensor systems“ ..57

5.1.1.2 Etablierung des USPS für den pflanzlichen Transkriptionsfaktor

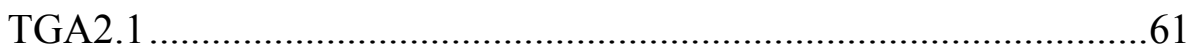

5.1.2 Herstellung einer cDNA-Bank aus Nicotiana tabacum ........................67

5.1.2.1 Isolierung der mRNA ................................................................67

5.1.2.2 Herstellung einer cDNA-Expressionsbank ........................................68

5.1.3 Analyse der primär positiven cDNA-Klone .............................................73

5.1.4 Analyse der sekundär positiven Klone .............................................8 80

5.1.5 Charakterisierung der Klone 117-1, 172-16, 175-1 und 184-1 .............81

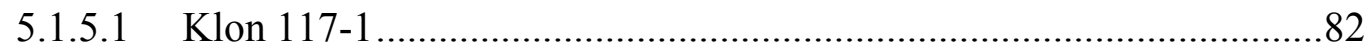

5.1.5.2 Klon 172-16 und Klon 175-1 …....................................................84

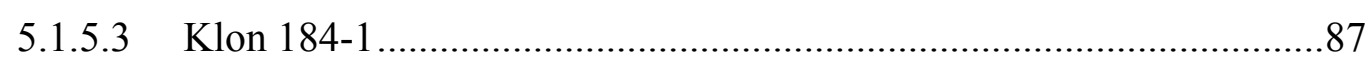

5.1.6 Testen der Interaktion der Klone mit TGA2.1 im Hefe-

Zweihybridsystem........................................................................89

5.1.7 Testen der Interaktion von Klon 184-1 mit TGA2.1 im modifizierten

„,One-Hybrid"-System..................................................................93

5.1.8 Zusammenfassung der Klonanalysen .................................................95

5.2 FUNKTIONSANALYSE DES BZIP-TRANSKRIPTIONSFAKTORS TGA2.1 IN

TRANSGENEN TABAKPFLANZEN.......................................................................96

5.2.1 Inhibierung der Nttga2.1-Genexpression durch RNAi in transgenen

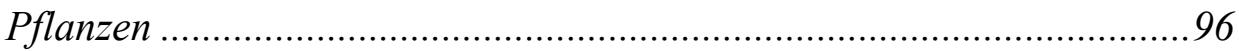

5.2.1.1 Herstellung der transgenen tga2.1RNAi-Pflanzen unter Verwendung des

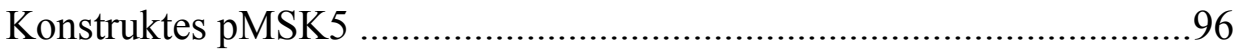

5.2.1.2 Herstellung der transgenen tga2.1RNAi-Pflanzen unter Verwendung des

Konstruktes pFGC2.1 
5.2.2 Phänotypische Veränderungen der tga2.1RNAi-Pflanzen

5.2.3 Northern-Blot-Analyse auxininduzierbarer Gene in tga2.1RNAi-

Pflanzen

5.2.4 Analyse der Auxinresponsivität von tga2.1RNAi-Pflanzen .

5.2.5 Northern-Blot-Analyse salicylsäureinduzierbarer Gene in tga2.1RNAiPflanzen

5.2.6 Analyse der Abwehrreaktion der tga2.1RNAi-Pflanze \#2 nach einer TMVInfektion

\section{DISKUSSION}

6.1 VERWENDUNG DES „UBIQUITIN-BASED SPLIT-PROTEIN SENSOR SYSTEMS“ ZUR DURCHMUSTERUNG EINER CDNA-BANK

6.2 IDENTIFIZIERUNG EINER DEAD-BOX-RNA-HELICASE UND EINER E2-LIGASE ALS POTENTIELLE INTERAKTIONSPARTNER DES BZIP-TRANSKRIP-TIONSFAKTORS

TGA2.1 MIT HILFE DES „UBIQUITIN-BASED SPLIT-PROTEIN SENSOR SYSTEM“ “..119

6.3 StABILITÄT DES RNAI-EFFEKTES IN TRANSGENEN PFLANZEN.

6.4 AUSWIRKUNG DER REDUZIERTER TGA2.1-MENGEN AUF DIE EXPRESSION VON NT103 UND PR1A

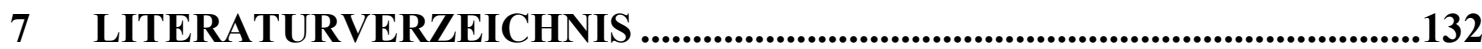

8 ANHANG

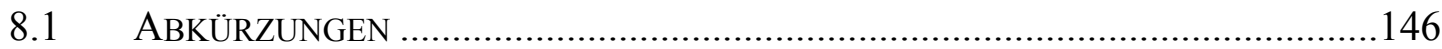

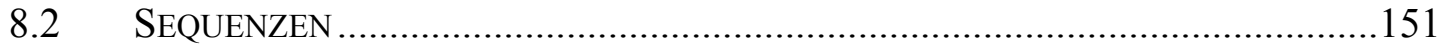

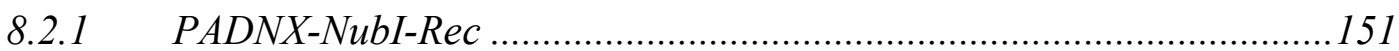

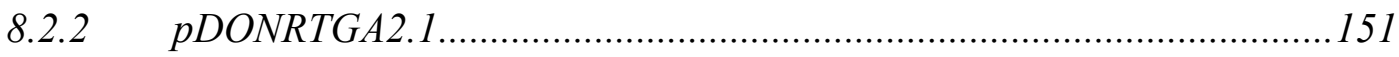

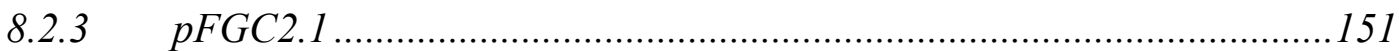

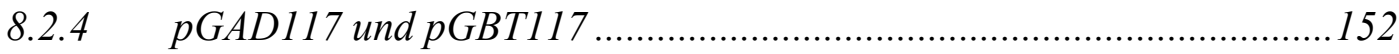

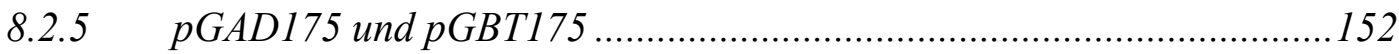

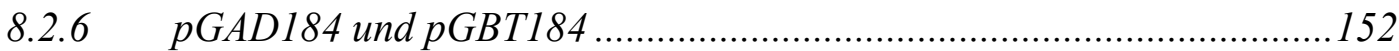

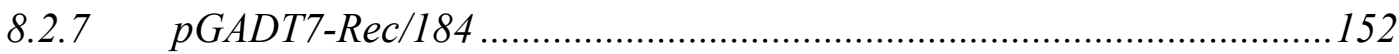

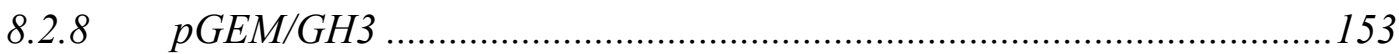

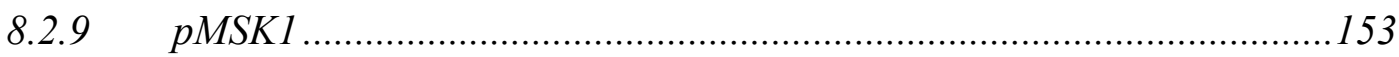

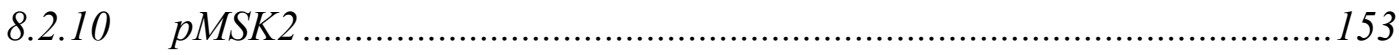

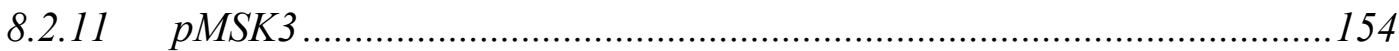

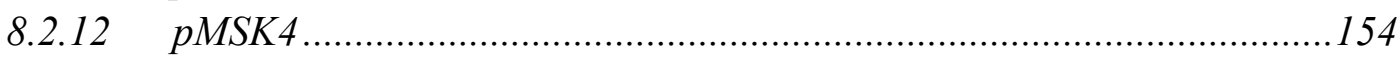

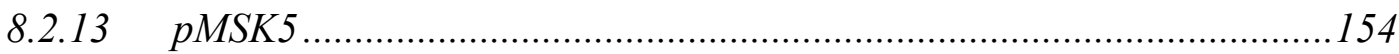

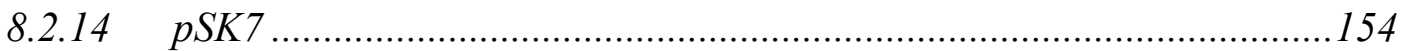

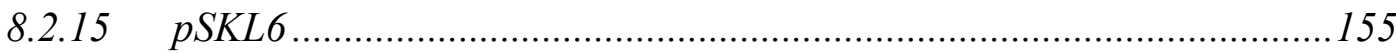




\section{Zusammenfassung}

Cis-regulatorische, as-1-ähnliche Elemente vermitteln auxin- und salicylsäureinduzierbare Genexpression in Pflanzen. Sie sind als funktionelle Elemente in einer Reihe von Promotoren enthalten, die im Verlauf pflanzlicher Abwehrreaktionen bei einem Pathogenbefall aktiviert werden. Als Komponenten des pflanzlichen Proteinkomplexes ASF-1 aus Nicotiana tabacum, der an das as-1 Element binden kann, konnten die Klasse II TGA-Faktoren TGA2.2 und TGA2.1 identifiziert werden.

Zur Identifizierung potentieller Interaktionspartner von TGA2.1 wurde im Rahmen dieser Arbeit eine cDNA-Bank aus Tabakblättern hergestellt und unter Verwendung des „Ubiquitin-based split-protein sensor systems“ durchgemustert. Es konnte eine DEADbox RNA-Helicase und eine E2-Ligase als Interaktionspartner identifiziert werden. Zusätzlich konnte im Hefe-Zweihybridsystem eine Wechselwirkung der E2-Ligase mit TGA2.1 nachgewiesen werden, die die Reportergenaktivität des Hefestammes reduzieren kann. Diese Wechselwirkung scheint spezifisch für aktivierende TGAFaktoren zu sein, da die Koexpression der E2-Ligase zusammen mit TGA1a und TGA10 ebenfalls eine Reduzierung der Reportergenaktivität zur Folge hat.

Das gezielte Ausschalten der tga2.1-Expression über RNA-Interferenz in planta zeigte, dass TGA2.1 für die auxin- und salicylsäureabhängige Regulation des frühen Gens Nt103 nicht essentiell ist. Möglicherweise sind die Klasse II TGA-Faktoren TGA2.1 und TGA2.2 in Bezug auf die Regulation des Nt103-Promotors redundant. Für die tga2.1RNAi-Linien im SNN-Hintergrund konnte eine konstitutive PRla-Expression nachgewiesen werden, die jedoch nicht zu einer erhöhten Resistenz gegenüber einer TMV-Infektion führte. Eine repressorische Funktion von TGA2.1 in Bezug auf die Regulation des späten Gens PRIa sowie die funktionelle Redundanz von TGA2.1 und TGA2.2 wird diskutiert. Zusätzlich zeigten die tga2.1RNAi-Linien im SNN-Hintergrund morphologische Veränderungen. Die transgenen Pflanzen zeichnen sich durch einen geringeren Wuchs, eine vermehrte Bildung von Seitensprossen, eine veränderte Blattform und teilweise durch Sterilität aus. 


\section{Einleitung}

\subsection{Abwehrmechanismen von Pflanzen gegenüber Pathogenen}

Pflanzen sind wie alle Lebewesen in ihrer Umwelt einer Vielzahl von Organismen ausgesetzt, die ernste Schäden verursachen oder tödlich wirken können. Dazu zählen neben Fraßfeinden vor allem bakterielle und virale Pathogene sowie Pilze. Obwohl es eine Vielzahl von Pathogenen gibt, sind die meisten Pflanzen gegen eine Infektion resistent. Diese Resistenz wird durch Abwehrmechanismen vermittelt, die entweder schon vorhanden sind (passive Abwehr) oder noch aktiviert werden müssen (aktive Abwehr). Zur passiven Abwehr zählen mechanische Barrieren wie die Zellwand oder die Kutikula sowie chemische Abwehrstoffe, die die Pflanze unspezifisch vor Pathogenen schützen.

Werden diese passiven Schutzmechanismen trotzdem überwunden, kann eine Vielzahl von Reaktionen ausgelöst werden, die die Begrenzung des Erregers auf einen möglichst kleinen Gewebebereich zum Ziel haben. Dieser Vorgang wird als hypersensitive Reaktion (HR) bezeichnet. Lokaler Zelltod, Bildung antimikrobieller Substanzen (Phytoalexine) und Verstärkung der Zellwände sind wichtige Komponenten von aktiven Abwehrmechanismen, die im Rahmen der HR dem Pathogen entgegengestellt werden. Voraussetzung für die Auslösung dieser Abwehrreaktionen ist die Erkennung von Pathogenen durch die Pflanze. Dabei spielen exogene und endogene Signalmoleküle eine Rolle, die als Elicitoren bezeichnet werden (EBEL und SCHEEL, 1997; BONAS und VAN DEN ACKERVEKEN, 1999). Exogene Elicitoren sind zumeist Oberflächenstrukturen der pathogenen Organismen (HAMMOND-KOSACK und JONES, 1996) oder sekretierte Substanzen, die zum Teil auch in die Pflanzenzelle eindringen können (BONAS und VAN Der ACKerVeKen, 1999; JiA et al., 2000), wie z. B. Oligosaccharide, Proteine, Peptide, Glyko- oder Lipoproteine und Fettsäuren, während endogene Elicitoren Zellwandbruchstücke der Pflanzen sind, die durch hydrolytische Enzyme aus ihr herausgelöst werden (RYAN und FARMER, 1991).

In einer Wirt-Pathogen-Interaktion gibt es ein Paar komplemetärer Gene, auf Seiten des Wirts ein Resistenzgen $(R)$ und auf Seiten des Pathogens ein Avirulenzgen $(A v r)$. Die $R$-Genprodukte, die Rezeptoren, können direkt oder indirekt mit den Avr-Genprodukten, 
den Elicitoren, in Gen-für-Gen-spezifischer Weise interagieren (wirtsspezifische Resistenz, HAMmOND-KoSACK und JONES, 1996). Dabei verhalten sich Rezeptor und Elicitor nach dem Schlüssel-Schloss-Prinzip. Verliert die Pflanze ihr $R$-Gen oder das entsprechende Pathogen sein avr-Gen, so findet eine Aktivierung der Pflanzenabwehr nicht mehr oder nur sehr verspätet statt. Das Pathogen kann sich nun in der Pflanze ausbreiten. Neben dieser wirtsspezifischen Resistenz zeigen viele Pflanzen auch eine nichtwirtsspezifische Resistenz. Die Abwehr erfolgt hier offensichtlich nicht über eine R/Avr-Genkombination; allerdings laufen sehr ähnliche biochemische Prozesse ab wie bei der wirtsspezifischen Resistenz.

Die hypersensitive Reaktion geht nicht nur mit lokalem Zelltod, Verstärkung der Zellwand und Synthese von Phytoalexinen einher. Zusätzlich kommt es zu einer de novo-Synthese von Proteinen, den PR-Proteinen (,pathogenesis-related proteins“) (KOMBRINCK und SOMSSICH, 1997). Zunächst findet man sie vor allem im Bereich der nekrotischen Läsionen, jedoch breitet sich ihre Expression nach und nach über das infizierte Blatt und schließlich über die gesamte Pflanze aus. Bei PR-Proteinen handelt es sich um saure, extrazelluläre bzw. basische, vakuoläre Proteine. Einige zeigen antimikrobielle Aktivität, bei anderen handelt es sich um hydrolytische Enzyme. Die Funktion einiger PR-Proteine ist noch nicht bekannt.

Die Akkumulation von PR-Proteinen geht mit einer weiteren Abwehrreaktion einher, die nicht wie die HR lokal, auf einen infizierten Gewebebereich beschränkt ist (VAN LOON und AnTONIw, 1982). Sie breitet sich im Anschluss an die HR über die gesamte Pflanze aus und wurde als systemisch erworbene Resistenz („systemic acquired resistance“, SAR) bezeichnet. Die systemisch erworbene Resistenz erstreckt sich nicht nur auf das Pathogen der ersten Infektion, sondern auch unspezifisch auf ein breites Spektrum von anderen pathogenen Pilzen, Bakterien und Viren (RYALs et al., 1996). Zudem kann ihre Wirkung über mehrere Monate andauern.

Für die Auslösung der HR und der SAR gilt Salicylsäure als entscheidendes, regulatorisches Molekül (DoNG, 1998). Ein erster Hinweis für die Bedeutung der Salicylsäure (SA) ergab sich aus der Bestimmung der endogenen SA-Konzentrationen von resistenten Tabakpflanzen nach einer Infektion mit dem Tabakmosaikvirus (TMV). Im Rahmen der HR war die SA-Menge um den Faktor 50 erhöht, im Rahmen der SAR um den Faktor 10 (MALAMY et al., 1990). Spätere Untersuchungen ergaben, dass exogen 
zugeführte Salicylsäure bei vielen Pflanzen eine SAR induziert, ohne dass diese eine Primärinfektion durchgemacht hatten (KLESSIG und MALAMY, 1994). Zudem konnte für Tabak und Arabidopsis gezeigt werden, dass durch die Behandlung mit Salicylsäure dieselbe Gruppe an PR-Genen angeschaltet wird, die von der Pflanze auch im Rahmen einer SAR exprimiert werden (WARD et al., 1991; UKNES et al., 1993a). Die Expression einer bakteriellen Salicylathydroxylase $(n a h G)$, die eine Akkumulation der Salicylsäure durch die Umwandlung in inaktives Catechol verhindert, führte in transgenen Pflanzen zu einer verminderten Resistenz gegenüber Pathogenen. Die Expression von $P R$-Genen und die Ausbildung der SAR unterbleibt. Werden dagegen bakterielle Enzyme, die Chorismat zu Salicylsäure umwandeln, in Pflanzen exprimiert, weisen diese eine konstitutive SA-Akkumulation und somit eine gesteigerte Resistenz auf (VERBERNE et al., 2000; MAUCH et al., 2001).

In der Pflanze werden neben den $P R$-Genen auch viele andere Abwehrgene durch die Salicylsäure reguliert (MALECK et al., 2000; SCHENK et al., 2000). Diese lassen sich in zwei Klassen unterteilen, abhängig davon wie schnell sie nach Stimulus exprimiert werden (DURNER et al., 1997). Die Induktion der frühen Gene ist unabhängig von einer Proteinneusynthese, d. h. die an der Regulation beteiligten Proteine müssen bereits vorhanden sein. Frühe Gene kodieren u. a. für Glutathion-S-Transferasen (z. B. Nt103-1, Nt103-35 aus Tabak; BooT et al., 1993) und Glucosyltransferasen (IEGT aus Tabak; HoRvath und ChUA, 1996). Die Induktion der späten Gene, zu denen die $P R$-Gene gehören, ist abhängig von einer Proteinneusynthese. Ihre Expression wird durch den Proteinsyntheseinhibitor Cycloheximid verhindert (UKNES et al., 1993b; QIN et al., 1994).

\subsection{Das as-1 Element}

Untersuchungen am Promotor des PRla-Gens aus Tabak ergaben, dass dieser zahlreiche cis-Elemente enthält. Durch die Bindung von verschiedenen Transkriptionsfaktoren an diese cis-Elemente wird seine Aktivität reguliert. Die Deletion eines dieser cis-Elemente führte $\mathrm{zu}$ einer deutlichen Verringerung der Induzierbarkeit des Promotors durch Salicylsäure und TMV-Infektion (STROMPEN et al., 1998). Das an dieser SA-Antwort des PRla-Promotors beteiligte Element ähnelt dem as-1 Element (activating 
sequence-1). Das as-1 Element wurde ursprünglich als ein funktionelles cis-Element im 35S-Promotor des Cauliflower Mosaic Virus (CaMV) beschrieben (BENFEY et al., 1989). Der CaMV ist ein DNA-Virus mit weit ausgedehntem Wirtsbereich. Er umfasst verschiedene Arten von Nachtschattengewächsen (Solanaceae), Kreuzblütlern (Brassicaceae) und Monokotylen (Fromm et al., 1985). Das 8,2 kb lange Genom enthält die Promotoren CaMV 19S und CaMV 35S. Odell et al. (1985) haben gezeigt, dass der CaMV 35S-Promotor in fast allen pflanzlichen Geweben die konstitutiv hohe Expression eines nachgeschalteten Reportergens vermittelt. Gleiches gilt für transiente Expressionssysteme. Für diese konstitutive Genexpression ist in allen Geweben der transformierten Pflanze eine 351 bp lange Promotorsequenz verantwortlich, die den Bereich von -343 bis +8 (relativ zum Transkriptionsstart) umfasst (Ow et al., 1987). Mit Hilfe von Deletionsanalysen und der Bestimmung des Expressionsmusters einzelner Promotorfragmente wurde der Aufbau des CaMV 35S-Promotors analysiert. Dieser zeichnet sich durch die Domäne A (-90 bis +8$)$ und die Domäne B (-343 bis -90$)$ aus. Während Domäne A eine Genexpression in Wurzeln und in der Region des Sprossapikalmeristems vermittelt, ist Domäne B überwiegend für die Expression von Genen in den oberirdischen Bereichen der Pflanze, wie den Blättern und dem Gefäßsystem, verantwortlich (BENFEY und CHUA, 1990). Die Domäne B wurde in fünf Subdomänen unterteilt, die charakteristische Expressionsspezifitäten zeigen und miteinander in Wechselwirkung treten. Die Analysen haben gezeigt, dass der CaMV 35S-Promotor aus Modulen aufgebaut ist, die nicht nur additiv, sondern auch synergistisch wirken (BENFEY et al., 1989; BENFEY und CHUA, 1990).

Die Domäne A des CaMV 35S Promotors vermittelt die Expression eines nachgeschalteten Reportergens in Wurzelspitzen, Kalluszellen, Protoplasten und in auxin- oder salicylsäureinduzierten Blättern (BENFEY et al., 1989; FrOMM et al., 1989; LIU und LAM, 1994; QIN et al., 1994). Dieses gewebespezifische und induzierbare Expressionsmuster ist auf das 17 bp lange cis-Element, welches 34 bp stromaufwärts der TATA-Box lokalisiert ist, zurückzuführen. Das sogenannte as-1 Element (activating sequence-1) enthält zwei unvollkommene Kopien des Palindroms TGACGTCA:

\section{5'-TGACGTAAgggaTGACGCA-3'}

Beide TGACG-Motive sind essentiell für die Funktion des as-1 Elementes (LAM et al., 1989). 
As-1-ähnliche Elemente sind neben dem Promotor des Cauliflower Mosaic Virus auch in den Promotoren des Figwort mosaic Virus (Bouchez et al., 1989; CoOKE, 1990) und des Commelina Yellow Mottle Virus (MEDBERry et al., 1992) zu finden. In den Promotoren des pflanzenpathogenen Bakteriums Agrobacterium tumefaciens findet man ebenfalls as-1-ähnliche Elemente. Als Beispiel sind der Octopin-Synthase-Promotor (ocs-Element; Bouchez et al., 1989; FrOMM et al., 1989), der Mannopin-SynthasePromotor (mas-Element; FelTKAMP et al., 1994) und der Nopalin-Synthase-Promotor (nos-Element; LAM et al., 1990) zu nennen. As-1-ähnliche Elemente werden also von Bakterien und Viren zur Expression pathogenkodierter Gene in der Pflanze verwendet.

In bisher identifizierten pflanzlichen Promotoren ist das as-1-ähnliche Element anteilig nur gering vertreten (ELLIS et al., 1993). Neben dem PRla-Promotor enthalten weitere Promotoren pflanzlicher Abwehrgene as-1-ähnliche Elemente. Beispiele sind die Tabakgene Nt103-1, Nt103-35 (VAN DER ZAAL et al., 1991) und par A (TAKAHASHI et al., 1989), sowie das Sojabohnengen GH2/4 (ELLIS et al., 1993). Diese frühen Gene, die sehr schnell nach Stimulus exprimiert werden, unterscheiden sich dadurch von dem späten Gen PRla, dass sie einen konservierten Abstand von 12 bp zwischen den palindromischen Symmetrieachsen aufweisen. Dieser Abstand und das Vorhandensein beider Palindrome sind für die Funktionalität der isolierten $a s-1$-ähnlichen Elemente in transienten Expressionsstudien essentiell (BOUCHEZ et al., 1989; SINGH et al., 1989; ELLIS et al., 1993; KRAWCZYK et al., 2002). Diese Sequenzunterschiede der as-1ähnlichen Elemente spiegeln sich auch in ihrer Responsivität wider. Während die frühen Gene und das isolierte $a s-1$ Element durch Salicylsäure und Auxin induzierbar sind (QIN et al., 1994; LIU und LAM, 1994; ZHANG et al., 1994; DROOG et al., 1995; TAKAHASHI et al., 1989; DONG, 1998), ist das PRla-Gen nur durch Salicylsäure induzierbar (DoNG, 1998). Kinetik, Responsivität und Sequenzvergleiche deuten darauf hin, dass die salicylsäureabhängige Regulation der $a s$-1-ähnlichen Elemente in den PR-Promotoren über andere Mechanismen verläuft als die Regulation der frühen Gene.

Die Verwendung unphysiologischer Konzentrationen von Salicylsäure und Auxin könnte ein Hinweis dafür sein, dass die Wirkung dieser Pflanzenhormone eher ihrer Phytotoxität zuzuordnen ist als ihrer Wirkungsweise als Signalmolekül (PASCUZZI et al., 1998). Das Sojabohnengen GH2/4 kodiert für eine Glutathion-S-Transferase, die als multifunktionelles Enzym an der Detoxifikation cytotoxischer Produkte und am Schutz 
des Gewebes vor oxidativen Schäden beteiligt ist (DANIEL, 1993; LEVINE et al., 1994). Die Beobachtung, dass der Promotor dieses Gens mit erhöhten Mengen aktiver und inaktiver Derivate von Salicylsäure und Auxin induzierbar ist (UlmASOV et al., 1994), weist zusätzlich auf einen durch chemischen Stress induzierbaren Signaltransduktionsweg hin.

Zusammenfassend lässt sich sagen, dass as-1-ähnliche Elemente in die koordinierte Induktion pflanzlicher Abwehrgene involviert sind. Sowohl für die Regulation der Expression von frühen als auch von späten salicylsäureinduzierbaren Genen konnte eine funktionelle Bedeutung belegt werden. Zudem stellt das isolierte as-1 Element ein gutes Modellsystem für die Untersuchung hormonvermittelter Transkriptionsaktivierung dar. Die Identifizierung der an das $a s-1$ Element bindenden Faktoren und ihrer Regulation ist somit ein wichtiger Schritt bei der Analyse der durch eine Pathogeninfektion induzierten Signaltransduktionskette.

\subsection{Die Familie der TGA-Faktoren}

1989 konnten KATAGIRI et al. mit dem hexl Element, das nur ein TGACG-Motiv enthält, den cDNA-Klon aus Tabak isolieren, der für das Protein TGA1a kodiert. Aus der Aminosäuresquenz konnte geschlossen werden, dass dieses Protein in die Klasse der bZIP-Proteine eingeordnet werden kann. Mit Hilfe von Deletionsanalysen war es möglich, die einzelnen Domänen von TGA1a zu identifizieren und zu charakterisieren (KATAGIRI et al., 1992) (Abbildung 2-1).

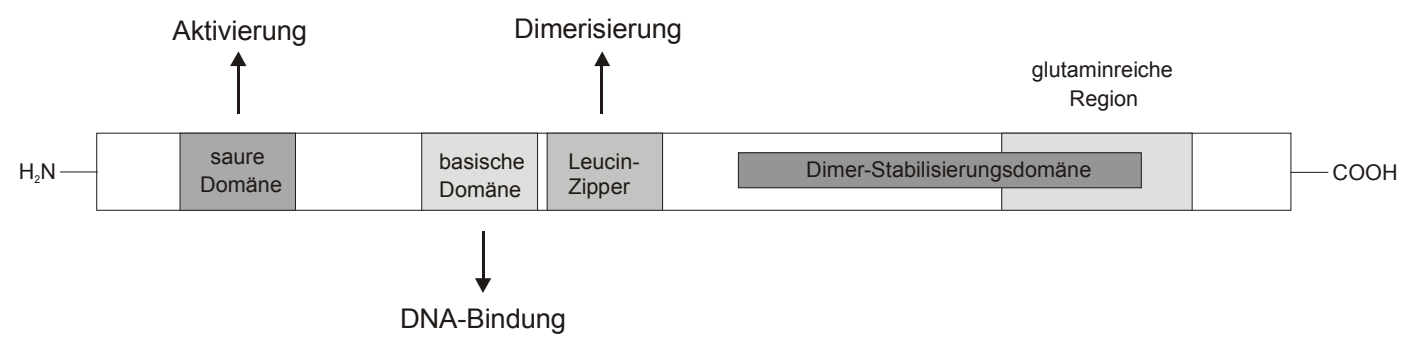

Abbildung 2-1: Domänenstruktur der Primärsequenz des bZIP-Transkriptionsfaktors TGA1a aus Nicotiana tabacum. 
Die basische Domäne, die innerhalb der Mitglieder der TGA-Familie hochgradig konserviert ist, ist für die Bindung des Proteins an die DNA verantwortlich. Die sich direkt anschließende Leucin-Zipper-Region ermöglicht die Dimerisierung. Die Bildung des Dimers wird zusätzlich durch eine carboxyterminale Domäne stabilisiert. Am CTerminus befindet sich zudem eine glutaminreiche Region, die für die Transkriptionsaktivierung von Bedeutung ist (PASCUZZI et al., 1998). NEUHAUS et al. (1994) haben nachgewiesen, dass für die Transkriptionsaktivierung in vivo auch die aminoterminal lokalisierte saure Domäne essentiell ist. Somit repräsentieren TGA-Faktoren eine Klasse von pflanzlichen bZIP-Transkriptionsfaktoren, die als Homo- oder Heterodimere an cis-Elemente, die ein TGACG-Motiv enthalten, binden.

Mittlerweile konnten auch aus Mais (SINGH et al., 1990; FOLEY et al., 1993; WALSH et al., 1997), Weizen (TABATA et al., 1991), Ackerbohne (EHrLich et al., 1993), Kartoffel FELTKAMP et al., 1994), Sojabohne (CHEONG et al., 1994), Tomate (ZHANG et al.,1999) und Reis (CHERN et al., 2001) weitere TGA-Faktoren isoliert werden.

Aus Arabidopsis thaliana wurde bisher die größte Anzahl von TGA-Faktoren isoliert. Basierend auf der Aminosäurehomologie wurden sie in verschiedene Subklassen unterteilt (XIANG et al., 1997):

Klasse I: $\quad$ TGA1 (SCHINDLER et al., 1992)

TGA4 (= OBF4; ZHANG et al., 1993)

Klasse II: $\quad$ TGA2 (= HBP1b; KAWATA et al., 1992)

TGA5 (= OBF5; ZHANG et al., 1993)

TGA6 (XIANG et al., 1995)

Klasse III: $\quad$ TGA3 (MiAO et al., 1994)

AtbZIP50 (unveröffentlicht)

Klasse IV: PERIANTHIA (CHUANG et al., 1999)

Klasse V: AtbZIP21 (unveröffentlicht)

Klasse VI: AtbZIP65 (unveröffentlicht) 
Die bZIP-Domäne und der C-Terminus von PERIANTHIA ähneln mehr den TGAFaktoren der Klasse II als den Faktoren der Klasse I und III. Doch aufgrund des sehr langen N-Terminus wurde PERIANTHIA in die neue Klasse IV eingeordnet. Zusätzlich zu den bereits publizierten TGA-Faktoren lassen sich aus der genomischen Sequenz von Arabidopsis thaliana drei weitere ableiten, deren korrespondierende cDNAs im Rahmen des REGIA-Projektes kloniert wurden: AtbZIP21, AtbZIP50 und AtbZIP65.

In Nicotiana tabacum konnten bisher fünf TGA-Faktoren isoliert werden. TGA1a und PG13 (Fromm et al., 1991) sind in die Subklasse einzuordnen, die der Klasse I aus Arabidopsis homolog ist. Mit Hilfe der TGA5-Sonde aus Arabidopsis thaliana konnten die TGA-Faktoren TGA2.1 und TGA2.2 (Niggeweg et al., 2000a) aus Nicotiana tabacum isoliert werden. Da TGA2.1 und TGA2.2 in Bezug auf die bZIP-Domäne und den C-Terminus einen hohen Homologiegrad der Aminosäuresequenz von 85 \% bzw. $91 \%$ gegenüber TGA2 aus Arabidopsis thaliana aufweisen, konnten sie als Klasse II TGA-Faktoren klassifiziert werden. Jedoch unterscheiden sie sich deutlich in der Länge der N-Termini voneinander. TGA2.1 zeichnet sich durch einen 170 Aminosäuren langen N-Terminus aus, während TGA2.2 einen kürzeren N-Terminus von 43 Aminosäuren besitzt. SCHIERMEYER et al. (2003) konnten das bZIP-Protein TGA10 aus Tabak isolieren. TGA10 zeigt relativ geringe Homologien $\mathrm{zu}$ bekannten TGA-Faktoren der Subklassen I bis III. Jedoch besteht eine $70 \%$-ige Homologie des C-Terminus zu AtbZIP65. Deshalb wurden diese beiden TGA-Faktoren zusammen in die neue Klasse VI eingeordnet.

Die meisten TGA-Faktoren werden auf mRNA-Ebene, wenn auch mit unterschiedlicher Häufigkeit, ubiquitär in den Pflanzen exprimiert (DE PATER et al., 1996; NiGGEWEG et al., 2000a). Ausnahmen stellen PERIANTHIA aus Arabidopsis, Linguleless2 aus Mais und TGA10 aus Tabak dar. Ihre Expression ist gewebe- bzw. entwicklungsspezifisch. Allerdings unterliegt die Induktion der Expression der TGAGene unterschiedlichen Stimuli (CHEN et al., 2002). Während z. B. die Expression von tga5 durch Pathogene induzierbar ist, kann die Expression von tgal zusätzlich auch durch Seneszenz induziert werden.

In vitro Bindestudien mit Kernextrakten aus Tabakblättern, bei denen als DNAFragment das as-1 Element verwendet wurde, führten zur Identifizierung eines Proteinkomplexes (LAM et al., 1989; PRAT et al., 1989). Dieser Komplex wird als 
ASF-1 (activating sequence factor-1) bezeichnet. Die genaue Zusammensetzung diese Proteinkomplexes konnte bis jetzt noch nicht vollständig aufgeklärt werden. Da alle Mitglieder der in den verschiedenen Pflanzenarten vorkommenden TGA-Familie an das as-1 Element binden, stellen sie alle potentielle Komponenten von ASF-1 dar. Für Arabidopsis thaliana konnte gezeigt werden, dass TGA2 ein Bestandteil von ASF-1 in Kernextrakten aus Wurzeln und Blättern ist (LAM und LAM, 1995). Da auf den Transkriptionsfaktor TGA2 nur maximal $33 \%$ der ASF-1-Aktivität in WurzelKernextrakten und maximal $50 \%$ ASF-1-Aktivität in Blatt-Kernextrakten zurückzuführen sind, kann TGA2 jedoch nicht alleiniger Bestandteil von ASF-1 sein. Obwohl fast alle der bisher identifizierten TGA-Gene aus Arabidopsis thaliana sowohl in Blättern als auch in Wurzeln exprimiert werden, konnten u. a. die TGA-Faktoren TGA1 und TGA3 als Bestandteile von ASF-1 nicht nachgewiesen werden (LAM und LAM, 1995). LAM und LAM (1995) postulieren, dass TGA1 und TGA3 nicht in der Lage sind, sich an der Bildung von ASF-1 zu beteiligen. Unklar ist allerdings noch, ob die beiden Faktoren unter den gegebenen Bedingungen nicht vorhanden sind, oder ob sie nicht in der Lage sind, in vitro an das cis-Element zu binden. Für Nicotiana tabacum konnte gezeigt werden, dass die Klasse II TGA-Faktoren TGA2.2 ( zu $80 \%)$ und TGA2.1 (zu $10 \%$ ) im ASF-1 enthalten sind, TGA1a dagegen nicht (NIGGEWEG et al., 2000b).

Mutationen im as-1 Element haben einerseits eine Verminderung der Aktivität und andererseits eine Reduktion der DNA-Bindung von ASF-1 zur Folge (LAM et al., 1989). Somit könnte eine Funktion von ASF-1 die Aktivierung der Transkription vermittelt durch das as-1 Element sein. Diese Hypothese wurde durch folgendes Ergebnis bekräftigt. Transgene Pflanzen, die dominant negative TGA-Mutanten mit einer veränderten oder deletierten DNA-Bindedomäne exprimieren (RIEPING et al., 1994; Miao und Lam, 1995; Niggeweg et al., 2000b; Kegler, 2001; PonTier et al., 2001), zeigen sowohl eine verringerte as-1-Aktivität in vivo als auch eine reduzierte Menge an ASF-1 in vitro, was wahrscheinlich auf die Bildung bindeinaktiver Heterodimere zwischen den Komponenten von ASF-1 und den TGA-Mutanten zurückzuführen ist. PONTIER et al. (2001) konnten zusätzlich zeigen, dass die Expression der transdominant negativen TGA2-Mutante zu einer verstärkten Aktivität des PR1-Promotors in vivo führt. Somit können TGA-Faktoren die durch das as-1 Element vermittelte Transkription sowohl aktivieren als auch reprimieren. 
LIU und LAM (1994) haben gezeigt, dass eine auxininduzierte Transkriptionsaktivierung eines $a s$-1-abhängigen Promotors weder von einem erhöhten ASF-1-Spiegel noch von einer de novo Proteinsynthese abhängig ist. Aufgrund der Arbeiten von PASCUZZI et al. (1998), KLINEDINST et al. (2000) und JOHNSON et al. (2001a; 2001b) konnte für den TGA-Faktor TGAla aus Tabak gezeigt werden, dass, obwohl er nicht als Komponente von ASF-1 identifiziert werden konnte, er direkt an der Regulation der auxininduzierbaren Gene Nt103-1 und Nt103-35 beteiligt ist. In BY-2 (,Bright Yellow-2")-Tabaksuspensionskulturen bindet ein 120 kD-Korepressor an die C-terminale Domäne von TGA1a und verhindert somit die Bindung an das as-1 Element und dessen Aktivierung. In Anwesenheit von Auxin löst sich der Korepressor ab und TGA1a kann an das as-1 Element in den Promotoren der Gene Nt103-1 und Nt103-35 binden und so deren Expression induzieren.

Die frühe Geninduktion durch Salicylsäure wird vermutlich in Tabakblättern ebenfalls über einen Inhibitor der DNA-Bindung reguliert. Mit Hilfe von Gelretardationsexprerimenten konnte gezeigt werden, dass die Bindeaktivität von ASF-1 in salicylsäureinduzierten Blättern höher ist als in nicht induzierten Blättern (JuPIN und ChuA, 1996; StAnge et al., 1997). JuPIN und ChUA (1996) konnten zeigen, dass die salicylsäureinduzierte Bindung unabhängig von der Proteinneusynthese ist und sich die Bindung von ASF-1 in nicht induzierten Blättern durch Zugabe von Detergenzien steigern lassen kann. Somit postulierten sie, dass die beteiligten TGAFaktoren bereits in der inaktiven Form in der Zelle vorliegen, gebunden an das inhibitorische Protein SAI (,SA-inhibitor"). Zusätzlich konnte gezeigt werden, dass Phosphorylierungsreaktionen an der Regulation der Bindeaktivität von ASF-1 beteiligt sind (JUPIN und CHUA, 1996; StANGE et al., 1997). Somit könnte man sich vorstellen, dass nach Salicylsäurebehandlung entweder das inhibitorische Protein SAI oder ASF-1 phosphoryliert wird, was zur Ablösung des Inhibitors von ASF-1 führt. Da TGAla nicht im ASF-1 nachgewiesen werden konnte, handelt es sich vermutlich bei dem postulierten SAI nicht um den $120 \mathrm{kD}$ großen Korepressor, dem Bindungsinhibitor von TGAla in BY2-Zellen. Zudem konnte nach Auxinbehandlung keine Steigerung der ASF-1Aktivität beobachtet werden (LIU und LAM, 1994; JOHNSON et al., 2001a) 
Im Hefe-Zweihybridsystem konnte ein interagierendes Protein der TGA-Faktoren identifiziert werden. Dabei handelt es sich um NPR1 aus Arabidopsis thaliana, einem Schlüsselregulator bei der Signaltransduktion, die zur Entwicklung der systemischen Resistenz (SAR) in der Pflanze führt. NPR1 ist ein $65 \mathrm{kD}$ großes Protein mit vier Ankyrinmotiven und einer BTB/POZ-Domäne, die für die Interaktion mit anderen Proteinen wichtig sein kann (CAO et al., 1997; RYALS et al., 1997). NPR1 liegt als Oligomer in der Zelle vor (Mou et al., 2003). Diese Oligomerisierung wird durch intermolekulare Disulfidbrücken ermöglicht. Im Rahmen der SAR liegt NPR1 dagegen in reduzierter Form vor und akkumuliert als Monomer im Zellkern (MoU et al., 2003; KINKEMA et al., 2000). Wird diese salicylsäureabhängige Akkumulation unterbunden, so ist die Expression der PR-Gene reprimiert. Man kann sich vorstellen, dass NPR1 mit Transkriptionsfaktoren im Zellkern interagiert und so die Expression der $P R$-Gene induziert. Mehrere Arbeitsgruppen konnten eine Interaktion von NPR1 mit TGAFaktoren nachweisen, die über den C-Terminus der TGA-Faktoren vermittelt wird (ZHANG et al., 1999; DESPRÉs et al., 2000; ZHOU et al., 2000; CHERN et al., 2001; FAN und DONG, 2002; DESPRÉS et al., 2003). Die Interaktion zwischen NPR1 und TGA2, der Hauptkomponente von ASF-1 aus Arabidopsis thaliana, kann durch Salicylsäure induziert werden und findet vornehmlich im Zellkern statt (SUBRAMANIAM et al., 2001). Zudem kann die Interaktion mit NPR1 die Bindung von TGA2 an das as-1 Element in vitro verstärken (DESPRÉS et al., 2000). FAN und DONG (2002) konnten zusätzlich zeigen, dass die Anwesenheit von NPR1 für die DNA-Bindeaktivität von TGA2 notwendig ist.

nprl-Mutanten, die eine stark verringerte Expression der PR-Gene nach Salicylsäurebehandlung aufweisen und nicht in der Lage sind, eine SAR auszubilden, verhalten sich wieder wie WT-Pflanzen, wenn ein zweites Gen, SNII (,suppressor of npr1-1, induciblec), mutiert ist (LI et al., 1999). SNI1 kodiert für ein 48,8 kD leucinreiches Protein. Genetischen Analysen zufolge könnte SNI1 als Repressor der PRGene und damit als negativer Regulator der SAR fungieren. Nach dem Modell von Li et al. (1999) hebt das durch Salicylsäure aktivierte NPR1-Protein die Wirkung des möglichen Repressors SNI1 auf. Da in der snil/npr1-Doppelmutante keine starke konstitutive $P R$-Genexpression zu finden ist, muss ein zweiter, von NPR1 unabhängiger Aktivierungsschritt postuliert werden. Möglicherweise wird dabei ein Transkriptionsfaktor als positiver Regulator durch die Wirkung der Salicylsäure 
aktiviert. JOHNSON et al. (2003) konnten kürzlich zeigen, dass die Bindung von TGA2 an den PR1-Promotor durch Salicylsäure induziert und über NPR1 vermittelt wird. Es wäre somit vorstellbar, dass die Interaktion von NPR1 und TGA2 eine Rekrutierung des TGA-Faktors in den Promotorkontext der $P R$-Gene zur Folge hat, was zu einer Aktivierung der PR1-Genexpression führt, wodurch der Effekt des putativen Repressors überwunden werden kann.

\subsection{Fragestellung und experimentelle Ansätze dieser Arbeit}

Um ein Verständnis für die $a s-1$-abhängige Promotoraktivität zu erlangen, ist es wichtig, einerseits die Zusammensetzung und die Regulation der Bindeaktivität des ASF-1 Komplexes zu analysieren und andererseits die bekannten TGA-Faktoren genau zu charakterisieren. Da die Klasse II TGA-Faktoren TGA2.1 und TGA2.2 als Bestandteile von ASF-1 identifiziert werden konnten (NIGGEWEG et al., 2000b), ist ihre Charakterisierung sehr hilfreich, um Informationen über die molekularen Mechanismen der pflanzlichen Pathogenabwehr in Nicotiana tabacum zu erhalten.

Im Mittelpunkt dieser Arbeit steht der bZIP-Transkriptionsfaktor TGA2.1 aus Nicotiana tabacum. TGA2.1 ist ein $50 \mathrm{kD}$ großes Protein, das sich durch seinen langen N-Terminus von 170 Aminosäuren auszeichnet. TGA2.1 wird sowohl in Blättern als auch in Wurzeln exprimiert. Die relative Expressionstärke ist dabei 4-5 mal stärker als die für den verwandten Transkriptionsfaktor TGA2.2 (NIGGEWEG et al., 2000b). Trotzdem haben Supershiftanalysen mit spezifischen Seren gegen TGA2.1 und TGA2.2 gezeigt, dass TGA2.1 nicht die Hauptkomponente von ASF-1 ist. In Kernextrakten aus Tabakblättern ist TGA2.2 6-7 mal stärker im ASF-1 vertreten als TGA2.1 (NIGGEWEG et al., 2000b). In Gesamtzellextrakten ist dieses Verhältnis nur etwa halb so stark. In vitro Bindestudien haben zudem gezeigt, dass Bereiche in dem langen N-Terminus von TGA2.1 dafür verantwortlich sind, dass dieser für eine effektive Bindung an das as-1 Element im Gegensatz zu den anderen bekannten Faktoren zwei benachbarte TGACGMotive benötigt (KRAWCZYK, 1999). 
Nach dem von JUPIN und CHUA (1996) postulierten Modell wird die Bindeaktivität von ASF-1 über die Interaktion mit einem Bindungsinhibitor reguliert. Neben einem solchen Protein könnten auch andere Proteine, wie z. B. Coaktivatoren, Repressoren oder modifizierende Proteine (Kinasen, Phosphatasen) die Funktion von ASF-1 kontrollieren. THUROW (2001) konnte mit NtNPR2 ein mit TGA2.1 interagierendes Protein bereits identifizieren. Um weitere Proteine $\mathrm{zu}$ finden, die mit TGA2.1 interagieren, sollte im Rahmen dieser Arbeit eine cDNA-Bank aus Tabakblättern hergestellt und unter der Verwendung von TGA2.1 als Köderprotein durchgemustert werden. Da TGA2.1 als Aktivator in Hefe fungiert (THUROw, 2001), konnte das Hefe-Zweihybridsystem nicht verwendet werden. Aus diesem Grund wurde das „Ubiquitin-based split-protein sensor system“ (JOHNSON und VARSHAVSKY, 1994) für den pflanzlichen Transkriptionsfaktor TGA2.1 etabliert.

Um die in vivo-Relevanz von TGA2.1 $\mathrm{zu}$ belegen, wurden bereits verschiedene transgene Tabakpflanzen untersucht. Pflanzen, die TGA2.1 überexprimieren, zeigen eine verstärkte Expression des as-1-kontrollierten Zielgens Nt103 nach Salicylsäure- und Auxinbehandlung (Kegler, 2001). Pflanzen, die ein Fusionsprotein, bestehend aus der konstitutiven Aktivierunsdomäne des viralen Proteins 16 und TGA2.1, überexprimieren, zeigen ebenfalls eine verstärkte Expression dieses Gens nach Salicylsäurebehandlung (LENK, 2001). Diese Beobachtung impliziert eine salicylsäureinduzierte Bindung von TGA2.1 an das as-1 Element. Umgekehrt führt die Überexpression transdominanter Suppressorvarianten von TGA2.1 in den transgenen Pflanzen $\mathrm{zu}$ einer verringerten Expression von Nt103 nach Salicylsäurebehandlung (KEGLER, 2001). Für die Regulation des späten Gens PRla konnte keine Funktion von TGA2.1 nachgewiesen werden. Um die in vivo-Funktion von TGA2.1 noch weiter zu charakterisieren, wurden im Rahmen dieser Arbeit transgene Tabakpflanzen, die eine verringerte Menge von tga2.1mRNA aufweisen, regeneriert und anschließend die salicylsäure- und auxinabhängige Expression von as-1-kontrollierten Zielgenen untersucht. 


\section{Material}

\subsection{Geräte}

\begin{tabular}{|c|c|c|}
\hline Gerät & Modell & Hersteller / Bezugsquelle \\
\hline Autoklav & $3870 \mathrm{ELV}$ & Tuttnauer \\
\hline Automatische Pipetten & & Gilson \\
\hline Bioimager (Phosphoimager) & BAS-1000 & Fuji \\
\hline Elektroporationsapparatur & Gene pulser ${ }^{\circledast} \mathrm{II}$ & BioRad \\
\hline Fluorometer & $\begin{array}{l}\text { CytoFluorII } \\
\text { Reader }\end{array}$ & PerSeptive \\
\hline Gefriertrocknungsanlage & L 05 & WKF \\
\hline Geldokumentationsstation & & MWG Biotech \\
\hline Gelelektrophoresekammern, horizontal & & Werkstatt der Universität \\
\hline \multirow[t]{3}{*}{ Gelelektrophoresekammern, vertikal } & Joey $^{\mathrm{TM}}$ \#JGC-4 & AGS \\
\hline & V $15-17$ & GIBCO BRL \\
\hline & & Werkstatt der Universität \\
\hline Geltrockner & Phero-Temp & Biotec-Fischer \\
\hline Handmonitor & Contamat & Eberline \\
\hline Heizblock & & Boekel Scientific \\
\hline Heizrührer & RCT basic & IKA Labortechnik \\
\hline Heizschüttler & Thermomixer 5436 & Eppendorf \\
\hline Hybridisierungsofen & & Bachhofer \\
\hline Hybridisierungswasserbad & Belly Dancer & Stovall \\
\hline Inkubationsschränke & & WTC binder; Memmert \\
\hline Kühlzentrifuge & Sorvall RC 5B Plus & DuPont \\
\hline Magnetic Particle Concentrator & Dynal MPC-E-1 & Dynal \\
\hline Netzgeräte & E 323 & Benedikt Heinemann \\
\hline Netzgeräte & EC 105 & EC Apparatus Corporation \\
\hline PCR-Gerät & MiniCycler ${ }^{\mathrm{TM}}$ PTC-150 & MJ Research \\
\hline pH-Meter & HI 9321 & Hanna Instruments \\
\hline Photometer & Unikon 720 LC & Kontron \\
\hline RNA-/DNA-Calculator & GeneQuant II & Pharmacia \\
\hline Scanner & ScanJet 4c & Hewlett Packard \\
\hline
\end{tabular}




\begin{tabular}{|c|c|c|}
\hline Gerät & Modell & Hersteller / Bezugsquelle \\
\hline Sequenzanalysegerät & ABI PRISM 310 & Perkin-Elmer \\
\hline Spektralphotometer für Mikrotiterplatten & $\begin{array}{l}\text { MRX Dynex Plate } \\
\text { Reader }\end{array}$ & Dynex \\
\hline Standzentrifuge mit Ausschwingrotor & UJ3S & Christ \\
\hline Sterilbank, horizontales Gebläse & Microflow Laminar & Nunc \\
\hline Sterilbank, vertikales Gebläse & Microflow Biohazard & Nunc \\
\hline Szintillationsmeßgerät & & $\begin{array}{l}\text { raytest Isotopenmeßgeräte } \\
\text { GmbH }\end{array}$ \\
\hline Tischzentrifuge & Biofuge pico & Heraeus Christ \\
\hline Tischzentrifuge, kühlbar & 5403 & Eppendorf \\
\hline Ultraschallgerät & Soniprep 150 & Scientific Instruments \\
\hline Ultrazentrifuge & Centrikon T-1065 & Kontron \\
\hline UV-Transilluminator & FLX-20 M & Vilber Lourmat \\
\hline Vortex & L46 & Labinco BV, Niederlande \\
\hline Wasseraufbereitungsanlage & Option 4, Maxima & ELGA \\
\hline Zählkammer & Fuchs-Rosenthal & Brand \\
\hline Zentrifuge, Ausschwingrotor & Universal 16A & Hettich \\
\hline
\end{tabular}

\subsection{Verbrauchsmaterialien}

\begin{tabular}{ll}
\hline Produkt & Hersteller / Bezugsquelle \\
\hline Centricon 10-Säulen & Millipore \\
Dialyseschläuche (Typ 8) & Biomol \\
Glasperlen $\varnothing 425-600 \mu \mathrm{m}$, säurebehandelt & Sigma \\
Elektroporationsküvetten & BioRad \\
Fließpapier 3MM & Whatman \\
Gläser für Pflanzensterilkultur & Weck \\
Kunststoff-Einwegmaterial & Eppendorf; Greiner; Roth; Sarstedt \\
Micro Spin ${ }^{\text {TM }}$ G25 Column & Pharmacia \\
Mikrotiterplatten & Roth \\
Miracloth & Calbiochem \\
Nylon-Membran Hybond ${ }^{+}$ & Amersham \\
PVDF-Membran Immobilon ${ }^{\text {TM }}$-P & Millipore \\
Röntgenfilme Cronex 4, Cronex 10T & DuPont \\
\hline
\end{tabular}




\subsection{Chemikalien}

\begin{tabular}{|c|c|}
\hline Chemikalie & Hersteller/Lieferant \\
\hline $30 \%(w / v)$ Acrylamid:N,N'-Methylenbisacrylamid $(37,5: 1)$ & Roth \\
\hline $40 \%$ (w/v) Acrylamid:N,N'-Methylenbisacrylamid (19:1) & Roth \\
\hline Agarose SeaKem LE & Biozym \\
\hline Ampicillin & AGS \\
\hline Antipain & Applichem \\
\hline APS (Ammoniumpersulfat) & Biometra \\
\hline Aprotinin & Sigma \\
\hline Bakto Pepton & Difco \\
\hline$\beta$-Bactyl & Duchefa \\
\hline Benzamidin & Applichem \\
\hline 6-Benzylaminopurin (6-BAP) & Sigma \\
\hline Bradford-Reagenz & Roth \\
\hline Bromphenolblau & Roth \\
\hline BSA (Rinder-Serum-Albumin) & Serva \\
\hline Cefotaxim & Duchefa \\
\hline Chymostatin & Sigma \\
\hline Coomassie Brilliant Blue G-250 & BioRad \\
\hline CSM (Complete Supplement Mixture)-ADE-HIS-LEU-TRP & BIO 101 \\
\hline CSM (Complete Supplement Mixture)-HIS-LEU-TRP-URA & BIO 101 \\
\hline CSM (Complete Supplement Mixture)-LEU-TRP-URA & BIO 101 \\
\hline$\left[\alpha-{ }^{32} \mathrm{P}\right] \mathrm{dATP} ; 800 \mathrm{Ci} / \mathrm{mmol}$ & Hartmann Analytic \\
\hline 2,4-Dichlorphenoxyessigsäure (2,4-D) & Sigma \\
\hline Diethylpyrocarbonat (DEPC) & Roth \\
\hline N,N-Dimethylformamid (DMF) & J.T. Baker Chemicals B. V. \\
\hline Dimethylsulfoxid (DMSO) & Sigma \\
\hline Dithiothreitol (DTT) & Sigma \\
\hline dNTPs & MBI; Roth \\
\hline E-64 & Sigma \\
\hline Ethylendiamintetraacetat (EDTA) & AppliChem \\
\hline Ethidiumbromid & Roth \\
\hline 5-Fluoroorotic acid (5-FOA) & Duchefa \\
\hline HEPES & Roth \\
\hline Heringssperma-DNA (HSP) & Sigma \\
\hline Hydroxyethyl-Cellulose medium vis. (HEC) & Fluka \\
\hline Isopropylthiogalactosid (IPTG) & BioTech Trade \\
\hline
\end{tabular}




\begin{tabular}{|c|c|}
\hline Chemikalie & Hersteller/Lieferant \\
\hline Kanamycin & Sigma \\
\hline Leupeptin & Sigma \\
\hline Magermilchpulver & Glücksklee \\
\hline$\beta$-Mercaptoethanol & Roth \\
\hline Metothrexat & Sigma \\
\hline 2[N-Morpholino] ethansulfonsäure (MES) & Sigma \\
\hline Murashige und Skoog Medium & Duchefa \\
\hline NAA ( $\alpha$-Naphthalinessigsäure) & Sigma \\
\hline Orange $\mathrm{G}$ & Sigma \\
\hline Pefabloc SC & Applichem \\
\hline Pepstatin A & Applichem \\
\hline Phenol & AppliChem \\
\hline Phenylmethansulfonylchlorid (PMSF) & Fluka \\
\hline Polydesoxyinosin-desoxycytidylsäure (PolydI/dC) & Sigma \\
\hline Ponceau S & Sigma \\
\hline Rifampicin & Duchefa \\
\hline Röntgen-Entwickler LX24 & Kodak \\
\hline Röntgen-Fixierer AL4 & Kodak \\
\hline Salicylsäure (SA) & Merck \\
\hline Select Agar & Life Technologies \\
\hline Select Yeast Extract (Hefeextrakt) & GIBCO BRL \\
\hline TEMED & Roth \\
\hline Trypton & Oxoid \\
\hline Triton X-100 & Roth \\
\hline Tween 20 & Roth \\
\hline X-Gal & BioTech Trade \\
\hline Xylencyanol FF & Roth \\
\hline Yeast Nitrogen Base (ohne Aminosäuren) & Difco \\
\hline
\end{tabular}

Die weiteren verwendeten Standard-Chemikalien wurden von den Firmen Boehringer, Fluka, Merck, Serva, Sigma oder Roth bezogen. 


\subsection{Kits}

\begin{tabular}{|c|c|}
\hline Kit & Hersteller / Bezugsquelle \\
\hline BigDye $^{\mathrm{TM}}$ Terminator Cycle Sequencing Ready Reaction Kit & Perkin-Elmer Corporation \\
\hline Enhanced Chemiluminescence Plus ${ }^{\mathrm{TM}}$ Kit $(\mathrm{ECL}+)$ & Amersham Life Science \\
\hline Gateway BP Clonase Enzyme Mix & GIBCOBRL \\
\hline GATEWAy LR Clonase Enzyme Mix & GIBCOBRL \\
\hline MATCHMAKER Library Construction \& Screening Kit & Clontech \\
\hline Megaprime $^{\mathrm{TM}}$ DNA Labelling Systems & Amersham Life Science \\
\hline Oligotex $^{\mathrm{TM}}$ & Qiagen \\
\hline pGEM $^{\circledR}$-T Vector System & Promega \\
\hline Qiagen Plasmid-Preparation-Kits (Midi, Maxi) & Qiagen \\
\hline QIAprep Spin Miniprep Kit & Qiagen \\
\hline QIAquick Gel Extraction Kit & Qiagen \\
\hline RNeasy Plant Mini Kit & Qiagen \\
\hline T-cloning Kit & MBI Fermentas \\
\hline
\end{tabular}

\subsection{Proteine}

\subsubsection{Enzyme}

\begin{tabular}{ll}
\hline Enzym & Hersteller / Bezugsquelle \\
\hline AmpliTaq $^{\circledR}$ DNA Polymerase, FS & ABI PRISM $^{\mathrm{TM}}$ \\
Klenow-DNA-Polymerase & MBI Fermentas \\
Klenow-DNA-Polymerase exo & MBI Fermentas \\
Restriktionsenzyme & MBI Fermentas, GIBCOBRL, NEB \\
RNase A (DNase-frei) & Qiagen \\
T4 DNA-Ligase & MBI Fermentas \\
\hline
\end{tabular}




\subsubsection{Proteinstandard}

Zur Ermittlung des Molekulargewichts von Proteinen wurde der „BENCHMARK ${ }^{\mathrm{TM}}$ Prestained Protein Ladder" der Firma GIBCOBRL (Karlsruhe) verwendet.

\subsubsection{Antikörper}

\begin{tabular}{|c|c|c|c|}
\hline Bezeichnung & Spezifität & Eigenschaft & Referenz \\
\hline$\alpha \mathrm{TGA} 2.1$ & N-Terminus von TGA2.1 & $\begin{array}{l}\text { polyklonal aus Kaninchen, affinitäts- } \\
\text { aufgereinigt }\end{array}$ & $\begin{array}{l}\text { NIGGEWEG } \\
(1999)\end{array}$ \\
\hline$\alpha$ TGA2.x & $\begin{array}{l}\text { C-Terminus von TGA2.2 und } \\
\text { TGA2.1 }\end{array}$ & $\begin{array}{l}\text { polyklonal aus Kaninchen, affinitäts- } \\
\text { aufgereinigt }\end{array}$ & $\begin{array}{l}\text { NICKOLOV } \\
(2002)\end{array}$ \\
\hline anti rabbit Ig & Kaninchen-Immunglobulin & $\begin{array}{l}\text { Peroxidase gekoppelt, polyklonal aus } \\
\text { Esel }\end{array}$ & Amersham \\
\hline
\end{tabular}

\subsubsection{E. coli-Extrakte mit rekombinant exprimiertem TGA-Faktor}

Rohextrakte aus E. coli-Zellen (BL21 DE3), die rekombinant exprimiert TGA2.1 enthalten, wurden mir freundlicherweise von Ricarda Niggeweg (beschrieben in NiggEWEG, 1999, Kapitel 4.12) zur Verfügung gestellt. Die entsprechenden Proteine sind in Denaturierungspuffer ( $8 \mathrm{M}$ Harnstoff, $0,1 \mathrm{M} \mathrm{NaH}_{2} \mathrm{PO}_{4}$, $10 \mathrm{mM}$ Tris- $\mathrm{HCl} \mathrm{pH} 8,0)$ gelöst.

\subsection{Nukleinsäuren}

\subsubsection{Oligonukleotid}

Die Oligonukleotide wurden nach Auftragssynthese von den Firma MWG geliefert.

\begin{tabular}{ll}
\hline Oligonukleotid & Sequenz $\mathbf{5}^{\prime} \rightarrow \mathbf{3}^{\prime}$ \\
\hline SKL1 & AGC TTC GGA CTA GTC CGA \\
\hline SKL2 & AAT TCC GGA CTA GTC CGG \\
\hline SKL5 sense & TCG ACG GTG GTG GG \\
\hline SKL5 antisense & TCG ACC CAC CAC CG \\
\hline SMART III $^{\text {TM }}$ Oligo & AAG CAG TGG TAT CAA CGC AGA GTG GCC ATT ATG GCC GGG \\
\hline
\end{tabular}




\subsubsection{Primer}

Die Primer wurden nach Auftragssynthese von den Firmen MWG, metabion und Qiagen geliefert bzw. entstammen dem „MATCHMAKER Library Construction \& Screening Kit“ von Clontech.

\begin{tabular}{|c|c|}
\hline Primer & Sequenz $5^{\prime} \rightarrow 3^{\prime}$ \\
\hline 117 lower & GTC GAC AAG ACC AAA ACA CAT TAC ATG \\
\hline 117 upper & GAA TTC GGG AAG GAA AAT CCT AG \\
\hline $117 \mathrm{a}$ & AGG TGA GGG AGC GAT TGA AG \\
\hline $172 \mathrm{a}$ & CCT TGA ACT TGC AGC ACA ACT TAG C \\
\hline $175 B g l \mathrm{II}$ & AGA TCT TTT GAA GCT AAT ACT TAG AAT ATC A \\
\hline 175 lower & GTC GAC TTT GAA GCT AAT ACT TAG AAT ATC AGG \\
\hline $175 \mathrm{NdeI}$ & GGC ATA TGC AGA TTT TCG TCA AGA C \\
\hline 175 upper & GAA TTC GAA GAT GAT GGA ATT AGA AAA G \\
\hline $184 \mathrm{a}$ & CCC AAA TGT TGA TGA GAT GTC TGG C \\
\hline $184 d$ & TGT CAG AAA TAT GCA AAG CC \\
\hline 3' PCR-Primer & GTA TCG ATG CCC ACC CTC TAG AGG CCG AGG CGG CCG ACA \\
\hline $5^{\prime}$ PCR-Primer & TTC CAC CCA AGC AGT GGT ATC AAC GCA GAG TGG \\
\hline pADH primer & CAT TGT TCT CGT TCC CTT TCT TCC \\
\hline CDS III Primer & $\begin{array}{l}\text { AAT CTA GAG GCC GAG GCG GCC GAC ATG-d(T) }{ }_{30} \mathrm{VN}, \mathrm{N}=\mathrm{A}, \mathrm{G} \text {, } \\
\mathrm{C} \text { oder } \mathrm{T} ; \mathrm{V}=\mathrm{A} \text {, G oder C }\end{array}$ \\
\hline CDS III/6 Primer & $\begin{array}{l}\text { AAT CTA GAG GCC GAG GCG GCC GAC ATG-NNNNNN, N = A, G, } \\
\text { C oder T }\end{array}$ \\
\hline CHS back & CAC TTA CTT ACA CTT GCC TTG GAG \\
\hline CHS front & CCA ATT AAG ATA AAA CGT TGA ATG \\
\hline gateway $2.1 \mathrm{rev}$ & $\begin{array}{l}\text { GGG GAC CAC TTT GTA CAA GAA AGC TGG GTG CGT GAA CCA } \\
\text { GAA TCT }\end{array}$ \\
\hline GW TGA2.1 upper & $\begin{array}{l}\text { GGG GAC AAG TTT GTA CAA AAA AGC AGG CTT GCA ATA TCT } \\
\text { TGG ATT CCG }\end{array}$ \\
\hline LTGA2.1 lower (NotI) & GCG GCC GCT CAT ACT AAC TGC TCT CGT GGT CTG \\
\hline Ntgh3 lower & CAA AAT AAC CCA TGT TTG GCA TG \\
\hline Ntgh3 upper & CCT CAC TAG CTC TGG AAC GTC AG \\
\hline NubI lower & AGT GAA TTC GAG CTG GCC \\
\hline NubI upper & ACC TAC CCA TAC GAT GTT CC \\
\hline pBD2 & TCA TCG GAA GAG AGT AGT AAC \\
\hline REC lower & ATA TAG CGG CCG CCG TAT CGA TGC CCA CCC TC \\
\hline REC upper & GCG ATC TCG AGC TTC CAC CCA AGC AGT GGT ATC \\
\hline reverse 24 & TTC ACA CAG GAA ACA GCT ATG ACC \\
\hline SK2 sense & GAG CCC GGG GGG AGG AGG TGG TTC AGG \\
\hline SK2611-L & CCC GGG TCA TAC TAA CTG CTC TCG TGG \\
\hline
\end{tabular}




\begin{tabular}{ll}
\hline Primer & Sequenz $\mathbf{5}^{\prime} \rightarrow \mathbf{3}^{\prime}$ \\
\hline SK2611-U & CCC GGG ATG GCT AGT AAG ATT GGT ACA G \\
\hline T7 Primer & TAA TAC GAC TCA CTA TAG GG \\
\hline TGA2.1 lower (SalI) & GTC GAC TGA ACC ACC ACC TCC GGA TCC ACC TC \\
\hline TGA2.1 lower (Seq) & CCA GTA GTA CCA CTT CTA TTG CCT G \\
\hline TGA2.1N120upper & GAA TTC AAA AAA AAT GGC TAG TAA GAT TGG TAC AG \\
\hline TGA2.1 upper (Seq) & TTG CAA TAA ATG AAT ATT TTT CAC GTC TTC G \\
\hline universal 24 & ACG ACG TTG TAA AAC GAC GGC CAG \\
\hline
\end{tabular}

\subsubsection{Plasmide}

\begin{tabular}{|c|c|c|}
\hline Plasmid & Beschreibung & Referenz \\
\hline $\mathrm{p} 2.1 \mathrm{GBT}$ & $\begin{array}{l}\text { pGBT9 KpnI-Bgl II-Derivat, enthält die } \\
\text { Kodierregion der tga2.1-cDNA fusioniert } \\
\text { an das 5'-Ende der } G A L 4-B D \text { über einen } \\
2 \times\left(\mathrm{G}_{4} \mathrm{~S}\right)_{3} \text {-Linker, TRP1, amp }{ }^{r}\end{array}$ & THUROW, 2001 \\
\hline PADNX-NubI & 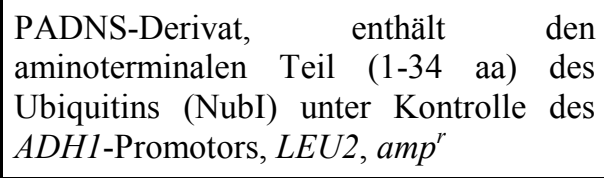 & LEHMING, unveröffentlicht \\
\hline PADNX-NubI-117 & $\begin{array}{l}\text { PADNX-NubI-Rec-Derivat, enthält die } \\
\text { cDNA des Klons } 117, \text { LEU2, } a m p^{r}\end{array}$ & diese Arbeit \\
\hline PADNX-NubI-175 & $\begin{array}{l}\text { PADNX-NubI-Rec-Derivat, enthält die } \\
\text { cDNA des Klons 175, LEU2, } a m p^{r}\end{array}$ & diese Arbeit \\
\hline PADNX-NubI-184 & $\begin{array}{l}\text { PADNX-NubI-Rec-Derivat, enthält die } \\
\text { cDNA des Klons 184, LEU2, amp }{ }^{r}\end{array}$ & diese Arbeit \\
\hline PADNX-NubI-Rec & $\begin{array}{l}\text { PADNX-NubI-Derivat, enthält die } \\
\text { Rekombinationsstellen von pGADT7- } \\
\text { Rec für eine in vivo-Klonierung in Hefe, } \\
\text { LEU2, amp }{ }^{r}\end{array}$ & diese Arbeit, Kapitel 4.6.1.3 \\
\hline Pcup1-Cub-Rura 314 & $\begin{array}{l}\text { pRS314-Derivat, } \quad \text { enthält } \\
\text { carboxyterminalen } \quad(35-76 \quad \text { aa }) \text { des } \\
\text { Ubiquitins (Cub), } \mathrm{Cu}^{2+} \text {-induzierbarer } \\
\text { Promotor Pcupl ist vorgeschaltet, TRP1, } \\
\text { amp }^{r}\end{array}$ & JOHNSSON, unveröffentlicht \\
\hline $\mathrm{pDONR}^{\mathrm{TM}} 207$ & $\begin{array}{l}\text { Donor Vektor des GATEWAY Systems, } \\
\mathrm{Gm}^{r}, \mathrm{Cm}^{r}\end{array}$ & GIBCOBRL \\
\hline pDONRTGA2.1 & \begin{tabular}{|lccc} 
pDONR $^{\mathrm{TM}} 207$ & Derivat, enthält ein & 257 \\
bp-Fragment des $\quad$ N-Terminus & von \\
TGA2.1, Gm & & &
\end{tabular} & diese Arbeit, Kapitel 4.6.2.2 \\
\hline
\end{tabular}




\begin{tabular}{|c|c|c|}
\hline Plasmid & Beschreibung & Referenz \\
\hline $\mathrm{pFGC} 2.1$ & $\begin{array}{l}\text { pFGC5941 gatewayRNAi-Derivat, enthält } \\
257 \text { bp-Fragmente des aminoterminalen } \\
\text { Teils von tga2.1 in entgegengesetzter und } \\
\text { korrekter Orientierung verbunden durch } \\
\text { das CHSA-Intron unter Kontrolle des } \\
\text { CaMV 35S-Promotors, } \text { kan }^{r}, P P T\end{array}$ & diese Arbeit, Kapitel 4.6.2.2 \\
\hline pFGC5941 gatewayRNAi & $\begin{array}{l}\text { pFGC5941-Derivat (binärer Vektor) des } \\
\text { GATEWAY Systems zur Herstellung von } \\
\text { RNAi-Konstrukten unter Kontrolle des } \\
\text { CaMV 35S-Promotors, } \mathrm{kan}^{r}, P P T^{r}\end{array}$ & $\begin{array}{l}\text { http://ag.arizona.edu/ } \\
\text { chromatin/fgc5941.html }\end{array}$ \\
\hline pGAD(-AD)2.1fl & 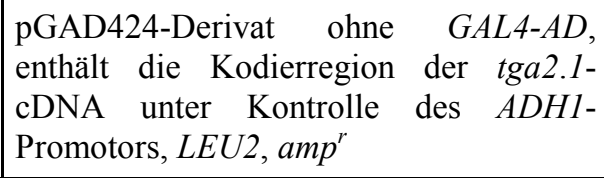 & THUROW, unveröffentlicht \\
\hline pGAD(-AD)2.1-141 & $\begin{array}{l}\text { pGAD424-Derivat ohne GAL4-AD, } \\
\text { enthält die Kodierregion für ein N- } \\
\text { terminales Deletionsderivat von TGA2.1, } \\
\text { dem die Aminosäuren } 2 \text { bis } 30 \text { fehlen, } \\
\text { unter Kontrolle des } A D H 1 \text {-Promotors, } \\
L E U 2, a m p^{r}\end{array}$ & THUROW, unveröffentlicht \\
\hline pGAD117 & $\begin{array}{l}\text { pGAD424-Derivat, enthält die cDNA des } \\
\text { Klons } 117 \text { fusioniert an das } 3^{\prime} \text {-Ende der } \\
G A L 4-A D, L E U 2, a m p^{r}\end{array}$ & diese Arbeit, Kapitel 4.6.1.5 \\
\hline pGAD175 & $\begin{array}{l}\text { pGAD424-Derivat, enthält die cDNA des } \\
\text { Klons } 175 \text { fusioniert an das } 3^{\prime} \text {-Ende der } \\
G A L 4-A D, L E U 2, a m p^{r}\end{array}$ & diese Arbeit, Kapitel 4.6.1.6 \\
\hline pGAD184 & $\begin{array}{l}\text { pGAD424-Derivat, enthält die cDNA des } \\
\text { Klons } 184 \text { fusioniert an das } 3^{\prime} \text {-Ende der } \\
G A L 4-A D, L E U 2, a m p^{r}\end{array}$ & diese Arbeit, Kapitel 4.6.1.7 \\
\hline pGAD424 & $\begin{array}{l}\text { Vektor für die Expression von GAD- } \\
\text { Fusionsproteinen unter Kontrolle des } \\
\text { ADH1-Promotors in Hefe, GAL4 } \\
\text { Aktivierunsdomäne, } L E U 2, a m p^{r}\end{array}$ & Clontech \\
\hline pGAD-NPR1 & $\begin{array}{l}\text { pGAD424-Derivat, enthält die } \\
\text { Kodierregion der NPR1-cDNA fusioniert } \\
\text { an das } 3 \text {-Ende der GAL4-AD, LEU2, } \\
a m p^{r}\end{array}$ & THUROW, 2001 \\
\hline pGAD-SCL14 & $\begin{array}{l}\text { pGAD424-Derivat, enthält die } \\
\text { Kodierregion der SCL14-cDNA } \\
\text { fusioniert an das } 3^{\prime} \text {-Ende der } G A L 4-A D, \\
L E U 2, a m p^{r}\end{array}$ & SIEMSEN, unveröffentlicht \\
\hline pGADT7-Rec & $\begin{array}{l}\text { pGAD424-Derivat, enthält die GAL4-AD } \\
\text { unter Kontrolle des T7-Promotors, wird } \\
\text { für die in vivo-Klonierung in Hefe } \\
\text { verwendet, } L E U 2, a m p^{r}\end{array}$ & Clontech \\
\hline pGADT7-Rec/184 & $\begin{array}{l}\text { pGADT7-Rec-Derivat, enthält die cDNA } \\
\text { des Klons } 184 \text { fusioniert an das } 3^{\prime} \text {-Ende } \\
\text { der GAL4-AD, cDNA wurde über } \\
\text { Rekombination in den Vektor inseriert, } \\
L E U 2, a m p^{r}\end{array}$ & diese Arbeit, Kapitel 4.6.1.7 \\
\hline
\end{tabular}




\begin{tabular}{|c|c|c|}
\hline Plasmid & Beschreibung & Referenz \\
\hline pGAD-TGA1a & $\begin{array}{l}\text { pGAD424-Derivat, enthält die } \\
\text { Kodierregion der tgala-cDNA fusioniert } \\
\text { an das } 3 \text {-Ende der } G A L 4-A D, L E U 2, \\
a^{r} p^{r}\end{array}$ & THUROW, 2001 \\
\hline pGAD-TGA2.1-141 & $\begin{array}{l}\text { pGAD424-Derivat, enthält die } \\
\text { Kodierregion für ein N-terminales } \\
\text { Deletionsderivat von TGA2.1, dem die } \\
\text { Aminosäuren } 2 \text { bis } 30 \text { fehlen, unter } \\
\text { Kontrolle des } A D H 1 \text {-Promotors, LEU2, } \\
a m p^{r}\end{array}$ & THUROW, unveröffentlicht \\
\hline pGAD-TGA2.2 & $\begin{array}{l}\text { pGAD424-Derivat, enthält die } \\
\text { Kodierregion der tga2.2-cDNA fusioniert } \\
\text { an das } 3 \text {-Ende der } G A L 4-A D, L E U 2, \\
a^{r} p^{r}\end{array}$ & THUROW, 2001 \\
\hline pGAD-TGA10 & $\begin{array}{l}\text { pGAD424-Derivat, enthält die } \\
\text { Kodierregion der tga10-cDNA fusioniert } \\
\text { an das } 3 \text {-Ende der } G A L 4-A D, L E U 2, \\
a_{m p}^{r}\end{array}$ & THUROW, 2001 \\
\hline pGBT117 & $\begin{array}{l}\text { pGBT9-Derivat, enthält die cDNA des } \\
\text { Klons } 117 \text { fusioniert an das } 3^{\prime} \text {-Ende der } \\
G A L 4-B D, T R P 1, a m p^{r}\end{array}$ & diese Arbeit, Kapitel 4.6.1.5 \\
\hline pGBT175 & $\begin{array}{l}\text { pGBT9-Derivat, enthält die cDNA des } \\
\text { Klons } 175 \text { fusioniert an das } 3^{\prime} \text {-Ende der } \\
G A L 4-B D, T R P 1, a m p^{r}\end{array}$ & diese Arbeit, Kapitel 4.6.1.6 \\
\hline pGBT184 & $\begin{array}{l}\text { pGBT9-Derivat, enthält die cDNA des } \\
\text { Klons } 184 \text { fusioniert an das } 3^{\prime} \text {-Ende der } \\
G A L 4-B D, T R P 1, a m p^{r}\end{array}$ & diese Arbeit Kapitel 4.6.1.7 \\
\hline pGBT9 & $\begin{array}{l}\text { Vektor für die Expression von GBD- } \\
\text { Fusionsproteinen unter Kontrolle des } \\
A D H 1 \text {-Promotors in Hefe, GAL4 } 4_{(1-147)^{-}} \\
\text {DNA-Bindedomäne, TRP1, amp }{ }^{r}\end{array}$ & Clontech \\
\hline pGBT-BZI-1 & $\begin{array}{l}\text { pGBT9-Derivat, enthält die } B Z I-1 \text {-cDNA } \\
\text { fusioniert an das } 3 \text {-Ende der } G A L 4-B D \text {, } \\
T R P 1, a m p^{r}\end{array}$ & STRATHMANN, 2003 \\
\hline pGBT-TGA2.1-141 & $\begin{array}{l}\text { pGBT9-Derivat, enthält die Kodierregion } \\
\text { für ein N-terminales Deletionsderivat von } \\
\text { TGA2.1, dem die Aminosäuren } 2 \text { bis } 30 \\
\text { fehlen, fusioniert an das 3'-Ende der } \\
G A L 4-B D \text {, unter Kontrolle des } A D H 1- \\
\text { Promotors, TRP1, } a m p^{r}\end{array}$ & THUROW, unveröffentlicht \\
\hline pGBT-NPR1 & $\begin{array}{l}\text { pGBT9-Derivat, enthält die Kodieregion } \\
\text { der NPR1-cDNA fusioniert an das 3'- } \\
\text { Ende der GAL4-BD, TRP1, amp }{ }^{r}\end{array}$ & WEIGEL et al., 2001 \\
\hline pGEM/GH3 & $\begin{array}{l}\text { pGEM-Derivat, enthält ein } 900 \text { bp PCR- } \\
\text { Fragment des GH3-Gens aus Nicotiana } \\
\text { tabacum }\end{array}$ & diese Arbeit, Kapitel 4.6.3 \\
\hline
\end{tabular}




\begin{tabular}{|c|c|c|}
\hline Plasmid & Beschreibung & Referenz \\
\hline pGEM-T & $\begin{array}{l}\text { pGEM-5Zf(+)-Derivat, nach } \\
\text { Linearisierung mit EcoRV wurden dT- } \\
\text { Überhänge an die } 3^{\prime} \text {-Enden angehängt, } \\
\text { Klonier- und Sequenziervektor für PCR- } \\
\text { Produkte, lacZ } \alpha, \text { amp }^{r}\end{array}$ & Promega \\
\hline pHBT-2.1-sGFP & $\begin{array}{l}\text { pHBT-sGFP-Derivat, enthält die } \\
\text { Kodierregion der tga2.1-cDNA fusioniert } \\
\text { an das 5'-Ende von } s G F P\end{array}$ & NICKOLOV, 2002 \\
\hline pM35 & $\begin{array}{l}\text { pM001-Derivat, enthält eine CaMV 35S- } \\
\text { pAocs-Cassette als EcoRI / HindIII- } \\
\text { Fragment inseriert, } a m p^{r}, M T X^{r}\end{array}$ & $\begin{array}{l}\text { LENK, } \\
\text { unveröffentlicht }\end{array}$ \\
\hline pMSK1 & 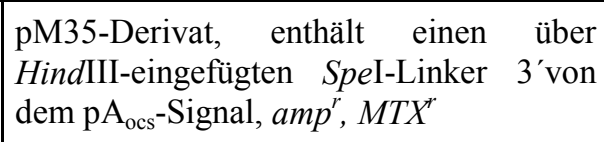 & diese Arbeit, Kapitel 4.6.2.1 \\
\hline pMSK2 & $\begin{array}{l}\text { pM35-Derivat, enthält einen über EcoRI- } \\
\text { eingefügten SpeI-Linker } \quad 5^{\prime} \text { vom } \\
\text { CaMV35S-Promotor, } a m p^{r}, M T X^{r}\end{array}$ & diese Arbeit, Kapitel 4.6.2.1 \\
\hline pMSK3 & $\begin{array}{llr}\text { pMSK1-Derivat, enthält } & \text { die } \\
\text { Kodierregion der tga2.1-cDNA in } \\
\text { korrekter Orientierung, } a m p^{r}, M T X^{r}\end{array}$ & diese Arbeit, Kapitel 4.6.2.1 \\
\hline pMSK4 & $\begin{array}{l}\text { pMSK2-Derivat, enthält } \\
\text { Kodierregion der tga2.1-cDNA in } \\
\text { entgegengesetzter Orientierung, } a m p^{r}, \\
M T X^{r}\end{array}$ & diese Arbeit, Kapitel 4.6.2.1 \\
\hline pMSK5 & $\begin{array}{l}\text { pMSK3-Derivat, enthält } \\
\text { Kodierregion der tga2.1-cDNA unter } \\
\text { Kontrolle des CaMV } \\
\text { korrekter und-Promotors in } \\
\text { Orientierung, } \mathrm{amp}^{r}, \mathrm{MTX}^{r}\end{array}$ & diese Arbeit, Kapitel 4.6.2.1 \\
\hline pNubI-Sbh1 cup 314 & $\begin{array}{l}\text { pRS314-Derivat, enhält } \\
\text { Fusionsprotein bestehend aus dem } \\
\text { aminoterminalen Teil des Ubiquitins } \\
(1-34 \text { aa) fusioniert an Sbh1, unter } \\
\text { Kontrolle des Cup1-Promotors, TRP1, } \\
\text { amp }^{r}\end{array}$ & JOHNSSON, unveröffentlicht \\
\hline pSK2611 & $\begin{array}{l}\text { pSK-Derivat, enthält das } 2,1 \mathrm{kB} \text { cDNA- } \\
\text { Fragment von Klon 26-1-1, tga2.1-cDNA } \\
\text { aus Nicotiana tabacum vollständig mit 5' } \\
\text { und 3'UTR, amp }\end{array}$ & NiGGEWEG, 1999 \\
\hline pSK7 & $\begin{array}{l}\text { PADNX-NubI-Derivat, enthält die } \\
\text { Kodierregion der tga2.1-cDNA fusioniert } \\
\text { über einen }\left(\mathrm{G}_{4} \mathrm{~S}\right)_{3} \text {-Linker an das } 5^{\prime} \text {-Ende } \\
\text { von NubI, } L E U 2, \text { amp }^{r}\end{array}$ & diese Arbeit, Kapitel 4.6.1.2 \\
\hline pSKL6 & $\begin{array}{l}\text { Pcup1-Cub-Rura314-Derivat, enthält die } \\
\text { Kodierregion der tga2.1-cDNA fusioniert } \\
\text { über einen }\left(\mathrm{G}_{4} \mathrm{~S}\right)_{3} \text {-Linker an das 3'-Ende } \\
\text { von Cub, } T R P 1, \mathrm{amp}^{r}\end{array}$ & diese Arbeit, Kapitel 4.6.1.1 \\
\hline
\end{tabular}




\begin{tabular}{l|l|l}
\hline Plasmid & Beschreibung & Referenz \\
\hline pTxFGC2.1 & $\begin{array}{l}\text { pFGC5941 gatewayRNAi-Derivat, enthält } \\
257 \text { bp-Fragmente des aminoterminalen } \\
\text { Teils von tga2.1 in entgegengesetzter und } \\
\text { korrekter Orientierung verbunden durch } \\
\text { das CHSA-Intron unter Kontrolle des Tx- } \\
\text { Promotors, } \text { kan }^{r}, P P T\end{array}$ & \\
\hline pTxBluescript & $\begin{array}{l}\text { pSK-Derivat, enthält den Tx-Promotor, Kapitel 4.6.2.3 } \\
\text { amp }\end{array}$ & HERRANN, 2003 \\
\hline pUC572.1VPs & $\begin{array}{l}\text { enthält die 1818 bp lange Kodierregion } \\
\text { für ein Fusionsprotein bestehend aus } \\
\text { TGA2.1-VP16-Aktivierungsdomäne- }\end{array}$ & LENK, 2001 \\
& Streptag ${ }^{\circledR}$ II in pUC57, amp & \\
\hline pUC57VP2.1s & $\begin{array}{l}\text { enthält die 1812 bp lange Kodierregion } \\
\text { für ein Fusionsprotein bestehend aus } \\
\text { VP16-Aktivierungsdomäne-TGA2.1- } \\
\text { Streptag }{ }^{\circledR} \text { II in pUC57, amp }\end{array}$ & LENK, 2001 \\
\hline
\end{tabular}

\subsubsection{Hybridisierungssonden}

\begin{tabular}{|c|c|c|}
\hline Sonde & Eigenschaften & Referenz \\
\hline Nt103 & $\begin{array}{l}900 \text { bp EcoRI-Fragment aus dem } \\
\text { Vektor pSKNT } 103\end{array}$ & VAN DER ZAAL et al., 1991 \\
\hline$N t G H 3$ & $\begin{array}{l}900 \text { bp NcoI / BcuI-Fragment aus } \\
\text { dem Vektor pGEM/GH3 }\end{array}$ & PERROT-RECHENMANN, 1997 \\
\hline PRla & $\begin{array}{lcr}531 \text { bp } & \text { EcoRI / BamHI-Fragment } \\
\text { aus } & \text { dem } & \text { Vektor } \\
\text { pPR-1a } & & \end{array}$ & $\begin{array}{l}\text { CUTT et al., 1988, Plasmid von M. } \\
\text { DRÖGE }\end{array}$ \\
\hline $\operatorname{tg} a 2.1$ & $\begin{array}{l}1700 \text { bp Acc65I / BamHI- } \\
\text { Fragment aus dem Vektor pSK } 2.1 \\
\text { in vitro }\end{array}$ & NIGGEWEG und GATZ, 1997 \\
\hline $\operatorname{tga} 2.2$ & $\begin{array}{l}1300 \text { bp Acc65I / BamHI- } \\
\text { Fragment aus dem Vektor pSK } 2.2 \\
\text { in vitro }\end{array}$ & NIGGEWEG, 1999 \\
\hline
\end{tabular}

\subsubsection{DNA-Fragmente für Gelretardationsanalysen}

Als Gelshift-Sonde wurde das ,as-1 short“ Element (84 bp) verwendet, welches durch einen Verdau mit BpiI aus dem Vektor pUC18 as-1 BpiI (KEGLER, 2001) herausgespalten wurde:

TTTTGCGTCTTCGCATGCCTGCAGGTCGACTctagaTGACGtaagggaTGACGcactCTAGAGGATCC CCGGGTACGAAGACGC 


\subsubsection{DNA-Fragmentlängenstandard}

Die Größe von DNA-Fragmenten wurde im Agarosegel durch Vergleich mit DNA-Längenstandards bestimmt. Die Fragmentgrößen dieser Marker (in bp) sind aufgeführt.

$1 \mathrm{~kb}$-Leiter (GIBCO BRL):

12216 / 11198 / 10180 / 9162 / 8144 / 7126 / 6108 / 5090 / 4072 / 3054 / 2036 / 1636 / 1018 / 517 / 506 / $396 / 344$ / $298 / 220 / 201 / 154 / 134 / 75$

pUC19HpaII (aus Eigenherstellung):

$501 / 489$ / 404 / 331 / 242 / 190 / 147 / 111 / 110 / 67

\subsection{Organismen}

\subsubsection{Bakterien und Hefe}

\begin{tabular}{|c|c|c|}
\hline Bakterien- / Hefestamm & Eigenschaften & Referenz \\
\hline $\begin{array}{l}\text { Escherichia coli } \\
\text { DH5 } \alpha\end{array}$ & $\begin{array}{l}\mathrm{F}^{-}, \text {gyrA96 (Nalr), recA1, relA1, end } \mathrm{A} 1, \text { thi-1, } \\
\text { hsdR17 (rk-mk+), glnV44, deo R, D (lacZYA- } \\
\operatorname{argF}) \mathrm{U} 169 \text { [p80dD(lacZ)M15] }\end{array}$ & HANAHAN, 1983 \\
\hline $\begin{array}{l}\text { Escherischia coli } \\
\text { DB3.1 }\end{array}$ & 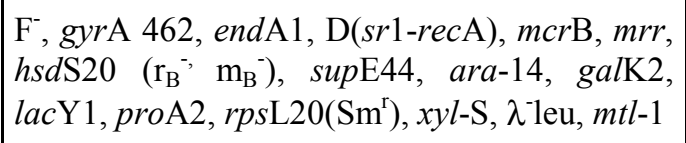 & BERNARD, 1993 \\
\hline $\begin{array}{l}\text { Agrobacterium tumefaciens } \\
\text { pGV3101 (pMP90RK) }\end{array}$ & rif $^{r}, \mathrm{kan}^{r}$ & $\begin{array}{l}\text { KONCZ und SCHELL, } \\
1986\end{array}$ \\
\hline $\begin{array}{l}\text { Agrobacterium tumefaciens } \\
\text { C58-C1-R pGV2260 }\end{array}$ & $\mathrm{rif}^{r}, \mathrm{~cm}^{r}$ & DEBLAERE et al., 1985 \\
\hline $\begin{array}{l}\text { Saccharomyces cerevisiae } \\
\text { NLY2 }\end{array}$ & $\begin{array}{l}\text { ADE2-, HIS3 } \triangle 200, \text { LEU2-1, LYS2::hisG, } \\
\text { TRP1::hisG, URA3-52, GAL4', GAL80" } \\
\text { MAT } \alpha\end{array}$ & $\begin{array}{l}\text { JOHNSSON, } \\
\text { unveröffentlicht }\end{array}$ \\
\hline $\begin{array}{l}\text { Saccharomyces cerevisiae } \\
\text { JD53 Ssh1CubRura303 }\end{array}$ & $\begin{array}{l}\text { URA3-52, } \quad \text { LEU2 } 3,112, \quad \text { TRP1- } \Delta 63, \\
\text { SSH1::Cub-RURA3 HIS3, LYS2-801 }\end{array}$ & $\begin{array}{l}\text { JOHNSSON, } \\
\text { unveröffentlicht }\end{array}$ \\
\hline $\begin{array}{l}\text { Saccharomyces cerevisiae } \\
\text { PJ69-4A }\end{array}$ & $\begin{array}{l}\text { MAT } \alpha, \operatorname{trp} 1-901, \text { leu2-3,112, ura3-52, his3- } \\
200, \quad \text { gal4 } \Delta, \quad \text { gal80 } \Delta, \quad \text { GAL2-ADE2, } \\
\text { LYS2 ::GAL1-HIS3, met2::GAL7-lacZ }\end{array}$ & JAMES et al.,1996 \\
\hline $\begin{array}{l}\text { Saccharomyces cerevisiae } \\
\text { YTSH1 }\end{array}$ & $\begin{array}{l}\text { YM4271-Derivat mit HIS3 unter Kontrolle } \\
\text { von } 3 \mathrm{x} \text { as-1MAT } \alpha \text {, URA3-52, HIS3-200, } \\
\text { ADE2-101, LYS2-801, LEU2-3, 112, TRP1- } \\
\text { 901, TYR1-501, GAL4- } \Delta 512 \text {, GAL80- } \Delta 538 \text {, } \\
\text { ADE5::hisG }\end{array}$ & SIEMSEN, 2002 \\
\hline
\end{tabular}




\subsubsection{Pflanzen}

Als Wildtyppflanzen wurde das Kultivar Samsun NN (SNN) von Nicotiana tabacum verwendet. Die eingesetzten transgenen Pflanzen sind in der nachfolgenden Übersicht aufgelistet.

\begin{tabular}{|c|c|c|}
\hline Pflanze & Beschreibung & Referenz \\
\hline SNN2.2UE \#8 & $\begin{array}{l}\text { enthält } \quad \text { pBINHyg-TGA2.2UE, } \\
\text { Hyg }^{r}\end{array}$ & NiGGEWEG, 1999 \\
\hline SNN pMSK5 & $\begin{array}{l}\text { Ausgangspflanze SNN: } \\
\text { enthält das tga2.1RNAi-Konstrukt } \\
\text { pMSK5 unter Kontrolle des } \\
\text { CaMV } 35 S \text {-Promotors, } M T X^{r}\end{array}$ & diese Arbeit \\
\hline SNN2.2UE pMSK5 & $\begin{array}{l}\text { Ausgangspflanze: SNN } \\
\text { enthält das tga2.1RNAi-Konstrukt } \\
\text { pMSK5 unter Kontrolle des } \\
\text { CaMV } 35 S \text {-Promotors, Hyg } \\
M T X^{r}\end{array}$ & diese Arbeit \\
\hline SNN pFGC2.1 & $\begin{array}{l}\text { Ausgangspflanze SNN: } \\
\text { enthält das tga2.1RNAi-Konstrukt } \\
\text { pFGC2.1 unter Kontrolle des } \\
\text { CaMV 35S-Promotors, } \mathrm{Hyg}^{r}, P P T^{r}\end{array}$ & diese Arbeit \\
\hline SNN2.2UE pFGC2.1 & $\begin{array}{l}\text { Ausgangspflanze: SNN } \\
\text { enthält das tga2.1RNAi-Konstrukt } \\
\text { pFGC2.1 unter Kontrolle des } \\
\text { CaMV 35S-Promotors, } \mathrm{Hyg}^{r}, P P T^{r}\end{array}$ & diese Arbeit \\
\hline Hö20.20 & $\begin{array}{l}\text { enthält TetR unter Kontrolle des } \\
C a M V \text { 35S-Promotors, } \mathrm{Km}^{r}\end{array}$ & HÖFGEN, unveröffentlicht \\
\hline Hö pTxFGC2.1 & $\begin{array}{l}\text { Ausgangspflanze: Hö20.20 } \\
\text { enthält das tga2.1RNAi-Konstrukt } \\
\text { pTxFCG2.1 unter Kontrolle des } \\
T x \text {-Promotors, } \mathrm{Km}^{r}, P P T^{r}\end{array}$ & diese Arbeit \\
\hline
\end{tabular}




\subsection{Nährmedien und Zusätze}

\subsubsection{Nährmedien für Bakterien}

LB-Medium: $\quad 10$ g/l Trypton, 5 g/l Hefeextrakt, 10 g/1 NaCl

dYT-Medium: $\quad 20 \mathrm{~g} / \mathrm{l}$ Trypton, $10 \mathrm{~g} / \mathrm{l}$ Hefeextrakt, $10 \mathrm{~g} / 1 \mathrm{NaCl}$

SOC-Medium: $\quad 20 \mathrm{~g} / \mathrm{l}$ Trypton, $5 \mathrm{~g} / 1$ Hefeextrakt, $10 \mathrm{mM} \mathrm{NaCl} ; 2,5 \mathrm{mM} \mathrm{KCl}$, nach dem Autoklavieren sterilfiltriert zugeben: $10 \mathrm{mM} \mathrm{MgCl}_{2}, 10 \mathrm{mM} \mathrm{MgSO}, 20 \mathrm{mM}$ Glukose

YEB-Medium: $\quad 5 \mathrm{~g} / 1$ Rinderextrakt, $2 \mathrm{~g} / \mathrm{l} \mathrm{Hefeextrakt,} 5 \mathrm{~g} / 1$ Pepton, $5 \mathrm{~g} / 1$ Saccharose, $2 \mathrm{mM} \mathrm{MgSO}_{4}$

Für die Herstellung von Festmedien wurden $15 \mathrm{~g} / \mathrm{l}$ bakteriologischer Agar zugesetzt.

\subsubsection{Nährmedien für Hefe}

YPDA-Medium: $\quad 10 \mathrm{~g} / 1$ Select Yeast Extract, $20 \mathrm{~g} / 1$ Pepton, $20 \mathrm{~g} / 1$ Glucose-Monohydrat, $100 \mathrm{mg} / \mathrm{l}$ L-Adenin-Hemisulfat, $\mathrm{pH}$ 6,0 mit HCl

SD-Medium:

6,7 g/l Yeast Nitrogen Base (ohne Aminosäuren), 20 g/l Glukose-Monohydrat, 0,61 g/1 CSM-ADE-HIS-LEU-TRP oder 0,62 g/1 CSM-TRP-LEU-URA oder $0,61 \mathrm{~g} / 1$ CSM-HIS-TRP-LEU-URA, pH 5,6 mit $\mathrm{NaOH}$, nach dem Autoklavieren die fehlenden Komponenten aus Stocklösungen zugeben

40 x ADE-Stocklösung: $400 \mathrm{mg} / \mathrm{l} \mathrm{L}-\mathrm{Adenin}-\mathrm{Hemisulfat}$ in $\mathrm{H}_{2} \mathrm{O}$

$40 \times$ HIS-Stocklösung $800 \mathrm{mg} / \mathrm{l}$ L-Histidin in $\mathrm{H}_{2} \mathrm{O}$

$40 \times$ LEU-Stocklösung $\quad 4 \mathrm{~g} / \mathrm{l}$ Leucin in $\mathrm{H}_{2} \mathrm{O}$

$40 \times$ URA-Stocklösung $2 \mathrm{~g} / 1$ Uracil in $\mathrm{H}_{2} \mathrm{O}$

$\mathrm{CuSO}_{4}$-Stocklösung $\quad 1 \mathrm{M} \mathrm{CuSO}_{4}$ in $\mathrm{H}_{2} \mathrm{O}$ 
5-FOA-Stocklösung $\quad 1 \mathrm{~g} \mathrm{5-FOA} \mathrm{in} 100 \mathrm{ml} \mathrm{H}_{2} \mathrm{O}$ lösen, $\mathrm{pH}$ 7,0 mit $\mathrm{NaOH}$ einstellen

3-AT-Stocklösung $\quad 1 \mathrm{M}$ 3-amino-1,2,4-triazol in $\mathrm{H}_{2} \mathrm{O}$

Für die Herstellung von Festmedien wurden 8 g/l Select Agar zugesetzt.

\subsubsection{Nährmedien für Pflanzen}

2 MS-Medium: $\quad$ 4,59 g/l Murashige und Skoog Medium, 20 g/l Saccharose, 6,4 g/l Select-Agar, $\mathrm{pH}$ mit $\mathrm{KOH}$ auf 5,7

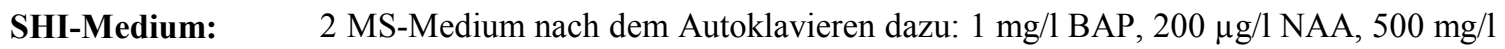
Cefotaxim oder $250 \mathrm{mg} / 1$-Bactyl, sowie das entsprechende Selektionsantibiotikum

\subsubsection{Zusätze}

\begin{tabular}{l|c|l}
\hline Zusatz & Endkonzentration [mg/l] & Stammlösung [mg/ml] \\
\hline Ampicillin & 100 & 100 in $\mathrm{H}_{2} \mathrm{O}$ \\
\hline$\beta$-Bactyl & 125 & 125 in $\mathrm{H}_{2} \mathrm{O}$ \\
\hline Cefotaxim & 500 & 250 in $\mathrm{H}_{2} \mathrm{O}$ \\
\hline Gentamycin & 25 & 25 in $\mathrm{H}_{2} \mathrm{O}$ \\
\hline IPTG & 50 & 23,8 in $\mathrm{H}_{2} \mathrm{O}$ \\
\hline Kanamycin & 50 & 50 in $\mathrm{H}_{2} \mathrm{O}$ \\
\hline Methotrexat & 0,5 & 0,5 in $\mathrm{H}_{2} \mathrm{O}$ \\
\hline Phosphinotrizin & 6 & $10 \quad$ in $\mathrm{H}_{2} \mathrm{O}$ \\
\hline Rifampicin & 50 & 10 in $\mathrm{Methanol}$ \\
\hline X-Gal & 40 & 20 in $\mathrm{DMF}$ \\
\hline
\end{tabular}




\section{Methoden}

\subsection{Anzucht von Organismen}

\subsubsection{Bakterien}

Die Anzucht von E.coli erfolgte auf LB-Festmedium oder in dYT-Flüssigmedium über Nacht bei $37^{\circ} \mathrm{C}$.

Agrobacterium tumefaciens wurde auf YEB-Festmedium oder in YEB-Flüssigmedium bei $28^{\circ} \mathrm{C}$ über zwei bis drei Tage angezogen.

Die Medien enthielten entsprechende Antibiotika, um das Wachstum von Resistenz-tragenden Bakterien unter Selektionsdruck zu gewährleisten. Die Inkubation von Flüssigkulturen wurde im Schüttler bei $250 \mathrm{rpm}$ durchgeführt.

\subsubsection{Hefen}

Das Wachstum von Saccharomyces cerevisiae erfolgte bei $30^{\circ} \mathrm{C}$, wobei Flüssigkulturen bei 250 rpm geschüttelt wurden. Die Stämme NLY2, PJ69-4A und YTSH1 wurden auf YPDA-Platten über zwei Tage, in YPDA-Flüssigmedium über Nacht angezogen. Transformierte Hefezellen wurden auf SDPlatten für drei bis sieben Tage selektioniert oder in SD-Flüssigmedium über Nacht angezogen. Dem Medium fehlten die Komponenten, die bei Expression der entsprechenden Selektionsgene von den Zellen selbst synthetisiert werden konnten.

\subsubsection{Tabakpflanzen}

Tabakpflanzen wurden unter sterilen Bedingungen auf 2MS-Festmedium (MURASHIGE und SKOOG, 1962) in Gläsern kultiviert. Die Anzucht erfolgte in Klimakammern bei $24^{\circ} \mathrm{C}$ am Tag und $22^{\circ} \mathrm{C}$ in der Nacht in einem Licht-Dunkel-Rhythmus von 16 h/8 h. Subkultiviert wurden die Pflanzen durch Abschneiden und Umsetzen der Sproßspitze auf frisches Medium.

Für die Kultivierung unter unsterilen Bedingungen wurden die Pflanzen aus der Sterilkultur in Erde umgesetzt und in Klimakammern bei $22^{\circ} \mathrm{C}$ am Tag und $19^{\circ} \mathrm{C}$ in der Nacht bei $85 \%$ Luftfeuchte in einem Licht-Dunkel-Rhythmus von $16 \mathrm{~h} / 8 \mathrm{~h}$ angezogen.

\subsection{Induktion der Genexpression in Tabakpflanzen}

Für die Induktion wurden vier bis sechs Wochen alte in Erde kultivierte Tabakpflanzen verwendet. Aus den Blättern wurden mit Hilfe eines Korkbohrers Blattscheiben ausgestochen (Durchmesser $2,6 \mathrm{~cm}$ ) und mit der Blattunterseite auf $50 \mathrm{mM}$ Kaliumphosphatpuffer $\mathrm{pH} 5,8$ gelegt. Die Induktionschemikalien wurden unmittelbar vor dem Start des Versuches zugesetzt. Die Inkubation der Blattscheiben erfolgte in Petrischalen im Klimaschrank bei $24^{\circ} \mathrm{C}$ am Tag und $22^{\circ} \mathrm{C}$ in der Nacht in einem Licht-Dunkel-Rhythmus von $16 \mathrm{~h} / 8 \mathrm{~h}$ und $75 \%$ Luftfeuchte. Zu verschiedenen Zeitpunkten wurden jeweils zwei Blattscheiben auf Zellstoff leicht abgetrocknet und bei $-80^{\circ} \mathrm{C}$ gelagert. 


\begin{tabular}{lll}
\hline Chemikalie & Stammlösung & Endkonzentration \\
\hline 2,4-D & $50 \mathrm{mM}$ in DMSO & $50 \mu \mathrm{M}$ \\
\hline Salicylsäure & $1 \mathrm{M}$ in DMSO & $1 \mathrm{mM}$ \\
\hline
\end{tabular}

\subsection{Epinastietest}

Die Reaktion einer Tabakpflanze auf externe Auxinzugaben kann mit Hilfe eines Tests, der die epinastische Krümmung von Blattstreifen in Puffer mit und ohne Auxinzugabe untersucht, (KELLER und VAN VOLKENBURG, 1997) bestimmt werden.

Dazu wurden 10 x 1,5 mm große Streifen parallel zu den sekundären Blattadern mit einer Rasierklinge aus den Blättern ausgeschnitten und in Epinastiepuffer (10 mM Saccharose, $10 \mathrm{mM} \mathrm{KCl}$, 0,5 mM MES/ BisTris-Propan pH 6,0) mit oder ohne Zugabe von $10 \mu \mathrm{M}$ 1-NAA überführt, welches unmittelbar vor Beginn des Versuches als $10 \mathrm{mM}$ Stammlösung in DMSO angesetzt und entsprechend in Epinastiepuffer verdünnt wurde. Die Inkubation erfolgte für $24 \mathrm{~h}$ in Petrischalen im Klimaschrank bei $24^{\circ} \mathrm{C}$ am Tag und $22^{\circ} \mathrm{C}$ in der Nacht bei einer Luftfeuchte von 75 \%. Die Proben durften dabei nicht einer direkten Lichteinstrahlung ausgesetzt sein.

\subsection{Infektion von Tabakpflanzen mit dem Tabak-Mosaik-Virus (TMV)}

Die Infektion von Tabakpflanzen mit dem Tabak-Mosaik-Virus (TMV) erfolgte nach YALPANI et al., 1999. Für die Infektion wurden vier bis sechs Wochen alte, in Erde kultivierte Tabakpflanzen verwendet. Pro Blatt wurden $5 \mathrm{mg}$ TMV, suspendiert in $50 \mathrm{mM}$ Kaliumphosphatpuffer $\mathrm{pH}$ 7,0, mit Carborundum und Wattepads auf die Blattoberseite gerieben. Die infizierten Tabakpflanzen wurden in der Klimakammer bei $22^{\circ} \mathrm{C}$ am Tag und $19^{\circ} \mathrm{C}$ in der Nacht bei $85 \%$ Lufteuchte in einem Licht-Dunkel-Rhythmus von $16 \mathrm{~h} / 8 \mathrm{~h}$ weiterkultiviert.

\subsection{Molekulargenetische Standardmethoden}

\subsubsection{Isolierung von Plasmid-DNA aus Bakterien}

\subsubsection{Analytische Mengen}

\subsection{Alkalische Lyse}

Für die schnelle Präparation von Plasmid-DNA zu analytischen Zwecken wurde eine modifizierte alkalische Lyse zum Aufschluss von der Bakterien durchgeführt (LE GOUILL et al., 1994). 1,5 ml einer stationären E.coli-Kultur wurden in einer Tischzentrifuge (1 min, $13.000 \mathrm{rpm}$, RT) pelletiert und die Zellen nach Dekantieren des Überstandes in $100 \mu$ l Puffer I (50 mM Tris-HCl pH 8,0, 10 mM EDTA, $100 \mu \mathrm{g} / \mathrm{ml}$ RNaseA) resuspendiert. Die Lyse der Bakterien erfolgte durch Zugabe von $200 \mu 1$ Puffer II $(0,2 \mathrm{M} \mathrm{NaOH}, 1 \%(\mathrm{w} / \mathrm{v}) \mathrm{SDS})$ und $200 \mu \mathrm{l}$ Chloroform. Nach einminütiger Inkubation wurden $150 \mu \mathrm{l}$ Puffer III (29,4 g Kaliumacetat, 5 ml Eisessig, $\mathrm{H}_{2} \mathrm{O}$ ad $100 \mathrm{ml}$ ) zur Neutralisation zugegeben, die Ansätze gevortext und die entstandenen Präzipitate durch zweiminütige Zentrifugation bei $13.000 \mathrm{rpm}$ abgetrennt. Die obere, wässrige Phase $(400 \mu \mathrm{l})$ wurde in neue Reaktionsgefäße überführt und zur Fällung der Plasmid- 
DNA mit 2 Vol. eiskaltem Ethanol gemischt. Nach anschließender Zentrifugation für zwei Minuten bei $13.000 \mathrm{rpm}$ wurde die sedimentierte DNA mit $70 \%(\mathrm{v} / \mathrm{v})$ Ethanol gewaschen und für 20 min bei RT getrocknet. Die Plasmid-DNA wurde in 30-50 $\mu \mathrm{H}_{2} \mathrm{O}$ gelöst und konnte dann für Restriktionsanalysen (jeweils 2-5 $\mu \mathrm{l}$ ) eingesetzt werden.

\subsection{Plasmidisolation mit dem QIAprep Spin Miniprep-Kit}

Für Sequenzierreaktionen wurde hochreine Plasmid-DNA mit Hilfe des QIAprep Spin Miniprep-Kits isoliert. Die Präparation erfolgte nach Herstellerangaben, wobei die als optional angeführten Schritte immer berücksichtigt wurden. Abweichend vom Protokoll wurden stets $3 \mathrm{ml}$ stationäre E. coli-Kultur eingesetzt und die DNA mit $30 \mu \mathrm{l}$ EB-Puffer $(10 \mathrm{mM}$ Tris-HCl, pH 8,5) eluiert.

\subsubsection{Präparative Mengen}

Größere Mengen Plasmid-DNA mit hohem Reinheitsgrad wurden mit Hilfe der Midi- und Maxi-Kits der Firma Qiagen isoliert. Die Durchführung erfolgte gemäß den Herstellerangaben.

\subsubsection{Gewinnung von Plasmid-DNA aus Hefe}

Um Plasmide aus Hefezellen zu isolieren, wurden zunächst 1,5 ml einer unter Selektionsbedingungen angezogenen Übernachtkultur abzentrifugiert ( $1 \mathrm{~min}, 13.000 \mathrm{rpm}, \mathrm{RT}$ ). Nach dem Entfernen des Mediums wurde das Zellpellet in $30 \mu \mathrm{l}$ Lyticase-Lösung (5 U/ $\mu$ l in TE, $\mathrm{pH} 7,5)$ resuspendiert und unter Schütteln

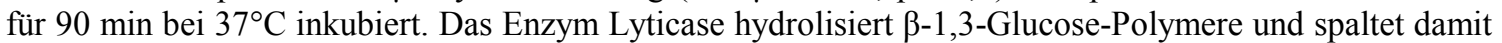
das Glucan der Hefezellwände. Aus den resultierenden Sphäroplasten wurde die Plasmid-DNA mit Hilfe des QIAprep Spin Miniprep-Kits gewonnen. Die Präparation erfolgte wie vom Hersteller für E. coli angegeben, wobei die als optional angeführten Schritte immer berücksichtigt wurden. Die DNA wurde mit $30 \mu$ EB-Puffer (10 mM Tris-HCl, pH 8,5) eluiert. Da Ausbeute und Reinheit (Kontamination mit genomischer DNA) der Hefe-Plasmidpräparation für analytische Zwecke nicht ausreichen, wurden jeweils $10 \mu l$ der eluierten DNA in E. coli-Zellen transformiert (Kapitel 4.5.15.2) und nach Amplifikation aus den Bakterien erneut isoliert (Kapitel 4.5.1.1.1).

\subsubsection{Ethanolfällung von Nukleinsäuren aus wässrigen Lösungen}

Um Nukleinsäuren aus wässrigen Lösungen von Salzen zu reinigen und um eine definierte Konzentration zu erreichen, wurden sie einer Ethanolfällung unterzogen. Dabei wurde der Nukleinsäure-Lösung 1/10 Volumen 3 M Natriumacetat, pH 5,2 zugegeben und mit zwei Volumen $100 \%$ Ethanol gemischt. Die Nukleinsäure fällt aus, während Salze und Verunreinigungen gelöst bleiben. Die Fällung erfolgte bei $-20^{\circ} \mathrm{C}$ für mindestens zwei Stunden. Danach wurde die Nukleinsäure für $20 \mathrm{~min}$ bei $13.000 \mathrm{rpm}$ in einer Tischzentrifuge pelletiert, mit $70 \%$ Ethanol gewaschen, getrocknet und in einem definierten Volumen $\mathrm{H}_{2} \mathrm{O}$ gelöst.

\subsubsection{Isolierung von RNA aus Nicotiana tabacum}

Zur Präparation von Gesamt-RNA aus Blattgewebe wurde der RNeasy Plant Mini-Kit der Firma Qiagen verwendet. Poly(A)-mRNA wurde aus Gesamt-RNA mit dem Qiagen Oligotex Mini Kit isoliert. Die Isolierung erfolgte jeweils nach Herstellerangaben. 


\subsubsection{Konzentration- und Reinheitsbestimmung von Nukleinsäuren}

Die Konzentration von einer wässrigen Nukleinsäurelösung kann man bestimmen, indem man ihre Absorption im UV-Licht bei einer Wellenlänge von $260 \mathrm{~nm}$ misst. Das Absorptionsmaximum von Nukleinsäuren bei dieser Wellenlänge hat seine Ursache in der Anregung der $\pi$-Elektronen in den Heterozyklen der Basen durch elektromagnetische Strahlung. Eine $\mathrm{OD}_{260}=1,0$ entspricht einer Nukleinsäurekonzentration von $50 \mu \mathrm{g} / \mathrm{ml}$ bei dsDNA und $40 \mu \mathrm{g} / \mathrm{ml}$ bei RNA in einer Schichtdicke von $1 \mathrm{~cm}$. Bei einer Wellenlänge von $280 \mathrm{~nm}$ haben die aromatischen Seitenketten der Proteine ihr Absorptionsmaximum. Bestimmt man sowohl die $\mathrm{OD}_{260}$ als auch $\mathrm{OD}_{280}$ einer Nukleinsäurelösung, so stellt der Quotient der beiden Werte $\mathrm{OD}_{260} / \mathrm{OD}_{280}$ ein $\mathrm{Ma} 3$ für den Reinheitsgrad der Nukleinsäure dar. Er sollte idealerweise zwischen 1,8-2,0 liegen. Die Messungen erfolgten mit dem Gene Quant II der Firma Pharmacia, wobei die Nukleinsäuren soweit verdünnt wurden, dass die $\mathrm{OD}_{260}$ im Messbereich des Gerätes zwischen 0,1 und 1,0 lag.

\subsubsection{Gelelektrophorese von Nukleinsäuren}

\subsubsection{Auftrennung von DNA in Agarosegelen}

Die elektrophoretische Auftrennung von DNA für analytische und präparative Zwecke wurde in horizontalen Agarosegelen (10 cm x $7 \mathrm{~cm}$ x 0,3 cm, 16 Taschen) mit 1 x TAE (40 mM Tris- $\mathrm{HCl} \mathrm{pH} 8,0$, $1,15 \%$ (v/v) Essigsäure, $1 \mathrm{mM}$ EDTA) als Laufpuffer durchgeführt. Für DNA-Moleküle im Größenbereich von 500 bp bis 14 kb wurden Gele mit einer Konzentration von $1 \%$ oder 0,7 \% (w/v) Agarose in $1 \times$ TAE benutzt. Für die Auftrennung kleinerer Moleküle wurden sogenannte HEC-Gele (1\% (w/v) Agarose und 0,7 \% (w/v) Hydroxyethylcellulose (HEC) in 1 x TAE) eingesetzt (PERLMAN und HALVORSON, 1987). Die DNA-Proben wurden zunächst mit 1/10 Volumen Probenpuffer (10 x Probenpuffer: $67 \%$ Saccharose, $50 \mathrm{mM}$ EDTA pH 8,0, jeweils 0,42 \% (w/v) Bromphenolblau, Xylencyanol FF und Orange G) versetzt und bei 90-120 V über einem Zeitraum von 0,5-1,5 Stunden elektrophoretisch aufgetrennt. Der Verlauf der Elektrophoresefront konnte anhand der Farbmarker verfolgt werden. Um die DNA im Anschluss an den Lauf sichtbar zu machen, wurde das Gel 10 min in einer Ethidiumbromidlösung ( $1 \mathrm{mg} / \mathrm{l} \mathrm{EtBr}$ in $\mathrm{H}_{2} \mathrm{O}$ ) inkubiert, anschließend der Gelhintergrund kurz in $\mathrm{H}_{2} \mathrm{O}$ entfärbt und der Bandenverlauf auf dem UV-Transilluminator $(302 \mathrm{~nm})$ mit Hilfe der Geldokumentationanslage dokumentiert.

\subsubsection{Auftrennung von DNA in Polyacrylamidgelen}

Polyacrylamid(PAA-)gele eignen sich für die Auftrennung von sehr kleinen Fragmenten (1-300 bp). In der vorliegenden Arbeit kamen native $5 \%$-ige PAA-Vertikalgele $(17 \mathrm{~cm} \mathrm{x} 15,5 \mathrm{~cm} \mathrm{x}$ $0,15 \mathrm{~cm}, 11$ Taschen, Kammersystem von GIBCO BRL) bei Gelretardationsexperimenten zum Einsatz, wo sie für die Präparation der radioaktiv markierten DNA-Fragmente und als Retardationsgele verwendet wurden (Kapitel 4.5.12.2).

Für ein PAA-Gel $(50 \mathrm{ml})$ wurde eine Lösung aus $5 \%(\mathrm{w} / \mathrm{v})$ Acrylamid: N,N'-Methylenbisacrylamid (19:1), $10 \%$ (v/v) Glycerin, und 1 x TBE (0,1 M Tris, 0,1 M Borsäure, 2 mM EDTA) mit 0,04 \% (v/v) TEMED und $0,06 \%$ (v/v) APS versetzt und zügig zwischen zwei Glasplatten gegossen. Vor dem Auftragen der Proben sollte das Gel mindestens fünf Stunden auspolymerisiert sein. Die Elektrophorese erfolgte in $1 \mathrm{x}$ TBE $\left(0,1 \mathrm{M}\right.$ Tris, $0,1 \mathrm{M}$ Borsäure, $2 \mathrm{mM}$ EDTA) als Laufpuffer bei $150 \mathrm{~V}$ und $4^{\circ} \mathrm{C}$, um ein Überhitzen des Gels zu vermeiden. Die Farbmarker der Auftragspuffer (Kapitel 4.5.6.1) wandern in einem nativen $5 \%$-igen PAA-Gel wie folgt:

Bromphenolblau verhält sich wie ein 35 bp-DNA-Fragment

Xylencyanol FF verhält sich wie ein 130 bp-DNA-Fragment 


\subsubsection{Auftrennung von RNA in denaturierenden Agarosegelen}

Die elektrophoretische Auftrennung von RNA erfolgte unter denaturierenden Bedingungen, um das Ausbilden von Sekundärstrukturen zu verhindern. Die Elektrophorese fand in horizontalen, formaldehydhaltigen Agarosegelen (1\%(w/v) Agarose, 5,5\% (v/v) Formaldehyd) statt mit 1 x MEN (20 mM MOPS, 5 mM Natriumacetat, 1 mM EDTA, pH 7,0 mit NaOH) als Puffersystem. Die Gele hatten eine Größe von $15 \mathrm{~cm}$ x $10 \mathrm{~cm}$ x $1 \mathrm{~cm}$ und besaßen 15 ,große“ (90 $\mu$ l Probenvolumen) oder 20 „kleine“" (60 $\mu$ l Probenvolumen) Taschen. Vor dem Auftragen wurden jeweils $10 \mu \mathrm{g}$ der RNA mit RNase-freiem $\mathrm{H}_{2} \mathrm{O}$ auf gleiche Volumina gebracht und mit 3 x RNA-Probenpuffer ( 3 x MEN, 3,7 \% (v/v) Formaldehyd, $43 \%$ (v/v) Formamid, $10 \%$ (v/v) Glycerin, 4 mM EDTA, 0,1 \% (v/v) gesättigte Bromphenolblaulösung) versetzt, welcher $1 \mu \mathrm{g}$ Ethidiumbromid pro Ansatz enthielt. Die RNA-Proben wurden anschließend durch Inkubation bei $65^{\circ} \mathrm{C}$ für 5 min denaturiert und bis zum Auftragen auf Eis gelagert. Die Elektrophorese erfolgte nach Beladen des Gels und dem vollständigen Auffüllen (mit 1 x MEN) der Taschen bei 12 Watt für $0,2 \mathrm{kVh}$. Als Laufpuffer wurde $1 \mathrm{x}$ MEN verwendet, lediglich an das Gel angeschichtet, ohne es zu bedecken. Die Auftrennung der RNA wurde auf dem UV-Transilluminator mit Hilfe der Geldokumentationsanlage sichtbar gemacht.

\subsubsection{Elution von DNA-Fragmenten aus Elektrophoresegelen}

\subsubsection{Elution aus Agarosegelen}

Für die Isolierung von DNA-Fragmenten aus Agarosegelen wurde das QIAquick Gel Extraction Kit von Qiagen verwendet. Die Aufreinigung erfolgte nach Herstellerangaben. Die DNA wurde in $30 \mu 1$ EB-Puffer (10 mM Tris-HCl pH 8,5) von der Säule eluiert.

\subsubsection{Elution aus Polyacrylamidgelen}

Das gewünschte DNA-Fragment wurde aus dem Polyacrylamid(PAA-)Gel ausgeschnitten und das Gelstück in ein Reaktionsgefäß überführt. Die Elution der DNA erfolgte nach Zugabe von $400 \mu 1 \mathrm{TE}$ (10 mM Tris-HCl, $1 \mathrm{mM}$ EDTA pH 8,0), versetzt mit $5 \mathrm{mM} \mathrm{MgCl}_{2}$, bei $37^{\circ} \mathrm{C}$ über Nacht. Das PAA wurde durch fünfminütige Zentrifugation bei $13.000 \mathrm{rpm}$ in einer Tischzentrifuge sedimentiert und der Überstand in ein neues Reaktionsgefäß überführt. Die Methode der DNA-Elution aus PAA-Gelen kam bei der Präparation von radioaktiv markierten Fragmenten für Gelretardationsexperimente zum Einsatz.

\subsubsection{Hybridisierung von einzelsträngigen Oligonukleotiden zu Doppelsträngen}

Jeweils $1 \mathrm{nmol}$ der beiden komplementären, einzelsträgigen Oligonukleotide wurden in einem Gesamtvolumen von $20 \mu \mathrm{l}$ in einem Schraubdeckel-Reaktionsgefäß vereint und zur Auflösung von Sekundärstrukturen $10 \mathrm{~min}$ bei $100^{\circ} \mathrm{C}$ im Wasserbad aufgekocht. Die Hybridisierung erfolgte beim langsamen Abkühlen des Wasserbades auf Raumtemperatur.

\subsubsection{Restriktionsspaltung}

Doppelsträngige DNA kann mit Hilfe von Restriktionsenzymen des Typs II sequenzspezifisch gespalten werden. Je nach Enzym entstehen dabei 3'- oder 5'- überhängende (,sticky“) oder glatte (,,blunt“) DNAEnden. Die für die verschiedenen Restriktionsenzyme optimalen Reaktionsbedingungen wurden mit zehnfach konzentrierten Restriktionspuffern der Firma MBI Fermentas eingestellt. Die Aktivität von Restriktionsendonukleasen wird in „Units“ (U) angegeben, wobei mit 1 U die Enzymmenge definiert ist, die $1 \mu \mathrm{g} \lambda$-DNA (48500 bp) innerhalb von 60 Minuten unter optimalen Bedingungen vollständig spaltet. 
Die minimale Enzymmenge $\left(\mathrm{U}_{\mathrm{min}}\right)$, die $1 \mu \mathrm{g}$ einer Proben-DNA in einer Stunde komplett schneidet, errechnet sich nach folgender Formel:

$$
U \min =\frac{b p[\lambda] x \text { Schnittstellen }[D N A]}{\text { Schnittstellen }[\lambda] x b p[D N A]} \quad(\mathrm{bp}[\lambda]=48500)
$$

Da Art und Reinheitsgrad der DNA die Enzymaktivität beeinflussen, wurde für einen vollständigen Verdau meist ein Überschuss an Restriktionsenzym eingesetzt oder die Reaktionszeit verlängert. Um unspezifische Reaktionen durch zu hohe Glycerinkonzentrationen in den Spaltungsansätzen zu vermeiden, wurden die Volumina so gewählt, dass der Anteil der Enzymlösung am Gesamtvolumen unter $10 \%$ lag. Die Inkubation der Restriktionsansätze erfolgte in der Regel bei $37^{\circ} \mathrm{C}$, dem Temperaturoptimum der meisten Enzyme.

\subsubsection{Ligation}

Die T4-DNA-Ligase katalysiert eine Phosphordiesterbindung zwischen benachbarten 5'-Phosphat- und 3'$\mathrm{OH}-G r u p p e n$. Als Kosubstrat muss ATP in geeigneter Konzentration im Puffermedium vorliegen. Das zu inserierende DNA-Fragment wurde in 10-fachem molaren Überschuss zu der gespaltenen Vektor-DNA (50 fmol) zugegeben. Die Ligation erfolgte im Ligationspuffer (40 mM Tris-HCl, $10 \mathrm{mM} \mathrm{MgCl}, 10 \mathrm{mM}$ DTT, 0,5 mM ATP pH 7,5) mit 3 Units T4-DNA-Ligase. Bei „,blunt-end“ Ligationen wurde zusätzlich $5 \%$ (w/v) PEG 4000 in den Reaktionsansatz gegeben. Die Ligationsansätze mit einem Endvolumen von $15 \mu \mathrm{l}$ wurden mindestens $1 \mathrm{~h}$ bei RT inkubiert.

\subsubsection{Das GATEWAY ${ }^{\mathrm{TM}}$-Kloniersystem}

Das GATEWAY ${ }^{\text {тM }}$-Kloniersystem erlaubt die schnelle Klonierung eines Gens oder eines anderen DNAFragments in verschiedene Plasmide. Die Integration des Gens in den gewünschten Vektor erfolgt dabei mit hoher Effizienz und hoher Spezifität, da Orientierung und Leseraster erhalten bleiben. Dies ist besonders dann hilfreich, wenn durch die Integration des Gens in den Vektor neue Fusionsgene entstehen sollen. Im Vergleich zur herkömmlichen Klonierung mit Restriktionsenzymen und Ligasen beruht diese Methoden auf der orts- oder sequenzspezifischen Rekombination des Bakteriophagen $\lambda$ in das Wirtsgenom von E.coli. Die Integration des Phagengenoms in das Wirtsgenom basiert auf verschiedenen Erkennungssequenzen, der Phagen att $\mathrm{P}$ - und der Bakterien attB-sites. Für die Rekombination der attPsites und der attB-sites werden eine vom Bakteriophagen $\lambda$ codierte Integrase, sowie ein ,Integration host factor" (IHF) des Bakteriums benötigt (LEWIN, 1994). Durch die Rekombination wird das Phagengenom in das Bakteriengenom integriert und die Rekombinationsstellen attP und attB bleiben mit einer leichten Veränderung flankierend im Phagengenom als $a t t \mathrm{R}$-sites und $a t t \mathrm{~L}$-sites erhalten. Die att $\mathrm{L}$ - und attR-sites können wiederum genutzt werden, um das Phagengenom durch Rekombination aus dem Wirtsgenom freizusetzen und den lytischen Zyklus zu starten. Neben der Integrase und dem „Integration host factor“" wird hierfür noch eine Excisionase benötigt. Unter dem Zusammenwirken dieser Faktoren rekombinieren die $a t t \mathrm{R}$-sites und $a t t \mathrm{~L}$-sites miteinander und setzen das Phagengenom aus dem Wirtsgenom frei.

Die Ausgangsplasmide des GATEWAY ${ }^{\mathrm{TM}}$-Systems zeichnen sich dadurch aus, dass zwischen den Rekombinationsstellen das $c c d$ B-Gen inseriert ist, dessen Produkt toxisch für die Bakterien ist. Nur wenn dieses Gen bei der Rekombination durch das gewünschte DNA-Fragment erfolgreich ausgetauscht worden ist, können die Bakterien wachsen. Für die Amplifikation der Ausgangsvektoren, die das $c c d$ B-Gen enthalten, existiert der E. coli-Stamm DB3.1 (Kapitel 3.7.1), der aufgrund einer Mutation in der Gyrase gegenüber dem Produkt des $c c d \mathrm{~B}-\mathrm{Gens}$ resistent ist.

Die BP-Reaktion, welche der Phagenintegration entspricht, dient zur Herstellung von Eingangsplasmiden, bei der attB-sites eines PCR-Produktes mit den attP-sites eines Donor-Vektors rekombiniert werden. Damit das PCR-Produkt in der richtigen Orientierung in den Vektor rekombiniert wird, gibt es zwischen den $a t t \mathrm{~B} 1$ - und $a t t \mathrm{~B} 2$-sites wie zwischen den $a t t \mathrm{P} 1$ und $a t t \mathrm{P} 2$-sites kleine DNA-Sequenz-Unterschiede, die dazu führen, dass attB1 immer mit attP1 und attB2 immer mit attP2 rekombiniert. Durch die Rekombination entsteht das Eingangsplasmid, ohne $c c d$ B-Gen, jedoch mit dem eingefügten PCR-Produkt. Die Eingangsplasmide können durch eine Antibiotikaresistenz selektioniert werden. 
Die Herstellung der Expressionsvektoren (LR-Reaktion) aus Eingangsplasmiden entspricht der Phagengenom-Excisionsreaktion. Hierbei rekombinieren die zwei attL-sites des Eingangsplasmids mit den attR-sites des Zielvektors. Auch hier bleibt durch geringfügige DNA-Sequenzunterschiede zwischen L1 und L2 sowie R1 und R2 die gewollte Orientierung der Inserts erhalten. Aus dem Expressionsvektor lässt sich das gewünschte Gen über eine weitere BP-Reaktion wieder in ein Eingangsplasmid rekombinieren.

Die Klonierung mit dem GATEWAY ${ }^{\text {TM}}$-System wurde nach Herstellerangaben durchgeführt (Instruction Manuel GATEWAY ${ }^{\mathrm{TM}}$ Cloning Technonlogy, GIBCOBRL LIFE TECHNOLOGIES ${ }_{\mathbb{R}}$ )

\subsubsection{Die Aufreinigung von GATEWAYTM-PCR-Produkten}

Die Aufreinigung des PCR-Produktes ist notwendig, um Primer-Dimere zu entfernen, die in den Eingangsvektor rekombiniert werden könnten.

Zu $50 \mu \mathrm{l}$ PCR-Ansatz wurden $150 \mu \mathrm{l} 1 \mathrm{x}$ TE (10 mM Tris, $1 \mathrm{mM}$ EDTA pH 8,0), $100 \mu 130 \%$ PEG $8000 / 30 \mathrm{mM} \mathrm{MgCl}_{2}$ gegeben und gründlich gevortext. Es wurde sofort $15 \mathrm{~min}$ bei $10.000 \mathrm{~g}$ und RT abzentrifugiert und das Pellet in $1 \mathrm{x}$ TE aufgenommen.

\subsubsection{Die BP-Reaktion}

Die BP-Reaktion dient dazu, den DNA-Abschnitt zwischen den attB-sites in einen Donor-Vektor mit attPsites zu transferieren. Dabei entsteht ein Eingangsplasmid mit attL-sites.

Dazu wurden 50-200 ng attB-PCR-Produkt oder linearisierter Donor-Vektor in ein 1,5 ml Reaktionsgefäß gegeben und 150 ng Eingangs-Vektor sowie $2 \mu 1$ 5x BP Reaktions-Puffer zugegeben. Der Reaktionsansatz wurde mit 1 x TE $(10 \mathrm{mM}$ Tris, $1 \mathrm{mM}$ EDTA $\mathrm{pH}$ 8,0) auf $9 \mu$ l aufgefüllt. Danach wurde $1 \mu \mathrm{l}$ BP CLONASE Enzym Mix zugegeben, kurz gevortext und über Nacht bei $25^{\circ} \mathrm{C}$ inkubiert. Nach der Inkubation wurde $1 \mu \mathrm{l}$ Proteinase $\mathrm{K}$ zugegeben und $10 \mathrm{~min}$ bei $37^{\circ} \mathrm{C}$ inkubiert. Anschließend wurden $5 \mu \mathrm{l}$ des Ansatzes in $100 \mu \mathrm{l}$ chemisch kompetente DH5 $\alpha$-Zellen transformiert.

\subsubsection{Die LR-Reaktion}

Die LR-Reaktion dient dem Transfer der DNA zwischen den attL-sites eines Eingangsplasmids in einen Zielvektor mit attR-sites. Die Effizienz ist am größten, wenn beide Vektoren linearisiert werden.

100-200 ng Eingangsvektor, $200 \mathrm{ng}$ Ziel-Vektor und $2 \mu \mathrm{l}$ 5 LR Reaktions-Puffer wurden in ein Reaktionsgefäß gegeben. Der Reaktionsansatz wurde mit 1 x TE $(10 \mathrm{mM}$ Tris, $1 \mathrm{mM}$ EDTA pH 8,0) auf $9 \mu \mathrm{l}$ aufgefüllt. Dann wurde $1 \mu \mathrm{l}$ LR CLONASE Enzym Mix zugegeben, kurz gevortext und über Nacht bei $25^{\circ} \mathrm{C}$ inkubiert. Nach der Inkubation wurde $1 \mu$ l Proteinase $\mathrm{K}$ zugegeben und 10 min bei $37^{\circ} \mathrm{C}$ inkubiert. Anschließend wurden $5 \mu \mathrm{l}$ des Ansatzes in $100 \mu \mathrm{l}$ chemisch kompetente DH5a-Zellen transformiert.

\subsubsection{Radioaktive Markierung von DNA}

\subsubsection{DNA-Fragmente für Gelretardationsanalysen}

Die Eigenschaft der Klenow-Polymerase, 3'-OH-Enden komplementär zum überhängenden 5'-PhosphatEnde aufzufüllen, wurde genutzt, um die Sonden für Gelretardationsanalysen ${ }^{32} \mathrm{P}$-radioaktiv zu markieren.

1,7 pmol BpiI gespaltener Vektor pUC18 as-1 BpiI wurde zu einem Markierungsansatz $(20 \mu \mathrm{l})$ mit den Endkonzentrationen 0,5 x KGB-Puffer (50 mM Kaliumglutamat, 12,5 Tris-Acetat pH 7,5, $1 \mathrm{mM} \mathrm{Mg-}$ Acetat, $5 \mu \mathrm{g} / \mathrm{ml}$ BSA (deacetyliert), 0,5 mM DTT), 4,0 $\mu \mathrm{l}\left[\alpha_{-}{ }^{32} \mathrm{P}\right]-\mathrm{dATP}(40 \mu \mathrm{Ci})$ und 4 U KlenowPolymerase (exo-) gegeben und $2-3$ h bei $37^{\circ} \mathrm{C}$ inkubiert. Die Zugabe von $20 \mathrm{mM}$ EDTA $(\mathrm{pH} 8,0)$ stoppte 
die Reaktion. Zur Abtrennung nicht eingebauter Nukleotide wurde eine Micro Spin ${ }^{\mathrm{TM}}$ G25 Column der Firma Amersham entsprechend den Herstellerangaben verwendet. Die weitere Aufarbeitung des Fragmentes erfolgte mittels eines $5 \%(\mathrm{v} / \mathrm{v})$ nativen Polyacrylamidgels (4.5.6.2), bei dem der gesamte Ansatz aufgetrennt wurde. Das gewünschte Fragment wurde schließlich durch Exposition des Gels auf einem Röntgenfilm lokalisiert und ausgeschnitten. Die Sonde wurde aus dem PAA-Gel eluiert (4.5.7.2). Die Strahlung der Sonde im Überstand wurde im Szintillationsmeßgerät quantifiziert. $1 \mu 1$ der präparierten Sondenlösung enthielt 1,3-1,6 fmol markiertes Fragment.

\subsubsection{Hybridisierungssonden}

Für die Herstellung radioaktiv markierter Hybridisierungssonden wurden die entsprechenden DNAFragmente nach Restriktionsspaltung aus einem Agarosegel eluiert (Kapitel 4.5.7.1). Die Markierunsreaktion erfolgte nach der Random-Prime-Labelling-Methode von FEINBERG und VOGELSTEIN (1983), bei der Hexanukleotide zufälliger Sequenz an die Matrizen-DNA binden. Diese Hexanukleotide dienen dann als Primer für die Neusynthese des komplementären Stranges durch die Klenow-DNAPolymerase (exo', d. h. ohne Exonukleaseaktivität) in Gegenwart von radioaktiven Nukleotiden. Ein Reaktionsansatz wurde wie folgt hergestellt:

25-50 ng Sonden-DNA und 2,5 $\mu$ g Randomprimer (GIBCOBRL) wurden mit $\mathrm{H}_{2} \mathrm{O}$ auf ein Endvolumen von $50 \mu \mathrm{l}$ aufgefüllt und für $5 \mathrm{~min}$ bei $100^{\circ} \mathrm{C}$ denaturiert. Nach Abkühlen auf RT wurden 10 x KlenowPolymerasepuffer (500 mM Tris- $\mathrm{HCl} \mathrm{pH} 8,0,50 \mathrm{mM} \mathrm{MgCl} 2,10 \mathrm{mM}$ DTT) und je $50 \mu \mathrm{M} \mathrm{dCTP,} \mathrm{dTTP,}$ dGTP sowie $25 \mu \mathrm{Ci}\left[\alpha_{-}{ }^{32} \mathrm{P}\right]$ dATP zugefügt. Die Reaktion wurde durch Zugabe von 2 U KlenowPolymerase (exo $)$ gestartet. Nach zweistündiger Inkubation bei $37^{\circ} \mathrm{C}$ wurde die Reaktion durch Zugabe von $100 \mu \mathrm{l} \mathrm{H}_{2} \mathrm{O}$ gestoppt. Nicht eingebaute Nukleotide wurden über eine Sephadex G50-Säule abgetrennt. Als Säule diente eine $1 \mathrm{ml}$ Einwegspitze, die mit einem Fließpapierkügelchen verschlossen und dann mit dem Säulenmaterial beladen wurde. Das Packen der Säule sowie die Elution der Sonde erfolgte jeweils durch Zentrifugation bei $1500 \mathrm{rpm}$ für $5 \mathrm{~min}$ in der Hettichzentrifuge mit Ausschwingrotor. Die gereinigte Sonde wurde in einem verschraubbaren Reaktionsgefäß aufgefangen.

\subsubsection{Polymerasekettenreaktion (PCR)}

Mithilfe der Polymerasekettenreaktion (MULLIS und FALOONA, 1987) können unter Verwendung zweier gegenläufiger Primer spezifische Sequenzen eines DNA-Templates amplifiziert werden. Die als Matrize dienende Template-DNA wird zunächst denaturiert. Nach Anlagerung der Primer an die komplementären Sequenzen der DNA-Einzelstränge synthetisiert eine hitzestabile DNA-Polymerase komplementäre DNAStränge an der Matrizen-DNA. Dieser Zyklus aus Denaturieren, Primeranlagerung und DNA-Synthese wird mehrfach wiederholt und führt exponentiell zu einer selektiven Anreicherung der DNA-Sequenz. Die Länge und die Temperatur der einzelnen Schritte eines Zyklus, sowie die Anzahl von Zyklen wurde durch den Schmelzpunkt der Primer und die Länge der zu amplifizierenden Sequenz bestimmt. Die Zyklen starteten nach zweiminütiger Denaturierung bei $94^{\circ} \mathrm{C}$. Die anschließende Denaturierung erfolgte in der Regel für $30 \mathrm{~s}$ bei $92^{\circ} \mathrm{C}$, das Primer-Annealing für $30 \mathrm{~s}$ bei der für die Primer charakteristischen Temperatur und die Elongation für $1 \mathrm{~min} / \mathrm{kb}$ bei $72^{\circ} \mathrm{C}$.

Die Schmelztemperatur $T_{m}$ eines Primers berechnet sich nach einer empirischen Formel, die sowohl den relativen molaren GC-Gehalt (\% GC), als auch die Länge der Oligonukleotide (n) berücksichtigt (BOLTON und MCCARTHY, 1962):

$\mathrm{T}_{\mathrm{m}}\left[{ }^{\circ} \mathrm{C}\right]=69,3+0,41 \times(\% \mathrm{GC})-(650 / \mathrm{n})$ 


\subsubsection{PCR zu Charakterisierung rekombinanter Klone}

Zur Charakterisierung rekombinanter Klone wurde das DNA-Insert mit Hilfe geeigneter Primer amplifiziert. Die PCR-Reaktion erfolgte in einem Volumen von $25 \mu \mathrm{l}$ in 1 x Taq-Puffer $(20 \mathrm{mM}$ Tris- $\mathrm{HCl}$ $\left.\mathrm{pH} 8,55,1,5 \mathrm{mM} \mathrm{MgCl} 2,16 \mathrm{mM}\left(\mathrm{NH}_{4}\right)_{2} \mathrm{SO}_{4}\right)$ mit jeweils 10 pmol Primer, 0,2 $\mathrm{mM}$ dNTPs und 1,5 U Taq-Polymerase. Zum Analysieren vieler Bakterienklone wurden die zu testenden Kolonien jeweils in ein Reaktionsgefäß überführt, in $100 \mu \mathrm{H}_{2} \mathrm{O}$ suspendiert und dann für 5 min durch Erhitzen auf $100^{\circ} \mathrm{C}$ aufgebrochen. Nach Abzentrifugieren für $1 \mathrm{~min}$ bei $13.000 \mathrm{rpm}$ in einer Tischzentrifuge wurden $2 \mu \mathrm{l}$ des Überstandes für die PCR als Template eingesetzt.

\subsubsection{Klonierung von PCR-Produkten}

Die Taq-Polymerase besitzt neben ihrer 5 ' $\rightarrow \quad 3^{\prime}$-Polymeraseaktivität auch eine terminale Desoxynukleotidyl-Transferaseaktivität, welche häufig zu einer Addition von Desoxyadenosin (dA) am 3'-Ende des amplifizierten DNA-Moleküls führt. Die PCR-Produkte mit einem zusätzlichen überhängenden $\mathrm{dA}$ an den 3'-Enden können direkt in Vektoren kloniert werden, die komplementär dTÜberhänge an ihren 3'-Enden besitzen (MARCHUK et al., 1991, MEAD et al., 1991). In dieser Arbeit wurde der Vektor pGEM $^{\circledR}$-T von Promega für die Klonierung von PCR-Produkten benutzt. Das Plasmid war von dem Hersteller über die EcoRV-Schnittstelle linearisiert und mit terminaler DesoxynukleotidylTransferase behandelt worden, so dass jeweils ein überhängendes Didesoxythymidin (ddT) an den 3'Enden des geöffneten Vektors vorlag. Die Ligation erfolgte nach Herstellerangaben.

\subsubsection{Sequenzierung}

DNA-Sequenzierungen erfolgten mit Hilfe des BigDye ${ }^{\mathrm{TM}}$ Terminator Cycle Sequencing Ready Reaction Kits von Perkin-Elmer. Das Prinzip beruht auf der Kettenabbruchmethode (SANGER et al., 1977). Im Reaktionsansatz für die Amplifikation der zu sequenzierenden DNA (lineare PCR mit einem Primer) befinden sich neben den vier Desoxynukleotiden auch die entsprechenden Didesoxynukleotide (Terminatoren), welche bei Einbau einen Abbruch der DNA-Synthese herbeiführen. Die vier Terminatoren sind mit verschiedenen Fluoreszenzfarbstoffen markiert, so dass die Nukleotid-spezifischen Kettenabbruchprodukte während der Elektrophorese im Analysegerät (Kapillarsequenzer ABI Prism 310 von Applied Biosystems) detektiert werden können.

Für die PCR-Reaktion mit einem Gesamtvolumen von $10 \mu$ wurden 500 ng Plasmid-DNA, 5 pmol Primer und $2 \mu \mathrm{l}$ RR-(ready reaction) Mix eingesetzt. Im Thermocycler wurden folgende Schritte $25 \mathrm{x}$ durchlaufen: $10 \mathrm{~s} 95^{\circ} \mathrm{C}, 5 \mathrm{~s} 50^{\circ} \mathrm{C}$ und $4 \mathrm{~min} 60^{\circ} \mathrm{C}$. Anschließend fand eine Ethanol-Fällung statt, um nicht eingebaute Nukleotide zu entfernen. Hierzu wurde der Ansatz mit 9,5 $\mu \mathrm{l} \mathrm{H}_{2} \mathrm{O}$ und 30,5 $\mu 1 \mathrm{EtOH}$ abs. versetzt und für 15 min bei RT inkubiert. Nach Zentrifugation bei $13.000 \mathrm{rpm}$ für 15 min in einer Tischzentrifuge wurde der Überstand vollständig abgenommen, das DNA-Pellet mit $100 \mu 170 \%$ (v/v) EtOH gewaschen, $1 \mathrm{~min}$ bei $95^{\circ} \mathrm{C}$ getrocknet und in $20 \mu \mathrm{l}$ TSR (Template Suppression Reagent von Perkin-Elmer) resuspendiert. Nach dem Denaturieren bei $95^{\circ} \mathrm{C}$ für 2 min wurde die Probe sofort 2 min auf Eis gehalten und für die Sequenzanalyse im ABI Prism 310 in spezielle Sequenziergefäße überführt. 


\subsubsection{Transformation kompetenter Bakterienzellen}

Da weder E. coli noch A. tumefaciens über ein natürliches System zur Aufnahme nackter DNA aus dem umgebenden Medium verfügen, müssen Bakterienzellen mit geeigneten Verfahren kompetent gemacht werden.

\subsubsection{Herstellung kompetenter E. coli-Zellen}

Für die Herstellung kompetenter Zellen nach einer modifizierten Methode von INOUE et al., 1990 wurden Bakterien des E. coli-Stammes DH5 $\alpha$ verwendet.

Von einer frisch ausgestrichenen Platte wurde zunächst eine Vorkultur in SOC-Medium angeimpft, die nach etwa $8 \mathrm{~h}$ Inkubation als Inokulum für eine $5 \mathrm{ml}$ (SOC-Medium) Übernachtkultur diente. Die Übernachtkultur wurde am nächsten Tag in $300 \mathrm{ml}$ SOC-Medium verdünnt und bis zu einer $\mathrm{OD}_{600}$ von $0,2-0,25$ bei $37^{\circ} \mathrm{C}$ in einem 21 Erlenmeyerkolben geschüttelt. Das weitere Wachstum der Zellen erfolgte dann bei einer Temperatur von $18^{\circ} \mathrm{C}$. Bei einer $\mathrm{OD}_{600}$ von $0,4-0,5$ wurden die Bakterien durch Zentrifugation (4000 rpm, $4^{\circ} \mathrm{C}$, Eppendorf-Kühlzentrifuge) pelletiert und in $90 \mathrm{ml}$ eiskaltem, sterilem Transformationspuffer (10 mM PIPES, $15 \mathrm{mM} \mathrm{CaCl}_{2}, 250 \mathrm{mM} \mathrm{KCl}, 55 \mathrm{mM} \mathrm{MnCl}_{2}$, pH 6,7 vor Zugabe von $\mathrm{MnCl}_{2}$ eingestellt) vorsichtig resuspendiert. Nach einer 15- minütigen Inkubation auf Eis wurden die Zellen erneut pelletiert und in $30 \mathrm{ml}$ Transformationspuffer aufgenommen. Es folgte der zweimalige Zusatz von je $1050 \mu \mathrm{l}$ DMSO, wobei die Zellen nach jeder Zugabe 5 min auf Eis inkubiert wurden. Die Zellen wurden aliquotiert, in flüssigem Stickstoff eingefroren und bei $-80^{\circ} \mathrm{C}$ gelagert. Die Transformationseffizienz betrug $10^{7} \mathrm{cfu} / \mu \mathrm{g}$ DNA.

\subsubsection{Transformation von E. coli}

Kompetente $E$. coli-Zellen sind in der Lage nackte DNA aus dem Umgebungsmedium auszunehmen. Mit Hilfe der nachfolgenden Methode (HANAHAN, 1983) wurden E. coli-Zellen mit Plasmid-DNA transformiert. $200 \mu \mathrm{l}$ kompetente Zellen wurden auf Eis aufgetaut, dann erfolgte die Zugabe der PlasmidDNA und Inkubation für 10 min auf Eis (Anheftung der DNA an die Zellen). Durch einen Hitzeschock der Zellen für 3 min bei $42^{\circ} \mathrm{C}$ erfolgte die Aufnahme der DNA. Eine Regeneration der Zellen schloss sich nach Zugabe von $800 \mu \mathrm{l}$ SOC-Medium für $30 \mathrm{~min}$ bei $37^{\circ} \mathrm{C}$ an. Danach wurde der Transformationsansatz auf LB-Selektionsmedium ausplattiert.

\subsubsection{Blau-Weiß-Selektion}

Eine wesentliche Erleichterung zur Identifizierung von E. coli-Kolonien, welche nach der Transformation ein rekombinantes Plasmid tragen, bietet die Blau-Weiß-Selektion. Sie wird z. B. bei der Klonierung von PCR-Produkten mit dem Vektor pGEM ${ }^{\circledR}$-T eingesetzt. Das Verfahren beruht auf der $\alpha$-Komplementation des Enzyms $\beta$-Galaktosidase. Die ersten 146 aminoterminalen Aminosäuren ( $\alpha$-Peptid) können zusammen mit einem inaktiven Enzym, dem die Aminosäuren 11 - 14 fehlen, eine funktionierende $\beta$-Galaktosidase bilden. Das aktive Enzym hydrolysiert z. B. das Substrat X-Gal, das daraufhin durch Luftoxidation eine blaue Färbung zeigt. Bakterienstämme mit dem inaktiven Enzym können durch Aufnahme eines Plasmids, das die für das $\alpha$-Peptid codierende DNA trägt, X-Gal umsetzen. Als Induktor der Genexpression wurde IPTG eingesetzt. Die zur Blau-Weiß-Selektion eingesetzten Agarplatten wurden kurz vor Gebrauch mit jeweils $50 \mu \mathrm{l}$ der X-Gal und der IPTG-Stammlösungen beschichtet. Wird die das $\alpha$-Peptid codierende Sequenz durch Einbau von fremder DNA unterbrochen, so bleiben die Bakterienkolonien weiß. Bakterienklone, die kein rekombinantes Plasmid aufgenommen haben und somit das $\alpha$-Peptid synthetisieren, sind an ihrer Blaufärbung zu erkennen. 


\subsubsection{Herstellung kompetenter Agrobakterien}

Für die Herstellung kompetenter Zellen wurden Agrobakterien der Stämme pGV3101 pMP90RK (KONCZ und SCHELL, 1986) und C58-C1-R pGV2260 (DEBLAERE et al., 1985) verwendet. 5 ml einer Agrobakterienkultur wurden für $5 \mathrm{~min}$ bei $5000 \mathrm{rpm}$ abzentrifugiert und dreimal durch Resuspendieren und erneutes Abzentrifugieren in sterilem Wasser gewaschen. Das Pellet wurde in $500 \mu$ l sterilem Wasser aufgenommen und in $100 \mu \mathrm{l}$ Aliquots in flüssigem Stickstoff eingefroren.

\subsubsection{Transformation von Agrobacterium tumefaciens}

Agrobacterium tumefaciens-Zellen wurden mittels Elektroporation (DowER et al., 1988) transformiert. Durch Erzeugen kurzer Spannungspulse wird die Membran kompetenter Bakterienzellen permeabilisiert. Dadurch wird die Aufnahme von freier DNA aus dem Medium in die Zelle ermöglicht. Nach der Zugabe der zu transformierenden DNA zu den kompetenten Zellen wurde der Transformationsansatz in sterile Elektroporationsküvetten (Elektrodenanstand: $2 \mathrm{~mm}$ ) überführt. Die Elektroporation erfolgte am Gene pulser $^{\circledR}$ II von BioRad mit 2,5 kV, $25 \mu \mathrm{F}, 400 \Omega$. Der Transformationsansatz wurde anschließend in ein Reaktionsgefäß überführt und mit $1 \mathrm{ml}$ LB-Medium aufgefüllt. Die Regeneration erfolgte bei $28^{\circ} \mathrm{C}$ für $2 \mathrm{~h}$ im Roller. Anschließend wurden die Zellen auf YEB-Selektionsmedium ausplattiert und für 2-3 Tage bei $28^{\circ} \mathrm{C}$ inkubiert.

\subsubsection{Gentransfer in Saccharomyces cerevisiae}

Um Plasmide in Hefezellen zu transformieren wurde das Protokoll von DOHMEN et al., 1990 befolgt. Die Transformationseffizienz war unabhängig von der Qualität der Plasmid-DNA. Es konnte daher auch DNA aus einer Präparation von kleinen Mengen Plasmid-DNA aus E. coli verwendet werden, die nicht aufgereinigt war.

\subsubsection{Herstellung kompetenter Hefezellen}

Zur Herstellung kompetenter Hefezellen wurde eine 5 ml-Übernachtkultur in YPDA-Medium herangezogen. Die Kultur wurde bei $3000 \mathrm{~g}$ abzentrifugiert und der Zellniederschlag in $500 \mu 1$ Überstand resuspendiert. Mit dieser Zellsuspension wurde eine $100 \mathrm{ml-YPDA-Kultur}$ inokuliert und bis zu einer $\mathrm{OD}_{600}$ von 0,6 kultiviert (ca. 3-4 h). Die Zellen wurden durch Zentrifugation bei $3000 \mathrm{~g}$ geerntet und in $20 \mathrm{ml}$ Lösung A (10 mM Bicine, 1 M Sobitol, 3 \% Ethylenglycol (v/v), pH 8.35) gewaschen. Nach einem weiteren Zentrifugationsschritt wurden sie in $2 \mathrm{ml}$ Lösung A resuspendiert und in $100 \mu$ l Aliquots langsam bei $-70^{\circ} \mathrm{C}$ eingefroren und gelagert. Die Zellen können mehrere Monate gelagert werden ohne wesentlichen Verlust ihrer Kompetenz.

\subsubsection{Transformation von Hefezellen}

Zur Transformation der kompetenten Hefezellen wurde 0,1-1 $\mu$ g Plasmid-DNA zu $50 \mu \mathrm{g}$ HeringsspermaDNA $(10 \mathrm{mg} / \mathrm{ml}$ in TE) gegeben und auf ein Aliquot der gefrorenen, kompetenten Hefezellen pipettiert. Nach dem Auftauen der Zellen bei $37^{\circ} \mathrm{C}$ für 3 min wurde $1 \mathrm{ml}$ Lösung B (200 mM Bicine, $40 \%$ Polyethylenglycol $1000(\mathrm{w} / \mathrm{v}), \mathrm{pH} 8,35)$ zugegeben, gemischt und eine Stunde bei $30{ }^{\circ} \mathrm{C}$ inkubiert. Die Zellen wurden schließlich durch Zentrifugation bei $13.000 \mathrm{rpm}$ für $20 \mathrm{~s}$ in einer Tischzentrifuge geerntet und in $800 \mu \mathrm{l}$ Lösung $\mathrm{C}(10 \mathrm{mM}$ Bicine, $150 \mathrm{mM} \mathrm{NaCl}, \mathrm{pH} \mathrm{8,35)}$ gewaschen. Nach einem weiteren Zentrifugationsschritt wurden sie in $100 \mu \mathrm{l}$ Lösung $\mathrm{C}$ resuspendiert und auf Selektionsmedium ausplattiert. 


\subsubsection{Stabile Transformation von Nicotiana tabacum}

Die stabile Transformation von Nicotiana tabacum wurde über Agrobakterien-vermitteltem Gentransfer erreicht und erfolgt nach der Blattscheiben-Methode (modifiziert nach HoRSCH et al., 1985). Hierzu wurden Blätter von steril angezogenen Tabakpflanzen in 1-2 $\mathrm{cm}^{2}$ große Stücke zerteilt und für 2-3 min in eine Suspension aus Agrobacterium tumefaciens getaucht. Zur Herstellung der Suspension wurde $1 \mathrm{ml}$ einer 2d-Kultur von zuvor mit einem binären Plasmid transformierten Agrobakterien in $20 \mathrm{ml}$ YEBFlüssigmedium verdünnt. Die Blattstücke wurden anschließend dreimal in sterilem Leitungswasser abgespült und mit sterilem Fließpapier abgetupft, um überschüssige Bakteriensuspension zu entfernen, und danach mit der Blattunterseite auf MS-Festmedium gelegt. Es folgte eine zweitägige Inkubation der abgedunkelten Platten bei $24^{\circ} \mathrm{C}$ im Klimaschrank. Während dieser Kokultivierung können die Agrobakterien ihre T-DNA in die Pflanzenzellen transferieren, so dass eine stabile Integration der FremdDNA in das Pflanzengenom möglich wird. Nach dieser Phase wurden die Blattstücke auf SHI-Medium umgelegt und im Klimaschrank in einem Licht-Dunkel-Rhythmus von $16 \mathrm{~h} / 8 \mathrm{~h}$ bei $28^{\circ} \mathrm{C}$ kultiviert. Die Hormone des Mediums induzieren die Bildung von Kallusgewebe, aus dem sich Sprosse regenerieren können. Die dem SHI-Medium beigefügten Antibiotika dienen zum einen dem Abtöten der Agrobakterien und zum anderen der Selektion transgener Pflanzenzellen. Das Umlegen der Blattstücke auf frisches SHIMedium wurde in den ersten drei Wochen wöchentlich, anschließend 14-täglich bis zur Ausbildung von Sprossen wiederholt. Anschließend wurden die Spitzen von regenerierten Sprossen zur Bewurzelung auf hormonfreies MS-Medium mit Antibiotikazusatz umgesetzt.

\subsubsection{Northern-Blot-Analyse}

Im Northern-Blot-Verfahren (SAMBROCK et al., 1989) wird die zu analysierende RNA durch eine denaturierende Agarosegelelektrophorese (Kapitel 4.5.6.3) aufgetrennt und mittels Kapillar-Blot auf eine Nylonmembran transferiert. Die auf der Membran immobilisierte RNA kann nun durch Hybridisierung mit radioaktiv markierten DNA-Sonden (Kapitel 4.5.12.2) analysiert werden.

\subsubsection{Transfer der RNA auf Nylonmembranen}

Mittels Kapillar-Blot wurde die durch eine denaturierende Agarosegelelektrophorese aufgetrennte RNA auf eine Nylonmembran transferiert. Dazu wurden zwei Lagen Fließpapier mit 10 x SSC $(1,5 \mathrm{M} \mathrm{NaCl}, 150 \mathrm{mM}$ Natriumcitrat, $\mathrm{pH}$ 7,0 mit $\mathrm{HCl})$ äquilibriert und so auf einer ebenen Glasplatte aufgebracht, dass die Enden in ein 10 x SSC-Pufferreservoir tauchten. Das RNA-Gel wurde luftblasenfrei mit der Oberseite nach unten auf das Fließpapier gelegt. Die Kanten des Gels wurden mit Haushaltsfolie abgedeckt. Die Nylonmembran (Hybond $\mathrm{N}^{+}$von Amersham) wurde luftblasenfrei auf das Gel gelegt, mit zwei Lagen Fließpapier und Papiertüchern bedeckt und mit einem Gewicht (ca. 500 g) gleichmäßig beschwert. Der Kapillarblot erfolgte für mindestens $14 \mathrm{~h}$. Die RNA wurde durch kurze UV-Bestrahlung auf dem Transilluminator und durch zweistündige Inkubation bei $80^{\circ} \mathrm{C}$ auf der Membranoberfläche fixiert.

\subsubsection{Hybridisierung der Northern-Blot-Membran}

Die Hybridisierung erfolgte in modifizierter Form nach der Methode von CHURCH und GILBERT (1984). Alle Inkubationen erfolgten bei $65^{\circ} \mathrm{C}$ im Rotations-Hybridisierungsofen. Die zu hybridisierende Membran wurde in Hybridisierungsröhren überführt und $60 \mathrm{~min}$ in $15 \mathrm{ml}$ Church-Lösung (1 mM EDTA, 7 \% (w/v) SDS, 0,5 M NaHPO, pH 7,2) vorhybridisiert. Die radioaktive Sonde wurde nach 5-minütiger Denaturierung bei $100^{\circ} \mathrm{C}$ im Wasserbad zugegeben. Die Inkubation erfolgte für mindestens $14 \mathrm{~h}$. 


\subsubsection{Waschen der Northern-Blot-Membran}

Nach der Hybridisierung wurde die Membran standardmäßig zweimal für 15 min mit Waschlösung I ( $2 \mathrm{x}$ SSC, 0,1 \% (w/v) SDS) und zweimal mit Waschlösung II (1 x SSC, 0,1 \% (w/v) SDS) im Hybridisierungsschüttler bei $65^{\circ} \mathrm{C}$ gewaschen. Durch Waschschritte unter Verwendung von Waschlösungen unterschiedlicher Salzkonzentrationen werden unspezifisch bindende Sondenmoleküle entfernt. Bei hohen Salzkonzentrationen ist die Stabilität unspezifischer DNA-RNA-Hybride größer als bei geringen Salzkonzentrationen. Nach dem Waschen wurde der Filter feucht in Haushaltsfolie eingeschweißt und in einer Expositionscassette mit einem Bioimager-Screen für einige Stunden oder Tage exponiert. Die Auswertung des Screens erfolgte am Bioimager (BAS-1000 von Fuji). Für die Quantifizierung wurden die Programme PCBAS ${ }^{\circledR} 2.09$ und TINA ${ }^{\circledR} 2.0$ der Firma raytest Isotopenmeßgeräte benutzt. Eine Normalisierung der Signale wurde über den Vergleich mit der dokumentierten Ethidiumbromidfärbung der RNA (Kapitel 4.5.6.3) erzielt.

\subsubsection{Rehybridisierung}

Die auf der Membranoberfläche fixierte RNA kann nacheinander mit mehreren verschiedenen Sonden hybridisiert werden. Dazu müssen die auf dem Filter befindlichen radioaktiven Sonden aus der vorhergehenden Hybridisierung durch Denaturierung der RNA-DNA-Hybride in Waschlösung bei hoher Temperatur abgelöst werden. Die Membran wurde durch Zugabe kochendheißer $0,1 \%$ iger SDS-Lösung für eine Stunde bei $65^{\circ} \mathrm{C}$ gewaschen. Danach war der Filter für eine erneute Hybridisierung einsetzbar.

\subsection{Konstruktion der verwendeten Plasmide}

\subsubsection{Plasmide für die Expression von Proteinen in Hefe}

\subsubsection{1 pSKL6}

Für einen Bankscreen wurde der Transkriptionsfaktor TGA2.1 als Köderprotein verwendet (Kapitel 5.1.1.1). Dazu wurde er an das 3'-Ende des carboxyterminalen Teils des Ubiquitins (aa 35-76) über einen $\left(\mathrm{G}_{3} \mathrm{~S}\right)_{4}$-Linker fusioniert.

Mit den Primern TGA2.1N120upper und TGA2.1lower (Sal) wurde eine PCR durchgeführt, um ein 1430 bp großes Fragment aus dem Plasmid pUC572.1VPs (LENK, 2001) zu amplifizieren. Gleichzeitig wurde 5' eine EcoRI-Schnittstelle und 3' eine SalI-Schnittstelle eingefügt. Das PCR-Produkt wurde in den pGEM $^{\circledR}$-T (Promega) subkloniert und sequenziert. Anschließend wurde es mit EcoRI und SalI wieder herausgespalten und in den mit EcoRI und SalI geöffneten Vektor Pcup1-Cub-Rura314 (JOHNSSON, unveröffentlicht) ligiert. Danach wurde der entstandene Vektor mit SalI linearisiert und der Linker SKL5 eingefügt.

\subsubsection{2 pSK7}

Als mögliches Beuteprotein wurde in einen Vortest für den Bankscreen TGA2.1 verwendet, fusioniert an das 3'-Ende des aminoterminalen Teils vom Ubiquitin (aa 1-34) über einen $\left(\mathrm{G}_{3} \mathrm{~S}\right)_{4}$-Linker.

Mit den Primern SK2 sense und LTGA2.1lower wurde eine PCR durchgeführt, um ein 1430 bp Fragment aus dem Plasmid pUC57VP2.1s (LENK, 2001) zu amplifizieren. Gleichzeitig wurde 5'eine SmaISchnittstelle und 3'eine Not I-Schnittstelle eingefügt. Das PCR-Produkt wurde in den pGEM $^{\circledR}-\mathrm{T}$ (Promega) subkloniert und sequenziert. Anschließend wurde es mit SmaI und NotI wieder herausgespalten und in den mit SmaI und NotI geöffneten Vektor PADNX-NubI (LEHMING, unveröffentlicht) ligiert. 


\subsubsection{PADNX-NubI-Rec}

Der Bankvektor für das „Ubiquitin-based split-protein sensor system“ PADNX-NubI (LEHMING, unveröffentlicht) wurde so verändert, dass eine in vivo-Klonierung einer cDNA-Bank in Hefe möglich war.

Mit den Primern REC upper und REC lower wurde eine PCR durchgeführt, um die Rekombinationsstellen aus dem Plasmid pGADT7-Rec (Clontech) zu amplifizieren. Gleichzeitg wurde 5' eine XhoI-Schnittstelle und 3' eine NotI-Schnittstelle eingefügt. Das PCR-Produkt (120 bp) wurde mit XhoI und NotI gespalten und in den mit XhoI und NotI geöffneten Vektor ligiert. Über eine SmaI-Schnittstelle, die zwischen den Rekombinationsstellen lokalisiert ist, kann der Vektor linerarisiert und so für die in vivo Klonierung eingesetzt werden.

\subsubsection{PADNX-NubI-117, PADNX-NubI-175, PADNX-NubI-184}

Der Bankvektor PADNX-NubI-Rec wurde mit SmaI linearisiert. Die Sequenzen beiderseits des Schnitts sind den beidseitigen Ankersequenzen der aus Blatt-mRNA von Nicotiana tabacum hergestellten cDNA homolog. Innerhalb der Hefezellen wurde der lineare Vektor, bei gleichzeitiger Intergration der cDNA, zirkularisiert. Die daraus resultierenden Plasmide sind PADNX-NubI-117, PADNX-NubI-175 und PADNX-NubI-184.

\subsubsection{5 pGAD117 und pGBT117}

Mit den Primern 117 upper und 117 lower wurde eine PCR auf dem Vektor PADNX-NubI-117 durchgeführt, um die cDNA des Klons $117 \mathrm{zu}$ amplifizieren. Gleichzeitig wurde 5' eine EcoRISchnittstelle und 3' eine SalI-Schnittstelle eingefügt. Das PCR-Produkt wurde in den Vektor pGEM ${ }^{\circledR}-T^{-}$ (Promega) subkloniert und sequenziert. Anschließend wurde es über eine Spaltung mit EcoRI und SalI in den mit EcoRI und SalI geöffneten Vektor pGAD424 bzw. pGBT9 (Clontech) ligiert.

\subsubsection{6 pGAD175 und pGBT175}

Mit den Primern 175 upper und 175 lower wurde eine PCR auf dem Vektor PADNX-NubI-175 durchgeführt, um die cDNA des Klons $175 \mathrm{zu}$ amplifizieren. Gleichzeitig wurde 5' eine EcoRISchnittstelle und 3' eine Sall-Schnittstelle eingefügt. Das PCR-Produkt wurde in den Vektor pGEM ${ }^{\circledR}$-T (Promega) subkloniert und sequenziert. Anschließend wurde es über eine Spaltung mit EcoRI und SalI in den mit EcoRI und SalI geöffneten Vektor pGAD424 bzw. pGBT9 (Clontech) ligiert.

\subsubsection{7 pGADT7-Rec/184}

Mit den Primern 5' PCR-Primer und 3' PCR-Primer wurde eine PCR auf dem Vektor PADNX-NubI-184 durchgeführt, um die cDNA des Klons $184 \mathrm{zu}$ amplifizieren. Anschließend wurde das Produkt über eine in vivo-Klonierung in Hefe in den mit SmaI-linearisierten Vektor pGADT7-Rec (Clontech) ligiert.

\subsubsection{8 pGAD184 und pGBT184}

Die cDNA des Klons 184 wurde durch einen Verdau mit EcoRI und XhoI aus dem Plasmid pGADT7Rec/184 herausgespalten und in den mit EcoRI und SalI geöffneten Vektor pGAD424 bzw. pGBT9 (Clontech) ligiert. 


\subsubsection{Binäre Plasmide für die stabile Pflanzentransformation von Nicotiana tabacum}

Um transgene Tabakpflanzen zu erzeugen, die keine Nttga2.1-mRNA mehr bilden, wurden spezielle DNA-Konstrukte in die Pflanzen eingebracht, die durch doppelsträngige RNA-Interferenz (RNAi; CHUANG et al., 2000) zu posttranskriptionellem Abschalten (PTGS, ,post transcriptional gene silencing“) des Nttga2.1-Gens führen sollten.

\subsubsection{1 pMSK5}

Durch eine gleichzeitige Expression von korrekter und entgegengesetzter DNA durch zwei unabhängige Promotoren, ist es möglich PTGS zu induzieren (WATERHOUSE et al., 1998).

Der binäre Vektor pM35 (LENK, unveröffentlicht) wurde über eine HindIII-Schnittstelle, die 3' vom pA ocs$^{-}$ Signal lokalisiert ist, geöffnet und ein Linker, der eine SpeI-Schnittstelle besitzt, eingefügt. Anschließend wurde das entstandene Konstrukt pMSK1 über eine EcoRI-Schnittstelle, 5'vom CaMV35S-Promotor, linearisiert und ebenfalls ein Linker mit einer SpeI-Schnittstelle eingefügt. Parallel dazu wurde eine PCR mit den Primern SK2611-U und SK2611-L durchgeführt, um die tga2.1-cDNA aus dem Vektor pSK2611 zu amplifizieren und gleichzeitig SmaI-Schnittstellen einzufügen. Das PCR-Produkt (1377 bp) wurde in den Vektor pGEM ${ }^{\circledR}-\mathrm{T}$ (Promega) zur Sequenzierung subkloniert. Anschließend konnte es über einen Verdau mit SmaI wieder herausgespalten werden. Zwischen dem CaMV35S-Promotor und dem $\mathrm{pA}_{\mathrm{ocs}^{-}}$ Signal befindet sich eine SmaI-Schnittstelle, über die die zuvor hergestellten Vektoren pMSK1 und pMSK2 linearisiert wurden. Das PCR-Fragment konnte nun in die geöffneten Vektoren ligiert werden. Danach wurden die entstandenen Vektoren pMSK3 und pMSK4 mit SpeI gespalten und das 2166 bp große Fragment (CaMV35S-tga2.1-pA $\mathrm{pcs}_{\text {ocs }}$ ) aus dem Vektor pMSK4 in den Vektor pMSK3 ligiert. Das fertige Konstrukt pMSK5 konnte anschließend zur Pflanzentransformation verwendet werden.

\subsubsection{2 pFGC2.1}

Basierend auf der Arbeit von WATERHOUSE et al. (2000) wurde ein Konstrukt zur Induktion von PTGS hergestellt, welches einen Teilbereich der tga2.1-cDNA (bp 147- bp 404) sowohl in entgegengesetzter als auch in korrekter Orientierung, verbunden durch ein Intron, unter Kontrolle des CaMV35S-Promotors enthält. Für die Klonierung wurde das GATEWAY ${ }^{\mathrm{TM}}$ System von GIBCOBRL verwendet.

Es wurde eine PCR mit den Primern GW TGA2.1 upper und gateway 2.1 rev durchgeführt, um ein 257 bp großes Fragment aus dem Vektor pHBT-TGA2.1-sGFP zu amplifizieren. Das PCR-Produkt wurde über eine BP-Reaktion in den Vektor pDONR 207 (GIBCOBRL) rekombiniert. Über eine sich anschließende LR-Reaktion wurde das PCR-Fragment aus dem entstandenen Vektor pDONTGA2.1 in den Vektor pFGC5941gatewayRNAi rekombiniert. Das entstandene Konstrukt pFGC2.1 wurde mit den Primern CHS back und CHS front sequenziert.

\subsubsection{3 pTxFGC2.1}

Um das PTGS-vermittelnde Konstrukt des Vektors pFCG2.1 auch induzierbar vorliegen zu haben, wurde der CaMV35S-Promotor gegen den Tetracyclin-induzierbaren Tx-Promotor ausgetauscht. Dazu wurde der $T x$-Promotor aus dem Vektor TxBluescript (HERRMANN, 2003) mit EcoRI und XhoI herausgespalten und in den ebenfalls mit EcoRI und XhoI geöffneten Vektor pFGC2.1 ligiert. 


\subsection{3 $\mathrm{pGEM/GH3}$}

Es wurde eine PCR mit den Primern Ntgh3 upper und Ntgh3 lower durchgeführt, um ein 900 bp großes DNA-Fragment des auxininduzierbaren Gens Ntgh3 (RouX und PERROT-REChENMANN, 1997) aus genomischer DNA zu isolieren. Das PCR-Produkt wurde in den Vektor pGEM ${ }^{\circledR}$-T (Promega) kloniert und sequenziert.

\subsection{Proteinchemische Methoden}

\subsubsection{Proteinextraktion aus Hefezellen}

Um Proteine aus Hefezellen zu gewinnen, wurden nach PRINTEN und SPRAGUE (1994) vorgegangen. Mit den Zellen einer $5 \mathrm{ml}$ Übernachtkultur in Selektionsmedium wurde eine $50 \mathrm{ml}$ YPDA-Kultur angeimpft. Diese wurde bis zu einer $\mathrm{OD}_{600}$ von 0,5-0,8 unter Schütteln inkubiert. Die Kultur wurde zur Hälfte in einen mit Eis gefüllten Zentrifugenbecher gegossen und $5 \mathrm{~min}$ bei $3000 \mathrm{~g}$ zentrifugiert. Nachdem der Zellniederschlag mit $50 \mathrm{ml} \mathrm{H} \mathrm{H}_{2} \mathrm{O}$ gewaschen war, wurde er resuspendiert und in ein $2 \mathrm{ml}$ Reaktionsgefäß überführt, das mit flüssigem Stickstoff übergossen wurde. Der Zellniederschlag konnte nun eingefroren und bei $-70^{\circ} \mathrm{C}$ gelagert oder sofort weiterverarbeitet werden. Zum Aufschluss der Zellen wurden sie in $400 \mu \mathrm{l}$, auf $60^{\circ} \mathrm{C}$ vorgewärmtem, Aufschlusspuffer (8 M Harnstoff, $5 \%$ (w/v) SDS, $40 \mathrm{mM}$ Tris-HCl $\mathrm{pH}$ 6,8, 0,1 mM EDTA, 0,4 mg/ml Bromphenolblau, $1 \%$ (v/v) $\beta$-Mercaptoethanol, $875 \mu \mathrm{g} / \mathrm{ml} \mathrm{PMSF}, 7 \mu \mathrm{g} / \mathrm{ml}$ Pepstatin A, $2 \mu \mathrm{M}$ Leupeptin, $10 \mathrm{mM}$ Benzamidin) suspendiert und $10 \mathrm{~min}$ bei $70^{\circ} \mathrm{C}$ inkubiert. Nach Zugabe von $300 \mathrm{mg}$ Glasperlen erfolgte das Aufbrechen der Zellen durch einminütiges Schütteln auf dem Vortex-Mischer. Der flüssige Überstand $(10 \mu \mathrm{l})$ konnte direkt zur gelelektrophoretischen Analyse verwendet werden.

\subsubsection{Denaturierte Gesamtzellextrakte aus Tabakblättern}

Um denaturierte Gesamtzellextrakte für die SDS-Polyacrylamid-Gelelektrophorese zu erhalten, wurden die zu analysierenden Tabakblätter unter flüssigem Stickstoff zu feinem Pulver gemörsert und in ein Reaktionsgefäß überführt. Das Material wurde mit der dreifachen Menge $(\mathrm{mg}=\mu \mathrm{l})$ Extraktionspuffer (4 M Harnstoff, 16,6 \% (v/v) Glycerin, $5 \%(\mathrm{v} / \mathrm{v}) \beta$-Mercaptoethanol, $5 \%(\mathrm{w} / \mathrm{v})$ SDS, $0,5 \%(\mathrm{w} / \mathrm{v})$ Bromphenolblau) gründlich gemischt und für 10 min bei $65^{\circ} \mathrm{C}$ unter Schütteln inkubiert. Die Abtrennung unlöslicher Zellbestandteile erfolgte durch Zentrifugation bei $13.000 \mathrm{rpm}$ für $20 \mathrm{~min}$ bei RT in einer Tischzentrifuge. Der Überstand wurde in ein neues Reaktionsgefäß überführt und bei $-80^{\circ} \mathrm{C}$ gelagert. Eine Proteinbestimmung konnte aufgrund der Zusammensetzung des Extraktionspuffers nicht vorgenommen werden. Die Abschätzung relativer Proteinmengen in verschiedenen Ansätzen erfolgte über die densiometrische Auswertung eines mit Coomassie Brilliant Blue G-250 gefärbten SDS-Polyacrylamidgels (Kapitel 4.7.8). Für dieses Abgleichgel wurden jeweils $5 \mu \mathrm{l}$ der Proteinpräparation elektrophoretisch aufgetrennt.

\subsubsection{Native Gesamtzellextrakte aus Tabakblättern}

Um native Gesamtzellextrakte für Gelretardationsexperimente (Kapitel 4.7.7) zu erhalten, wurden die zu analysierenden Tabakblätter unter flüssigem Stickstoff $\mathrm{zu}$ feinem Pulver gemörsert und in ein Reaktionsgefäß überführt. Auf das Material wurde die zweifache Menge $(\mathrm{mg}=\mu \mathrm{l})$ vorgekühlten Extraktionspuffers (50 mM Hepes pH 7,5, $20 \mathrm{mM} \mathrm{KCl,} \mathrm{2,5} \mathrm{mM} \mathrm{DTT,} 2 \mathrm{mM}$ EGTA, $50 \mu \mathrm{g} / \mathrm{ml}$ Antipain, $2 \mu \mathrm{g} / \mathrm{ml}$ Aprotinin, $10 \mu \mathrm{g} / \mathrm{ml}$ Chymostatin, $5 \mu \mathrm{g} / \mathrm{ml}$ E-64, 0,5 $\mu \mathrm{g} / \mathrm{ml}$ Leupeptin, $1 \mathrm{mg} / \mathrm{ml}$ Pefabloc) gegeben. Das Mischen des Ansatzes erfolgte solange bis dieser vollständig aufgetaut war. Diese Arbeiten erfolgten im Kühlraum, um selbst partielle Erwärmungen des Pflanzenmaterials zu vermeiden. Bei dem anschließenden Zentrifugationsschritt mit $15.000 \mathrm{rpm}$ bei $4^{\circ} \mathrm{C}$ für 10 min (Eppendorf-Kühlzentrifuge) 
wurden die nichtlöslichen Zelltrümmer pelletiert und der Überstand als Proteinlösung gewonnen. Die Konzentrationsbestimmung der Proben erfolgte nach der Methode von BRADFORD (Kapitel 4.7.5). Man erhält Proteinkonzentrationen von 1-2 $\mu \mathrm{g} / \mu \mathrm{l}$. Nachdem die Proben aliquotiert worden waren, konnten sie bis zur Verwendung bei $-80^{\circ} \mathrm{C}$ aufbewahrt werden.

\subsubsection{Kernproteinextrakte}

Für die Isolierung von Kernproteinextrakten wurde stets frisches Blattmaterial verwendet, d. h. dass die Proben entweder sofort aufgearbeitet oder kurzfristig in flüssigem Stickstoff gelagert wurden.

Die Methoden von KEGLER (2001) wurden teilweise modifiziert. Alle Arbeitsschritte wurden im Kühlraum durchgeführt.

Unter flüssigem Stickstoff wurden $10 \mathrm{~g}$ Blattmaterial, aus dem die Mittelrippe entfernt worden ist, mit einem elektrischen Schermixer (Kaffeemühle) zu feinem Pulver zermahlen und in $40 \mathrm{ml}$ Puffer $1 \mathrm{~A}$ (1 M Hexylenglycol, 0,25 M Saccharose, $20 \mathrm{mM}$ TAPS pH 8,5, $10 \mathrm{mM} \mathrm{MgCl}_{2}, 0,15 \mathrm{mM}$ Spermin, 0,5 mM Spermindin, 0,6 \% Nonidet P-40, $80 \mathrm{mM} \beta$-Mercaptoethanol) aufgenommen. Die anschließende Filtration durch zwei Lagen Miracloth trennte die verbliebenden größeren Zelltrümmer von der Suspension mit den Organellen ab. Im folgenden Zentrifugationsschritt (SS34, $1000 \mathrm{rpm}, 4^{\circ} \mathrm{C}, 2 \mathrm{~min} 40 \mathrm{~s}$ ) wurden kleinere Zelltrümmer und Stärke von den in der Lösung verbliebenen Organellen separiert. Die Suspension wurde einer weiteren Zentrifugation zur Pelletierung der Zellkerne unterzogen (SS34, $2000 \mathrm{rpm}, 4^{\circ} \mathrm{C}, 3 \mathrm{~min}$ ) und der Überstand verworfen. Zur Entfernung von Chloroplasten wurde das Pellet anschließend dreimal gewaschen, indem es zunächst mit Hilfe eines feinen Haarpinsels in $8 \mathrm{ml}$ Puffer 0,5A (0,5 M Hexylenglycol, 0,25 M Saccharose, $20 \mathrm{mM}$ TAPS pH 8,5, $10 \mathrm{mM} \mathrm{MgCl}$, 0,15 mM Spermin, 0,5 mM Spermidin, 0,6 \% Nonidet P-40, $80 \mathrm{mM} \beta$-Mercaptoethanol) resuspendiert und die Suspension anschließend zentrifugiert wurde (SS34, $\left.2000 \mathrm{rpm}, 4^{\circ} \mathrm{C}, 5 \mathrm{~min}\right)$. Das Protokoll wurde auf zwei Arten weitergeführt.

\subsubsection{Denaturierte Kernproteinextrakte}

Das bei der Herstellung erhaltene Pellet wurde in $400 \mu$ l Harnstoffpuffer (4 M Harnstoff, 16,66 \% (v/v) Glycerin, $5 \%(\mathrm{w} / \mathrm{v}) \mathrm{SDS}, 5 \%(\mathrm{w} / \mathrm{v}) \beta$-Mercaptoethanol) aufgenommen und für 20 min bei $65^{\circ} \mathrm{C}$ inkubiert. Eine anschließende Ultraschallbehandlung fragmentierte die DNA und hob somit den viskosen Charakter der denaturierten Proteinlösung auf. Abschließend wurde die Mischung bei RT für 30 min in einer Tischzentrifuge bei $13.000 \mathrm{rpm}$ zentrifugiert. Der Überstand wurde in ein neues Reaktionsgefäß überführt und bei $-80^{\circ} \mathrm{C}$ gelagert. Eine Proteinbestimmung konnte aufgrund der Zusammensetzung des Extraktionspuffers nicht vorgenommen werden. Die Abschätzung relativer Proteinmengen in verschiedenen Ansätzen erfolgte über die densiometrische Auswertung eines mit Coomassie Brilliant Blue G-250 gefärbten SDS-Polyacrylamidgels (Kapitel 4.7.8). Für dieses Abgleichgel wurden jeweils $5 \mu 1$ der Proteinpräparation elektrophoretisch aufgetrennt.

\subsubsection{Native Kernproteinextrakte}

Alle Arbeitsschritte wurden bei $4^{\circ} \mathrm{C}$ durchgeführt. Das Pellet wurde in $4 \mathrm{ml}$ Lysispuffer $(110 \mathrm{mM} \mathrm{KCl}$, $15 \mathrm{mM}$ Hepes pH 7,6, $5 \mathrm{mM} \mathrm{MgCl} 2,1 \mathrm{mM}$ DTT, 0,2 mM PMSF, $50 \mu \mathrm{g} / \mathrm{ml}$ Antipain, $2 \mu \mathrm{g} / \mathrm{ml}$ Aprotinin, $10 \mu \mathrm{g} / \mathrm{ml}$ Chymostatin, $5 \mu \mathrm{g} / \mathrm{ml} \mathrm{E}-64,0,5 \mu \mathrm{g} / \mathrm{ml}$ Leupeptin, $1 \mathrm{mg} / \mathrm{ml}$ Pefabloc) aufgenommen und die chromosomale DNA im Homogenisator geschert. Die Zugabe von 1/9 Volumen 4 M Ammoniumsulfat erfolgte unter langsamem Rühren. Nach $1 \mathrm{~h}$ bei $4^{\circ} \mathrm{C}$ wurde die Kernmembran durch Zentrifugation (SS34, $30 \mathrm{~min}, 16.000 \mathrm{rpm}, 4^{\circ} \mathrm{C}$ ) von der flüssigen Phase getrennt. Zur Pelletierung der chromosomalen DNA wurde der Überstand sofort ultrazentrifugiert (TFT 65.13, $2 \mathrm{~h}, 55.000 \mathrm{rpm}, 4^{\circ} \mathrm{C}$ ) und sofort in ein Becherglas überführt und die Kernproteine durch Zugabe von 0,37 g/ml gemörsertem Ammoniumsulfat über Nacht gefällt (langsam Rühren).

Die Kernproteine wurden durch Zentrifugation (SS34, $\left.30 \mathrm{~min}, 16.000 \mathrm{rpm}, 4^{\circ} \mathrm{C}\right)$ pelletiert. Das Pellet wurde in Dialysepuffer (100 mM KCl, $20 \mathrm{mM}$ Hepes pH 7,6, 0,2 mM EDTA, $10 \%$ (v/v) Glycerin, 
0,5 mM DTT, 0,2 mM PMSF) versetzt, mit Proteaseinhibitoren (50 $\mu \mathrm{g} / \mathrm{ml}$ Antipain, $2 \mu \mathrm{g} / \mathrm{ml}$ Aprotinin, $10 \mu \mathrm{g} / \mathrm{ml}$ Chymostatin, $5 \mu \mathrm{g} / \mathrm{ml} \mathrm{E}-64,0,5 \mu \mathrm{g} / \mathrm{ml}$ Leupeptin, $1 \mathrm{mg} / \mathrm{ml}$ Pefabloc) aufgenommen und die Lösung gegen zweimal Dialysepuffer dialysiert. Der Proteingehalt der Proben wurde mit der Methode nach BRADFORD bestimmt (4.7.5). Die zu erwartenden Proteinmengen liegen zwischen 1-1,5 $\mu \mathrm{g} / \mu \mathrm{l}$. Die Proben wurden anschließend aliquotiert, in flüssigem Stickstoff schockgefroren und bei $-80^{\circ} \mathrm{C}$ gelagert.

\subsubsection{Konzentrationsbestimmung von Proteinextrakten}

Die Bestimmung der Proteinkonzentration nach BRADFORD (1976) beruht auf der Verschiebung des Absoprtionsmaximums von Coomassie Brilliant Blue G-250 (von $465 \mathrm{~nm} \mathrm{zu} 595 \mathrm{~nm}$ ) nach Bindung an ein Protein. Eine adäquate Menge des Proteinextraktes wurde in die Vertiefung (,,well“") einer 96-,,well“"Mikrotiterplatte vorgelegt und mit $200 \mu \mathrm{l}$ verdünnten (1:5 mit $\mathrm{H}_{2} \mathrm{O}$ ) Bradford-Reagenz (Roth) vermischt. Nach 5-minütiger Inkubation konnte die optische Dichte bei $595 \mathrm{~nm}$ im Spektralphotometer (MRX Dynex Plate Reader) bestimmt werden. Die Proteinkonzentration wurde anhand einer mit BSA-Standards $(1 \mu \mathrm{g}$, $3 \mu \mathrm{g}, 6 \mu \mathrm{g})$ erstellten Eichgerade ermittelt.

\subsubsection{Affinitätsaufreinigung des Antiserums}

Die Methode der Affinitätsaufreinigung von polyklonalen Antiseren nach OLMSTED (1981) stellt eine Modifikation des Western-Blots (4.7.10) dar. Hierzu wurde das aus der Affinitätschromatographie resultierende Fusionsprotein in einem präparativen 10 \%-igen (w/v) SDS-Gel (Kapitel 4.7.8) aufgetrennt.

Das Volumen des Eluats wurde so gewählt, dass ca. $1 \mathrm{mg}$ des Fusionsproteins darin enthalten waren. Die Proteine wurden anschließend mittels Semi-Dry-Blot (Kapitel 4.7.10.1) auf eine PVDF-Membran transferiert. Nach dem Anfärben der Membran mit Ponceau-Lösung (0,1\% (w/v) Ponceau S, 5 \% (v/v)

Essigsäure) wurde die Bande mit dem Fusionsprotein ausgeschnitten und in ca. 3 x $3 \mathrm{~mm}$ große Stücke zerteilt. Die Membranstücke wurden mit $10 \mathrm{ml} 5 \%(\mathrm{w} / \mathrm{v})$ Magermilch in PBS-T (140 mM NaCl, 2,7 mM KCl, 1,5 mM KH $\mathrm{PO}_{4}, 4,0 \mathrm{mM} \mathrm{Na}_{2} \mathrm{HPO}_{4}$, pH 7,4 mit 0,05 \% TWEEN 20) über Nacht bei $4^{\circ} \mathrm{C}$ inkubiert und anschließend $5 \mathrm{~min}$ in $10 \mathrm{ml}$ PBS-T bei RT gewaschen. $2 \mathrm{ml}$ des entsprechenden polyklonalen Antiserums wurden mit PBS $(140 \mathrm{mM} \mathrm{NaCl}, 2,7 \mathrm{mM} \mathrm{KCl}, 1,5 \mathrm{mM}$ $\mathrm{KH}_{2} \mathrm{PO}_{4}, 4,0 \mathrm{mM} \mathrm{Na} \mathrm{HPO}_{4}$, pH 7,4) auf $10 \mathrm{ml}$ aufgefüllt und die PVDF-Stückchen 2-3 $\mathrm{h}$ mit der Antikörperlösung inkubiert. Unspezifische gebundene Antikörper wurden durch Waschen mit $10 \mathrm{ml}$ PBS-T für 6 x 15 min entfernt. Im Anschluß wurden die spezifischen Antikörper mit 0,1 M Glycin pH 2,5 von der Membran eluiert. Die Elution wurde möglichst schnell durchgeführt und die Eluate sofort neutralisiert, um eine Schädigung der Antikörper $\mathrm{zu}$ vermeiden. Hierzu wurden $4 \mathrm{x}$ je $1 \mathrm{ml}$ Neutralisierungslösung $(0,3 \mathrm{ml} 1 \mathrm{M}$ Tris- $\mathrm{HCl} \mathrm{pH} 8$ mit $0,7 \mathrm{ml} \mathrm{PBS})$ auf Eis bereitgehalten. Zur Elution wurden $2 \mathrm{ml} \mathrm{0,1} \mathrm{M} \mathrm{Glycin} \mathrm{pH} \mathrm{2,5} \mathrm{auf} \mathrm{die} \mathrm{Membranstücke} \mathrm{gegeben,} \mathrm{diese} \mathrm{exakt} 30 \mathrm{~s}$ unter Invertieren mit der Lösung inkubiert und die Lösung unmittelbar im Anschluß in die Neutralisierungslösung überführt. Die Elution wurde unter gleichen Bedingungen dreimal wiederholt. Die Eluate mit den spezifischen Antikörpern wurden danach in Centricon 10-Säulen mit $2 \times 2 \mathrm{ml}$ PBS mit 0,02\% (v/v) Natriumazid umgepuffert und aufkonzentriert. $\mathrm{Zu}$ den Antiseren wurde BSA mit einer Endkonzentration von $5 \%$ gegeben. Danach konnten diese bei $-20^{\circ} \mathrm{C}$ gelagert werden. Die Qualität der affinitätsaufgereinigten Antikörpern wurde mittels Western-Blot-Analyse (4.7.10) mit denaturierten Gesamtzellextrakten (Kapitel 4.7.2) getestet.

\subsubsection{Gelretardationsanalysen (EMSA)}

DNA-Fragmente, an die Proteine binden, zeigen in einem nativen Polyacrylamidgel ein anderes Laufverhalten als ungebundene DNA. Der Protein-DNA-Komplex wandert aufgrund seines höheren Molekulargewichts weniger weit, verglichen mit dem proteinfreien Fragment. Diese Verzögerung im Laufverhalten wird als Retardierung oder ,shift“ bezeichnet. Man macht sich das Phänomen in Gelretardationsanalysen (Electrophoretic Mobility Shift Assay = EMSA) zunutze, um die spezifische Bindung von Proteinen an bestimmte DNA-Sequenzen nachzuweisen. Hierzu wird das entsprechende DNA-Fragment radioaktiv markiert und in einem geeigneten Puffer mit einem Proteinextrakt inkubiert. 
Nach Gelelektrophorese und Autoradiographie des Gels kann aus dem auftretenden Bandenmuster auf eine eventuelle Interaktion von Proteinen und DNA geschlossen werden.

Eine Variante der Gelretardationsanalyse ist der Supershiftassay, bei dem zusätzlich ein spezifischer Antikörper in den Bindeansatz gegeben wird. Erkennt dieser Antikörper Proteine, die Bestandteile des Protein-DNA-Komplexes sind, so bewirkt seine Bindung an diese Proteine eine weitere Retardierung des Komplexes (,Supershift“).

Für dieses Assay wurden $2 \mu \mathrm{g}$ native Kernproteinextrakte (Kapitel 4.7.4.1) und $20 \mu \mathrm{g}$ native Gesamtzellextrakte (Kapitel 4.7.3) verwendet. Die Bindereaktion erfolgte in einem Gesamtvolumen von $30 \mu \mathrm{l}$ in $1 \mathrm{x}$ Bindepuffer (25 mM Hepes $\mathrm{pH} 7,6,10 \mathrm{mM} \mathrm{MgCl}, 0,2 \mathrm{mM} \mathrm{CaCl}, 0,2 \mathrm{mM}$ DTT, $0,4 \mathrm{mM}$ PMSF $10 \%(\mathrm{v} / \mathrm{v})$ Glycerin). Die Proteinproben wurden in Gegenwart von $3 \mu \mathrm{g}$ polydI/dC (als Kompetitor für unspezische DNA-Bindeproteine) für $10 \mathrm{~min}$ auf Eis vorinkubiert. Bei Supershiftassays wurde zusätzlich jeweils $1 \mu \mathrm{l}$ des entsprechenden Antiserums in die Ansätze pipettiert. Nach Zugabe von $4 \mu$ radioaktiv markiertem DNA-Fragment (Kapitel 4.5.12.1) pro Ansatz folgte eine zehnminütige Inkubation bei Raumtemperatur. Die Proben wurden anschließend mit jeweils $10 \mu 1$ Auftragspuffer (50\% (v/v) Glycerin, $42 \%$ (v/v) 5 x Bindepuffer: $125 \mathrm{mM}$ Hepes pH 7,6, $50 \mathrm{mM} \mathrm{MgCl} 2,1 \mathrm{mM} \mathrm{CaCl}$, $5 \mathrm{mM}$ DTT, $2 \mathrm{mM}$ PMSF, $50 \%(\mathrm{v} / \mathrm{v})$ Glycerin) versetzt und in einem nativen, $5 \%$-igem Polyacrylamidgel (Kapitel 4.5.6.2) bei $4^{\circ} \mathrm{C}$ gelelektrophoretisch aufgetrennt. Das Gel war mindestens eine Stunde bei $150 \mathrm{~V}$ vorgelaufen. Die Elektrophorese der Proben erfolgte bei $65 \mathrm{~V}$. Für die Autoradiographie wurde das Gel auf Fließpapier transferiert und unter Haushaltsfolie $2 \mathrm{~h}$ bei $80^{\circ} \mathrm{C}$ auf einem Vakuumgeltrockner getrocknet. Nach mindestens vier Stunden Exposition auf einem IP-Screen erfolgte die Detektion der Signale im Bioimager (BAS-1000 von Fuji). Für die Auswertung wurden die Programme PCBAS ${ }^{\circledR} 2.09$ und TINA ${ }^{\circledR} 2.0$ der Firma raytest Isotopenmeßgeräte verwendet.

\subsubsection{Diskontinuierliche SDS-Polyacrylamid-Gelelektrophorese}

Bei der diskontinuierlichen SDS-Polyacrylamid-Gelelektrrphorese (SDS-DISKPAGE) werden Proteine unter denaturierenden Bedingungen in einem aus Sammel- und Trenngel bestehenden Polyacrylamidgel der Größe nach aufgetrennt (modifiziert nach LAEMMLI, 1970). In dieser Arbeit wurden große Vertikalgele (Trenngelgröße $18 \mathrm{~cm} \mathrm{x} 7 \mathrm{~cm}, 22$ Taschen, Eigenbau der Werkstatt) verwendet. Die Trenngele setzen sich aus $10 \%$ (w/v) Acrylamid: N,N'-Methylenbisacrylamid (19:1), 0,4 M Tris- $\mathrm{HCl} \mathrm{pH}$ 8,8, 0,1 \% (w/v) SDS, 0,1 \% (v/v) TEMED und 0,1\%(w/v) APS. Die Sammelgele bestanden aus $4 \%$ (w/v) Acrylamid: N,N'-Methylenbisacrylamid (37, 5:1), $125 \mathrm{mM}$ Tris-HCl pH 6,8, 0,1 \% (w/v) SDS, $0,2 \%(\mathrm{v} / \mathrm{v})$ TEMED und $0,1 \%(\mathrm{w} / \mathrm{v})$ APS.

Vor dem Auftragen wurden die Proteinextrakte mit SDS-Probenpuffer $(2 \mathrm{x}$ SDS-Probenpuffer: 0,2 M Tris, $15 \%$ (v/v) Glycerin, $6 \%$ (w/v) SDS, $10 \%$ (v/v) $\beta$-Mercaptoethanol, 0,05 \% (w/v) Bromphenolblau) versetzt und durch 5-minütige Inkubation bei $100^{\circ} \mathrm{C}$ inkubiert. Proteinextrakte, die bereits unter denaturierten Bedingungen präpariert worden waren, wurden vor Beladen des Gels $10 \mathrm{~min}$ bei $65^{\circ} \mathrm{C}$ inkubiert.

Die Elektrophorese erfolgte mit SDS-Laufpuffer (25 mM Tris, $190 \mathrm{mM}$ Glycin, 0,1 \% (w/v) SDS) bei $160 \mathrm{~V}$ bis die Bromphenolblaubande aus dem Gel herausgelaufen war. Zur Bestimmung der Molekulargewichte wurden auf jedem Gel $5 \mu$ eines Proteinstandards (Prestained SDS-PAGE Standard, Broad Range von BioRad) mit aufgetrennt. 


\subsubsection{Färbung von Proteinen in SDS-Polyacrylamidgelen}

Um Proteinbanden sichtbar zu machen, wurden SDS-Polyacrylamidgele mit dem Farbstoff Coomassie Brilliant Blue G-250 gefärbt.

Das Gel wurde zunächst $30 \mathrm{~min}$ in Fixierlösung (25 \% (v/v) Isopropanol, $10 \%$ (v/v) Essigsäure) geschwenkt und die Lösung anschließend gegen Coomassie-Färbelösung (10\% (v/v) Essigsäure, $0,006 \%$ (w/v) Coomassie Brilliant Blue G-250) ausgetauscht. Die Lösung wurde zusammen mit dem Gel auf etwa $50^{\circ} \mathrm{C}$ in der Mikrowelle erwärmt und unter ständiger Bewegung mindestens $1 \mathrm{~h}$ bei Raumtemperatur inkubiert. Die Entfärbung des Hintergrundes erfolgte mit Coomassie-Entfärbelösung (10 \% (v/v) Essigsäure) während mehrstündigen Schwenkens bei wiederholtem Wechsel der Lösung.

\subsubsection{Immunoblotting (Western-Blot-Analyse)}

Als Immunoblotting bezeichnet man generell immunologische Techniken, bei denen man auf Membranen transferierte, immobilisierte Proteine mit geeigneten Antikörpern reagieren lässt. Beim Western-Blot werden die Proteine zuvor in einer SDS-DISKPAGE aufgetrennt und aus dem Trenngel auf einem geeigneten Trägerfilter, z. B. PVDF oder Nitrocellulose, übertragen. Für die Western-Blot-Analyse wurden $10 \mu \mathrm{l}$ Hefeproteinextrakte (Kapitel 4.7.1), 10-20 $\mu$ l denaturierte Gesamtzellextrakte (Kapitel 4.7.2), 5-15 $\mu \mathrm{l}$ denaturierte Kernproteinextrakte (Kapitel 4.7.4.1) und 10 g native Kernproteinextrakte (Kapitel 4.7.4.2) verwendet.

\subsubsection{Semi-Dry Proteinblot}

In dieser Arbeit wurden Proteine aus SDS-Polyacrylamidgelen mit der „Semi-Dry-Blotting“-Methode (modifiziert nach KYSE und ANDERSON, 1984) im elektrischen Feld zwischen zwei Graphitplatten auf PVDF-Membranen übertragen. Die Auswahl der Transferbedingungen orientierte sich an den Angaben von DUNBAR (1994, Kapitel 4 und 5).

Das SDS-Gel wurde nach Abschluss der Elektrophorese $15 \mathrm{~min}$ in Kathodenpuffer (25 mM Tris, $40 \mathrm{mM}$ 6-aminohexansäure, $20 \%$ (v/v) Methanol, $\mathrm{pH}$ 9,4) und die zugeschnittene PVDF-Membran nach Aktivierung in Methanol in Anodenpuffer II (25 mM Tris, $20 \%$ Methanol, pH 10,4) äquilibriert. In der Elektroblotapparatur folgte auf zwei Lagen Anodenpuffer I (0,3 M Tris, $20 \%$ Methanol, pH 10,4) getränktes Filterpapier eine Lage Anodenpuffer II getränktes Filterpapier. Auf diese Lagen wurde die äquilibrierte PVDF-Membran gelegt, gefolgt vom Gel und drei Lagen in Kathodenpuffer getränktem Filterpapier. Bei Gelen der Dicke 0,8 mm-1 mm erfolgte der Transfer bei einer Stromstärke von $1 \mathrm{~mA} / \mathrm{cm}^{2}$ über einen Zeitraum von einer Stunde. Die Membran wurde entsprechend der Empfehlung des Herstellers in Methanol gewaschen und anschließend für die Lagerung getrocknet.

\subsubsection{Immunologische Detektion geblotteter Proteine}

Bei der hier angewendeten indirekten Nachweismethode wurden die Membranen nach Absättigung unspezifischer Bindestellen („Blocken“ durch Magermilchpulver) zunächst mit dem spezifischen Primärantikörper aus Kaninchen inkubiert. Gebundene Primärantikörper wurden nachfolgend von einem an Peroxidase gekoppelten anti-Kaninchen-Sekundärantikörper aus Esel (anti rabbit Ig von Amersham) erkannt. Die Detektion erfolgte über Chemilumizenz nach Umsetzung eines entsprechenden Substrates durch gekoppelte Peroxidase. Für diesen Nachweis wurde der ECL ${ }^{+}$-Kit der Firma Amersham den Herstellerangaben entsprechend verwendet. Die Exposition der Röntgenfilme (Cronex 10T) betrug 1 min bis 10 min, abhängig von den jeweiligen Signalstärken.

Alle Inkubationsschritte wurden bei Raumtemperatur unter Schütteln durchgeführt. Die Membran wurde zuvor in Methanol aktiviert und in $1 \mathrm{x}$ PBS-T $\left(140 \mathrm{mM} \mathrm{NaCl}, 2,7 \mathrm{mM} \mathrm{KCl}, 1,5 \mathrm{mM} \mathrm{KH}{ }_{2} \mathrm{PO}_{4}, 4,0 \mathrm{mM}\right.$ $\mathrm{Na}_{2} \mathrm{HPO}_{4}, \mathrm{pH} 7,4$ mit 0,05 \% (v/v) Tween-20) äquilibriert. 


\begin{tabular}{|c|c|}
\hline Blocken: & $1 \mathrm{~h}$ in $1 \times$ PBS-T mit $5 \%$ (w/v) Magermilchpulver \\
\hline Waschen: & $2 \times 5$ min in $1 \times$ PBS-T mit $1 \%(w / v)$ Magermilchpulver \\
\hline Primärantikörper: & $\begin{array}{l}2 \mathrm{~h} \text { in } 1 \mathrm{x} \text { PBS-T mit } 1 \%(\mathrm{w} / \mathrm{v}) \text { Magermilchpulver, } \alpha \mathrm{TGA} 2.1 / \alpha \mathrm{TGA} 2 . \mathrm{x} \\
(1: 1000)\end{array}$ \\
\hline \multirow[t]{2}{*}{ Waschen: } & $2 \times 5$ min in $1 \times$ PBS-T mit $1 \%(\mathrm{w} / \mathrm{v})$ Magermilchpulver \\
\hline & $2 \times 5 \min$ in $1 \times$ PBS- $T$ \\
\hline Sekundärantikörper: & $1 \mathrm{~h}$ in $1 \mathrm{x}$ PBS-T, anti rabbit $\operatorname{Ig}(1: 25.000)$ \\
\hline Waschen: & $5 \times 5$ min in $1 \times$ PBS-T \\
\hline
\end{tabular}

\subsubsection{Rehybridisierung}

Um eine Membran, mit der bereits eine Western-Blot-Analyse durchgeführt worden ist, mit einem weiteren Primärantikörper zu inkubieren, müssen die gebundenen Antikörper zunächst entfernt werden (,Strippen“). Dazu wurde die Membran mit Methanol aktiviert und in 1 x PBS-T (70 mM NaCl, 1,35 mM KCl, 0,75 mM KH $\mathrm{KO}_{4}, 4,05 \mathrm{Na}_{2} \mathrm{HPO}_{4}, \mathrm{pH} \mathrm{7,4}$ mit 0,05 \% (v/v) Tween-20) äquilibriert. Anschließend wurde die Membran $3 \mathrm{x}$ in 0,1 M Glycin pH 2,5 inkubiert. Die gestrippte Membran konnte nun erneut hybridisiert werden.

\subsection{Fusionsproteinanalysen in Hefe}

Das Hefe-Zweihybridsystem ist eine Methode zur Identifizierung und Charakterisierung von ProteinProtein-Interaktionen in vivo. Es wird häufig dazu verwendet, neue Proteine aus Signaltransduktionsketten $\mathrm{zu}$ finden, da diese Proteine oft miteinander interagieren, um ein Signal weiterzuleiten. Es gibt verschiedene Formen des Hefe-Zwei-Hybridsystems. In dieser Arbeit wurde das "Ubiquitin-based splitprotein sensor system“ (USPS) (JOHNSON und VARSHAVSKY, 1994) verwendet (Kapitel 5.1.1.1). Es beruht auf dem Protein Ubiquitin, welches bei der Proteindegradation eine Rolle spielt. Die aminoterminale Hälfte wird von einem PADNS-Derivat (COLICELLI et al., 1989) und die carboxyterminale Hälfte von einem RS314- Derivat (SIKORSKI und HIETER, 1989) kodiert. Zur Suche nach Interaktionspartnern eines Proteins wird eine Plasmid-cDNA-Bank im PADNS-Derivat durchgemustert. Eine cDNA-Bank kodiert für das Proteom eines Organismus. Ein Screen mit dem Hefe-Zweihybridsystem ist so angelegt, dass theoretisch jedes Protein, das als mRNA in einem Organismus vorlag, mit dem Köderprotein in einer Hefezelle zusammen exprimiert wird. Das Köderprotein ist dabei an das 5'-Ende der carboxyterminale Hälfte des Ubiquitins fusioniert, während das Beuteprotein, das durch eine cDNA kodiert wird, an das 3'-Ende der aminoterminalen Hälfte des Ubiquitins gekoppelt ist. Trifft in einer Zelle das Köderprotein auf ein interagierendes Protein, so kommen die aminoterminale und die carboxyterminale Hälfte des Ubiquitins in räumliche Nähe zueinander, das Ubiquitin wird rekonstituiert und ein Reportergen, welches zusätzlich an das 3'-Ende des carboxyterminalen Teils fusioniert ist, wird von spezifischen Proteasen abgespalten und abgebaut. Als Reportergen wird das URA3-Gen verwendet, welches Uracilprototrophie vermittelt und die Hefezellen sensitiv für 5-FOA macht, eine Substanz, die von den Hefezellen in den toxischen Stoff 5-Fluorouracil umgewandelt wird. 


\subsubsection{Herstellung einer cDNA-Bank mittels SMART-Technologie}

Die SMART-Methode basiert auf einer PCR-Amplifikation und führt zu einer hohen Ausbeute an cDNA. Die Erststrangsynthese wird durch die Bindung von Oligonukleotiden an komplementäre Regionen der mRNA initiiert. Die Oligonukleotide dienen als Primer für die MMLV-Reverse Transkriptase (MMLVRT), die die messenger-RNA in komplementäre einzelsträngige DNA transkribiert.

Das Protokoll von Clontech liefert zwei Erststrangprimer, einen modifizierten Oligo(dT)-Primer (CDS III) und einen random Primer (CDS III/6). Der Oligo(dT)-Primer hybridisiert am Poly(A)-Schwanz der mRNA, so dass Sequenzen am 5'-Ende der mRNA leicht unterpräsentiert aus der cDNA-Synthese hervorgehen können. Der random Primer hingegen bindet statistisch an die RNA-Sequenz, die resultierende Bibliothek sollte daher 3'- und 5'-Enden zu gleichen Teilen enthalten. Nach erfolgter Erststrangsynthese fügt die MMLV-RT über ihre terminale Transferase-Aktivität eine kurze (dC)-Folge am 3'-Ende der cDNA an. Das SMART-Oligonukleotid geht über seine 3'-(dG)-Sequenz Basenpaarungen mit dem (dC)-Überhang ein und bildet eine verlängerte Matrize für die Reverse Transkriptase. Es folgt ein template switching der Reversen Transkriptase, die jetzt das SMART-Oligonukleotid als neue Vorlage verwendet und dessen Basenabfolge repliziert. Die verlängerte ss cDNA enthält somit die vollständige Sequenzinformation des 5'-Endes der mRNA und die komplemetäre Sequenz des SMARTOligonukleotids als Ankersequenz. Der SMART-Anker fungiert ebenso wie die CDS-Sequenz als priming site für die folgende Amplifikation der cDNA über long distance PCR (LD-PCR). Bei diesem Schritt werden nur ss cDNAs, die den SMART-Anker enthalten, als Matrize akzeptiert. Nach erfolgter LD-PCR wird die cDNA aufgereinigt und kann für die Herstellung einer Fusionsbank eingesetzt werden.

Wird die Erststrangsynthese vor Erreichen des 5'-Endes der mRNA gestoppt, z. B. durch Sekundärstrukturen innerhalb der mRNA, fügt die Reverse Transkriptase keinen (dC)-Überhang an. Die terminale Transferase-Funktion des Enzyms wird erst bei Erreichen des 5'-Endes der mRNA-Matrize aktiviert. Das SMART-Oligonukleotid kann folglich nicht hybridisieren und die Amplifikation unterbleibt: somit sind die entsprechenden Sequenzen in der cDNA-Bank unterrepräsentiert. Die beschriebene Methode führt zur Entstehung von Vollängen-cDNAs, die auch die Sequenzinformationen der 5'-UTRS (,untranslated regions“) der mRNAs enthalten (ZHU et al., 2001). Liegt in diesem Bereich ein Stopcodon vor, wird die an die aminoterminale Hälfte des Ubiquitins fusionierte cDNA nicht exprimiert und ist im Hefe Zwei-Hybridsystem nicht als Bankprotein repräsentiert. Für die Herstellung der cDNA-Bank wurde das Protokoll nach „MATCHMAKER Library Construction \& Screening Kit User Manual“ von Clontech verwendet.

\subsubsection{Erststrang-cDNA-Synthese}

Alle Inkubationsschritte wurden in einem Thermocycler durchgeführt. In ein 0,25 ml PCR-Gefäß wurden 300 ng Poly(A)-RNA und $1 \mu$ l CDS III oder CDS III/6 mit einem Endvolumen von $4 \mu 1$ gegeben, gemischt und für 2 min bei $72^{\circ} \mathrm{C}$ inkubiert. Nachdem die Proben für 2 min auf Eis abgekühlt waren, wurden zusätzlich in das PCR-Gefäß $2 \mu \mathrm{l} 5$ x Erststrangpuffer $\left(250 \mathrm{mM}\right.$ Tris pH 8,3, $30 \mathrm{mM} \mathrm{MgCl}_{2}$, $375 \mathrm{mM} \mathrm{KCl}), 1 \mu \mathrm{l}$ DTT $(10 \mathrm{mM}), 1 \mu \mathrm{l}$ dNTP Mix $(10 \mathrm{mM})$ und $1 \mu \mathrm{l}$ MMLV Reverse Transkriptase gegeben und vorsichtig durchmischt. Wurde der random Primer für die Erststrangsynthese verwendet, folgte ein Inkubationsschritt bei $25-30^{\circ} \mathrm{C}$ für $10 \mathrm{~min}$. Anschließend wurde das PCR-Gefäß bei $42^{\circ} \mathrm{C}$ für 10 min inkubiert, $1 \mu \mathrm{l}$ SMART III Oligonukleotid zugegeben und wieder bei $42^{\circ} \mathrm{C}$ für $1 \mathrm{~h}$ inkubiert. Nach Abbruch der Erststrangsynthese durch Erhitzen der Probe bei $75^{\circ} \mathrm{C}$ für $10 \mathrm{~min}$, wurde die Probe auf Raumtemperatur abgekühlt. Die nicht umgesetzte mRNA wurde durch einen Rase H-Verdau abgebaut. Dazu wurde $1 \mu \mathrm{l}(2 \mathrm{U}) \mathrm{RNase} \mathrm{H}$ zu dem Ansatz gegeben und die Probe bei $37^{\circ} \mathrm{C}$ für 20 min inkubiert. Der Erststrangmix konnte nun für maximal drei Monate bei $-20^{\circ} \mathrm{C}$ gelagert werden. 


\subsubsection{Amplifikation der ds cDNA über long distance PCR}

Durch den Mechanismus der long distance PCR (CHENCHIK et al., 1998) wird die ds cDNA amplifiziert. Der dabei verwendete Advantage ${ }^{\circledR} 2$ Polymerase Mix besteht aus der TITANIUM ${ }^{\circledR}$ Taq DNA Polymerase, die über die aminoterminale Deletion nukleasedefizient ist, einem TaqStart ${ }^{\mathrm{TM}}$ Antikörper für den PCR hot start (KellogG et al., 1994) und einem geringen Anteil einer ,proofreading“ Polymerase. Diese PCRMixtur ermöglicht die Amplifikation langer Fragmente bis zu $20 \mathrm{~kb}$ mit einer signifikant höheren Replikationsgenauigkeit als herkömmliche Polymerase (BARNES et al., 1994)

In ein PCR-Gefäß wurden $2 \mu$ l Erststrangprobe, $70 \mu \mathrm{l} \mathrm{H} \mathrm{H}_{2} \mathrm{O}, 10 \mu 110$ x Advantage ${ }^{\circledR} 2$ PCR Puffer, $2 \mu \mathrm{l}$ 50 x dNTP-Mix (10 mM jedes), $2 \mu 1$ 5' PCR-Primer $(10 \mu \mathrm{M}), 2 \mu 1$ 3' PCR-Primer $(10 \mu \mathrm{M}), 10 \mu \mathrm{l}$ GCSchmelzlösung und $2 \mu 150 \times$ Advantage ${ }^{\circledR} 2$ Polymerase Mix gegeben. Die Proben wurden in einen bei $95^{\circ} \mathrm{C}$ vorgeheizten Thermocycler gestellt. Das verwendet PCR-Programm war folgendes:

$$
\begin{aligned}
& 95^{\circ} \mathrm{C} \quad 30 \mathrm{~s} \\
& 22 \text { Zyklen } \quad 95^{\circ} \mathrm{C} \quad 10 \mathrm{~s} \\
& 68^{\circ} \mathrm{C} \quad 6 \min ^{\mathrm{a}} \quad{ }^{\mathrm{a}} \text { für jeden folgenden Zyklus wird die Zeit um } 5 \mathrm{~s} \\
& \text { verlängert) } \\
& 68^{\circ} \mathrm{C} \quad 5 \mathrm{~min}
\end{aligned}
$$

Anschließend wurden $7 \mu$ der PCR-Probe in einem $1 \%$-igen (w/v) Agarosegel aufgetrennt. Die ds cDNA konnte bei $-20^{\circ} \mathrm{C}$ gelagert werden.

\subsubsection{Aufreinigung der ds cDNA}

Die zur Aufreinigung verwendeten CHROMA SPINTM + TE-400 Säulen ermöglichen eine Fraktionierung nach Größe. DNA-Moleküle, die größer als 200 bp sind, können sich wegen ihrer Größe nicht in die Poren der Säulenmatrix anlagern und werden selektioniert. Kleinere Moleküle verbleiben in der Matrix.

Die Säulen wurden vor Gebrauch solange invertiert, bis die Gelmatrix vollständig resuspendiert war. Nachdem das untere Plastikstück weggebrochen und der Säulendeckel abgenommen war, wurden die Säule und das Sammelgefäß in ein $15 \mathrm{ml}$-Plastikröhrchen plaziert und für 5 min bei $700 \times \mathrm{g}$ in einem Ausschwingrotor zentrifugiert. Der Durchfluss wurde verworfen. Die cDNA-Probe wurde nun auf die Mitte der Säule gegeben. Es folgte eine erneute Zentrifugation bei $700 \mathrm{~g}$ für $5 \mathrm{~min}$. Die aufgereinigte cDNA, welche in einen 1,5 ml Reaktionsgefäß aufgefangen wurde, wurde mit Hilfe einer Ethanolfällung (Kapitel 4.5.3) aufkonzentriert, in $20 \mu \mathrm{l} \mathrm{H} 2 \mathrm{O}$ aufgenommen und für die Hefetransformation (Kapitel 4.8.4) eingesetzt.

\subsubsection{Charakterisierung von Hefestämmen}

Um die Zellzahl einer Hefesuspension mit einem OD-Wert korrelieren zu können, wird der entsprechende Hefestamm charakterisiert. Ausgehend von einer über-Nacht-Kultur wird eine Verdünnungsreihe erstellt und die optische Dicht und die Zellzahl jeder Verdünnungsstufe ermittelt. Zusätzlich kann ein Zeitverlauf der Wachstumskurve erstellt werden, um optimale Animpfzeiten festzustellen. Bei einer gegeben Hefesuspension kann über die Ermittlung der optischen Dichte einer entsprechenden Verdünnung auf die Zellzahl der Kultur geschlossen werden. Die OD-Messung einer Zellsuspension erfolgt am Photometer bei einer Wellenlänge von $600 \mathrm{~nm}$. Die Probe wurde mit dem verwendeten Medium 1:10 bis 1:100 verdünnt und gegen das verwendete Medium gemessen. Parallel wurde die Zellzahl pro $\mathrm{ml}$ der Verdünnungsstufen mit Hilfe der Fuchs-Rosenthal-Zählkammer ermittelt:

$$
\text { Zellzahl }=\frac{\text { ZellzahlproKleinquadratx16xVerdünnung }}{0.0002}
$$




\subsubsection{Toxizitätstest des verwendeten Köderproteins}

Das Wachstum der mit dem Köderprotein transformierten Hefezellen sollte mit dem Wachstum „leerer“ Zellen verglichen werden, um seine Toxizität auszuschließen. Die Bestimmung der $\mathrm{OD}_{600}$ einer $50 \mathrm{ml}$ über-Nacht-Kultur, die unter Selektionsbedingungen angezogen worden war, gibt hierbei Aufschluss über mögliches verlangsamtes Wachstum.

Der $\mathrm{OD}_{600}$-Wert soll $\geq 0,8$ betragen. Liegt dieser Wert deutlich niedriger, ist von einer toxischen Wirkung des Köderptroteins auszugehen.

\subsubsection{Präparation ultrakompetenter Hefezellen}

Für die Präparation ultrakompetenter Hefezellen wurde das Protokoll nach „MATCHMAKER Library Construction \& Screening Kit User Manual, Appendix B“ von Clontech verwendet.

$50 \mathrm{ml}$ YPDA-Medium wurden mit 10-100 $\mu$ l Zellsuspension einer über-Nacht-Kultur angeimpft und über Nacht bei $30^{\circ} \mathrm{C}$ inkubiert. Nachdem die Kultur eine $\mathrm{OD}_{600}$ von $0,15-0,3$ erreicht hatte, wurde diese bei $700 \mathrm{x} \mathrm{g}$ für $5 \mathrm{~min}$ abzentrifugiert. Das Zellpellet wurde in $100 \mu 1$ YPDA-Medium resuspendiert und für 3-5 h bei $30^{\circ} \mathrm{C}$ inkubiert, bis die Kultur eine $\mathrm{OD}_{600}$ von 0,4-0,5 erreicht hatte. Die Hefesuspension wurde in $60 \mathrm{ml}$ sterilem $\mathrm{H}_{2} \mathrm{O}$ gewaschen und das Zellpellet in $3 \mathrm{ml} \mathrm{1,1 \times \textrm {TE } / \mathrm { LiAc } - L o ̈ s u n g}(1,1 \mathrm{ml} 10 \times \mathrm{TE}, 1,1$ $\mathrm{ml} 10 \mathrm{x}$ Li-Acetat, stammen aus dem Kit) resuspendiert. Die Lösung wurde auf zwei $1,5 \mathrm{ml}$ Reaktionsgefäße aufgeteilt, bei $13.000 \mathrm{rpm}$ für $15 \mathrm{~s}$ abzentrifugiert und in je $600 \mu 1$ 1,1 x TE/LiAc-Lösung aufgenommen.

Die kompetenten Zellen wurden direkt nach dieser Präparation für die Transformation eingesetzt. Sie konnten für einige Stunden bei Raumtemperatur gelagert werden, wobei sich die Kompetenz der Zellen nicht signifikant verringerte.

\subsubsection{Herstellung und Screening einer Nub-Fusionsbank}

Für die Herstellung und für den Screen wurde das Protokoll nach „MATCHMAKER Library Construction \& Screening Kit User Manual“" von Clontech verwendet.

Unter Verwendung dieses Protokolls können die Konstruktion einer cDNA-Bank und die Transformationsschritte für einen Hefe-Zweihybridsystem zeitgleich in einem geeigneten Hefestamm erfolgen. In der vorliegenden Arbeit wurde mittels dieser Vorschrift der Stamm NLY2 mit dem Köderplasmid pSKL6, dem Bankvektor PADNX-NubI-Rec und der zuvor konstruierten cDNA transformiert.

Der Bankvektor liegt linearisiert vor, die Sequenzen beiderseits des Schnitts sind den beidseitigen Ankersequenzen der cDNA homolog. Innerhalb der Hefezellen wird der lineare Vektor dann durch homologe Rekombination, bei gleichzeitiger Intergration der cDNA zirkularisiert. Die Summe aller entstehenden PADNX-NubI/cDNA-Vektoren bildet die Nub-Fusionsbank.

In ein steriles 15 ml-Gefäß wurden $20 \mu \mathrm{l}$ ds cDNA, $3 \mu \mathrm{g}$ Ködervektor, $5 \mu \mathrm{g}$ Bankvektor, $20 \mu \mathrm{l}$ Heringssperma carrier DNA (denaturiert) und $600 \mu \mathrm{l}$ kompetente Zellen gegeben und vorsichtig durchmischt. Anschließend erfolgte die Zugabe von 2,5 ml 1 x PEG/Li-Acetat-Lösung. Die Zellen wurden für $45 \mathrm{~min}$ bei $30^{\circ} \mathrm{C}$ inkubiert. Nach Zugabe von $160 \mu \mathrm{l}$ DMSO wurden die Zellen bei $42^{\circ} \mathrm{C}$ im Wasserbad für $20 \mathrm{~min}$ inkubiert. Es folgte eine Zentrifugation bei $700 \mathrm{x} \mathrm{g}$ für $5 \mathrm{~min}$. Das Pellet wurde in $3 \mathrm{ml} \mathrm{YPD}^{+}-$ Medium resuspendiert. Die Regeneration der Zellen erfolgte bei $30^{\circ} \mathrm{C}$ für $90 \mathrm{~min}$. Das Medium wurde durch erneute Zentrifugation bei $700 \mathrm{x}$ g für $5 \mathrm{~min}$ abgetrennt und das Pellet in $12 \mathrm{ml}$ einer $0,9 \%$-igen (w/v) NaCl-Lösung aufgenommen. Der Ansatz wurde auf Selektionsplatten ausplattiert, jeweils $150 \mu 1$ pro $150 \mathrm{~mm}$ Platte. Anschließend wurden die Platten bei $30^{\circ} \mathrm{C}$ für 4 Tage inkubiert. 


\subsubsection{Bestimmung der Transformationseffizienz}

Ein $30 \mu$ l-Aliquot wurde dem $6 \mathrm{ml}$-Hefeansatz entnommen, mit $720 \mu \mathrm{l}$ einer $0,9 \%$-igen (w/v) NaClLösung versetzt und jeweils $150 \mu \mathrm{l}$ auf $150 \mathrm{~mm}$-Platten: SD-LEU und SDTRP-LEU ausplattiert. Die Kolonien wurden ausgezählt und die Transformationseffizienz wie folgt bestimmt:

SD-LEU: $\quad$ Anzahl der Kolonien x $1000=$ Anzahl der Transformanden/3 $\mu$ g PADNX-NubIRec

(Erwartet werden $\geq 1 \times 10^{6}$ Transformanden/3 $\mu \mathrm{g}$ PADNX-NubI-Rec)

SD-TRP-LEU:

Anzahl der Kolonien x $1000=$ Anzahl der durchmusterten Klone

(Erwartet werden $\geq 5 \times 10^{5}$ Klone/Bank)

\subsubsection{Qualitativer Test einer Protein-Protein-Interaktion}

Für den qualitativen Test einer Interaktion wurden im Rahmen dieser Arbeit verschiedene Systeme verwendet.

\subsubsection{USPS-System („Ubiquitin-based split-protein sensor system“)}

Die zu testenden Fusionsproteine wurden über die entsprechenden Konstrukte in den Stamm NLY2 oder JD53 Ssh1CubRura303 (Kapitel 3.7.1) koexprimiert. Daraufhin wurden einzelne Transformanden über Nacht in $5 \mathrm{ml}$ Plasmidselektionsmedium angezogen, der Titer der Hefesuspensionen bestimmt und verschiedene Verdünnungsstufen $\left(10^{2}-10^{5}\right)$ davon auf analytisches Medium getropft, um die Aktivität des Reportergens zu testen („Growth Assay“). Neben dem analytischem Medium wurde stets Plasmidselektionsmedium verwendet, um zu überprüfen, ob die Hefezellen generell in der Lage sind zu wachsen.

\subsubsection{Das Hefe-Zweihybridsystem}

Das klassische Hefe-Zweihybridsystem beruht auf dem Hefe-Transkriptionsfaktor GAL4, dessen funktionelle Domänen von den Plasmiden pGBT9 und pGAD424 kodiert werden. Treffen in einer Zelle zwei interagierende Proteine aufeinander, so kommen Aktivierungsdomäne und Bindedomäne des GAL4Transkriptionsfaktors in räumliche Nähe zueinander, der GAL4-Transaktivator wird rekonstituiert und Reportergene, die unter Kontrolle eines durch GAL4 regulierbaren Promotors stehen und im Genom der Hefe inseriert sind, werden exprimiert. Als Reportergene werden hier das HIS3-Gen und das ADE2-Gen verwendet, auf die direkt selektioniert werden kann.

Die zu testenden Fusionsproteine wurden über die entsprechenden Konstrukte in dem PJ69-4A (Kapitel 3.7.1) koexprimiert. Daraufhin wurden einzelne Transformanden auf analytischem Medium subkultiviert, um die Aktivität der Reportergene zu testen. Zweierlei analytisches Medium wurden verwendet. Einerseits wurde SD-TRP-LEU-Medium mit Zusatz von nur 0,01 g/l Adenin verwendet. Bei dieser geringen Menge war genügend Adenin vorhanden, um ein Wachstum der Hefen auch ohne Reportegenaktivität zu ermöglichen, aber so wenig, dass sich die rotfarbene Vorstufe dieser Aminosäure in den Zellen, die nicht selbständig Adenin produzieren können, angereichert hatte. Interagieren die Fusionsproteine miteinander bleiben die Hefekolonien weiß. Andererseits wurde SD-TRP-LEU-ADE-HIS-Medium verwendet. Die Hefezellen können auf diesem Medium wachsen, wenn die zu testenden Proteine miteinander interagieren. 


\subsubsection{Das modifizierte „One-Hybrid“-System}

Zum Nachtesten von potentiellen Interaktionspartnern wurde ein modifiziertes „One-Hybrid“-System verwendet (SIEMSEN, 2002). Ein Reportergenkonstrukt, bestehend aus drei as-1 Elementen und dem HIS3Gen, wurde in das Hefegenom des Stammes YTSH1 integriert. Wird in diesem Stamm ein TGA-Faktor exprimiert, so kann dieser an die as-1 Elemente binden und die HIS3-Expression induzieren. Wird die Bindung von dem TGA-Faktor durch ein interagierendes Protein negativ beeinflusst, so sind die Hefezellen nicht mehr in der Lage auf Medium ohne Histidin zu wachsen.

Die zu testenden Proteine wurden über die entsprechenden Konstrukte in dem YTSH1 koexprimiert. Daraufhin wurden einzelne Transformanden auf analytischem Medium subkultiviert, um die Aktivität des Reportergens zu testen. Als analytisches Medium wurde SDTRP-LEU-HIS-Medium mit Zusatz von 30 mM 3-AT verwendet, um das HIS3-Protein kompetitiv zu hemmen und so den Hintergrund zu drücken.

\subsubsection{Verwendete Computerprogramme zur Suche nach homologen DNA- Sequenzen}

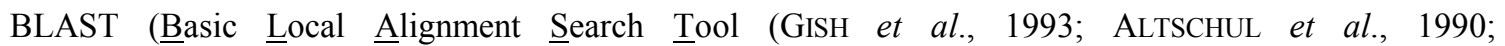
MADDEN et al., 1996)

Das Programm BLAST wird eingesetzt, um Homologien der im „Bankscreen“ identifizierten cDNAs zu bekannten Sequenzen in Datenbanken festzustellen. Um gegebenenfalls weitere Informationen $\mathrm{zu}$ den schon bekannten Proteinen $\mathrm{zu}$ erhalten, wird auf die Arabidopsis thaliana-Datenbank (www.mips.biochem.mpg.de/proj/thal/db) zurückgegriffen. 


\section{Ergebnisse}

\subsection{Identifikation von Protein-Interaktionspartnern des bZIP- Transkriptionsfaktors TGA2.1 mit Hilfe des „Ubiquitin-based split-protein sensor systems“"}

\subsubsection{Das „Ubiquitin-based split-protein sensor system“6}

\subsubsection{Charakteristika des „Ubiquitin-based split-protein sensor systems“}

Proteine, die mit den Komponenten des ASF-1-Komplexes interagieren, können potentielle Regulatoren der $a s-1$-vermittelten, salicylsäureinduzierbaren Genexpression sein. Um diese Proteine zu finden, können verschiedene Methoden verwendet werden.

Eine Möglichkeit stellt der biochemische Weg da. Dieser hat den Nachteil, dass nach der erfolgreichen Isolierung eines Proteins, das an ein Protein von Interesse bindet, ein weiterer Schritt notwendig ist, um das entsprechende Gen zu finden.

Das Hefe-Zweihybridsystem zum Finden und Charakterisieren von Protein-ProteinInteraktionen (FIELDS und SONG, 1998) hat diesen Nachteil nicht. Das in vivo-System beruht auf der modularen Struktur des Gal4-Transkriptionsfaktors, der in zwei funktionelle, unabhängige Einheiten unterteilt werden kann, die DNA-Bindedomäne (BD) und die Transkriptionsaktivierungsdomäne (AD). Kann das Protein von Interesse, fusioniert an die Aktivierungsdomäne, an ein anderes Protein, welches an die Bindedomäne fusioniert ist, binden, so kommen $\mathrm{AD}$ und $\mathrm{BD}$ in räumliche Nähe zueinander und der Transkriptionsfaktor wird rekonstituiert. Dieser kann dann über einen Gal4-abhängigen Promotor ein Reportergen aktivieren, das im Genom der Hefe inseriert ist. Jedoch weist dieses System auch einige Nachteile auf. Mit Hilfe des HefeZweihybridsystems ist es nicht möglich, Protein-Protein-Interaktion zu untersuchen, die nur kurzzeitig auftreten. Zudem findet die Detektion der Proteininteraktion im Zellkern statt, was die Verwendung von Transkriptionsfaktoren als Köderproteine einschränkt. Besitzt z. B. der Transkriptionsfaktor eine eigene Aktivierungsdomäne, so kann dieser fusioniert an eine Bindedomäne selbst die Expression der Reportergene induzieren, ohne 
dass eine Proteininteraktion vorausgegangen sein muss. Zusätzlich ist dieses System beschränkt auf die Analyse von löslichen Proteinen oder löslichen Domänen von Membranproteinen.

Das „Ubiquitin-based split-protein sensor system“ (USPS) (JOHNSSON und VARSHAVSKY, 1994) stellt eine Weiterentwicklung des Hefe-Zweihybridsystems dar. Die Proteininteraktion und die Detektion der Interaktion finden hier im Cytoplasma statt, so dass es nun möglich ist, die Interaktion von Membranproteinen (Sec63, WITTKE et al., 1999) und transkriptionellen Regulatoren (Gal4, LASER et al., 2000) zu untersuchen. Zudem kann man transiente Protein-Protein-Kontakte detektieren. Das in vivo-System basiert auf dem Protein Ubiquitin. Ubiquitin ist ein konserviertes, 76 Aminosäure langes, single-domain-Protein, welches in der Zelle entweder frei oder kovalent an ein anderes Protein gekoppelt vorliegt. Es spielt eine Rolle bei vielen Prozessen in der Zelle, vorrangig bei dem Abbau von Proteinen. 

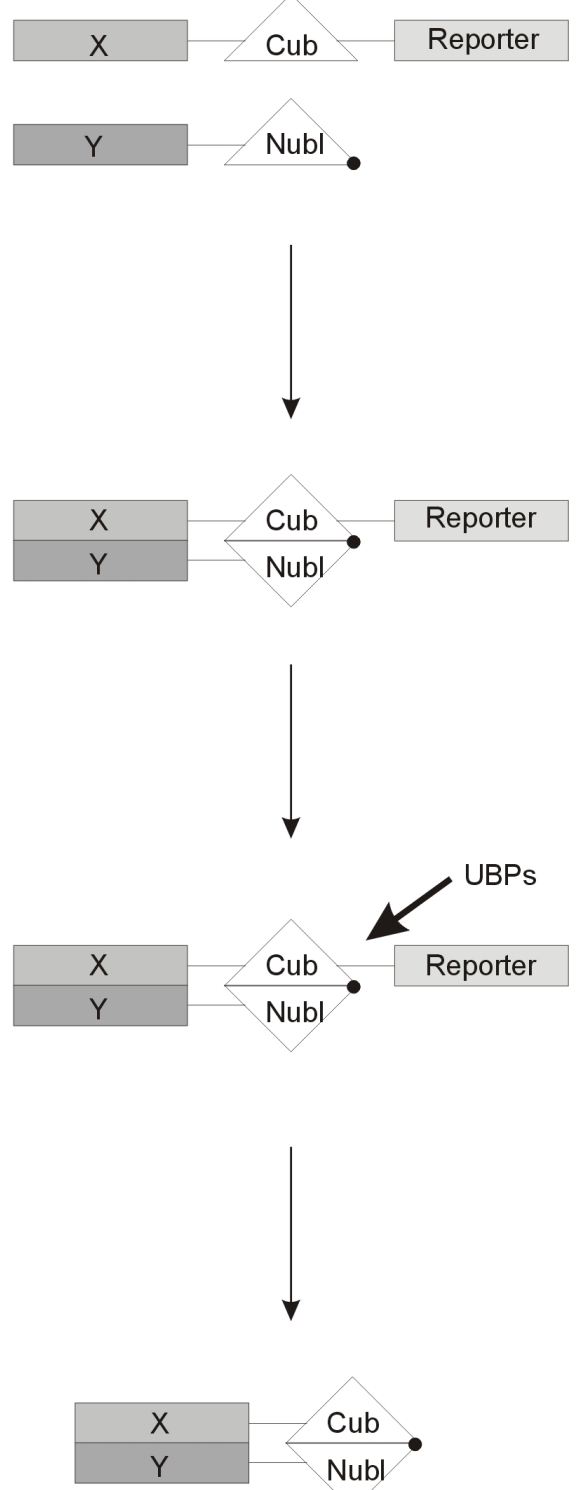

Reporter

Abbildung 5-1: Schematische Darstellung des Ubiquitin-based split-protein sensor system (USPS). Mit X und $\mathrm{Y}$ sind zwei interagierende Proteine gekennzeichnet. NubI: aminoterminaler Teil vom Ubiquitin (aa 1-34); Cub: carboxyterminaler Teil vom Ubiquitin (aa 35-76); UBPs: ubiquitinspezifische Proteasen; schwarzer Punkt: Mutation.

In Abbildung 5-1 wird das Prinzip des USPS dargestellt. Das Ubiquitin ist in zwei Einheiten unterteilt: Der aminoterminale Teil (Nub, aa 1-34) und der carboxyterminale Teil (Cub, aa 35-76), fusioniert an ein Reporterprotein. Die Affinität zwischen den beiden Einheiten wird durch eine Mutation im aminoterminalen Teil herabgesetzt. Wenn 
die beiden Ubiquitineinheiten jedoch an interagierende Proteine fusioniert werden, wird der Mutationseffekt überwunden, das Ubiquitin kann sich korrekt falten und das Reporterprotein wird vom carboyxterminalen Teil mit Hilfe von ubiquitin-spezifischen Proteasen (UBP) abgespalten. Von Nub gibt es drei verschiedene Varianten, die sich in Bezug auf die Affinität zum Cub unterscheiden: NubI, das ein Isoleucin auf Position 13 besitzt, hat eine größere Affinität zum Cub als entweder NubA, mit einem Alanin auf Position 13, oder NubG, mit einem Glycin auf Position 13. In dieser Arbeit wurde die NubI-Variante verwendet.

Als mögliche Reporter können drei verschiedene Proteine verwendet werden. Zum einen gibt es die Dihydrofolatreduktase aus Maus, markiert mit einen HA-Tag am C-Terminus. Dieses Enzym liegt nach Abspaltung stabil im Cytoplasma vor und kann mit Hilfe der Western-Blot-Analyse detektiert werden (JOHNSSON und VARSHAVSKY, 1994). Zum anderen gibt es das Fusionsprotein PLV, bestehend aus ProteinA, LexA und der VP16-Aktivierungsdomäne (STAGLJAR et al., 1998), welches nach Abspaltung vom carboxyterminalen Teil des Ubiquitins in den Zellkern diffundiert und dort an einen LexA-abhängigen Promotor bindet, und so die Expression von Reportergenen induziert. In dieser Arbeit wurde als Reporterprotein RUra3 verwendet (WITTKE et al., 1999) (Abbildung 5-2).

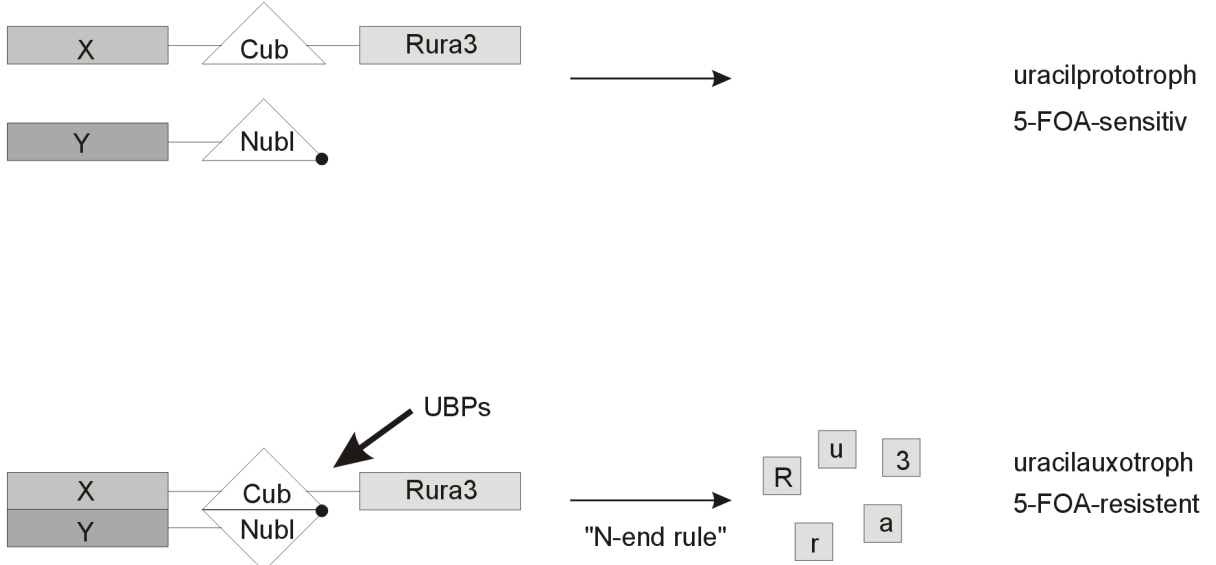

\footnotetext{
Abbildung 5-2: Das Reportergen Rura3 aus Saccharomyces cerevisiae. Mit X und Y sind zwei interagierende Proteine gekennzeichnet. NubI: aminoterminaler Teil vom Ubiquitin (aa 1-34); Cub: carboxyterminaler Teil vom Ubiquitin (aa 35-76); UBPs: ubiquitinspezifische Proteasen; schwarzer Punkt: Mutation.
} 
Das URA3-Gen aus Saccharomyces cerevisiae kodiert für eine Orotidin-5'-PhosphatDecarboxylase, ein Enzym, das bei der Biosynthese von Uracil eine Rolle spielt. Trotz der Fusion an den carboxyterminalen Teil des Ubiquitins ist Rura3 weiterhin funktionell. Die Orotidin-5'-Phosphat-Decarboxylase ist N-terminal modifiziert, d. h. der aminoterminale Rest ist ein Arginin. Diese Modifikation ermöglicht die schnelle Degradation des abgespaltenen Reporterproteins durch Enzyme des „N-end rule“Signalweges innerhalb von zwei Minuten (VARSHAVSKY, 1997). Neben seiner Aufgabe im Uracilbiosyntheseweg kann das Enzym Ura3 zusätzlich 5-FOA (,5-Fluoro orotic acid“) in 5-Fluorouracil umwandeln (BoEKE et al., 1984). 5-Fluorouracil ist ein Pyrimidinanalogon, das die Synthese von DNA blockiert. Findet in der Hefe eine Protein-Protein-Interaktion statt, sind die Hefezellen uracilauxotroph und 5-FOA-resistent, findet jedoch keine Interaktion statt, dann sind die Hefezellen uracilprototroph und 5-FOA-sensitiv.

\subsubsection{Etablierung des USPS für den pflanzlichen Transkriptionsfaktor TGA2.1}

Von den beiden im ASF-1-Komplex nachgewiesenen TGA-Faktoren, TGA2.2 und TGA2.1 (ThuROw, 2001), wurde TGA2.1 für einen Screen ausgewählt, da sein langer N-Terminus (170 Aminosäuren vor der bZIP-Domäne) möglicherweise zusätzliche Interaktionsdomänen enthält. Da TGA2.1 in Hefe als Aktivator der Genexpression fungiert (THUROW, 2001) konnte das Hefe-Zweihybridsystem nur schlecht verwendet werden. Aus diesem Grund sollte das USPS für den pflanzlichen Transkriptionsfaktor TGA2.1 etabliert werden.

Der erste Schritt bestand darin, das USPS mit bekannten interagierenden Proteinen zu testen. Dazu wurden die ER-Membran-Proteine Ssh1 und Sbh1 aus Saccharomyces cerevisiae als Cub bzw. Nub-Fusionen in Hefe exprimiert (Abbildung 5-3a). Das Plasmid und der entsprechende Hefestamm wurden von NILS JOHNSSON zur Verfügung gestellt. Das Protein Ssh1 ist an das 5'-Ende des carboxyterminalen Teils des Ubiquitins fusioniert. Das gesamte Konstrukt Ssh1-Cub-Rura3 liegt intergriert in das Genom des Hefestammes JD53 vor und wird von einem nativen Promotor exprimiert (Kapitel 3.7.1). Sbh1 ist an das 3'-Ende vom NubI fusioniert. Der Stamm JD53 Ssh1-Cub-Rura3 wurde mit dem Plasmid pNubI-Sbh1-Cup 314 bzw. dem leeren Vektor transformiert und direkt 
auf SD-TRP-HIS mit Zusatz von 5-FOA (2 mg/ml) ausplattiert. Das Ergebnis ist in Abbildung 5-3b dargestellt.

a)

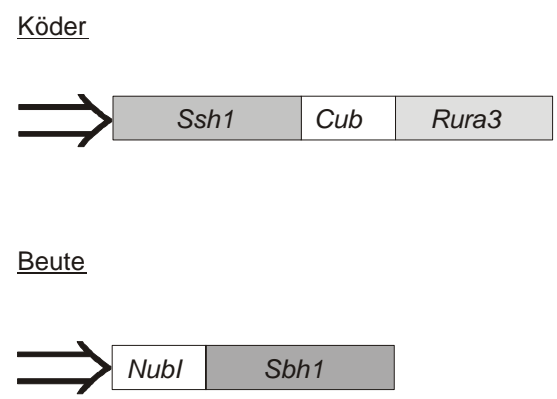

b)

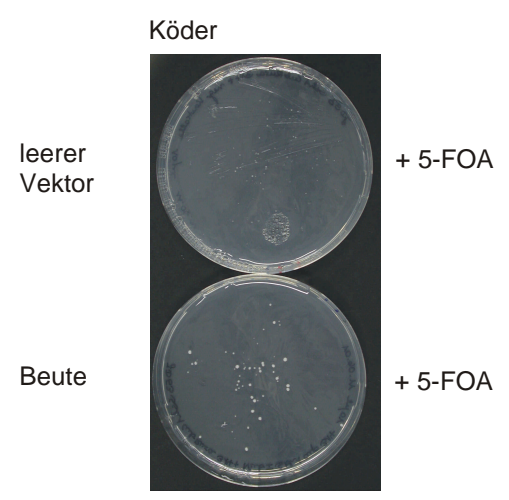

c)

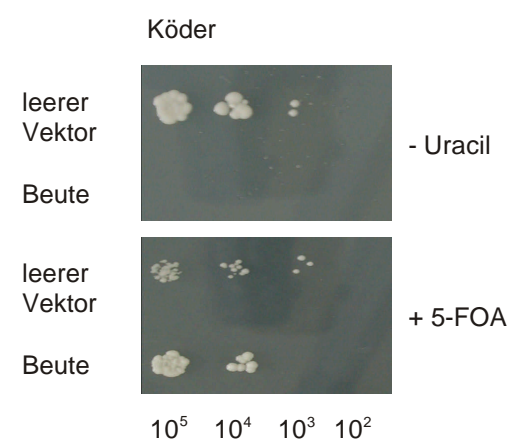

Abbildung 5-3: USPS mit den ER-Membran-Proteinen Ssh1 und Sbh1 aus Saccharomyces cerevisiae. (a) Schematische Darstellung der verwendeten Konstrukte. (b) Transformationsplatten. (c) „Growth Assay“ mit den transformierten Hefezellen. Unten sind die Zellzahlen aufgeführt, die auf das Medium getropft wurden.

Wird der Hefestamm nur mit dem leeren Vektor transformiert, sind sehr kleine Kolonien auf den Selektionsplatten sichtbar. Wird dagegen das Köderprotein zusammen mit dem Beuteprotein in den Hefezellen exprimiert, sind große Kolonien auf der Platte erkennbar. Wie man sehen kann, inhibiert der Zusatz von 5-FOA nicht vollständig das Wachstum bei der Negativkontrolle. Um ein eindeutigeres Ergebnis zu erlangen, wurde deswegen im Anschluss ein sogenannter „Growth Assay“ (Kapitel 4.8.6.1) durchgeführt. Die Zellen wurden nach der Transformation auf Medium ausplattiert, das nur auf das Vorhandensein der Konstrukte (SD-TRP-HIS) selektioniert. Anschließend wurde ein 
Klon über Nacht in SD-TRP-HIS-Flüssigmedium angezogen, die Zellzahl der Kultur bestimmt und verschiedene Verdünnungsstufen $\left(10^{5}\right.$ bis $\left.10^{2}\right)$ auf analytischem Medium (SD-TRP-HIS-URA bzw. SD-TRP-HIS mit dem Zusatz von 5-FOA) aufgetropft. Das Ergebnis ist in Abbildung 5-3c dargestellt. Betrachtet man das Wachstum der transformierten Hefezellen auf SD-TRP-HIS-URA, so können die Zellen, die zusätzlich den leeren Vektor tragen, sehr gut auf diesem Medium wachsen. Die Zellen, in denen dagegen eine Interaktion zwischen den beiden Membranproteinen stattfindet und Rura3 degradiert wird, sind nicht mehr in der Lage $\mathrm{zu}$ wachsen. Betrachtet man das Wachstumsverhalten auf Selektionsmedium mit der Zugabe von 5-FOA, so bekommt man ein entgegengesetztes Ergebnis. Die Zellen, in denen eine Interaktion stattfindet, können sehr gut auf diesem Medium wachsen, die Zellen, in denen keine Interaktion stattfindet, wachsen sehr viel schlechter. Die Selektion auf 5-FOA-Platten scheint im Gegensatz zu der Selektion auf Uracil nicht so stringent zu sein, da man stets ein Hintergrundwachstum detektieren kann. Jedoch ist ein Unterschied zwischen einer Interaktion und keiner Interaktion erkennbar.

Für den Hefescreen sollte das Fusionsprotein TGA2.1L-Cub-Rura3 als Köderprotein verwendet werden. Da die Expression dieses Fusionsproteins über den $\mathrm{Cu}^{2+}$ induzierbaren Promotor Cup1 reguliert ist, bestand nun der zweite Schritt darin, die Expressionsstärke herauszufinden, die den Hefezellen Uracilprototrophie vermitteln kann. Dazu wurde das Plasmid pSKL6 (Kapitel 3.6.3), welches für dieses Fusionsprotein kodiert in den Hefestamm NLY2 (Kapitel 3.7.1), transformiert. Im Anschluss wurde ein „Growth Assay“ (Kapitel 4.8.6.1) auf analytischem Medium (SD-URA) durchgeführt, welches unterschiedliche $\mathrm{Cu}^{2+}$-Konzentrationen enthielt. Dabei wurde die Expressionsstärke von TGA2.1L-Cub-Rura3 mit der Expressionsstärke von Ssh1-CubRura3 indirekt durch das Wachstum der Hefezellen verglichen. 
a)

Kontrolle

$\longrightarrow$\begin{tabular}{l|l|l|}
$\longrightarrow$ Ssh1 & Cub & Rura3 JD53
\end{tabular}

TGA2.1-Köderprotein

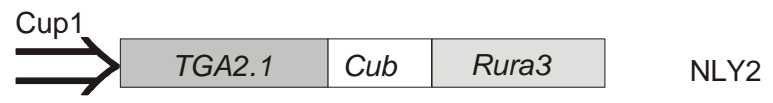

b)
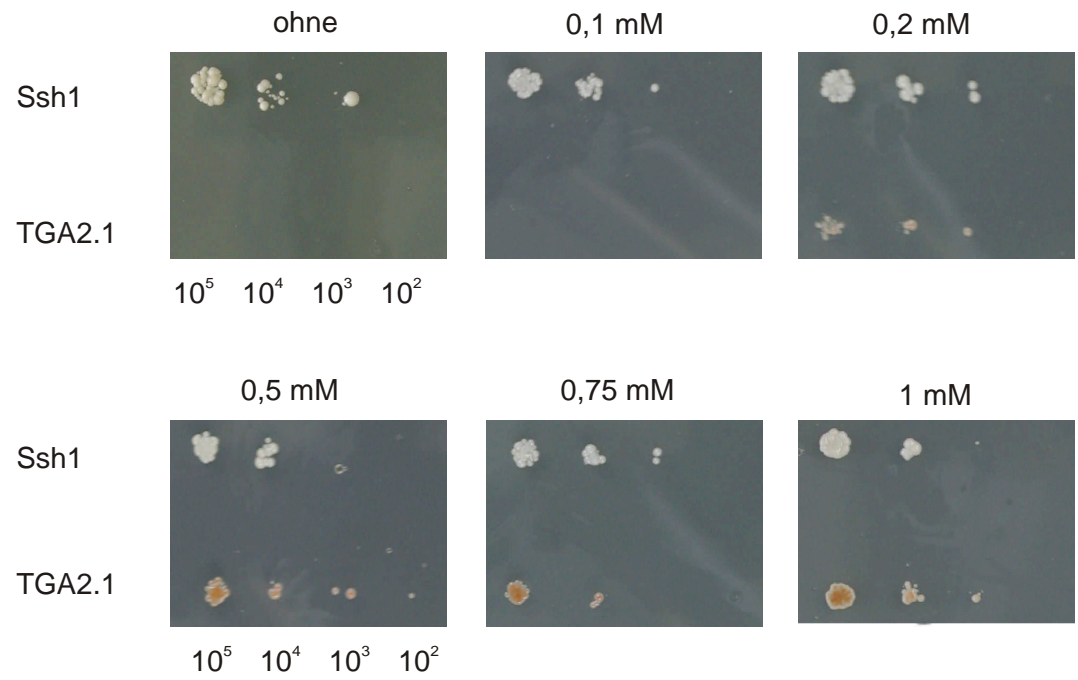

Abbildung 5-4: Bestimmung der optimalen Expressionsstärke für das Köderprotein TGA2.1L-Cub-Rura3 mit Hilfe des „Growth Assays“. (a) Schematische Darstellung der verwendeten Konstrukte. (b) „Growth Assay“. Unten: Die Zellzahlen, die auf das analytische Medium getropft worden sind. Oben: Die verwendeten Kupferkonzentrationen.

Die Ergebnisse in Abbildung 5-4 zeigen, dass die Kupferzugabe das Wachstum des Stammes JD53 Ssh1-Cub-Rura3 nicht negativ beeinflusst. Betrachtet man das Wachstum der Zellen auf dem analytischem Medium, so erkennt man, dass erst ab einer Konzentration von 0,2 $\mathrm{mM} \mathrm{CuSO}_{4}$ soviel TGA2.1L-Cub-Rura3-Protein gebildet wird, dass die Uracilauxotrophie des Stammes NLY2 ausgeglichen wird. Erst bei höheren $\mathrm{Cu}^{2+}$-Konzentrationen sind das Wachstum der verwendeten Hefestämme und somit die Mengen der jeweiligen Rura3-Fusionsproteine in der Hefezelle vergleichbar. 
Der dritte Schritt bestand anschließend darin, die Interaktion von TGA2.1 mit einem bekannten Interaktionspartner im USPS zu testen. Dazu wurde die Interaktion von TGA2.1 mit sich selbst verwendet. THUROW (2001) konnte im Hefe-Zweihybridsystem eine Interaktion zwischen dem vollständigen Protein TGA2.1 und der aminoterminalen Deletionsvariante TGA2.1-97 nachweisen. Da die Interaktion über den Leucin-Zipper des Proteins ermöglicht wird, sollte diese Interaktion auch zwischen zwei vollständigen Proteinen stattfinden. Der Stamm NLY2 wurde mit dem Köder-Plasmid pSKL6 und dem Beute-Plasmid pSK7 (Kapitel 3.6.3), welches für das NubI-TGA2.1-Fusionsprotein unter Kontrolle des konstitutiven ADH1-Promotors kodiert, bzw. mit dem leeren Vektor, transformiert (Abbildung 5-5a) und im Anschluss mit Hilfe des „Growth Assays“ (Kapitel 4.8.6.1) charakterisiert. Die Ergebnisse sind in Abbildung 5-5b dargestellt. 
a)

$\underline{\text { Köder }}$

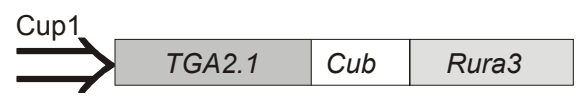

Beute

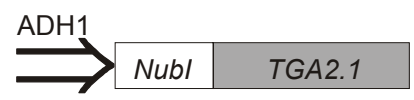

b)

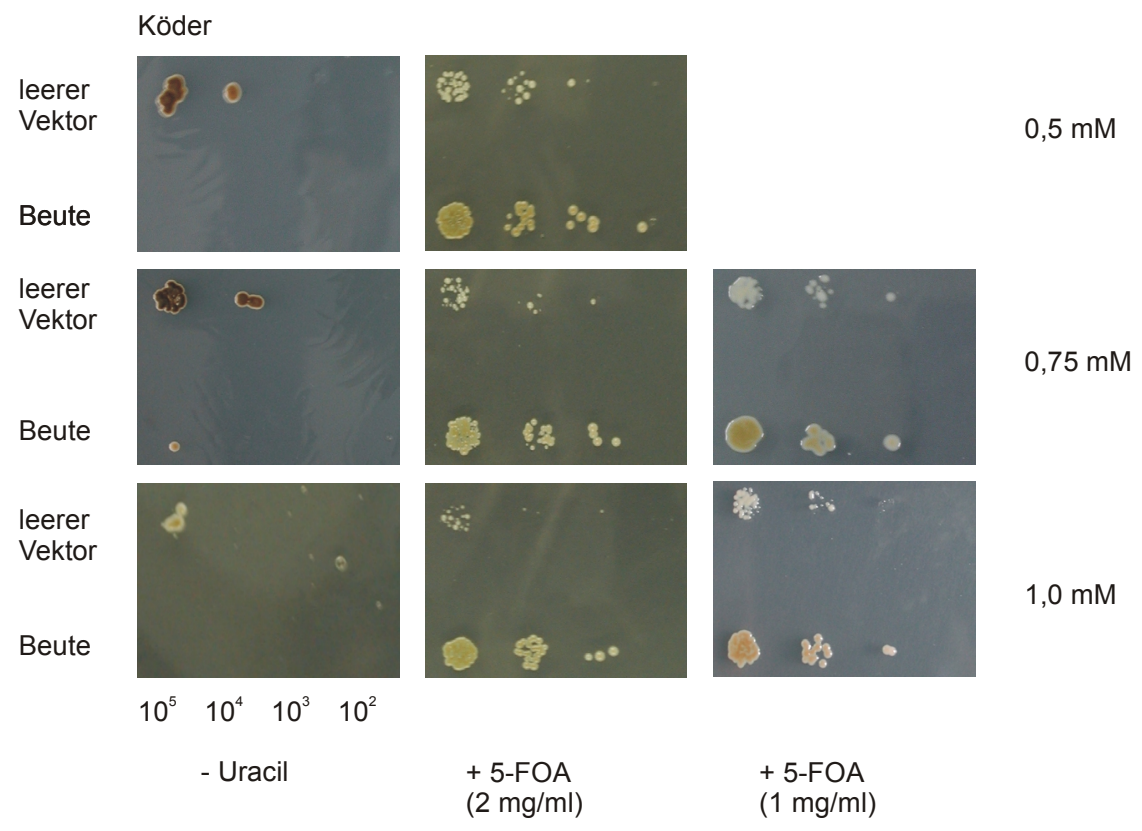

Abbildung 5-5: „Growth Assay“ zur Etablierung des USPS für den pflanzlichen bZIPTranskriptionsfaktor TGA2.1. (a) Schematische Darstellung der verwendeten Konstrukte. (b) „Growth Assay“. Unten: Die Zellzahlen, die auf das analytische Medium getropft worden sind. Rechts: Die verwendeten $\mathrm{Cu}^{2+}$-Konzentrationen.

Verschiedene Verdünnungsstufen der unterschiedlichen Transformanden wurden auf folgendem analytischen Medium untersucht: SD-TRP-LEU-URA, SD-TRP-LEU mit dem Zusatz von 5-FOA in den Konzentrationen $1 \mathrm{mg} / \mathrm{ml}$ und $2 \mathrm{mg} / \mathrm{ml}$. Zusätzlich wurde dem Medium $\mathrm{CuSO}_{4}$ in unterschiedlichen Konzentrationen zugesetzt. Betrachtet man das Wachstum der unterschiedlichen Klone, so erkennt man, dass in dem Fall, in dem keine Interaktion stattfindet, die Zellen sehr gut auf Medium, dem Uracil fehlt, wachsen können. Im Gegensatz dazu sind die Zellen, in denen die beiden TGA2.1- 
Fusionsproteine miteinander interagieren, uracilauxotroph. In der mittleren Spalte ist das Wachstum auf 5-FOA-Platten dargestellt. Man erkennt auch hier den Unterschied zwischen einer Interaktion bzw. keiner Interaktion. Allerdings ist zu sehen, dass der phänotypische Unterschied mit zunehmender $\mathrm{Cu}^{2+}$-Konzentration, d. h. mit zunehmender Menge des TGA2.1L-Cub-Rura3-Fusionsproteins, eindeutiger wird. Wird nur $1 \mathrm{mg} / \mathrm{ml} 5$-FOA für die Selektionsplatten verwendet, so ist der Hintergrund sehr viel stärker als bei der doppelten 5-FOA-Menge.

Anhand dieses Experimentes konnte gezeigt werden, dass das USPS für einen Screen mit TGA2.1L-Cub-Rura3 als Köder in Anwesenheit von 0,75 $\mathrm{mM} \mathrm{CuSO}_{4}$ und $2 \mathrm{mg} / \mathrm{ml}$ 5-FOA durchgeführt werden sollte, um möglichst eindeutige Ergebnisse zu bekommen.

\subsubsection{Herstellung einer cDNA-Bank aus Nicotiana tabacum}

Um cDNA zu isolieren, deren Genprodukte potentielle Interaktionspartner des Transkriptionsfaktors TGA2.1 aus Nicotiana tabacum darstellen, wurde aus mRNA, die aus Tabakblättern isoliert wurde, eine cDNA-Expressionsbank hergestellt und anschließend in einem USPS-Screen verwendet.

\subsubsection{Isolierung der mRNA}

Ausgangsmaterial für die Synthese der cDNA-Bank war Blattmaterial, das von sechs unabhängigen, auf Erde herangezogenen SNN-Pflanzen geerntet worden war. Die Präparation der Blatt-RNA erfolgte mittels „RNeasy Plant Mini Kit“ der Firma Qiagen. Aus 2,4 g Blattmaterial wurde $1 \mathrm{mg}$ Gesamt-RNA isoliert. Die photometrische Konzentrationsbestimmung ergab Werte zwischen $0,4 \mu \mathrm{g} / \mu 1$ und 2,0 $\mu \mathrm{g} / \mu \mathrm{l}$. Im nächsten Schritt erfolgte die Isolierung der mRNA. Der Anteil dieser RNA-Spezies am GesamtRNA-Pool beträgt nur 1-5 \%, ihre Anreicherung ist für eine effiziente cDNA-Synthese unabdingbar. Verwendet wurde hierzu das „Oligotex mRNA Spin-Column Protocol“ der Firma Qiagen. Aus ca. $250 \mu \mathrm{g}$ Gesamt-RNA konnte anhand photometrischer Bestimmung $8 \mu \mathrm{g}$ mRNA isoliert werden. Die Qualität von Gesamt-RNA und mRNA wurde mit Hilfe eines denaturierten RNA-Agarosegels untersucht. Die 
Fotodokumentation zeigt eine deutliche Abreicherung der typischen rRNA-Banden, die mRNA ist als „Schmier“ erkennbar (Abbildung 5-6). Die isolierte mRNA diente im Folgenden als Ausgangsmaterial für die cDNA-Synthese.

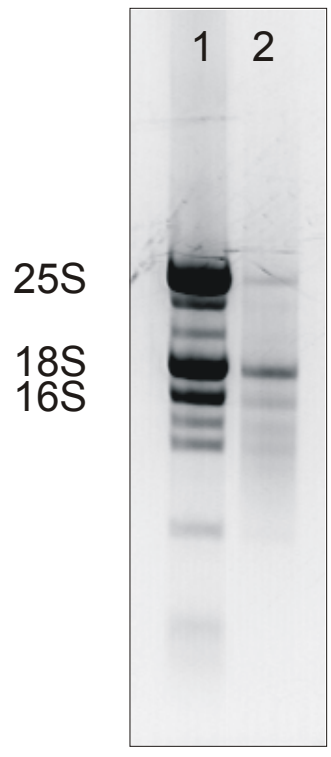

Abbildung 5-6: Gelelektrophoretische Auftrennung der verwendeten Gesamt-RNA und mRNA unter denaturierten Bedingungen. Spur 1: $5 \mu \mathrm{g}$ Gesamt-RNA; Spur 2: 0,75 $\mu \mathrm{g}$ poly(A)-mRNA. Links: Verschiedene rRNAs.

\subsubsection{Herstellung einer cDNA-Expressionsbank}

Das folgende Kapitel gibt einen Überblick über den theoretischen Hintergrund und den experimentellen Ablauf der Herstellung der cDNA-Expressionsbank. Die detaillierte Durchführung der einzelnen Teilschritte ist im Methodenteil ausführlich dargestellt Kapitel 4.8).

Für die Herstellung der cDNA-Expressionsbank wurde der „MATCHMAKER Library Construction and Screening Kit" der Firma Clontech verwendet. Abbildung 5-7 gibt einen Überblick über die Vorgehensweise bei der Herstellung der cDNA-Bank. 


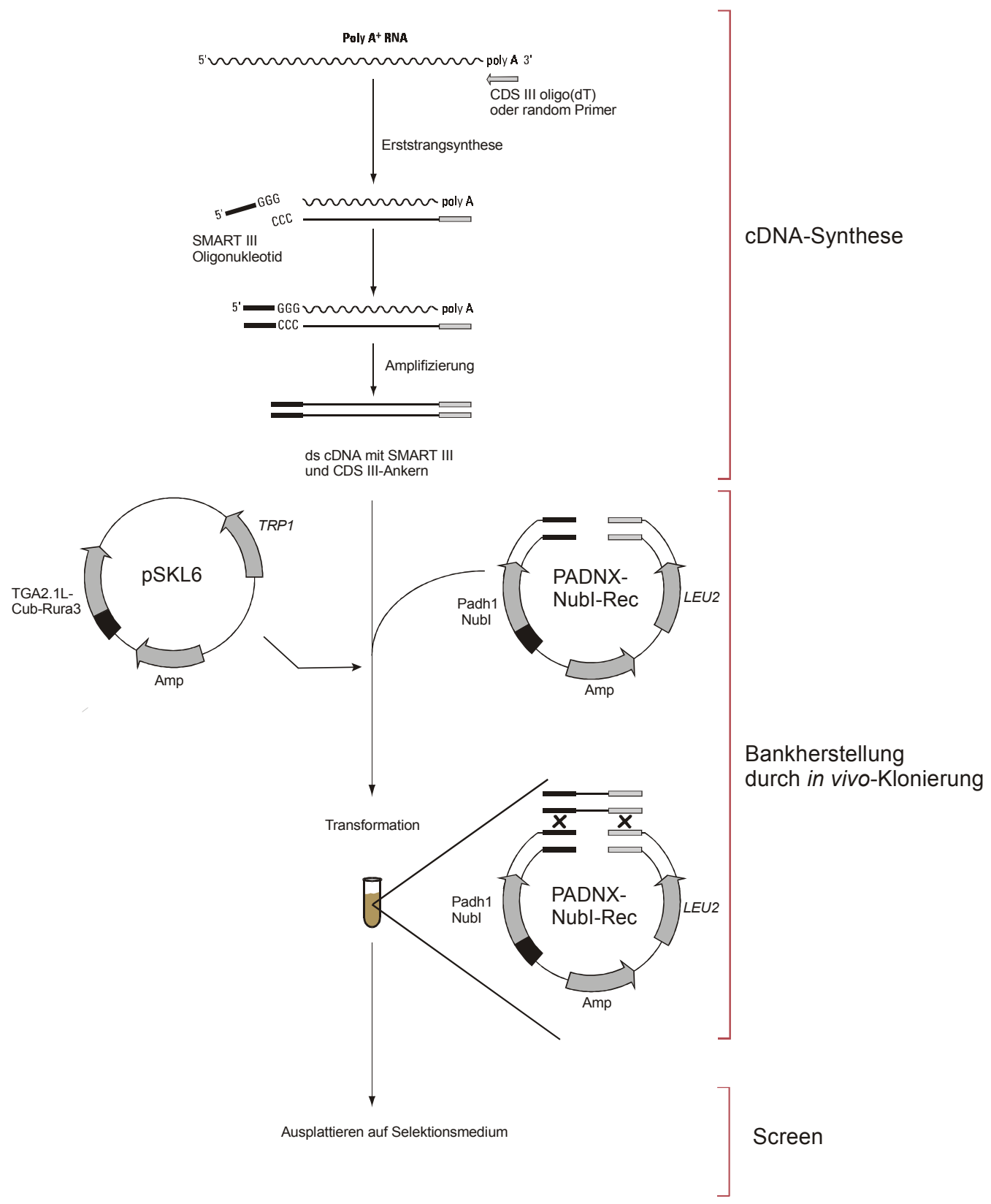

\begin{abstract}
Abbildung 5-7: Herstellung und Durchmusterung einer USPS-Bank unter Verwendung des „MATCHMAKER Library Construction and Screening Kits“ der Firma Clontech. Die MMLV-RT synthetisiert den ersten cDNA-Strang und fügt über ihre Terminale-Transferase-Aktivität eine Ankersequenz an. Im Anschluss wird die cDNA über LD-PCR amplifiziert. Die cDNA-Fragmente, der Rekombinationsvektor (PADNX-NubI-Rec) und der Köder-Vektor (pSKL6) können in einem Schritt in kompetente Hefezellen kotransformiert werden. Die cDNA wird über den Mechanismus der homologen Rekombination in den Bankvektor integriert. Das Wachstum auf Interaktionsmedium identifiziert positive Klone.
\end{abstract}


Die Umwandlung des Transkriptoms eines Gewebes in komplementäre DNA erfolgte

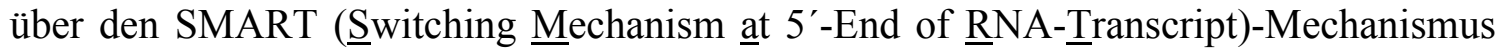
(Abbildung 5-7). Die SMART-Methode basiert auf einer PCR-Amplifikation und führt zu einer hohen Ausbeute an cDNA.

Das Protokoll von Clontech liefert für die Erststrangsynthese (Kapitel 4.8.1.1) zwei Primer, einen modifizierten Oligo(dT)-Primer (CDS III) und einem random Primer (CDS III/6). Der Oligo(dT)-Primer hybridisiert am Poly(A)-Schwanz der mRNA, so dass Sequenzen am 5'-Ende der mRNA leicht unterrepräsentiert aus der cDNA-Synthese hervorgehen können. Der random Primer hingegen bindet statistisch an die RNASequenz, die resultierende Bibliothek sollte daher 3'- und 5'-Enden zu gleichen Teilen enthalten. Im Rahmen dieser Arbeit wurden parallel zwei cDNA-Banken unter Verwendung des Oligo(dT)-Primers und des random Primers hergestellt. Als Ausgangsmaterial wurden $300 \mathrm{ng}$ poly(A)-mRNA verwendet (Kapitel 4.8.1.1). Nach erfolgter Erststrangsynthese fügt die MMLV-RT über ihre terminale TransferaseAktivität eine kurze (dC)-Folge am 3'-Ende der cDNA an. Das SMART-Oligonukleotid geht über seine $3^{\prime}$-(dG)-Sequenz Basenpaarungen mit dem (dC)-Überhang ein und bildet eine verlängerte Matrize für die Reverse Transkriptase. Es folgt ein template switching der Reversen Transkriptase, die jetzt das SMART-Oligonukleotid als neue Vorlage verwendet und dessen Basenabfolge repliziert. Die verlängerte ss cDNA enthält somit die vollständige Sequenzinformation des 5 '-Endes der mRNA und die komplemetäre Sequenz des SMART-Oligonukleotids als Ankersequenz. Wird die Erststrangsynthese vor Erreichen des 5'-Endes der mRNA gestoppt, z. B. durch Sekundärstrukturen innerhalb der mRNA, fügt die Reverse Transkriptase keinen (dC)-Überhang an. Die terminale Transferase-Funktion des Enzyms wird erst bei Erreichen des 5'-Endes der mRNA-Matrize aktiviert. Das SMART-Oligonukleotid kann folglich nicht hybridisieren und die Amplifikation unterbleibt; die entsprechenden Sequenzen sind in der cDNABank unterrepräsentiert. Die beschriebene Methode führt zur Entstehung von vollständigen cDNAs, die auch die Sequenzinformationen der 5'-UTRs (,untranslated regions") der mRNAs enthalten (ZHU et al., 2001).

Der SMART-Anker fungiert ebenso wie die CDS-Sequenz als priming site für die folgende Amplifikation der cDNA über long distance PCR (LD-PCR) (Kapitel 4.8.1.2). Bei diesem Schritt werden nur ss cDNAs, die den SMART-Anker enthalten, als Matrize 
akzeptiert. Die zuvor durchgeführte Erststrangsynthese (Kapitel 4.8.1.1) lieferte ausreichend Material für jeweils fünf unabhängige LD-PCR-Reaktionen. Verwendet wurden der 3'PCR- und der 5'PCR-Primer des MATCHMAKER-Kits (Kapitel 3.6.2). Das PCR-Programm wechselte zwischen einem Denaturierungsschritt bei $95^{\circ} \mathrm{C}$ für $10 \mathrm{~s}$ und einem Annealing- und Elongationsschritt bei $68^{\circ} \mathrm{C}$, der nach 6 min Dauer im ersten Durchlauf mit jeder neuen Runde um 5 s verlängert wurde. Nach erfolgter Amplifikation wurde jedem Ansatz ein $7 \mu$ l-Aliquot entnommen und auf einem $1 \%$-igen Agarosegel aufgetrennt (Abbildung 5-8a). Die cDNAs enthalten Moleküle in einem Größenbereich 0,1 und $3 \mathrm{~kb}$. Die cDNA, bei der zur Erststrangsynthese der random Primer verwendet wurde, ist jedoch deutlich schwächer konzentriert (Abbildung 5-8a).

a)

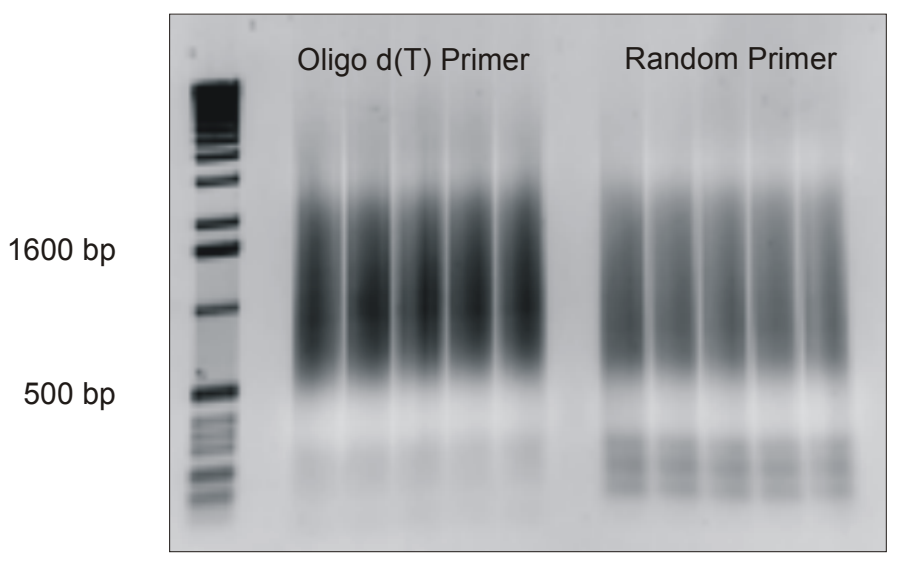

b)

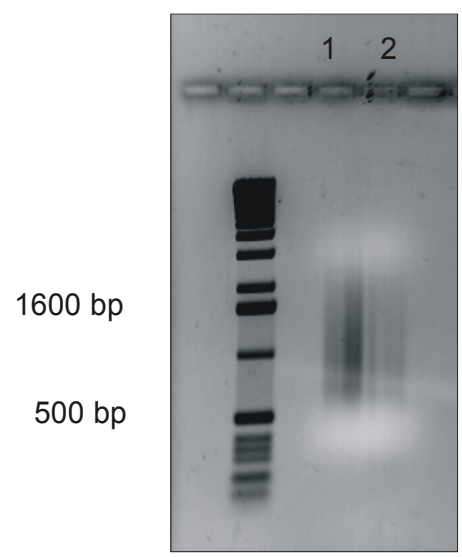

Abbildung 5-8: (a) Kontrolle der cDNA-Synthese. Aufgetragen wurden je $7 \mu$ der LD-PCR-Produkte. Die Synthese erfolgte jeweils in fünf parallelen Ansätzen, von denen ein Aliquot aufgetragen wurde. (b) zeigt die cDNA-Proben nach erfolgter Säulenaufreinigung. 1: cDNA-Synthese erfolgte mit dem Oligo d(T) Primer; 2: cDNA-Synthese erfolgte mit dem random Primer. Aufgetragen wurden je 0,5 $\mu$ l. Als Marker wurde die 1-kb-Leiter verwendet (GIBCO BRL).

Die PCR-Produkte wurden im Anschluss an die LD-PCR mittels CHROMA SPIN+TE400-Säulen aufgereinigt (Kapitel 4.8.3.1). Die Porengröße der Säulen selektioniert auf Moleküle größer als 200 bp und hält kleinere Moleküle zurück. Es wurden jeweils zwei PCR-Reaktionen vereinigt und auf eine CHROMA SPIN-Säule aufgetragen, zentrifugiert und anschließend mit Ethanol gefällt (Kapitel 4.5.3). Zur Quantifizierung und Verifizierung wurden jeweils $0,5 \mu 1$ auf ein 1,2 \%iges Agarosegel aufgetragen. Beide cDNA-Proben sind durch einen ,Schmier“ im Bereich von 0,5 und $3 \mathrm{~kb}$ im Gel 
erkennbar (Abbildung 5-8b). Die Abtrennung von Molekülen kleiner als 200 bp hat nachweisbar stattgefunden.

Die Herstellung der Nub-Fusionsbank erfolgte durch rekombinationsvermittelte Klonierung in Hefe. Der Hefestamm NLY2 (Kapitel 3.7.1) wurde mit dem KöderPlasmid pSKL6 (Kapitel 3.6.3), dem SmaI-linearisiertem PADNX-NubI-Rec (Kapitel 3.6.3) und der aufgereinigten cDNA (eine Mischung aus der CDS III-cDNA und der CDS III/6-cDNA) kotransformiert (Kapitel 4.8.5). Wie in Abbildung 5-7 dargestellt, sind die endständigen Sequenzen des Bankvektors den CDS III- bzw. CDS III/6- und SMART III-Ankern der cDNA homolog. Reparaturenzyme der Hefe erkennen die Schnittstelle innerhalb der Vektor-DNA und starten die gap repair über homologe Rekombination (FUSCO et al., 1999). Hierbei handelt es sich um einen wichtigen Reparaturweg bei Doppelstrangbrüchen in Hefe (PASTINK et al., 2001). Der Prozess entspricht einer in vivo-Klonierung und führte zur Zirkularisierung des Vektors. Hefezellen, die den NubI-cDNA-Expressionsvektor und damit ein funktionelles LEU2Gen enthalten, sind als positive Transformanden nachweisbar. Als Selektionsmedium wurde SD-TRP-LEU mit dem Zusatz von $0,75 \quad \mathrm{mM} \quad \mathrm{CuSO}_{4}$ und $2 \mathrm{mg} / \mathrm{ml}$ 5-FOA (Kapitel 5.1.1.1) gewählt. Zur Bestimmung der Transformationseffizienz wurden Aliquots auf SD-TRP-LEU- und auf SD-LEU-Platten ausplattiert. Alle Platten wurden bei $30^{\circ} \mathrm{C}$ für 4 Tage inkubiert. Die Zahl der Hefekolonien auf SD-TRPLEU-Platten und auf SD-LEU-Platten wurden ausgezählt und die Transformationseffizienz bestimmt. Die Werte sind in Tabelle 5.1 festgehalten. Die theoretischen Werte wurden annähernd erreicht und ähneln sehr den von H. RUNNE (2001) bei ihren „Screens“ erzielten Transformationseffizienzen. 
Tabelle 5.1: Transformationseffizienzen des Bankscreens.

\begin{tabular}{l|c|c|c|c}
\hline & $\begin{array}{c}\text { CDS III/ CDS } \\
\text { III/6 }\end{array}$ & $\begin{array}{c}\text { CDS III } \\
\text { RUNNE (2001) }\end{array}$ & $\begin{array}{c}\text { CDS III/6 } \\
\text { RUNNE (2001) }\end{array}$ & $\begin{array}{c}\text { theoretisch } \\
\text { erwartet }\end{array}$ \\
\hline $\begin{array}{l}\text { Transformanden/ } \\
3 \mu \mathrm{g} \text { Bankvektor }\end{array}$ & $7,0 \times 10^{5}$ & $2,5 \times 10^{5}$ & $4,0 \times 10^{5}$ & $1,0 \times 10^{6}$ \\
\hline Klone/ Bank & $1,0 \times 10^{5}$ & $1,0 \times 10^{5}$ & $2,0 \times 10^{5}$ & $5,0 \times 10^{5}$ \\
\hline
\end{tabular}

${ }^{1}$ Die CDS III-cDNA wurde mit Hilfe des Oligo(dT)-Primers hergestellt. Für die Synthese der CDS III/6cDNA wurde der random Primer verwendet.

Nach vier Tagen waren auf den Platten des USPS-Screens 238 Klone gewachsen. Diese Kolonien zeigten einen 5-FOA-resistenten Phänotyp. Ob in diesen Zellen ein Protein exprimiert wird, dass mit TGA2.1 interagiert, musste in weiteren Kontrollexperimenten und durch eine Charakterisierung der cDNA-Klone noch geklärt werden.

\subsubsection{Analyse der primär positiven cDNA-Klone}

Das Wachstum der 238 primär positiven Klone auf 5-FOA-Platten konnte theoretisch nur durch den Abbau des Reporterproteins Rura3 durch Enzyme des „N-end rule“Signalweges ermöglich werden. Um zu ermitteln, ob der 5-FOA-resistente Phänotyp auf der spezifischen Interaktion eines Proteins mit TGA2.1 beruht, wurden verschiedene Tests durchgeführt. Eine Zusammenfassung der Vorgehensweise ist in Abbildung 5-9 dargestellt. 
238 primäre Hefe-Klone

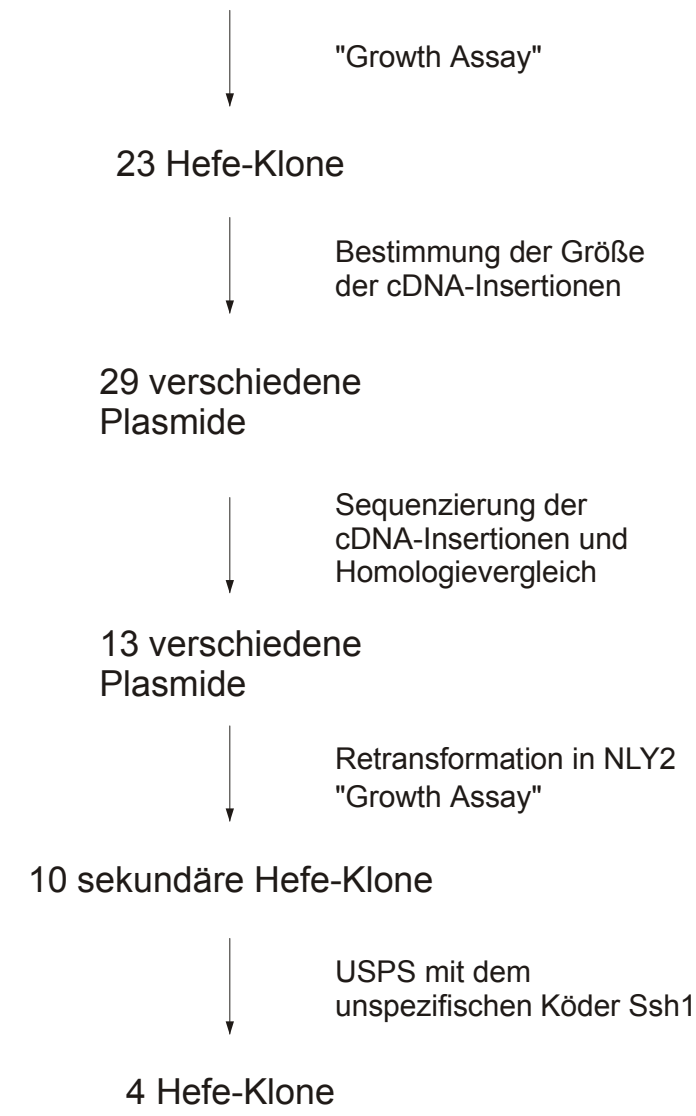

Abbildung 5-9: Zusammenfassende Darstellung der Vorgehensweise zur Charakterisierung der potentiellen positiven cDNA-Klone.

Als erstes wurde mit den Zellen ein „Growth Assay“ (Kapitel 4.8.6.1) durchgeführt. Dazu wurden die Hefeklone in SD-TRP-LEU-Medium über Nacht angezogen und auf analytischem Medium (SD-TRP-LEU-URA mit dem Zusatz von 0,75 $\mathrm{mM} \mathrm{CuSO}_{4}$ ) subkultiviert. Von den 238 primären Klonen blieben nur 23 Klone (9,7 \%) übrig, die auf dem angebotenen Medium nicht mehr wachsen konnten und somit den korrekten Phänotyp zeigten. Um sicherzustellen, dass die Zellen aber generell wachsen können, wurden die Hefezellen parallel auf SD-TRP-LEU-Medium inkubiert. Auf diesen Platten zeigte sich ein Wachstum.

Im nächsten Schritt wurden die verbliebenen Klone auf DNA-Ebene analysiert. Um die cDNA-Insertionen im Vektor PADNX-NubI-Rec charakterisieren zu können, wurden 
die Plasmide, wie in Kapitel 4.5.2 beschrieben, aus den Hefezellen extrahiert und in E. coli transformiert, um sie zu amplifizieren. Anschließend wurde die Größe der cDNA-Insertionen mit Hilfe eines Restriktionsverdaus mit XhoI und NotI bestimmt. Bei diesem Verdau wird neben der inserierten cDNA auch ein Vektoranteil mit herausgespalten. Bei Religanden, d. h. Bankplasmide ohne cDNA-Insert, wird ein 104 bp großes DNA-Stück herausgespalten. Da Hefezellen bei einer Transformation mehr als ein Plasmid aufnehmen können, konnten aus einigen Hefeklonen mehrere PADNX-NubI-cDNA-Plasmide isoliert werden, die sich durch die Größe des cDNAInserts unterscheiden. Ein Beispiel dafür ist Klon 96. Parallel dazu wurde der 5'-Bereich des cDNA-Inserts mit dem Primer NubI upper (Kapitel 3.6.2) ansequenziert und die aus den ermittelten 5'-cDNA-Sequenzen abgeleiteten Aminosäurensequenzen wurden mit Hilfe von Datenbankrecherchen auf Homologien zu bekannten Proteinen hin überprüft. In Tabelle 5.2 sind die Ergebnisse der Analysen dargestellt.

Tabelle 5.2: Homologien der im USPS-Screen identifizierten Klone

\begin{tabular}{|c|c|c|}
\hline Klon & $\begin{array}{l}\text { Insertgröße } \\
\quad[\mathrm{bp}]\end{array}$ & Homologie der ansequenzierten cDNA-Inserts $\mathrm{zu}^{1}$ \\
\hline \multirow[t]{2}{*}{$22-1^{2}$} & 524 & $52 \%$ zu AAF15285 (aa 50-116) \\
\hline & $(420)^{3}$ & copper chaperone homolog CCH (132 aa, Oryza sativa) \\
\hline \multirow[t]{3}{*}{$26-3$} & 850 & 93 \% zu CAB89082 (aa 248-344) \\
\hline & $(500+350)$ & S6 ribosomal protein kinase (454 aa, Asparagus officinalis) \\
\hline & $(413)$ & \\
\hline \multirow[t]{2}{*}{$52-1$} & 750 & $74 \%$ zu AAG13433 (aa 330-446) \\
\hline & $(465)$ & unknown protein (466 aa, Oryza sativa) \\
\hline \multirow[t]{2}{*}{ 64-1 } & 224 & Keine Homologie \\
\hline & $(120)$ & \\
\hline \multirow[t]{2}{*}{$64-2$} & 800 & $81 \%$ zu AAA86052 (aa 137-262) \\
\hline & $(400)$ & $\begin{array}{l}\text { water-stress-inducible protein DS2 (263 aa, Solanum } \\
\text { chacoense })\end{array}$ \\
\hline \multirow[t]{2}{*}{ 74-6 } & 534 & $93 \%$ zu CAC22613 (aa 23-54) \\
\hline & $(430)$ & squalene epoxidase (457 aa, Schizosaccharomyces pombe) \\
\hline \multirow[t]{2}{*}{ 74-7 } & 234 & $73 \%$ XP_115722 (aa 68-98) \\
\hline & $(130)$ & malonyl-CoA decarboxylase (130 aa, Homo sapiens) \\
\hline $96-3$ & 110 & Poly (A)-Schwanz \\
\hline
\end{tabular}




\begin{tabular}{|c|c|c|}
\hline Klon & $\begin{array}{l}\text { Insertgröße } \\
\quad[\mathrm{bp}]\end{array}$ & Homologie der ansequenzierten cDNA-Inserts zu ${ }^{1}$ \\
\hline \multirow[t]{2}{*}{ 96-4 } & 340 & $53 \%$ zu AAL32026 (aa 56-98) \\
\hline & $(236)$ & beta-galactosidase alpha fragment (155 aa) \\
\hline \multirow[t]{2}{*}{$96-5$} & 284 & $81 \%$ zu AAL06931 (aa 57-83) \\
\hline & $(180)$ & expressed protein (391 aa, Arabidopsis thaliana) \\
\hline \multirow[t]{2}{*}{$110-5$} & 570 & $46 \%$ zu BAA20281 (aa 55-132) \\
\hline & $(466)$ & keratin associated protein 6-2 (159 aa, Mus musculus) \\
\hline \multirow[t]{2}{*}{$117-1$} & 900 & $79 \%$ zu AAL24351 (aa 139-226) \\
\hline & $(480)$ & $\begin{array}{l}\text { metal-transporting P-type ATPase }(237 \text { aa, Arabidopsis } \\
\text { thaliana) }\end{array}$ \\
\hline \multirow[t]{2}{*}{$129-5$} & 454 & 60 \% zu XP_096708 (aa 13-53) \\
\hline & $(350)$ & $\begin{array}{l}\text { similar to high-mobility group protein } 1 \text { (184 aa Homo } \\
\text { sapiens) }\end{array}$ \\
\hline \multirow[t]{2}{*}{$153-11$} & 274 & $70 \%$ zu AAD2824 (aa 107-170) \\
\hline & $(170)$ & Calcium-binding protein (175 aa, Brassica napus) \\
\hline \multirow[t]{3}{*}{$160-12$} & 690 & $77 \%$ zu AAL24157 (aa 79-191) \\
\hline & $(500+190)$ & unknown protein (199 aa, Arabidopsis thaliana) \\
\hline & $(440)$ & \\
\hline \multirow[t]{2}{*}{ 171-15 } & 1500 & 70 \% zu AAK09431 (aa 759-898) \\
\hline & $(380)$ & translation initiation factor IF-2 (1012 aa, Phaseolus vulgaris) \\
\hline \multirow[t]{2}{*}{$172-1$} & 2000 & $96 \%$ zu CAA65048 (aa 534-650) \\
\hline & $(380)$ & zeaxanthin epoxidase (663 aa, Nicotiana plumbaginifolia) \\
\hline \multirow[t]{3}{*}{$172-16$} & 950 & $88 \%$ zu NP_173516 (aa 1052-1089) \\
\hline & $(500+450)$ & putative RNA helicase (1166 aa, Arabidopsis thaliana) \\
\hline & $(355)$ & \\
\hline \multirow[t]{3}{*}{$175-1$} & 950 & $72 \%$ zu NP_187573 (aa 810-843) \\
\hline & $(500+450)$ & putative RNA helicase (989 aa, Arabidopsis thaliana) \\
\hline & $(216)$ & \\
\hline 177-2 & 190 & Poly(A)-Schwanz \\
\hline \multirow[t]{2}{*}{$178-1$} & 600 & $100 \%$ zu CAC12823 (aa 61-74) \\
\hline & $(315)$ & metallothionin-like protein type 2 (74 aa, Nicotiana tabacum) \\
\hline
\end{tabular}




\begin{tabular}{lcl}
\hline Klon & $\begin{array}{c}\text { Insertgröße } \\
{[\mathrm{bp}]}\end{array}$ & Homologie der ansequenzierten cDNA-Inserts zu ${ }^{1}$ \\
\hline $184-1$ & 900 & $\begin{array}{l}72 \% \text { zu AAF03236 (aa 8-168) } \\
\text { ubiquitin carrier protein 4 (183 aa, Glycine max) }\end{array}$ \\
\hline $208-1$ & 750 & $\begin{array}{l}83 \% \text { zu CAA66481 (aa 227-346) } \\
\text { transcription factor (370 aa, Vicia faba) }\end{array}$ \\
\hline $\mathbf{2 3 7 - 2}$ & 330 & Poly(A)-Schwanz \\
\hline $\mathbf{2 3 7 - 3}$ & 250 & Poly(A)-Schwanz \\
\hline $\mathbf{2 3 8 - 1}$ & 650 & $\begin{array}{l}100 \% \text { zu CAA42623 (aa 58-113) } \\
\end{array}$ \\
\hline $\mathbf{2 4 2 - 1}$ & $6340)$ & PSI-D2 (204 aa, Nicotiana sylvestris) \\
& $(360)$ & similar to chromosome 15 ORF 2 (1048 aa, Homo sapiens) \\
\hline $261-1$ & 1200 & $86 \%$ zu AAK37555 (aa 93-122) \\
& $(184)$ & SHOOT1 protein (359 aa, Glycine max) \\
\hline $\mathbf{2 6 1 - 2}$ & 190 & Poly(A)-Schwanz \\
\hline
\end{tabular}

${ }^{1}$ Die Homologien wurden durch Datenbankrecherche mit demProgramm BLASTX2.2.1 (ALTSCHUL et al., 1997) ermittelt. Das Protein mit der jeweils größten Homologie ist mit Accession-Nummer, Originalnamen, Gesamtzahl an Aminosäuren und Ursprungsorganismus aufgeführt. ${ }^{2}$ Fett gedruckt sind die Klone, die aufgrund der Homologievergleiche aussortiert worden sind. ${ }^{3}$ Zusätzlich ist die Länge des eindeutig interpretierbaren Sequenzabschnittes angegeben, mit dem der Homologievergleich über die abgeleiteten Aminosäuren durchgeführt wurde.

Betrachtet man die Größe der cDNA-Inserts, so stellt man fest, dass diese in einem Größenbereich von 224 bp bis 2000 bp liegen, wobei 79 \% der Inserts eine Länge von $250 \mathrm{bp}$ bis $1000 \mathrm{bp}$ aufweisen. Nur drei cDNA-Inserts sind größer als 1000 bp. Aus anderen Arbeiten mit dem MATCHMAKER-Kit ist bekannt, dass diese Größenverteilung der cDNA-Insertionen den Erwartungen entspricht (HÜLPER (2003), KREBBE (persönliche Mitteilung)). Das Fehlen von größeren Fragmenten ist dadurch erklärbar, dass die cDNA-Fragmente nicht durch eine in vitro-Ligation sondern durch Rekombinationsereignisse in der Hefe in den Bankvektor inseriert wurden. Man kann sich vorstellen, dass kleinere Fragmente leichter inserierbar sind als größere Fragmente.

Aus den Homologieanalysen wird ersichtlich, dass viele primäre Klone anhand der Sequenz aussortiert werden konnten. Dazu zählen u. a. Klone, die anstelle einer kodierenden cDNA nur einen poly(A)-Schwanz aufweisen. Weitere Kriterien waren die Größe des inserierten Inserts, die Lokalisierung sowie die in vivo-Funktion des 
homologen Proteins. Zu den Klonen, die aussortiert wurden, zählen: 22-1, 64-1, 74-6, 74-7, 96-3, 96-4, 110-5, 129-5, 171-15, 177-2, 237-2, 237-3, 238-1, 242-1 und 261-2. Klon 117-1, dessen cDNA für eine „Metal-transporting P-type ATPase“ kodiert, wurde in allen weiteren Analysen als interne Kontrolle verwendet.

An diesem Punkt der Analyse der primären Klone wurde ersichtlich, dass der Hintergrund bei dem Screen sehr hoch gewesen ist. Zum einen zeigten nur 9,7 \% der primär gepickten Klone, die auf 5-FOA-Platten gewachsen sind, den uracilauxotrophen Phänotyp. Zum anderen mussten von den verbliebenden Klonen $50 \%$ aussortiert werden, da sie entweder anstelle eines kodierenden cDNA-Inserts einen langen poly(A)Schwanz aufwiesen, oder die inserierte cDNA für ein Protein kodierte, dass als möglicher Interaktionspartner von TGA2.1 nicht in Frage kommen konnte. Aufgrund dieses Ergebnisses war es nun umso wichtiger geworden, die verbliebenen Klone weiter zu charakterisieren.

Dazu wurden diese zusammen mit dem Köder-Plasmid pSKL6 (Kapitel 3.6.3) in den Stamm NLY2 (Kapitel 3.7.1) retransformiert. Mit Hilfe eines „Growth Assays“ (Kapitel 4.8.6.1) wurden vier unabhängige Transformanden auf Uracilauxotrophie (SD-TRPLEU-URA mit Zusatz von 0,75 $\mathrm{mM} \mathrm{CuSO}_{4}$ ) untersucht. Die Selektion auf Uracil wurde gewählt, da sich in den Vortests (Kapitel 5.1.1.2) gezeigt hatte, dass diese stringenter ist als die Selektion auf 5-FOA-Resistenz. Zudem wurde gleichzeitg sichergestellt, dass die Hefezellen generell in der Lage sind zu wachsen (SD-TRP-LEU). Als Positivkontrolle wurden die Hefezellen mit den Köder-Plasmid pSKL6 und dem Plasmid pSK7, welches für das NubI-TGA2.1-Fusionsprotein kodiert (Kapitel 3.6.3), transformiert. Im Fall der Negativkontrolle wurde anstelle von pSK7 das leere NubI-Plasmid verwendet. Die Ergebnisse sind in Tabelle 5.3 dargestellt. 
Tabelle 5.3: Ergebnisse der Retransformationsexperimente

\begin{tabular}{|c|c|c|}
\hline Klon & $\begin{array}{c}\text { Wachstum auf } \\
\text { Plasmidselektionsmedium }\end{array}$ & $\begin{array}{c}\text { Wachstum auf } \\
\text { Interaktionsmedium }\end{array}$ \\
\hline Positivkontrolle & ++ & - \\
\hline Negativkontrolle & ++ & ++ \\
\hline $26-3$ & ++ & ++ \\
\hline $52-1$ & ++ & ++ \\
\hline $64-2$ & ++ & - \\
\hline $96-5$ & ++ & ++ \\
\hline $117-1$ & ++ & - \\
\hline $153-11$ & ++ & - \\
\hline $160-12$ & ++ & - \\
\hline $172-1$ & ++ & - \\
\hline $172-16$ & ++ & - \\
\hline $175-1$ & ++ & - \\
\hline 184-1 & ++ & - \\
\hline 208-1 & ++ & + \\
\hline $261-1$ & ++ & + \\
\hline
\end{tabular}

Die Positiv- und die Negativkontrolle verhalten sich in diesem Experiment erwartungsgemäß, d. h. findet eine Interaktion zwischen dem Cub- und dem NubIFusionsprotein statt, so sind die Hefezellen uracilauxotroph. Findet dagegen keine Interaktion zwischen diesen Proteinen statt, so weisen die Zellen eine Uracilprototrophie auf.

Von den 13 getesteten Klonen verhalten sich zehn wie die Positivkontrolle, d. h. sie zeigen denselben Phänotyp wie unter „Screenbedingungen“. $\mathrm{Zu}$ diesen Klonen zählen: 64-1, 117-1, 153-11, 160-12, 172-1, 172-16, 175-1 und 184-1. Die Klone 208-1 und 261-1 können auf den Selektionsplatten wachsen, jedoch sehr viel schlechter als die Negativkontrolle. Die Klone 26-1, 52-1 und 95-5 zeichnen sich durch eine Uracilprototrophie aus, was bedeutet, dass in diesem Fall keine Interaktion stattgefunden hat. Mit diesen Klonen wurde nicht mehr weitergearbeitet. 


\subsubsection{Analyse der sekundär positiven Klone}

Nach der primären Analyse der Klone, bestehend aus der Charakterisierung der inserierten cDNA und Retransformation der Klone blieben von 238 Klonen zehn Klone übrig. Im nächsten Schritt wurde die Spezifität ihrer Interaktion mit TGA2.1 untersucht. Dazu wurden die cDNA-Klone mit dem unspezifischen Köderprotein Ssh1-Cub-Rura3 (Kapitel 5.1.1.2) nachgetestet.

Der Stamm JD53 Ssh1-Cub-Rura3 (Kapitel 3.7.1), in dem das Fusionsprotein im Hefegenom integriert vorliegt, wurde mit den Bankplasmiden transformiert. Anschließend wurde mit vier unabhängigen Tranformanden ein „Growth Assay“ (Kapitel 4.8.6.1) durchgeführt. Können die Transformanden auf Interaktionsmedium, d. h. Medium, dem Uracil fehlt wachsen, ist die Interaktion zwischen dem cDNA-Klon und TGA2.1 spezifisch. Können die Hefezellen auf diesem Medium nicht wachsen, so wird der Phänotyp unspezifisch vermittelt. Als Negativkontrolle wird der Stamm JD53 mit dem leeren Bankplasmid transformiert. Die Ergebnisse sind in Tabelle 5.4 dargestellt.

Tabelle 5.4: Ergebnisse des "Growth Assays" mit Ssh1-Cub-Rura3 als Köderprotein

\begin{tabular}{ccc}
\hline Klon & $\begin{array}{c}\text { Wachstum auf } \\
\text { Plasmidselektionsmedium }\end{array}$ & $\begin{array}{c}\text { Wachstum auf } \\
\text { Interaktionsmedium }\end{array}$ \\
\hline Negativkontrolle & ++ & ++1 \\
\hline $64-2$ & ++ & - \\
\hline $117-1$ & ++ & ++ \\
\hline $153-11$ & ++ & - \\
\hline $160-12$ & ++ & - \\
\hline $172-1$ & ++ & ++ \\
\hline $172-16$ & ++ & ++ \\
\hline $175-1$ & ++ & ++ \\
\hline $184-1$ & ++ & - \\
\hline $208-1$ & ++ & - \\
\hline $261-1$ & ++ & + gutes Wachstum. \\
\hline${ }_{(-)}=$kein Wachstum $(++)=$ & & + \\
\hline
\end{tabular}


Die in Tabelle 5.4 dargestellten Ergebnisse zeigen, dass sechs der potentiellen positiven Klone, 64-2, 153-11, 160-12, 172-1, 208-1 und 261-1, keine spezifischen Interaktionspartner von TGA2.1 darstellen. Die Uracilauxotrophie könnte durch die Interaktion mit dem ER-Membran-Protein Ssh1 aus Saccharomyces cerevisiae oder durch die Affinität von NubI zu Cub vermittelt werden. Jedoch verhält sich die Negativkontrolle, wo nur der leere Bankvektor PADNX-NubI-Rec in den Stamm JD53 Ssh1-Cub-Rura3 transformiert worden ist, erwartungsgemäß. Die Hefezellen können sehr gut wachsen, was dafür spricht, dass die Affinität zwischen Cub und NubI nicht so stark sein kann, um Uracilauxotrophie zu vermitteln. Es könnte somit sein, dass durch die Fusion mit diesen cDNAs die 34 aa große Domäne NubI stabilisiert und so die Wahrscheinlichkeit für eine Interaktion mit Cub erhöht wird. Die Hefezellen, die mit den Plasmiden der Klone 117-1, 172-16, 175-1 und 184-1 transformiert sind, sind eindeutig uracilprototroph, d. h. dass in diesen Zellen eindeutig keine Interaktion zwischen dem Fusionsprotein Ssh1-Cub-Rura3 und dem Fusionsprotein NubI-cDNA stattgefunden hat. Somit konnte die Zahl der spezifischen Interaktionspartner von TGA2.1 auf vier eingeengt werden.

\subsubsection{Charakterisierung der Klone 117-1, 172-16, 175-1 und 184-1}

Im nächsten Schritt wurden nun die verbliebenden Klone weiter charakterisiert. Dazu wurden zunächst die cDNA-Insertionen vollständig sequenziert und die abgeleiteten Aminosäuresequenzen nochmals mit Hilfe von Datenbankrecherchen auf Homologien zu bekannten Proteinen hin überprüft. In Tabelle 5.5 sind die Ergebnisse der Analysen dargestellt. 
Tabelle 5.5: Ergebnisse der Homologievergleiche der abgeleiteten Aminosäuresequenzen

\begin{tabular}{|c|c|c|}
\hline Klon & $\begin{array}{c}\text { Insertgröße } \\
{[\mathrm{bp}]}\end{array}$ & Homologie der sequenzierten cDNA-Inserts $\mathrm{zu}^{1}$ \\
\hline \multirow[t]{3}{*}{$117-1$} & $752 \mathrm{bp}$ & $78 \%$ NP_567924 (aa 128-226) \\
\hline & & Metal-transporting P-type ATPase (237 aa, \\
\hline & & Arabidopsis thaliana) \\
\hline \multirow[t]{2}{*}{$172-16$} & $840 \mathrm{bp}$ & $76 \%$ NP_173516 (aa 967-1166) \\
\hline & & DEAD box RNA helicase (1166 aa, Arabidopsis thaliana) \\
\hline \multirow[t]{2}{*}{$175-1$} & $840 \mathrm{bp}$ & $76 \%$ NP_173516 (aa 967-1166) \\
\hline & & DEAD box RNA helicase (1166 aa, Arabidopsis thaliana) \\
\hline \multirow[t]{2}{*}{$184-1$} & $733 \mathrm{bp}$ & $97 \%$ AAF03236 (aa 8-155) \\
\hline & & Ubiquitin carrier protein 4 (183 aa, Glycine $\max )$ \\
\hline
\end{tabular}

${ }^{1}$ Die Homologien wurden durch Datenbankrecherche mit dem Programm BLASTX2.2.1 (ALTSCHUL et al., 1997) ermittelt. Das Protein mit der jeweils größten Homologie ist mit Accession-Nummer, Originalnamen, Gesamtzahl an Aminosäuren und Ursprungsorganismus aufgeführt. Zusätzlich ist angegeben, in welchem Bereich die Homologie besteht.

\subsubsection{Klon 117-1}

Der Klon 117-1 weist eine 752 bp große cDNA-Insertion auf (Abbildung 5-10). Die Analyse der abgeleiteten Aminosäuresequenz ergab, dass von der cDNA ein 108 aa langes Protein im gleichen Leseraster wie die aminoterminale Domäne vom Ubiquitin kodiert wurde. 


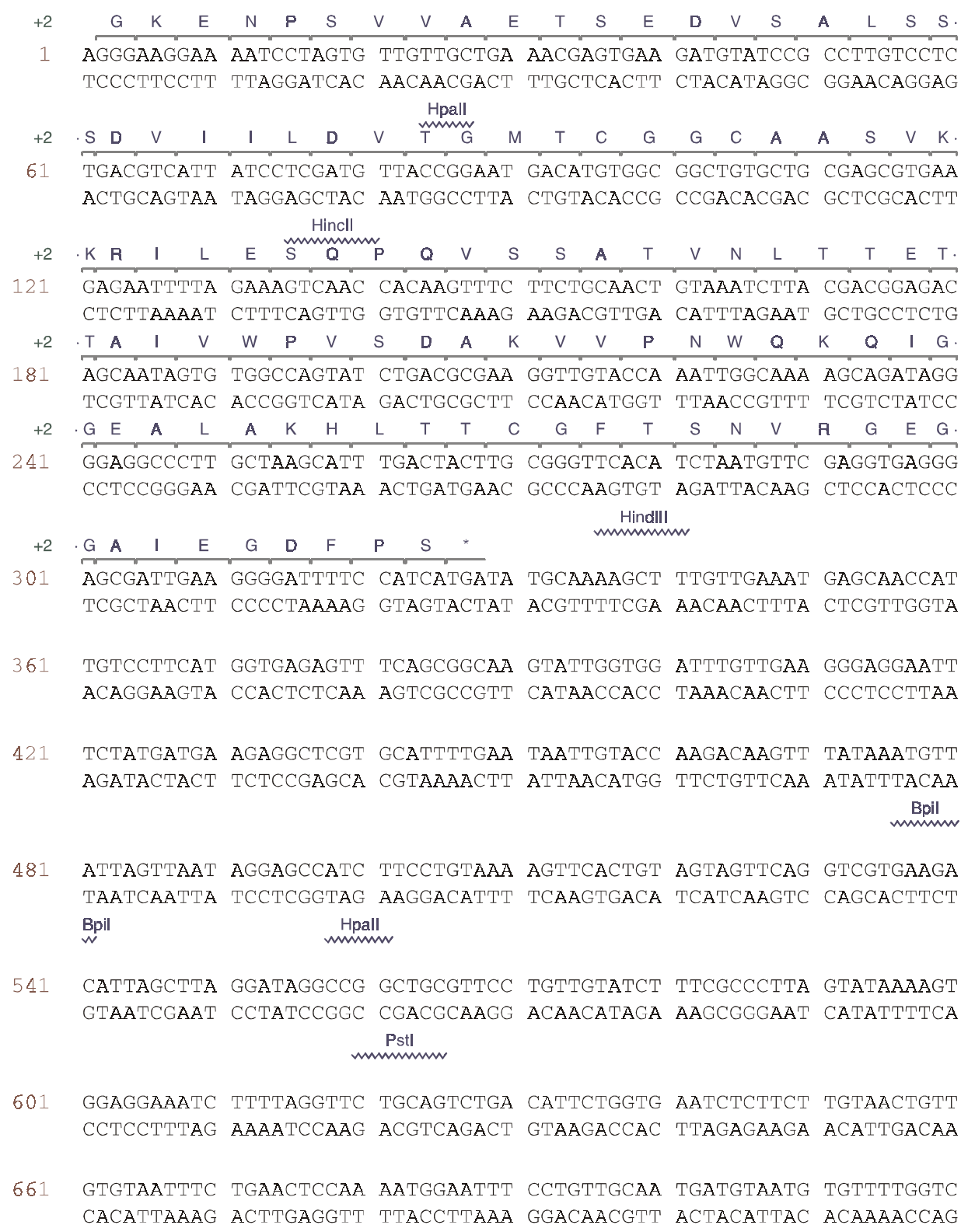

Abbildung 5-10: Nukleotid- und abgeleitete Aminosäuresequenz des Klon 117-1. Das Stopcodon ist durch ein Sternchen gekennzeichnet. Zusätzlich sind die Schnittstellen wichtiger Restriktionsenzyme eingetragen.

Dieses Protein zeigt eine 78 \%-ige Homologie zu einer „Metal-transporting P-type ATPase" aus Arabidopsis thaliana (von aa 128 bis aa 226) (Tabelle 5.5; Abbildung 5-11). Die Homologie erstreckt sich über die konservierte, 30 aa lange HMA-Domäne, die für den Transport von Schwermetallionen wichtig ist. 


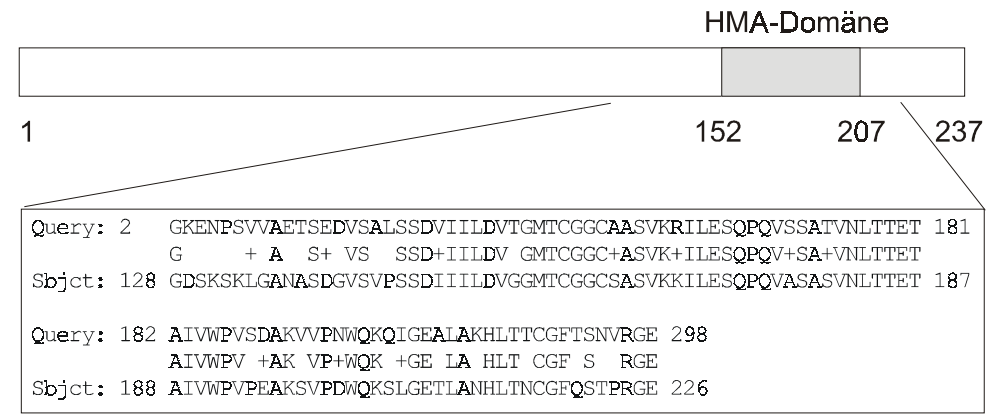

Abbildung 5-11: Vereinfachte Darstellung der „Metal transporting P-type ATPase“ aus Nicotiana tabacum. Zusätzlich ist der Homologievergleich von Klon 117-1 (Query) zu der ATPase (Sbjct) angegeben. Die Zahlen stehen für Aminosäuren.

Im allgemeinen sind P-Typ-ATPasen für den Transport von Ionen $\left(\mathrm{H}^{+}, \mathrm{Na}^{+} / \mathrm{K}^{+}, \mathrm{H}^{+} / \mathrm{K}^{+}\right.$, $\mathrm{Ca}^{2+}$ ), Schwermetallen und Lipiden in der Zelle zuständig. Die P-Typ-ATPasen-Familie zeichnet sich dadurch aus, dass für den Transport durch die Membran die Hydrolyse von ATP notwendig ist (BAXTER et al., 2003). Für die „Metal-transporting P-type ATPase“ aus Arabidopsis thaliana konnte gezeigt werden, dass dieses ein aminoterminales, chloroplastidäres Transitpeptid aufweist. Wird das Gen, welches für dieses Protein kodiert, mutiert, führt das dazu, dass der pflanzliche Elektronentransport beeinträchtigt ist und die Kupferkonzentration in den Chloroplasten reduziert ist. Somit scheint dieses Protein eine wichtige Komponente des Kupfertransportsystems in Chloroplasten zu sein (SHIKANAI et al., 2003). Aufgrund der Lokalisierung im Chloroplasten ist Klon 117-1 kein interessanter Interaktionspartner des Transkriptionsfaktors TGA2.1.

\subsubsection{Klon 172-16 und Klon 175-1}

Die Klone 172-16 und 175-1 weisen identische cDNA-Insertionen (840 bp) auf und kodieren jeweils für ein 209 aa langes Protein (Abbildung 5-11), welches ebenfalls in demselben Leseraster ist wie die aminoterminale Domäne vom Ubiquitin. 


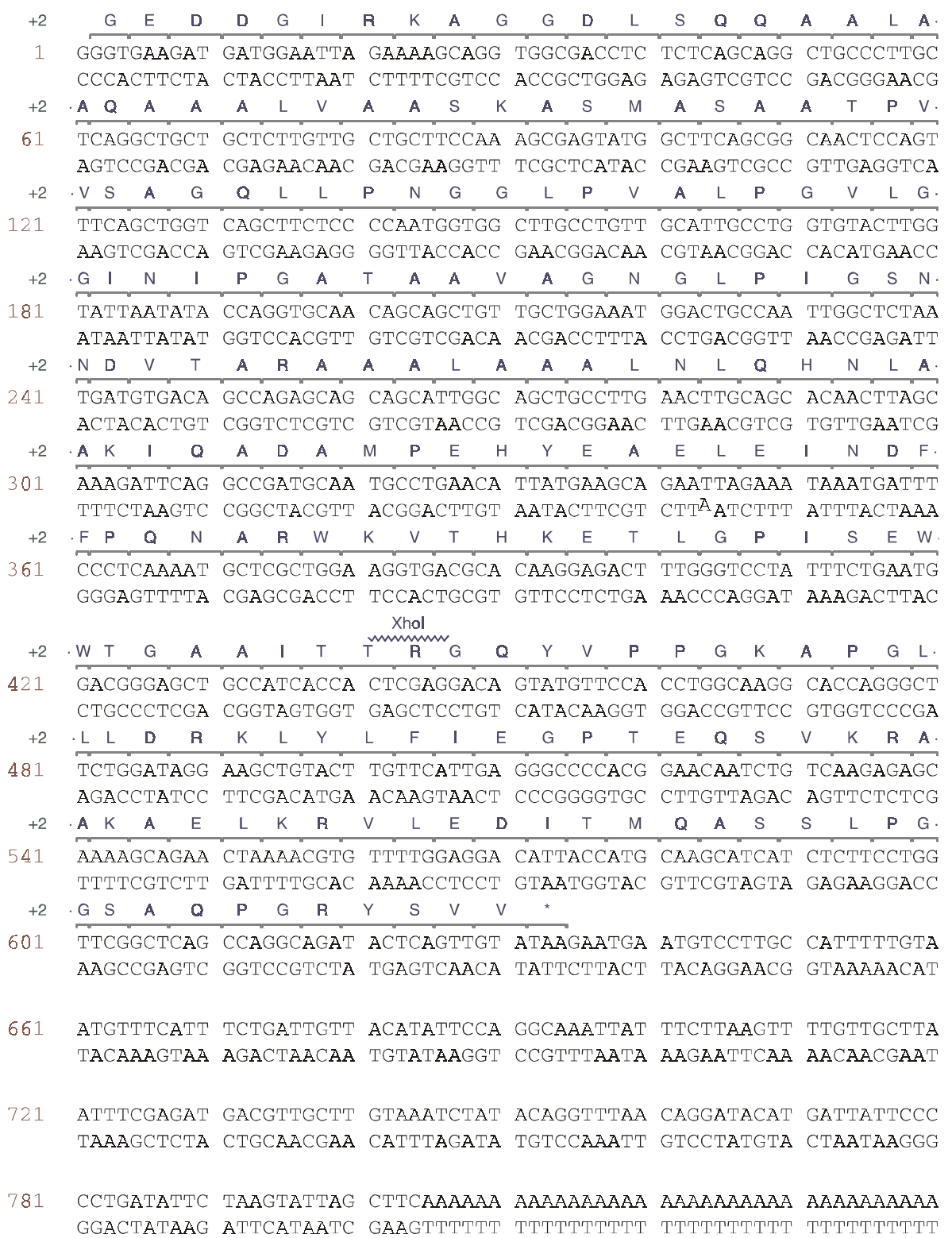

Abbildung 5-12: Nukleotid- und abgeleitete Aminosäuresequenz der Klone 172-16 und 175-1. Das Stopcodon ist durch ein Sternchen gekennzeichnet. Zusätzlich sind die Schnittstellen wichtiger Restriktionsenzyme eingetragen.

Diese Ergebnisse legen die Vermutung nahe, dass diese Klone aus einem einzigen Ursprungsklon entstanden sein müssen. Da sich beide Klone während der Nachtests stets identisch verhalten haben, spricht dies für die Spezifität der Interaktion mit TGA2.1. Das abgeleitete Protein weist eine 76 \%-ige Homologie zu dem carboxyterminalen Teil (aa 967 bis aa 1166) einer DEAD-Box-RNA-Helicase aus Arabidopsis thaliana auf (Tabelle 5.5; Abbildung 5-13). 


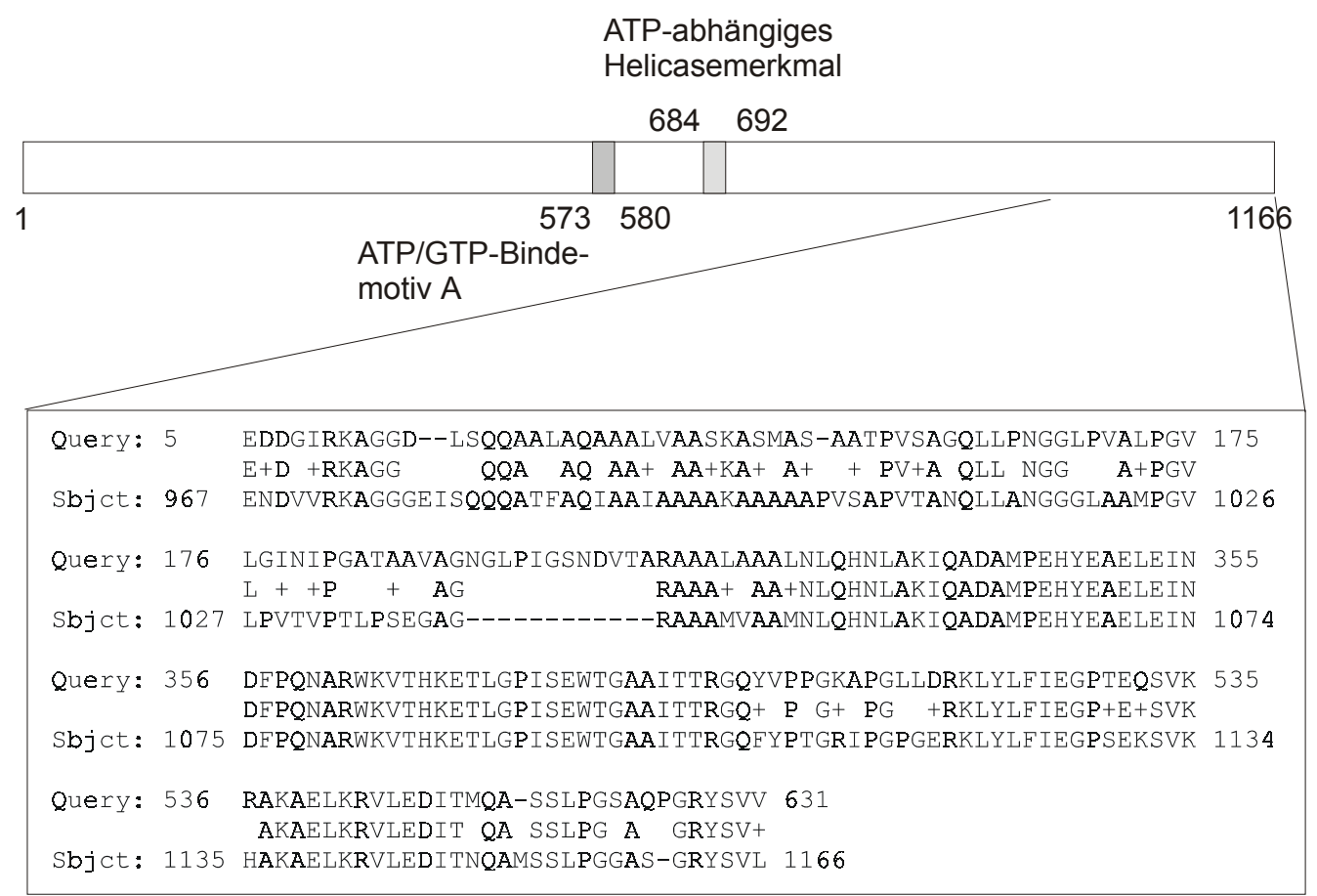

Abbildung 5-13: Vereinfachte Darstellung der „DEAD-Box-RNA-Helicase“ aus Nicotiana tabacum. Zusätzlich ist der Homologievergleich von Klon 175-1 (Query) zu der Helicase (Sbjct) angegeben. Die Zahlen stehen für Aminosäuren.

Mitglieder der DEAD-Box-Familie, die sich durch die charakteristische Sequenz AspGlu-Ala-Asp auszeichnen, kommen in Pro- und Eukaryoten vor. Sie spielen eine Rolle bei vielen Prozessen in der Zelle: Rekombination, Reparatur, Transkription, RNAProzessierung, Translation und posttranslationale Regulation (YAN et al., 2003). Für den Transkriptionsfaktor c-Jun aus Säugetierzellen konnte ebenfalls eine Interaktion mit einer DEAD-Box-RNA-Helicase nachgewiesen werden (WESTERMARCK et al., 2002). Nach Stimulus löst sich die Helicase aus den Nukleoli und liegt im Nukleoplasma vor, wo sie mit der aminoterminalen Aktivierungsdomäne von c-Jun interagiert, was zu einer c-Jun-abhängigen Genaktivierung führt. Da der Transkriptionsfaktor TGA2.1 dem Transkriptionsfaktor c-Jun sehr ähnlich ist und zusätzlich zumindest auch in Hefe eine aminoterminale Aktivierungsdomäne besitzt, wäre es denkbar, dass der Regulationsmechanismus aus Säugetierzellen auch auf pflanzliche Zellen übertragbar ist. 


\subsubsection{Klon 184-1}

Der Klon 184-1 weist eine 733 bp große cDNA-Insertion auf, die für ein 146 aa langes Protein kodiert (Abbildung 5-12). Wie auch schon für die Klone 117-1, 172-16 und 175-1 beschrieben ist dieses in demselben Leserahmen wie der aminoterminale Teil des Ubiquitins.

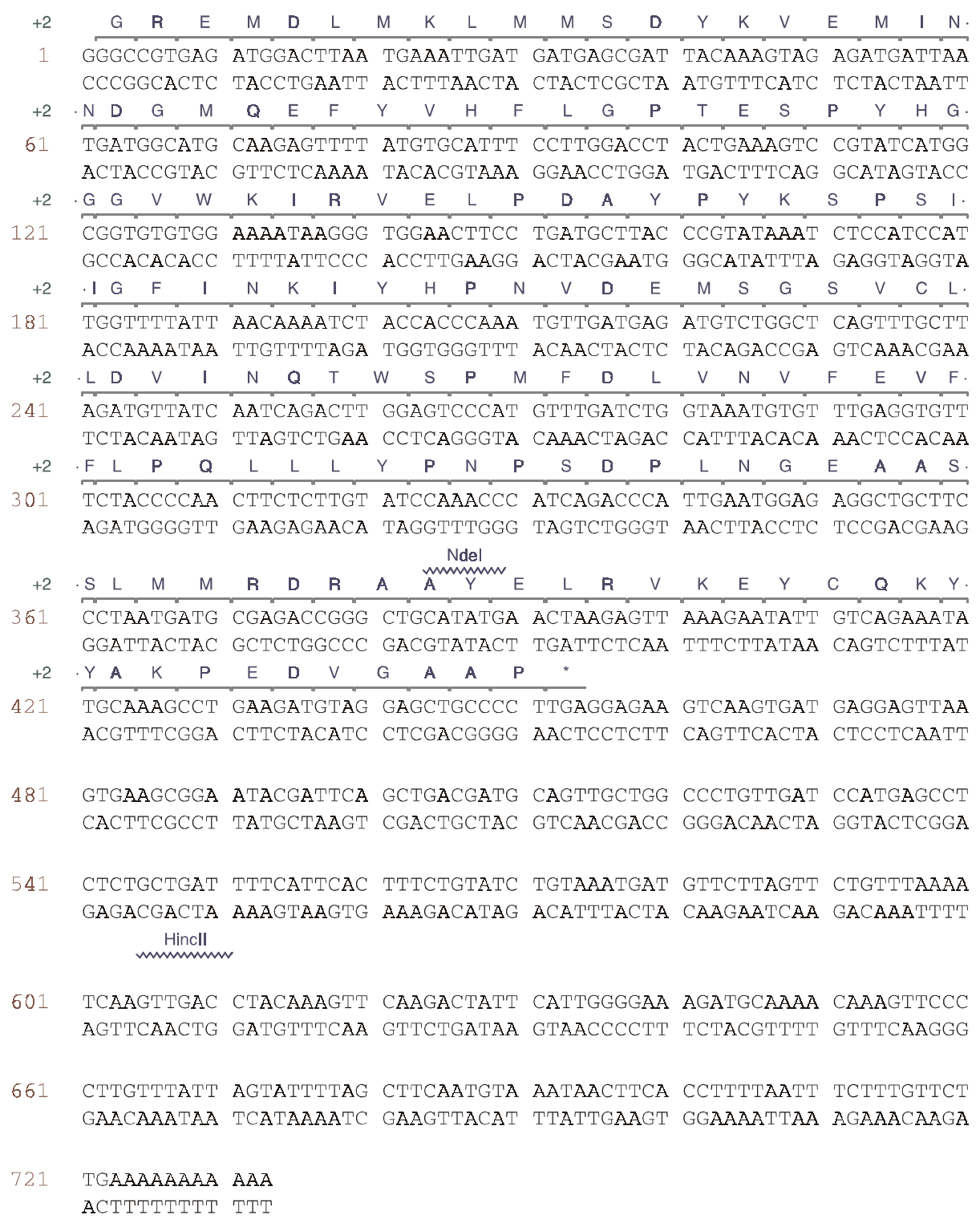

Abbildung 5-14: Nukleotid- und abgeleitete Aminosäuresequenz des Klon 184-1. Das Stopcodon ist durch ein Sternchen gekennzeichnet. Zusätzlich sind die Schnittstellen wichtiger Restriktionsenzyme eingetragen. 
Das Protein zeichnet sich durch eine 97 \%-ige Homologie zu dem „Ubiquitin carrier protein 4“, einer E2-Ligase, aus Glycine max (von aa 8 bis aa 155) aus. Die Homologie ist in diesem Fall sehr ausgeprägt und erstreckt sich fast über das gesamte Protein aus Glycine max und schließt das aktive Zentrum des Enzyms mit ein (Abbildung 5-15). Somit könnte die cDNA von Klon 184-1 fast vollständig vorliegen. Weitere Homologievergleiche zeigten, dass die E2-Ligase aus Glycine max den Klasse 2 E2Ligasen UBC4, UBC5 und UBC6 aus Arabidopsis thaliana zuzuordnen ist. Diese Klasse zeichnet sich durch eine carboxyterminale Extension aus (BACHMAIR et al., 2001).

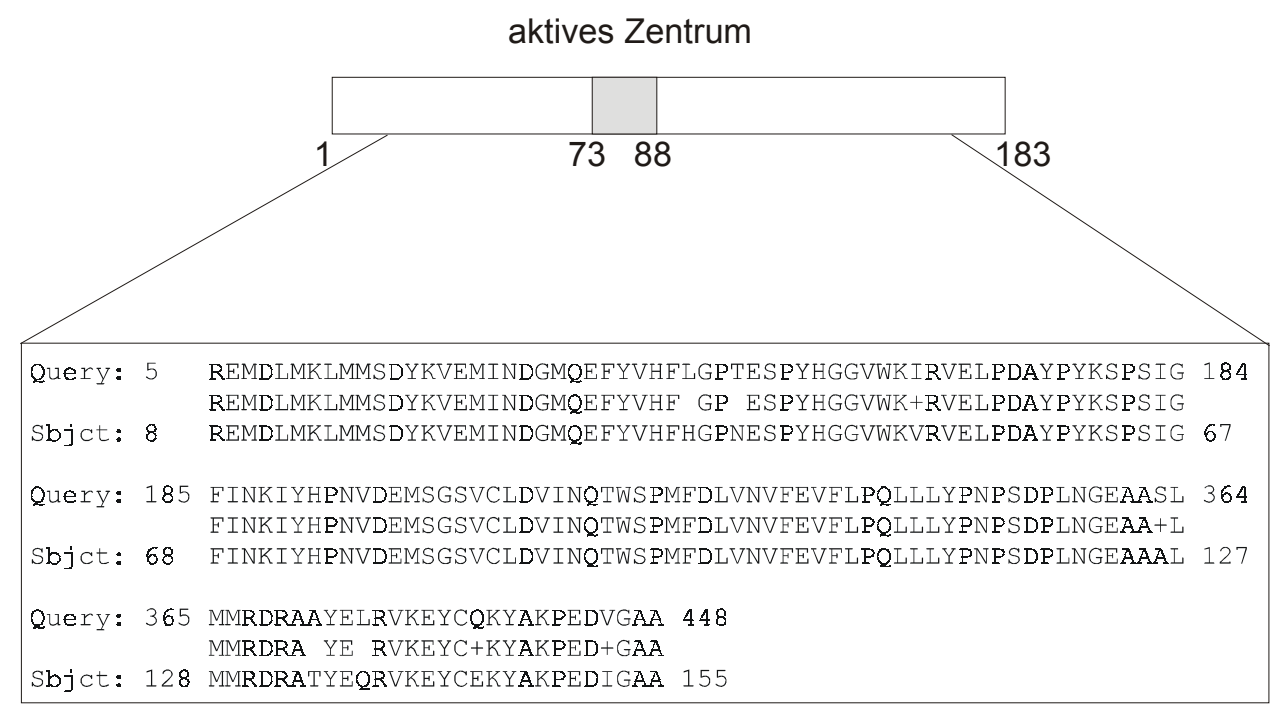

Abbildung 5-15: Vereinfachte Darstellung des „Ubiquitin carrier protein 4“ aus Glycine max. Zusätzlich ist der Homologievergleich von Klon 184-1 (Query) zu der E2-Ligase (Sbjct) angegeben. Die Zahlen stehen für Aminosäuren.

E2-Ligasen katalysieren die kovalente Verknüpfung von Ubiquitin an Zielproteine. Eine aktivierte Ubiquitineinheit wird von einem Ubiquitin-aktivierenden Enzym (E1) zu einer E2-Ligase transferiert. Diese ligiert die Ubiquitineinheit dann direkt an das Zielprotein mit oder ohne Hilfe von spezifischen E3-Ligasen (SULLIVAN et al., 1994). Diese posttranslationale Modifikation von Transkriptionsfaktoren ist z. B. für den auxinabhängigen Signalweg sehr gut untersucht. Eine Ubiquitinylinierung von Aux/IAA-Proteinen führt zu ihrer Degradation und resultierend $\mathrm{zu}$ einer Expression auxininduzierbarer Gene (BACHMAIR et al., 2001). Für den pflanzlichen Transkriptionsfaktor ERF3 aus Nicotiana tabacum, der an der ethylenabhängigen 
Antwort der Pflanze beteiligt ist, konnte im Hefe-Zweihybridsystem ebenfalls eine Interaktion mit der Klasse 2 E2-Ligase NtUBC2 nachgewiesen werden. Allerdings muss die biologische Relevanz dieser Interaktion noch getestet werden (KOYAMA et al., 2003).

\subsubsection{Testen der Interaktion der Klone mit TGA2.1 im Hefe-Zweihybridsystem}

Im Anschluss an die Charakterisierung der potentiellen Interaktionspartner Klon 117-1, 175-1 und 184-1 des pflanzlichen Transkriptionsfaktors TGA2.1 wurden diese im Hefe-Zweihybridsystem nachgetestet.

Das Hefe-Zweihybridsystem (FIELDS und SONG, 1998) beruht auf der modularen Struktur des Gal4-Transkriptionsfaktors, der in zwei funktionelle Einheiten unterteilt werden kann, die DNA-Bindedomäne (BD) und die Transkriptions-Aktivierungsdomäne (AD). Kann das Protein von Interesse, fusioniert an die Aktivierungsdomäne, mit einem anderen Protein, welches an die Bindedomäne fusioniert ist, interagieren, so kommen $\mathrm{AD}$ und $\mathrm{BD}$ in räumliche Nähe zueinander und der Transkriptionsfaktor wird rekonstituiert. Dieser kann dann, über einen Gal4-abhängigen Promotor, ein Reportergen aktivieren, das im Genom der Hefe inseriert ist. Als Reportergene wurden HIS3 und $A D E 2$ verwendet, auf die direkt selektioniert werden konnte.

Die zu testenden Fusionsproteine wurden über die entsprechenden Konstrukte in dem PJ69-4A (Kapitel 3.7.1) koexprimiert. Daraufhin wurden einzelne Transformanden auf analytischem Medium subkultiviert, um die Aktivität der Reportergene zu testen. Zweierlei analytische Medien wurden verwendet: Einerseits SD-TRP-LEU-Medium mit Zusatz von nur 0,01 g/l Adenin. Bei dieser geringen Menge war genügend Adenin vorhanden, um ein Wachstum der Hefen auch ohne Reportergenaktivität zu ermöglichen, aber so wenig, dass sich die rotfarbene Vorstufe dieser Aminosäure in den Zellen, die nicht selbständig Adenin produzieren können, angereichert hatte. Interagierten die Fusionsproteine miteinander, blieben die Hefekolonien weiß. Andererseits wurde SD-TRP-LEU-ADE-HIS-Medium verwendet. Die Hefezellen können auf diesem Medium wachsen, wenn die zu testenden Proteine miteinander interagieren. 
Die cDNAs wurden sowohl als Aktivierungsdomänen- als auch als Bindedomänenfusionen im Hefe-Zweihybridsystem getestet. Untersucht wurde die Interaktion mit TGA2.1, sowie einem Derivat von TGA2.1, das die aminoterminale Deletion der Aminosäuren 2-30 aufweist (TGA2.1-141). TGA2.1 wurde in diesem Test sowohl als carboxyterminale Bindedomänenfusion (BD-TGA2.1) als auch als aminoterminale Bindedomänenfusion (TGA2.1-BD) verwendet. Wie von THUROW (2001) beschrieben, wirkt das Fusionsprotein BD-TGA2.1 als starker Transkriptionsaktivator im Hefereporterstamm. Wird die Gal4-Bindedomäne an den C-Terminus von TGA2.1 fusioniert, vermittelt das resultierende Fusionsprotein TGA2.1-BD nur noch eine schwache Reportergenexpression. Als Negativkontrolle wurde nur die Bindedomäne (BD) zusammen mit der Aktivierungsdomäne (AD) in den Hefezellen exprimiert, als Positivkontrolle wurde die Interaktion von TGA2.1 mit NPR1 aus Arabidopsis thaliana, die zuerst von NigGewEG et al. (2000a) beschrieben wurde, verwendet. Die Ergebnisse sind in Tabelle 5.6 dargestellt.

Tabelle 5.6: Ergebnisse des Hefe-Zweihybridsystems

\begin{tabular}{ccc}
\hline Proteinkombination & $\begin{array}{c}\text { Färbung der } \\
\text { Hefezellen }\end{array}$ & $\begin{array}{c}\text { Wachstum auf } \\
\text { Interaktions- } \\
\text { medium }\end{array}$ \\
\hline
\end{tabular}

\begin{tabular}{lllll}
\hline Kontrollen & BD & AD & Rosa & -1 \\
\cline { 2 - 5 } & TGA2.1-BD & AD & Rosa & - \\
\cline { 2 - 5 } & TGA2.1-BD & AD-NPR1 & Rosa & ++ \\
\cline { 2 - 5 } & BD-TGA2.1-141 & AD & Weiß & +++ \\
\cline { 2 - 5 } & BD-TGA2.1-141 & AD-NPR1 & weiß & +++ \\
\cline { 2 - 5 } & BD & AD-TGA2.1-141 & Rosa & - \\
\cline { 2 - 5 } P-Typ ATPase & BD-NPR1 & AD-TGA2.1-141 & Weiß & +++ \\
\cline { 2 - 5 } & BDA2.1-BD & AD-117 & Rosa & - \\
\cline { 2 - 5 } & BD-117 & AD & Rosa & - \\
\hline RNA-Helicase & TGA2.1-BD & AD-175 & Rosa & - \\
\cline { 2 - 5 } & BD-175 & AD & Rosa & - \\
\cline { 2 - 5 } & BD-175 & AD-TGA2.1-141 & Rosa & - \\
\hline
\end{tabular}


Proteinkombination
Färbung der Wachstum auf

Hefezellen Interaktions-

medium

\begin{tabular}{llllc}
\hline E2-Ligase & TGA2.1-BD & AD-184 & Rosa & - \\
\cline { 2 - 5 } & BD-184 & AD & Weiß & ++ \\
\cline { 2 - 5 } & BD-184 & AD-TGA2.1-141 & Weiß & + \\
\cline { 2 - 5 } BD-TGA2.1-141 & AD-184 & Weiß & + \\
\hline
\end{tabular}

${ }^{I}(-)=$ kein Wachstum, $(+)=$ reduziertes Wachstum, $(+++)=$ sehr gutes Wachstum.

Betrachtet man zunächst die Kontrollen, so stellt man fest, dass diese sich erwartungsgemäß verhalten. Findet eine Interaktion statt, dann sind die Zellen weiß gefärbt und können auf Interaktionsmedium wachsen. Ist eine Interaktion jedoch nicht möglich, dann sind die Zellen rosa und wachsen nicht auf Interaktionsmedium. Eine Ausnahme stellt das Fusionsprotein BD-TGA2.1-141 dar. Wird dieses Protein nur zusammen mit der Aktivierunsdomäne (AD) exprimiert, dann weisen die Zellen eine weiße Färbung auf und können auf Interaktionsmedium wachsen. Dieser Phänotyp ist darauf zurückzuführen, dass TGA2.1 selbst eine Aktivierungsdomäne im N-Terminus besitzt (ThUROW, 2001). Wird der Transkriptionsfaktor nun an die Bindedomäne fusioniert, kann er an die Promotoren der Reportergene binden und deren Expression selbst aktivieren. Man spricht in diesem Fall von einer Autoaktivierung.

Die Klone 117-1 und 175-1 besitzen diese Autoaktivierung nicht. Werden diese beiden Klone jeweils zusammen mit dem Köderprotein TGA2.1 exprimiert, so können die Hefezellen nicht auf dem Interaktionsmedium wachsen. Der Klon 184-1 besitzt ein Autoaktivierungpotential, das mit dem von TGA2.1 vergleichbar ist. Hefezellen, die die cDNA von 184-1 exprimieren, sind weiß gefärbt und wachsen sehr gut auf Interaktionsmedium. Wird jedoch in den Hefezellen die cDNA zusammen mit TGA2.1 exprimiert, führt das $\mathrm{zu}$ einer deutlichen Reduktion des Wachstums auf Interaktionsmedium. Dieser Phänotyp war nicht zu beobachten, wenn das Fusionsprotein TGA2.1-BD als Köder verwendet wurde. Das Autoaktivierungspotential von TGA2.1 wird durch Lokalisierung der Bindedomäne am 3'-Ende so stark inhibiert, dass der Schwellenwert, der ein Wachstum auf Interaktionsmedium möglich macht, nicht erreicht wird (Thurow, 2001). Es muss also eine Protein-Protein-Interaktion zwischen dem „Ubiquitin carrier protein“ und dem Transkriptionsfaktor stattfinden, die die Reportergenexpression vermindert. 
Im nächsten Schritt wurde die Spezifität von dem Klon 184-1 gegenüber anderen TGAFaktoren bzw. anderen Proteinen mit Hilfe des Hefe-Zweihybridsystems getestet. Es wurden die TGA-Faktoren TGA2.2 (NIGGEWEG et al., 2000a), ein anderer Klasse-IIFaktor, TGA1a (KATAGIRI et al., 1989) und TGA10 (SCHIERMEYER et al., 2003) aus Nicotiana tabacum verwendet. Zudem wurde getestet, ob eine Interaktion mit SCL14 (SIEMSEN, 2002) aus Arabidopsis thaliana oder BZI-1 (HeInEKAMP et al., 2002) aus Nicotiana tabacum nachgewiesen werden kann. Von dem bZIP-Transkriptionsfaktor SCL14 ist bekannt, dass es mit AtTGA2 interagiert (SIEMSEN, 2002) und dadurch die as1-abhängige Expression eines nachgeschalteten Reportergens in Hefe aktivieren kann. STRATHMANN (2003) konnte für den bZIP-Transkriptionsfaktor BZI-1, der eine Rolle bei dem Auxinsignalweg spielt, eine Interaktion mit TGA-Faktoren nicht nachweisen. Die Ergebnisse sind in Tabelle 5.7 dargestellt.

Tabelle 5.7: Ergebnisse des Hefe-Zweihybridsystems mit Klon 184-1

\begin{tabular}{llcc}
\hline Proteinkombination & & $\begin{array}{c}\text { Färbung der } \\
\text { Hefezellen }\end{array}$ & $\begin{array}{c}\text { Wachstum auf } \\
\text { Interaktionsmedium }\end{array}$ \\
\hline BD-184 & AD & Weiß & +++1 \\
\hline BD-184 & AD-TGA2.1-141 & Weiß & + \\
\hline BD-184 & AD-TGA2.2 & Weiß & +++ \\
\hline BD-184 & AD-TGA1a & Weiß & ++ \\
\hline BD-184 & AD-TGA10 & Weiß & ++ \\
\hline BD-184 & AD-SLC14 & Weiß & +++ \\
\hline BD-TGA2.1-141 & AD & Weiß & +++ \\
\hline BD-TGA2.1-141 & BD-184 & Weiß & +++ \\
\hline BD-BZI-1 & BD & Weiß & +++ \\
\hline BD-BZI-1 & BD-184 & Weiß & + \\
\hline
\end{tabular}

${ }^{I}(-)=$ kein Wachstum, $(+)=$ reduziertes Wachstum, $(++)=$ Wachstum, $(+++)=$ sehr gutes Wachstum.

Anhand der in Tabelle 5.7 dargestellten Ergebnisse zeigt sich, dass das Protein 184-1 auch mit den TGA-Faktoren TGA1a und TGA10 eine Interaktion einzugehen scheint. Allerdings führt das im Gegensatz zu der Interaktion mit TGA2.1 nicht zu einer sehr starken Wachstumsreduzierung der Hefezellen auf Interaktionsmedium. Mit TGA2.2 scheint keine Interaktion stattzufinden. Interessant ist, dass auch die TGA-Faktoren 
TGA1a und TGA10 in Hefe Aktivierungspotential besitzen, TGA2.2 dagegen nicht (Thurow, 2001). Daraus resultierte die Frage, ob die Protein-Protein-Wechselwirkung vielleicht generell für aktivierende bZIP-Transkriptionsfaktoren $\mathrm{zu}$ beobachten ist. Deswegen wurde untersucht, ob eine Expression von 184-1 zusammen mit SCL14 aus Arabidopsis thaliana auch eine Wachstumsreduzierung zur Folge hat. Dieses war jedoch nicht $\mathrm{zu}$ beobachten. Dasselbe Ergebnis bekommt man für den bZIPTranskriptionsfaktor BZI-1 aus Nicotiana tabacum. Somit scheint 184-1 ein spezifischer Partner von TGA2.1 bzw. TGA-Faktoren mit Aktivierungsdomänen zu sein.

\subsubsection{Testen der Interaktion von Klon 184-1 mit TGA2.1 im modifizierten ,One- Hybrid"-System}

Für Klon 184-1 konnte im Hefe-Zweihybridsystem beobachtet werden, dass eine Wechselwirkung mit TGA2.1 eine Reduktion des Hefewachstums verursacht. Das kann zum einen damit begründet werden, dass die Wechselwirkung die Bindung an die Promotoren der Reportergene negativ beeinflusst oder zum anderen dadurch, dass der durch die Proteinwechselwirkung entstandene Proteinkomplex nicht stabil ist. Um diese Hypothesen zu überprüfen, wurde ein modifiziertes „One-Hybrid“-System verwendet (SIEMSEN, 2002). Ein Reportergenkonstrukt, bestehend aus drei as-1 Elementen und dem HIS3-Gen, wurde in das Hefegenom des Stammes YTSH1 integriert (Kapitel 3.7.1.). Wird in diesem Stamm der TGA-Faktor TGA2.1 exprimiert, kann dieser an die as-1 Elemente binden und die HIS3-Expression induzieren. Bindet TGA2.1 nicht mehr an die as-1 Elemente, so können die Hefezellen auf Medium ohne Histidin nicht wachsen (Abbildung 5-16). 
a)

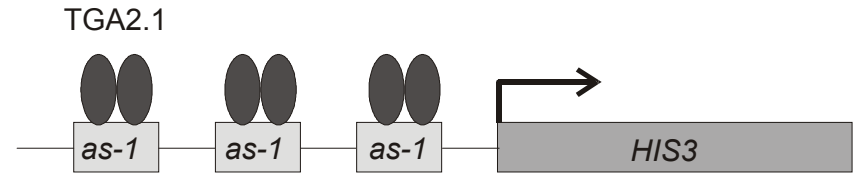

b)

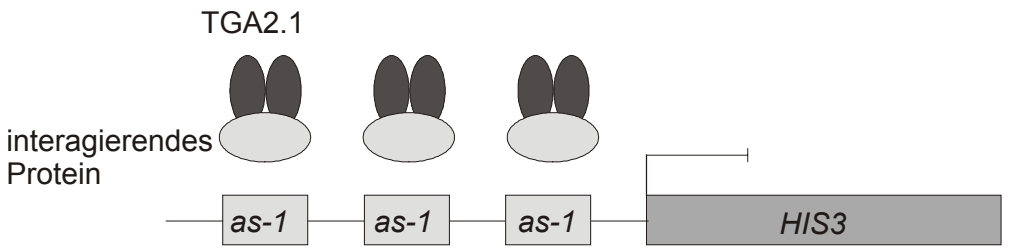

Abbildung 5-16: Schematische Darstellung des verwendeten Hefe „One-Hybrid“-Systems (SIEMSEN, 2002). Das abgebildete $H I S$-Reportergen liegt im Hefegenom integriert vor.

In diesem Experiment wurden verschiedene Derivate von TGA2.1 verwendet: Das aminoterminale Deletionsderivat TGA2.1-141 fusioniert an das 3'-Ende der Aktivierungsdomäne bzw. als unfusioniertes Protein. Zudem wurde auch der vollständige TGA2.1 unfusioniert eingesetzt. Klon 184-1 wurde als Bindedomänenfusion verwendet. Die $\mathrm{zu}$ testenden Proteine wurden über die entsprechenden Konstrukte in dem Hefestamm YTSH1 koexprimiert. Daraufhin wurden einzelne Transformanden auf analytischem Medium subkultiviert, um die Aktivität des Reportergens $\mathrm{zu}$ testen. Als analytisches Medium wurde SD-TRP-LEU-HIS-Medium mit Zusatz von 30 mM 3-AT verwendet. Die Ergebnisse sind in Tabelle 5.8 dargestellt. 
Tabelle 5.8: Ergebnisse des modifizierten "One-Hybrid“-Systems mit Klon 184-1

\begin{tabular}{llcc}
\hline $\begin{array}{l}\text { Protein- } \\
\text { kombination }\end{array}$ & $\begin{array}{c}\text { Wachstum auf } \\
\text { Plasmid- } \\
\text { selektionsmedium }\end{array}$ & $\begin{array}{c}\text { Wachstum auf } \\
\text { analytischem } \\
\text { Medium }\end{array}$ \\
\hline BD & AD & ++1 & - \\
\hline BD & AD-TGA2.1-141 & ++ & ++ \\
\hline BD & TGA2.1-141 & ++ & ++ \\
\hline BD & TGA2.1 & ++ & ++ \\
\hline BD-184 & AD-TGA2.1-141 & ++ & ++ \\
\hline BD-184 & TGA2.1-141 & ++ & ++ \\
\hline BD-184 & TGA2.1 & ++ & + \\
\hline $1(-)=$ kein Wachstum, $(++)=$ Wachstum & & +
\end{tabular}

Betrachtet man zunächst die Kontrollen, so stellt man fest, dass diese sich erwartungsgemäß verhalten. Wird TGA2.1 in den Hefezellen exprimiert, so wird die Reportergenexpression durch die Bindung von TGA2.1 an das as-1 Element induziert. Dabei war zwischen den einzelnen TGA2.1-Derivaten kein Unterschied detektierbar. Ist TGA2.1 nicht in den Hefezellen vorhanden, so findet keine Reportergenexpression statt und die Hefezellen sind nicht in der Lage auf analytischem Medium zu wachsen. Eine gleichzeitige Expression von TGA2.1 zusammen mit Klon 184-1 resultiert nicht in einer verringerten Reportergenaktivität. Die Hefezellen können sehr gut auf dem Selektionsmedium wachsen. Somit konnten die aufgestellten Hypothesen mit Hilfe dieses Ansatzes nicht bestätigt werden.

\subsubsection{Zusammenfassung der Klonanalysen}

Mit Hilfe des USPS mit TGA2.1 als Köderprotein konnten vier Klone als potentielle neue Interaktionspartner identifiziert werden. Dabei handelt es sich um Klon 117-1 („Metal-transporting P-type ATPase“), Klon 172-16 und Klon 175-1 (DEAD-Box-RNAHelicase) und Klon 184-1 („Ubiquitin carrier protein 4“). Im Hefe-Zweihybridsystem konnte nur für den Klon 184-1 eine Wechselwirkung mit TGA2.1 nachgewiesen werden, die die Reportergenaktivität des verwendeten Hefestammes vermindern kann. Diese 
Wechselwirkung scheint spezifisch für aktivierende TGA-Faktoren zu sein, da auch die Koexpression von Klon 184-1 zusammen mit TGA1a oder TGA10 eine Reduzierung der Reportergenaktivität der Hefezellen zur Folge hat, die jedoch nicht so stark ist wie im Fall von TGA2.1. Zudem wurde der Klon 184-1 im modifizierten „One-Hybrid“-System untersucht. Allerdings führte die Koexpression von TGA2.1 und Klon 184-1 nicht zu einer Verringerung der durch die Bindung von TGA2.1 an das as-1 Element vermittelten Reportergenexpression.

\subsection{Funktionsanalyse des bZIP-Transkriptionsfaktors TGA2.1 in transgenen Tabakpflanzen}

Zur Aufklärung der spezifischen Funktion des bZIP-Transkriptionsfaktors TGA2.1 aus Tabak sollten transgene Pflanzen hergestellt werden, in denen die Expression des Nttga2.1-Gens vermindert ist. Dazu wurden spezielle DNA-Konstrukte in die Pflanzen eingebracht, die durch doppelsträngige RNA-Interferenz (RNAi; CHUANG et al., 2000) zu posttranskriptionellem Abschalten (PTGS, ,post transcriptional gene silencing“) des Nttga.1-Gens führen sollten. Um PTGS zu induzieren, wurden im Rahmen dieser Arbeit zum einen das Konstrukt pMSK5 (Kapitel 5.2.1) und zum anderen das Konstrukt pFGC2.1 (Kapitel 5.2.2) verwendet.

\subsubsection{Inhibierung der Nttga2.1-Genexpression durch RNAi in transgenen Pflanzen}

5.2.1.1 Herstellung der transgenen tga2.1RNAi-Pflanzen unter Verwendung des Konstruktes pMSK5

Basierend auf der Arbeit von WATERHOUSE et al. (1998), in der gezeigt wurde, dass es möglich ist, durch eine gleichzeitige Expression von DNA in korrekter und entgegengesetzter Orientierung PTGS zu induzieren, wurde das Konstrukt pMSK5 hergestellt (Abbildung 5-17). 


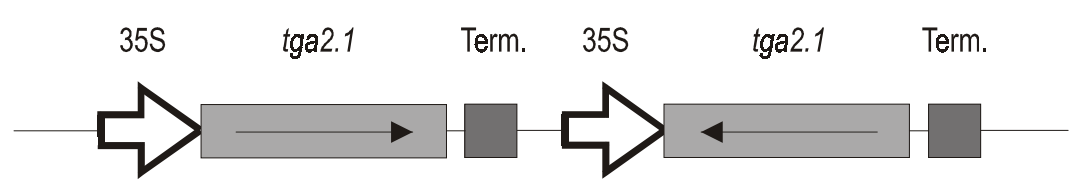

Abbildung 5-17: Schematische Darstellung des in die Tabakpflanzen eingebrachten RNAi-Konstruktes pMSK5.

Die Expression der vollständigen Kodierregion der tga2.1-cDNAs in den unterschiedlichen Orientierungen findet dabei unabhängig voneinander statt und steht unter Kontrolle von CaMV35S-Promotoren. Die transkribierte RNA kann einen kovalent verbundenen RNA-Doppelstrang ausbilden und nach dem Modell von WATERHOUSE et al. (1998) das PTGS homologer Sequenzen induzieren.

Das Konstrukt wurde in zwei verschiedene Ausgangspflanzen eingebracht. Neben SNN (Wildtyp-) Pflanzen wurden zusätzlich SNN2.2UE-Pflanzen (NIGGEwEG, 1999) transformiert. Letztere exprimieren das Protein TGA2.2 unter Kontrolle des CaMV35SPromotors. Diese Pflanzen wurden mit in die Untersuchung aufgenommen, da LENK (2001) einen regulatorischen Einfluss von TGA2.1 auf die Expression von tga2.2 festgestellt hatte. Falls eine Reduktion von TGA2.1 die Expression von tga2.2 negativ beeinflusst, wurde durch die Überexpression von $\operatorname{tga} 2.2$ sichergestellt, dass stets genügend TGA2.2 in der pflanzlichen Zelle vorhanden war.

Nach der Regeneration wurden von jeder Transformation 25 bis 30 unabhängige Methotrexat-resistente Individuen mit Hilfe einer Northern-Blot-Analyse untersucht. Eine Auswahl davon ist in Abbildung 5-18a dargestellt. 
a)

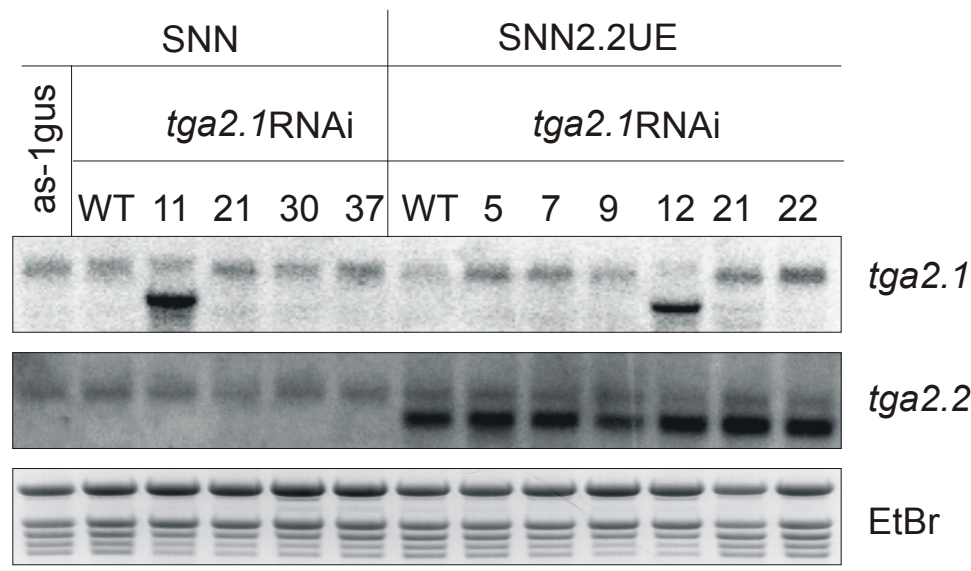

b)

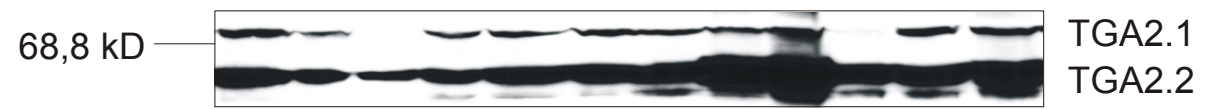

\begin{abstract}
Abbildung 5-18: (a) Northern-Blot-Analyse der tga2.1- und tga2.2-Genexpression zur Charakterisierung der transformierten Tabakpflanzen. Von jeder Pflanze wurden $10 \mu \mathrm{g}$ Gesamt-RNA analysiert. Die Nummern oberhalb der Spuren bezeichnen unabhängige Methotrexat-resistente Linien. Zusätzlich wurde eine transgene Pflanze verwendet, die ein as-1-gus-Konstrukt besitzt. Die Hybridisierung der Membran erfolgte wie rechts angegeben mit den radioaktiv markierten Sonden tga2.1 und tga2.2. Für die Beladungskontrolle ist weiterhin die Ethidiumbromidfärbung der geblotteten RNA dargestellt (EtBr). (b) Western-Blot-Analyse mit denaturierten Kernextrakten der transformierten Tabakpflanzen zum Nachweis von TGA2.1 und TGA2.2. Normalisierte Proteinmengen wurden mittels SDS-PAGE aufgetrennt und auf PVDF-Membranen geblottet. Proteine wurden im Immunoblot mittels des affinitätsaufgereinigten Antiserums gegen TGA2.x detektiert.
\end{abstract}

Für jede Transformation konnte jeweils nur eine Methotrexat-resistente Pflanze identifiziert werden, die eine reduzierte Nttga2.1-mRNA enthielt (Linie \#11 und \#12). Zusätzlich wurde in diesen beiden Linien ein weiteres, kleineres Signal detektiert, das wahrscheinlich auf die Expression der eingebrachten tga2.1-cDNA zurückzuführen ist. Dieses Signal ist im Vergleich zum endogenen kleiner, weil die UTRs (,untranslated regions") in diesem Fall nicht vorhanden sind. Durch das RNAi-Konstrukt wurde sowohl die endogene als auch die transgene Transkriptmenge von tga2.2 in den SNNbzw. in den SNN2.2UE-Pflanzen nicht beeinflusst. Bei denen als positiv identifizierten Pflanzen konnte zudem auch in denaturierten Kernextrakten kein TGA2.1-Protein nachgewiesen werden (Abbildung 5-18b), die Proteinmenge von TGA2.2 war nicht beeinflusst. Das Signal für den Transkriptionsfaktor TGA2.1 entspricht in der WesternBlot-Analyse einem Molekulargewicht von ca. $70 \mathrm{kD}$, das für TGA2.2 entspricht einem Molekulargewicht von 55 kD. Das errechnete Molekulargewicht für TGA2.1 beträgt 
jedoch $50 \mathrm{kD}$, das für TGA2.2 $36 \mathrm{kD}$. Diese Diskrepanz zwischen errechnetem und beobachtetem Molekulargewicht wurde bereits von NigGEWEG (1999) und KegLeR (2001) beschrieben. Bei der vom errechneten Molekulargewicht abweichenden Mobilität von TGA2.1 und TGA2.2 in der SDS-PAGE scheint es sich um eine intrinsische Eigenschaft der Proteine zu handeln.

Die Strategie, die endogene Expression von tga2.1 über eine gleichzeitige Expression von „sense“ (richtiger) und ,antisense“ (entgegengesetzter) tga2.1-cDNA zu verhindern, erwies sich zwar als erfolgreich, jedoch war die Effizienz sehr schlecht. Zudem war eine strukturierte Charakterisierung der beiden RNAi-Linien nicht möglich, da der RNAiEffekt nicht stabil war. Aus diesen Gründen wurde ein anderer Ansatz verwendet, um RNAi zu induzieren (Kapitel 5.2.1.2).

5.2.1.2 Herstellung der transgenen tga2.1RNAi-Pflanzen unter Verwendung des Konstruktes pFGC2.1

Basierend auf der Arbeit von WATERHOUSE et al. (2000) wurde ein Konstrukt zur Induktion von PTGS hergestellt, welches einen 257 bp großen Teilbereich (aa 50-135) der Kodierregion der tga2.1-cDNA (Kapitel 8.2.4) sowohl in entgegengesetzter als auch in korrekter Orientierung unter der Kontrolle des konstitutiven CaMV35S-Promotors enthält. Zwischen den beiden Orientierungen ist ein Intron lokalisiert (Abbildung 5-19).

konstitutiv

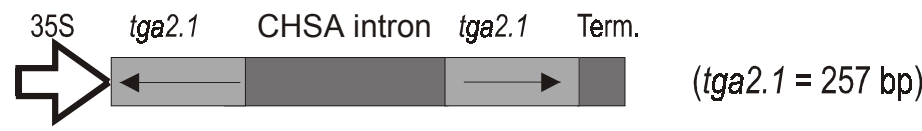

induzierbar

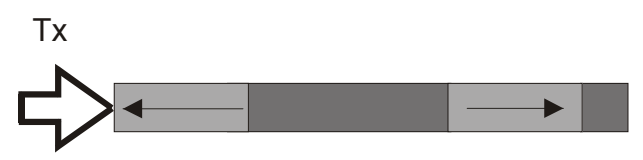

Abbildung 5-19: Schematische Darstellung der in die Tabakpflanzen eingebrachten RNAi-Konstrukte pFGC2.1 und pTXFGC2.1. 
In der Pflanze kann sich die transkribierte RNA über interne Basenpaarungen zwischen „sense“- und „antisense“-Bereichen zu einem kovalent verbundenen RNA-Doppelstrang zurückfalten (Haarnadelstruktur) und nach dem Modell von WATERHOUSE et al. (1998) das PTGS homologer Sequenzen induzieren. Konstrukte mit einem Intron zwischen den beiden gegenläufigen Sequenzabschnitten sind nach SMITH et al. (2000) besonders wirksam, da wahrscheinlich der Spleißvorgang die Ausbildung des RNADoppelstranges fördert. Parallel zu dem konstitutiven Konstrukt wurde ebenfalls eine induzierbare Version unter der Kontrolle des Tx-Promotors (GATZ et al., 1992) hergestellt. Dieser Promotor ist ein Derivat des CaMV35S-Promotors mit drei TetOperatoren im Bereich der TATA-Box. In Pflanzen, die den Tetracyclin-Repressor TetR exprimieren, kann der Promotor als induzierbares Expressionssystem verwendet werden, da die Zugabe von Tetracyclin zum Ablösen der Repressoren und zum Anschalten des Promotors führt. Dieser Ansatz wurde gewählt, um eventuell auftretende Regenerationsschwierigkeiten der transgenen Pflanzen, hervorgerufen durch die Verringerung der TGA2.1-Menge, zu verhindern. Der RNAi-Effekt kann somit erst in adulten Pflanzen induziert werden. Die Identifizierung und Charakterisierung der transgenen Pflanzen, die das induzierbare Konstrukt aufweisen, wurde von I. HERRMANN (2003) im Rahmen ihrer Diplomarbeit durchgeführt.

Das konstitutive Konstrukt wurde wiederum in SNN- und SNN2.2UE-Pflanzen (Kapitel 5.2.1.1) transformiert. Nach der Regeneration wurden jeweils 18 transgene Pflanzen im SNN-Hintergrund bzw. im SNN2.2UE-Hintergrund auf mRNA-Ebene untersucht. In Abbildung 5-20 sind die Ergebnisse dargestellt. 
a) Ausgangspflanze: SNN

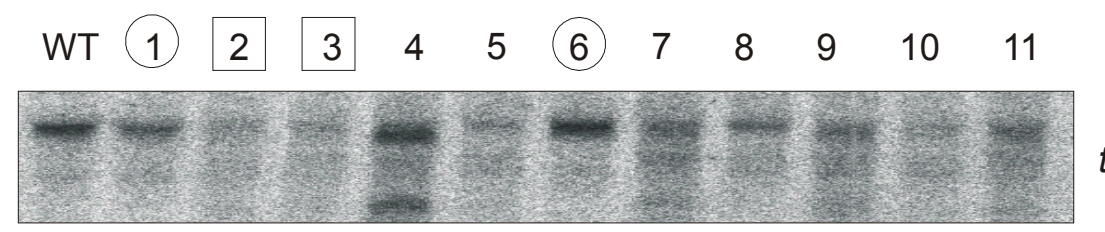

$\operatorname{tga2.1}$

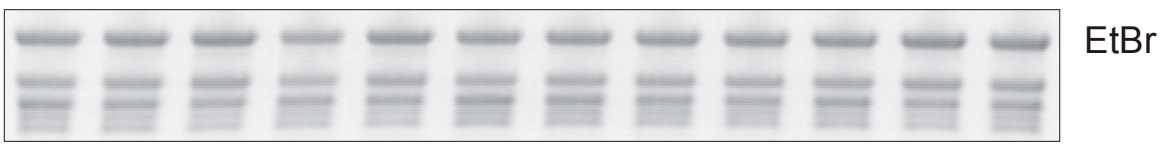

b) Ausgangspflanze: SNN2.2UE

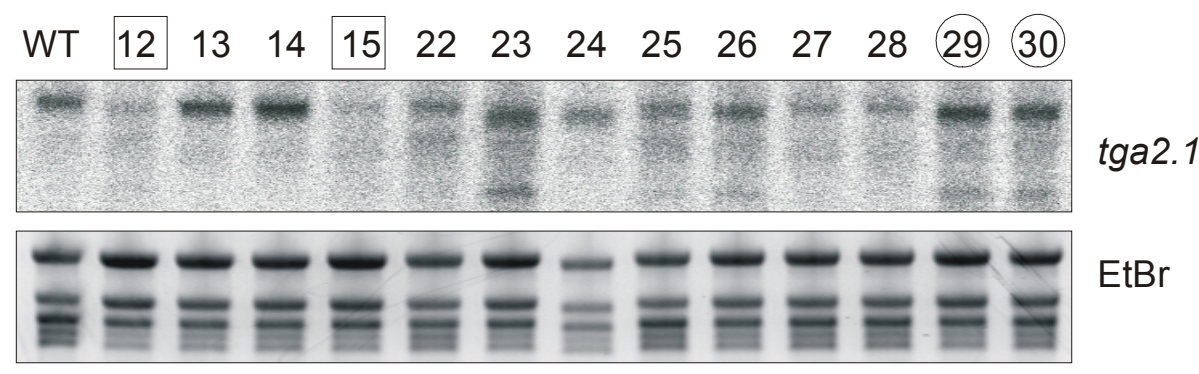

\begin{abstract}
Abbildung 5-20: Northern-Blot-Analyse der tga2.1-Genexpression zur Charakterisierung der transformierten Tabakpflanzen. Von jeder Pflanze wurden $10 \mu \mathrm{g}$ Gesamt-RNA analysiert. Die Nummern oberhalb der Spuren bezeichnen unabhängige Phophinotrizin-resistente Linien. Mit einem Quadrat sind die tga2.1RNAi-Linien angegeben, mit einem Kreis die Kontrollpflanzen. Die Hybridisierung der Membran erfolgte wie rechts angegeben mit den radioaktiv markierten Sonde tga2.1. Für die Beladungskontrolle ist weiterhin die Ethidiumbromidfärbung der geblotteten RNA dargestellt (EtBr).
\end{abstract}

Im SNN-Hintergrund konnten vier Linien (\#2, \#3, \#5 und \#10) identifiziert werden, in denen tga2.1-mRNA-Menge stark reduziert war. Die Linien \#7, \#8, \#9 und \#11 zeigten eine schwach reduzierte tga2.1-Transkriptmenge. Im SNN2.2UE-Hintergrund war nur in zwei Linien \#12 und \#15 eine starke Reduzierung der mRNA-Menge für TGA2.1 nachweisbar. Die Linien \#27 und \#28 zeigten eine schwach reduzierte tga2.1Transkriptmenge. Auch in diesem Fall ist neben dem endogenen tga2.1-Signal ein weiteres, kleineres Signal detektierbar, z. B. für Linie \#4 und für Linie \#23, das wahrscheinlich auf die Expression des Transgens zurückzuführen ist. Allerdings korreliert es im Gegensatz zu der Northern-Blot-Analyse mit den transgenen Pflanzen, die mit dem Konstrukt pMSK5 transformiert worden sind (Kapitel 5.2.1.1, Abbildung 
5-18), nicht mit der Ausprägung des RNAi-Effektes. Für die weiteren Analysen wurde mit folgenden Pflanzen gearbeitet (Tabelle 5.9):

Tabelle 5.9: Transgene Pflanzen für die weiteren Analysen

\begin{tabular}{lcc}
\hline Hintergrund & RNAi-Pflanzen & Kontrollen \\
\hline SNN & $\# 2, \# 3$ & $\# 1, \# 6$ \\
SNN2.2UE & $\# 12, \# 15$ & $\# 29, \# 30$
\end{tabular}

Mit Hilfe einer Northern-Blot-Analyse konnte zudem nachgewiesen werden, dass die Expression des RNAi-Konstruktes in diesen Pflanzen keinen Einfluss auf die endogene bzw. transgene tga2.2-Transkriptmenge hatte (Abbildung 5-21).

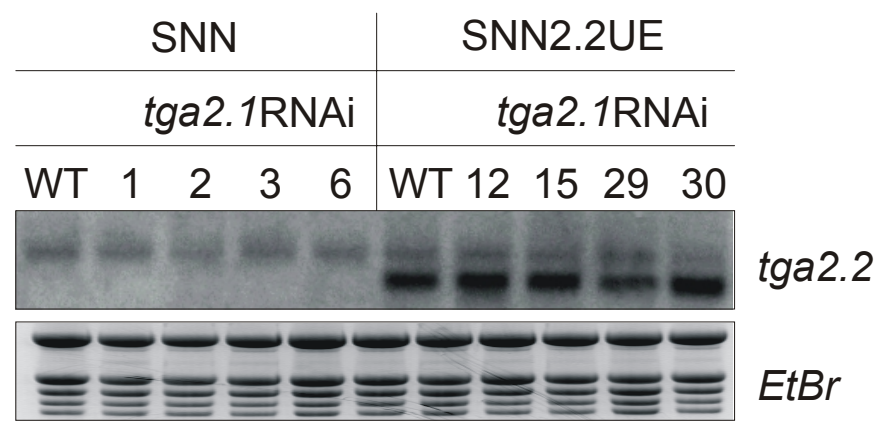

\begin{abstract}
Abbildung 5-21: Northern-Blot-Analyse der tga2.2-Genexpression zur Charakterisierung der ausgewählten RNAi-Pflanzen. Von jeder Pflanze wurden $10 \mu \mathrm{g}$ Gesamt-RNA analysiert. Die Hybridisierung der Membran erfolgte wie rechts angegeben mit der radioaktiv markierten Sonde tga2.2. Für die Beladungskontrolle ist weiterhin die Ethidiumbromidfärbung der geblotteten RNA dargestellt $(\mathrm{EtBr})$.
\end{abstract}

Für die Charakterisierung der ausgewählten Pflanzen auf Proteinebene wurden sowohl Western-Blot-Analysen als auch Gelretardationsexperimente durchgeführt. In Abbildung 5-22 sind die Ergebnisse der Western-Blot-Analysen dargestellt. Verwendet wurden denaturierte Gesamtzellextrakte (Abbildung 5-22a) und denaturierte Kernextrakte (Abbildung 55-22b). Für die Detektion wurde das affinitätsaufgereinigte Antiserum gegen TGA2.1 verwendet. Ebenfalls tritt hier, wie in Kapitel 5.2.1.1 beschrieben, die Diskrepanz zwischen detektiertem und errechnetem Molekulargewicht für TGA2.1 auf. Wie auf der Transkriptebene ist auch auf der Proteinebene TGA2.1 in den Linien \#2 und 
\#3 sowohl in Gesamtzellextrakten als auch in Kernextrakten nicht nachweisbar. Im Gegensatz zu der Northern-Blot-Analyse (Abbildung 5-20) ist dagegen in Linie \#12 TGA2.1-Protein detektierbar, dafür jedoch nicht in den Linien \#29 und \#30, die als transgene Kontrollen verwendet worden sind. Dieses Ergebnis zeigt, dass sich der RNAi-Effekt erst nach längere Zeit ausprägen kann bzw. nicht stabil ist.

a)

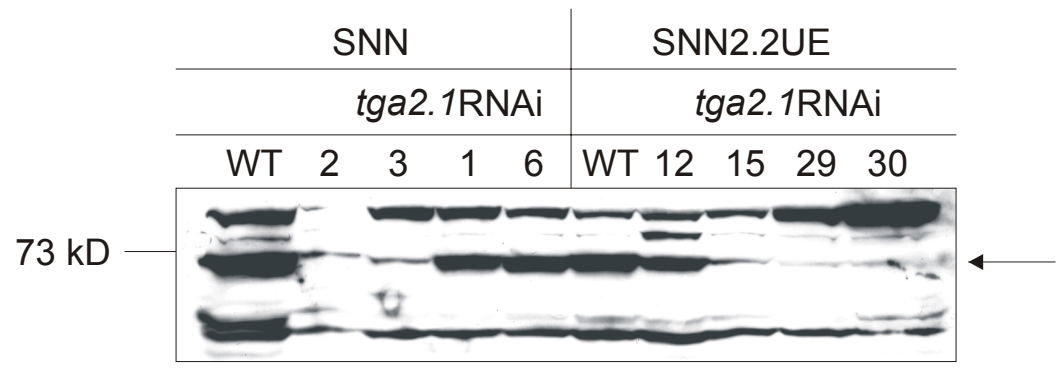

b)
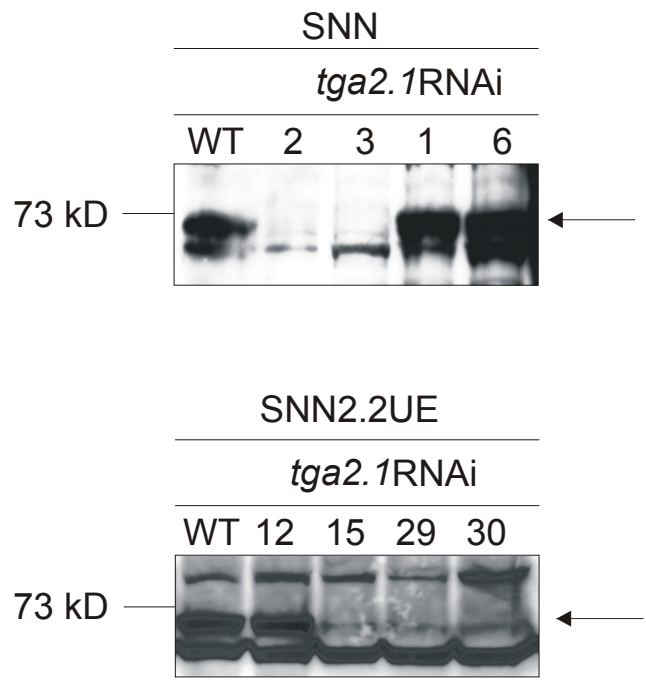

Abbildung 5-22: Western-Blot-Analyse mit denaturierten Gesamtzellextrakten (a) und denaturierten Kernextrakten (b) der transformierten Tabakpflanzen zum Nachweis von TGA2.1. Normalisierte Proteinmengen wurden mittels SDS-PAGE aufgetrennt und auf PVDF-Membranen geblottet. Die Proteine wurden im Immunoblot mittels des affinitätsaufgereinigten Antiserums gegen TGA2.1 detektiert. Die spezifische TGA2.1-Bande ist mit einem Pfeil gekennzeichnet.

Das Ergebnis der Western-Blot-Analysen manifestierte sich durch die Gelretardationsexperimente. Diese wurden mit nativen Kernextrakten und nativen Gesamtzellextrakten durchgeführt. In Abbildung 5-23 sind die Ergebnisse der Gelretardationsexperimente mit nativen Kernextrakten abgebildet. 
a) Ausgangspflanze: SNN

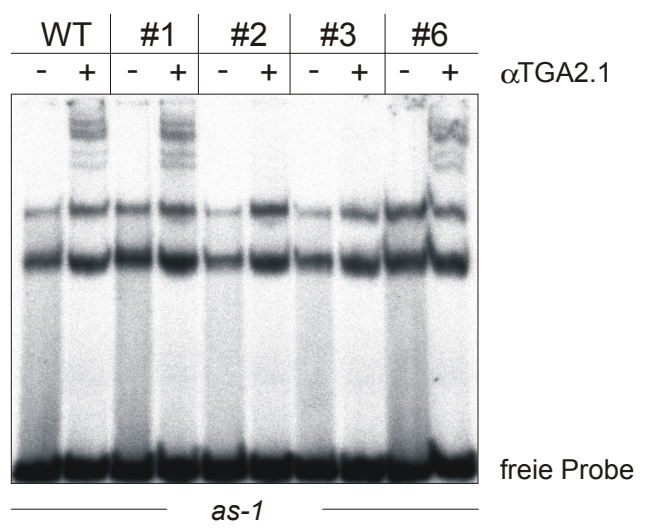

b) Ausgangspflanze: SNN2.2UE

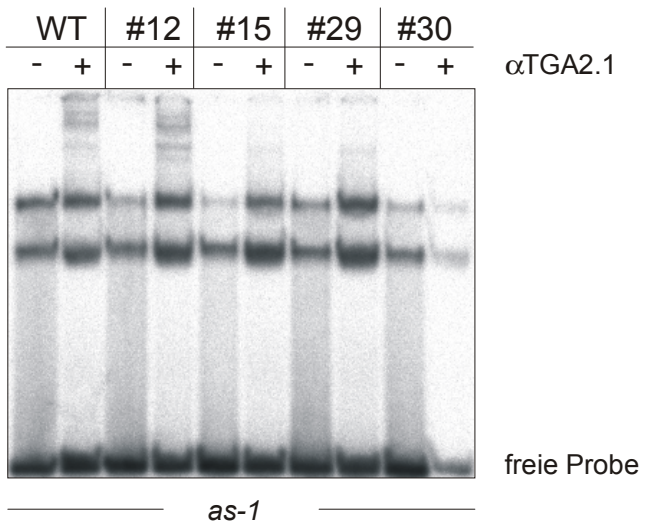

Abbildung 5-23: Analyse der Zusammensetzung von ASF-1 in den RNAi-Linien. Gelretardationexperimente mit $2 \mu \mathrm{g}$ nativen Kernextrakten. Als ${ }^{32}$ P-markiertes DNA-Fragment wurde das as-1 Element verwendet. Zur Detektion von TGA2.1 wurde 1,0 $\mu$ l des Antiserums gegen TGA2.1 eingesetzt. (a) zeigt das Bindungsmuster für Pflanzen in SNN-Hintergrund; (b) zeigt das Bindungsmuster für Pflanzen im SNN2.2UE-Hintergrund.

Für den Wildtyp (SNN) ist das typische Bindungsmuster von ASF-1 zusehen. Die untere Bande verkörpert die Besetzung eines einzelnen TGACG-Motivs des as-1 Elementes mit verschiedenen Proteindimeren: einem TGA2.2-Homodimer, einem TGA2.1/TGA2.2Heterodimer und einem TGA2.1-Homodimer. Die obere Bande repräsentiert die Bindung von TGA2.1- und TGA2.2-Dimeren an beide TGACG-Motive des as-1 Elementes (NiggeweG, 1999). Verwendet man das Antiserum gegen TGA2.1, so erkennt der Antikörper den Transkriptionsfaktor TGA2.1 in den nativen Kernextrakten und dieser wird retardiert.

In den Linien \#2 und \#3 erscheinen die untere und die obere Bande schwächer. Werden diese Kernextrakte mit dem Antiserum gegen TGA2.1 inkubiert, so wird kein TGA2.1 mehr erkannt, die Retardation unterbleibt. Ebenso verhält es sich bei den Linien \#15, \#29 und \#30 im SNN2.2UE-Hintergrund. Diese Ergebnisse zeigen somit, dass die Menge von TGA2.1 in den Kernextrakten der RNAi-Linien sehr stark reduziert ist. Dasselbe Ergebnis ergab die Analyse von nativen Gesamtzellextrakten mit Hilfe von Gelretardationsexperimenten (Daten nicht gezeigt).

Zusammenfassend kann man sagen, dass für die folgende Untersuchung der Funktion von TGA2.1 in vivo transgene Pflanzen zu Verfügung stehen, in denen die TGA2.1- 
Menge im Vergleich zu einer Wildtyppflanze eindeutig stark reduziert ist, dazu gehören die Linien \#2 und \#3 im SNN-Hintergrund und die Linien \#15, \#29 und \#30 im SNN2.2UE-Hintergrund.

\subsubsection{Phänotypische Veränderungen der tga2.1RNAi-Pflanzen}

Die transgenen tga2.1RNAi-Pflanzen \#2 und \#3 weisen im Vergleich zu einer Wildtyppflanze morphologische Veränderungen auf. Zum einen sind die Blätter rundlicher und an den Spitzen eingekerbt (Linie \#2) bzw. an den Rändern wellig und eingekerbt (Linie \#3) (Abbildung 5-24a). Zudem zeichnen sich beide Linien durch eine vermehrte Bildung von Seitensprossen aus (Abbildung 5-24b). Diese vermehrte Bildung von Seitensprossen konnte auch in transgenen Tabakpflanzen beobachtet werden, die den bZIP-Transkriptionsfaktor TGA10 überexprimieren (SCHIERMEYER et al., 2003).

a)
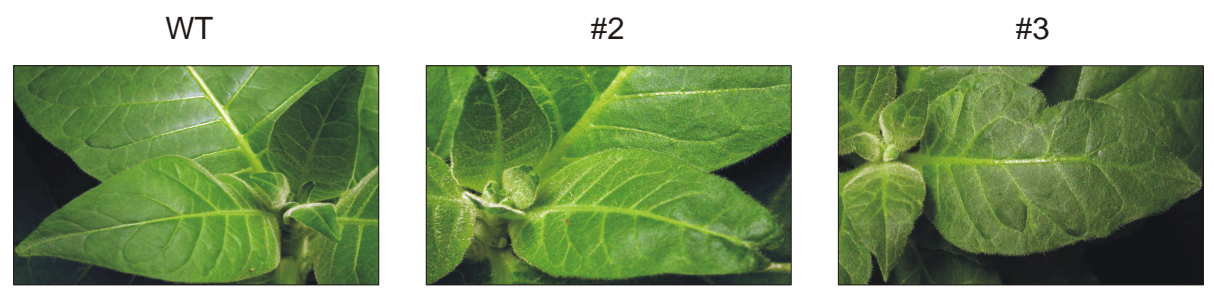

b)
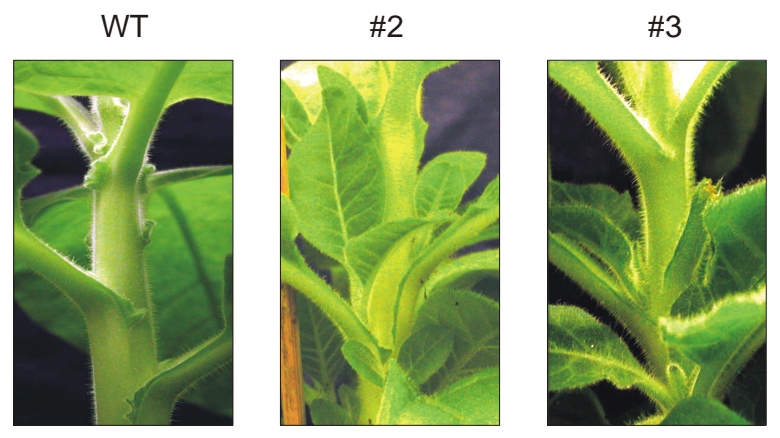

Abbildung 5-24: Phänotypische Veränderungen der RNAi-Pflanzen \#2 und \#3 im Vergleich mit einer Wildtyppflanze. (a) Veränderungen der Blattmorphologie. (b) Vermehrte Bildung von Seitensprossen. 
Zudem zeigt die RNAi-Linie \#2 ein verlangsamtes Wachstum. In Abbildung 5-25 sind vier Wochen alte Sterilkulturpflanzen dargestellt. Man erkennt, dass die Wurzelbildung bei der Linie \#2 deutlich verlangsamt ist, was wiederum $\mathrm{zu}$ einem verlangsamten Wachstum in Sterilkultur führt. Dieser Phänotyp konnte auch für Erdpflanzen beobachtet werden. Bei der Linie \#3 schwankt dieser Effekt in der Ausprägung. Für die RNAi-Linie \#11, die aus dem ersten Transformationsansatz mit dem Konstrukt pMSK5 resultiert (Kapitel 5.2.1.1), konnte ebenfalls eine Reduktion des Wurzelwachstums beobachtet werden.
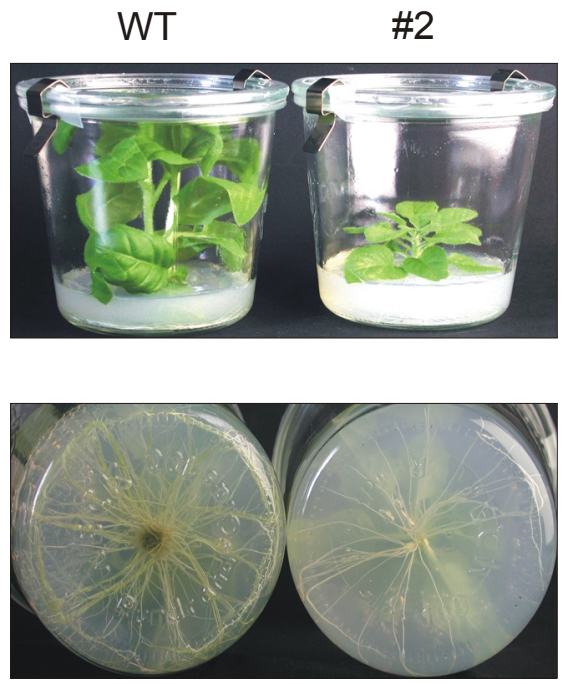

Abbildung 5-25: Wachstum der RNAi-Linie \#2 in Sterilkultur im Vergleich zu einer Wildtyppflanze. Die abgebildeten Pflanzen sind vier Wochen alt. Die RNAi-Linie \#2 zeigt eine deutlich reduzierte Wurzelbildung, was zu einem verlangsamtem Wachstum führt.
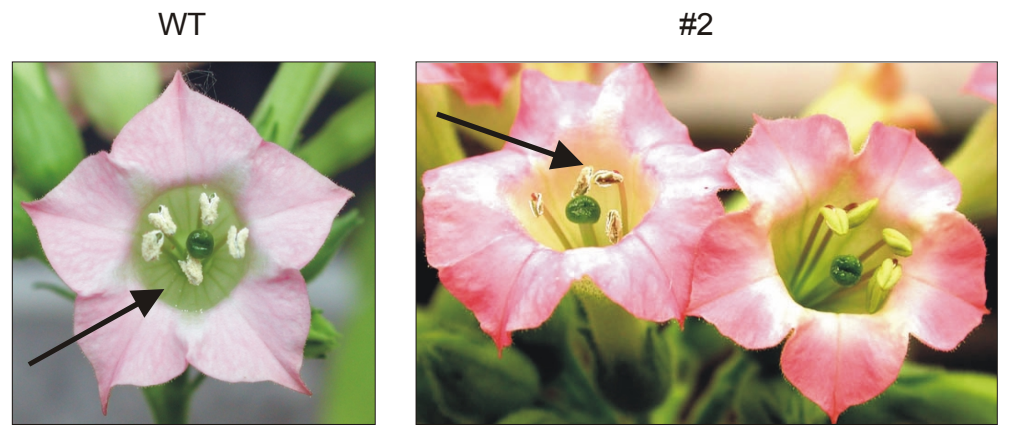

Abbildung 5-26: Vergleich der Blütenmorphologie der RNAi-Linie \#2 mit einer Wildtyppflanze. Die Pfeile deuten auf Staubblätter. Im Vergleich zur WT-Pflanze sind bei der transgenen Pflanze die Staubblätter vertrocknet, wodurch keine funktionsfähigen Pollen vorhanden ist. 
Die RNAi-Linie \#2 zeigt zudem eine Abweichung vom Wildtyp in Bezug auf die Blütenmorphologie (Abbildung 5-26). Zunächst entwickelt sich die Blüte mit den Staubblättern in der tga2.1RNAi-Pflanze \#2 ganz normal. Innerhalb weniger Stunden vertrocknen die Pollensäcke. Die Pflanze hat im Gegensatz zu der Wildtyppflanze keine funktionsfähigen Pollen, was zu einer Sterilität führt.

Zusammenfassend lässt sich sagen, dass die tga2.1RNAi-Pflanzen im SNN-Hintergrund, morphologische Abweichungen im Vergleich zu einer Wildtyppflanze zeigen, die besonders bei der Linie \#2 ausgeprägt sind. Die RNAi-Linien im SNN2.2UEHintergrund zeigen diese Veränderungen jedoch nicht. Diese Beobachtungen könnten darauf hindeuten, dass das Hormongleichgewicht (CHATFIELD et al., 2000) in den transgenen RNAi-Pflanzen gestört sein könnte bzw. dass der Klasse II-bZIPTranskriptionsfaktor TGA2.1 eventuell bei der Entwicklung der Pflanze wichtig sein könnte. Deswegen wurde im folgenden zunächst die Auxinantwort der transgenen Pflanzen im Vergleich zu einer Wildtyppflanze analysiert.

\subsubsection{Northern-Blot-Analyse auxininduzierbarer Gene in tga2.1RNAi-Pflanzen}

Die Funktion von TGA2.1 bei der auxinabhängigen Antwort sollte mit Hilfe der tga2.1RNAi-Pflanzen näher untersucht werden. In Zeitreihenexperimenten wurden Blattscheiben von Wildtyp- und RNAi-Pflanzen durch Aufschwimmen auf auxinhaltiger Pufferlösung inkubiert (Kapitel 4.2). Zwei verschiedene auxininduzierbare Gene, Nt103 und $N t G H 3$, wurden dann auf ihre Induzierbarkeit getestet. Von dem untersuchten Gen Nt103 ist bekannt, dass es ein $a s-1$-ähnliches Element im Promotor enthält (VAN DER ZAAL et al., 1987). Der Promotor des GH3-Gens aus Glycine max besitzt ein hex-1 Element, welches ein einzelnes TGACG-Motiv aufweist (LIU und LAM, 1994). Für den Promotor des GH3-Gens aus Nicotiana tabacum, der kürzlich isoliert werden konnte, ist bekannt, dass er $A C G T$-Motive aufweist, die ebenfalls als potentielle Bindemotive für bZIP-Transkriptionsfaktoren angesehen werden (DRÖGE-LASER, persönliche Mitteilung). Während Nt103 auch durch nicht aktive Auxinanaloga und Stressbedingungen induzierbar ist, ist das NtGH3-Gen spezifisch nur durch aktive Auxine induzierbar (Roux and PerRot-RechenmanN, 1997). 

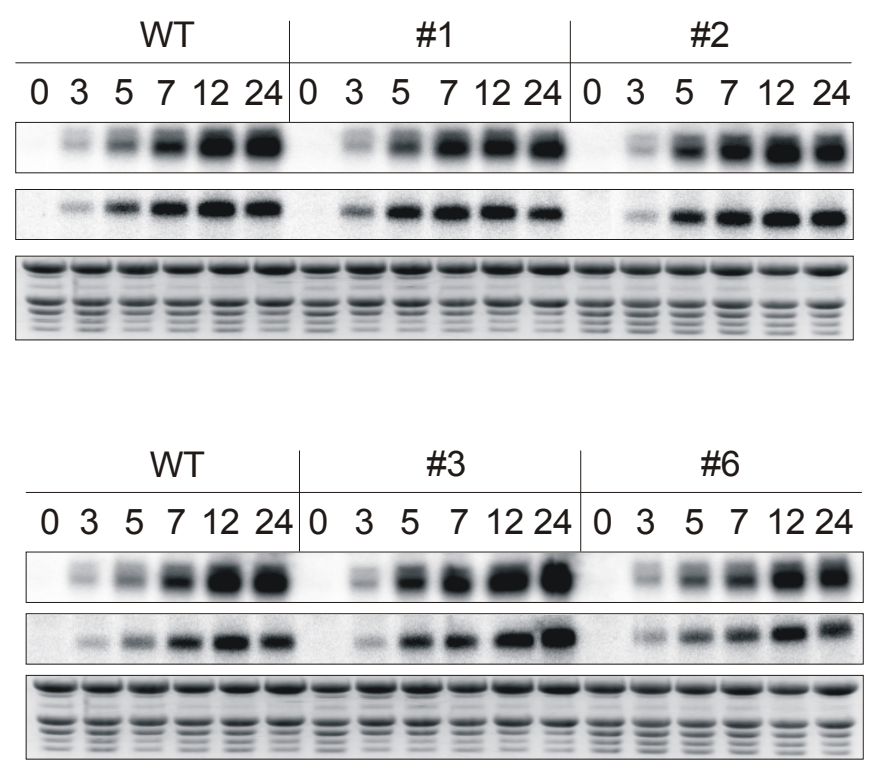

[h] nach Induktion

Nt103

$\mathrm{NtGH3}$

$\mathrm{EtBr}$
Nt103

$\mathrm{NtGH3}$

$\mathrm{EtBr}$

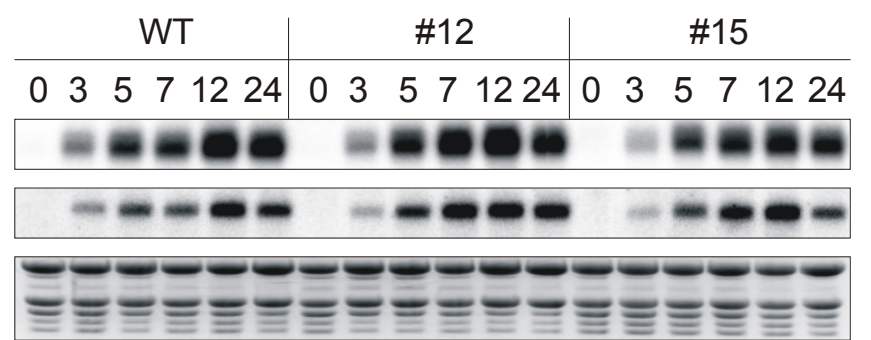

WT

\begin{tabular}{|c|c|c|}
\hline WT & \#29 & \#30 \\
\hline \begin{tabular}{llllll|}
0 & 3 & 5 & 7 & 12 & 24
\end{tabular} & $\begin{array}{llllll}0 & 3 & 5 & 7 & 1224\end{array}$ & $\begin{array}{llllll}0 & 3 & 5 & 7 & 12 & 24\end{array}$ \\
\hline $\mathrm{sec}$ & - $=00$ & is a \\
\hline$-\pi-\infty-\infty$ & $-0-00$ & ---100 \\
\hline
\end{tabular}

[h] nach Induktion

Nt103

$\mathrm{NtGH3}$

$\mathrm{EtBr}$

[h] nach Induktion

Nt103

$\mathrm{NtGH3}$

$\mathrm{EtBr}$

Abbildung 5-27: Einfluss der Nttga2.1-Expression auf die Auxininduktion von Nt103 und NtGH3 (Northern-Blot-Analyse). Blattscheiben von vier bis sechs Wochen alten Pflanzen wurden mit $50 \mu \mathrm{M}$ Auxin für die oberhalb der Spuren angegebene Zeit inkubiert. Für jeden Schritt wurden $10 \mu \mathrm{g}$ GesamtRNA analysiert. Rechts ist aufgeführt, mit welcher radioaktiv markierten Sonde die Membran jeweils hybridisiert wurde. Für die Beladungskontrolle ist unten die Ethidiumbromidfärbung der geblotteten RNA dargestellt (EtBr). (a) zeigt die Induktion für Pflanzen in SNN-Hintergrund; (b) zeigt die Induktion für Pflanzen im SNN2.2UE-Hintergrund. 
Die Gene Nt103 und NtGH3 zeigen dieselbe Kinetik. Die Expression setzt langsam nach drei Stunden ein, steigt dann transient an und erreicht das Maximum nach 12 Stunden. KEGLER (2001) hatte gezeigt, dass eine Überexpression des bZIP-Transkriptionsfaktors TGA2.1 in Tabakpflanzen nach Auxininkubation zu einer leicht erhöhten Expression (Faktor 1,5-2,0) des Zielgens NT103 führt. In zwei unabhängig voneinander durchgeführten Experimenten konnte jedoch gezeigt werden, dass eine Reduzierung der Menge des Transkriptionsfaktors TGA2.1 keinen Einfluss auf die Auxininduzierbarkeit des Gens NT103 hat (Abbildung 5-27). Zudem konnte auch kein Einfluss auf die Expression von $N t G H 3$ festgestellt werden. Die Zeitverläufe sehen für alle untersuchten Pflanzen gleich aus.

\subsubsection{Analyse der Auxinresponsivität von tga2.1RNAi-Pflanzen}

Die Reaktion einer Tabakpflanze auf externe Auxinzugaben kann mit Hilfe eines Tests, der die epinastische Krümmung von Blattstreifen in Puffer mit und ohne Auxinzugabe untersucht, (Keller und Van VolKenburg, 1997) bestimmt werden (Kapitel 4.3). Dazu wurden 10 x 1,5 mm große Streifen parallel zu den sekundären Blattadern mit einer Rasierklinge aus den Blättern geschnitten und in Puffer mit oder ohne Zugabe von $10 \mu \mathrm{M}$ 1-NAA für $24 \mathrm{~h}$ inkubiert. Die Ergebnisse sind in Abbildung 5-28 dargestellt. 
a) Ausgangspflanze: SNN

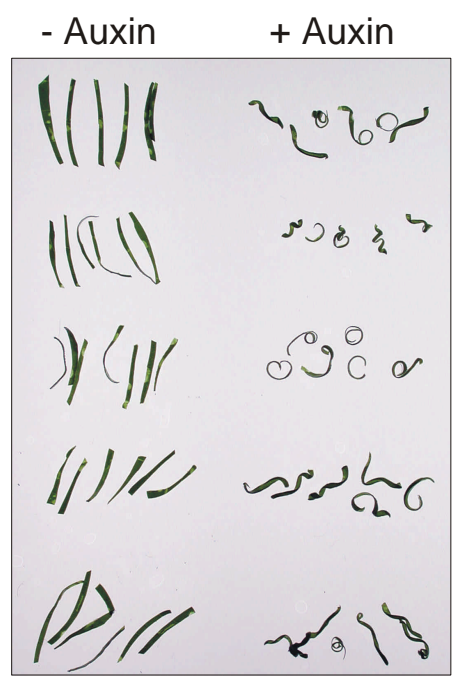

b) Ausgangspflanze: SNN2.2UE

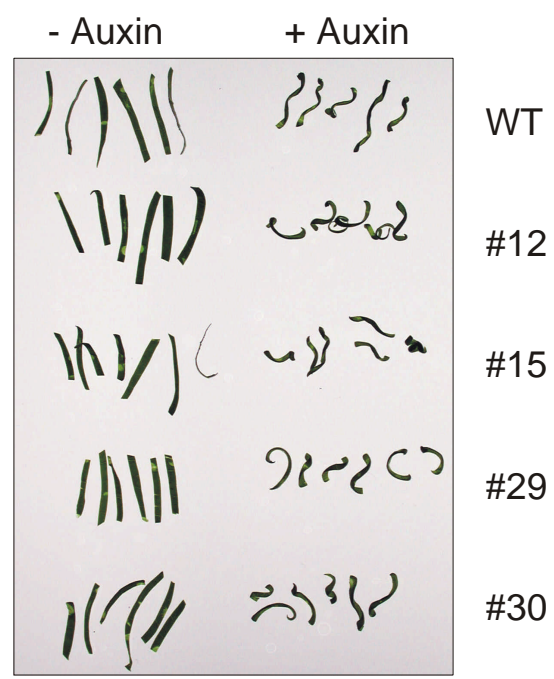

\begin{abstract}
Abbildung 5-28: Analyse der Auxinresponsivität von tga2.1RNAi-Pflanzen. 10 x 1,5 mm große Streifen wurden parallel zu den sekundären Blattadern mit einer Rasierklinge aus den Blättern geschnitten und in Puffer mit oder ohne Zugabe von $10 \mu \mathrm{M}$ 1-NAA für $24 \mathrm{~h}$ inkubiert. Anhand der epinastischen Krümmung der Blattstreifen kann die Reaktion der Pflanze auf externe Auxinzugaben bestimmt werden. (a): Untersuchung der Pflanzen im SNN-Hintergrund; (b): Untersuchung der Pflanzen im SNN2.2UEHintergrund. Rechts sind jeweils die verwendeten Linien aufgeführt.
\end{abstract}

Die Reduzierung der Menge des Transkriptionsfaktors TGA2.1 wirkt sich nicht auf die Auxinresponsivität der transgenen Pflanzen aus. Die epinastische Krümmung der Blattstreifen ist für alle Pflanzen gleich. Diese Beobachtung deckt sich mit den Ergebnissen der Northern-Blot-Analyse der auxininduzierbaren Expression der Gene $N t 103$ und $N t G H 3$. Die Überexpression von TGA2.2 zeigt ebenfalls keinen Einfluss auf die epinastische Krümmung der Blattstreifen.

\title{
5.2.5 Northern-Blot-Analyse salicylsäureinduzierbarer Gene in tga2.1RNAi- Pflanzen
}

Das Phytohormon Salicylsäure gilt als entscheidendes, regulatorisches Molekül der pflanzlichen Pathogenabwehr (DONG, 1998). Um die Funktion von TGA2.1 bei dieser Abwehrreaktion $\mathrm{zu}$ untersuchen, wurden Blattscheiben von Wildtyp- und RNAiPflanzen durch Aufschwimmen auf salicylsäurehältiger Pufferlösung inkubiert 
(Kapitel 4.2). Dadurch konnte ein Pathogenangriff simuliert werden. Zwei salicylsäureinduzierbare Gene, NT103 und PRla, wurden auf ihre Induzierbarkeit getestet. Von den untersuchten Genen ist bekannt, dass sie $a s-1$-ähnliche Elemente im Promotor enthalten (VAN DER ZAAL et al., 1987; PAYNE et al., 1988). Während NT103 zu den Genen der frühen Salicylsäureantwort gehört, zählt PRla zu den späten Genen (Kapitel 2.1). Bei dem frühen Gen Nt103 stieg die Transkriptmenge nach Zugabe von Salicylsäure transient an. Die Expression erreichte ihr Maximum nach drei Stunden und fiel danach ab. Das späte Gen PRla wurde erst nach sieben Stunden induziert. Die Expression stieg bis zum $12 \mathrm{~h}-$ Wert weiter an (Abbildung 5-29).

a) Ausgangspflanze: SNN

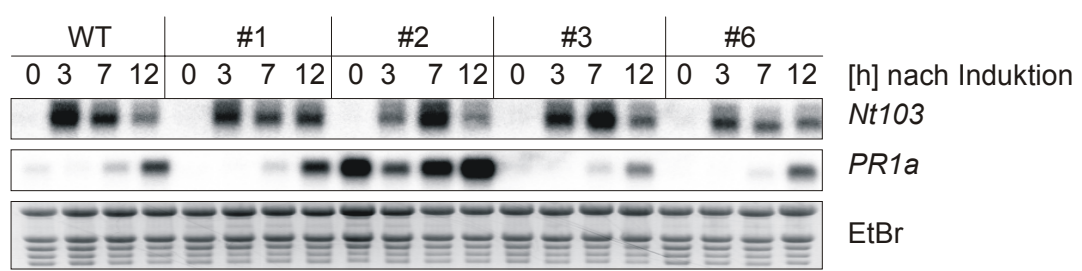

b) Ausgangspflanze: SNN2.2UE

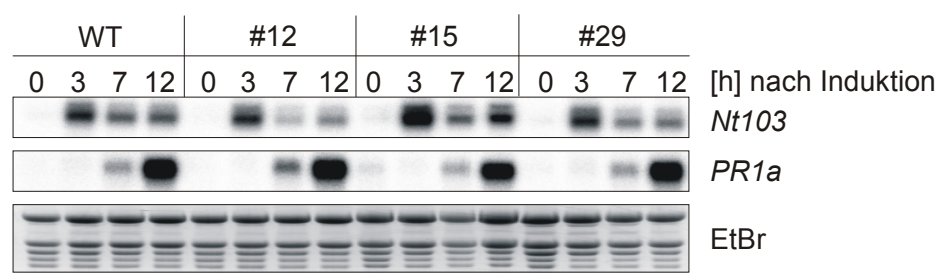

\begin{tabular}{|c|c|c|}
\hline WT & $\# 30$ & \\
\hline $\begin{array}{llll}0 & 3 & 7 & 12\end{array}$ & $\begin{array}{llll}0 & 3 & 7 & 12\end{array}$ & [h] nach Induktion \\
\hline $0=0$ & $=6$ & Nt103 \\
\hline$-\infty$ & $=0$ & PR1a \\
\hline$\equiv \equiv \equiv$ & $\equiv \equiv \equiv \equiv$ & $\mathrm{EtBr}$ \\
\hline
\end{tabular}

\footnotetext{
Abbildung 5-29: Einfluss der Nttga2.1-Expression auf die Salicylsäureinduktion von Nt103 und PR1a (Northern-Blot-Analyse). Blattscheiben von vier bis sechs Wochen alten Pflanzen wurden mit $1 \mathrm{mM}$ Salicylsäure für die oberhalb der Spuren angegebene Zeit inkubiert. Für jeden Schritt wurden $10 \mu \mathrm{g}$ Gesamt-RNA analysiert. Rechts ist aufgeführt, mit welcher radioaktiv markierten Sonde die Membran jeweils hybridisiert wurde. Für die Beladungskontrolle ist unten die Ethidiumbromidfärbung der geblotteten RNA dargestellt (EtBr). (a) zeigt die Induktion für Pflanzen in SNN-Hintergrund; (b) zeigt die Induktion für Pflanzen im SNN2.2UE-Hintergrund.
} 
Betrachtet man die Expression des frühen Gens Nt103 im SNN-Hintergrund, so erkennt man, dass das Maximum in den RNAi-Linien \#2 und \#3 nach hinten auf den 7 h-Wert verschoben ist. Zudem ist in der RNAi-Linie \#2 zusätzlich PRla konstitutiv an, in der Linie \#3 dagegen nicht. Eine parallele Untersuchung der Menge von TGA2.1 in denaturierten Gesamtzellextrakten mit Hilfe der Western-Blot-Analyse ergab, dass die TGA2.1-Menge zum Zeitpunkt der Salicylsäureinduktion nicht mehr reduziert war (Abbildung 5-30).

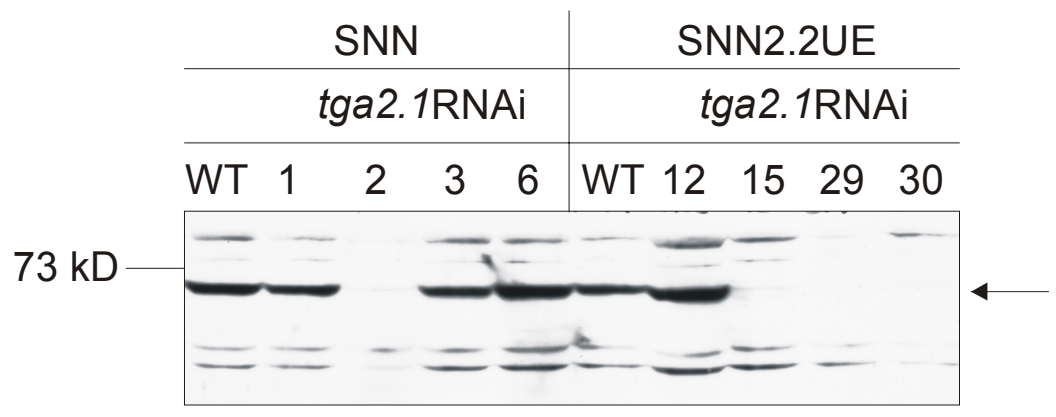

\begin{abstract}
Abbildung 5-30: Western-Blot-Analyse mit denaturierten Gesamtzellextrakten der transgenen Tabakpflanzen zum Nachweis von TGA2.1. Normalisierte Proteinmengen wurden mittels SDS-PAGE aufgetrennt und auf PVDF-Membranen geblottet. Die Proteine wurden im Immunoblot mittels des affinitätsaufgereinigten Antiserums gegen TGA2.1 detektiert. Die spezifische TGA2.1-Bande ist mit einem Pfeil gekennzeichnet.
\end{abstract}

Dieses Ergebnis bietet eine Erklärung dafür, dass in der Linie \#3 PRla nicht konstitutiv exprimiert wurde. Allerdings ist somit die veränderte Kinetik in den Linien \#2 und \#3 von Nt103 nicht auf die Reduzierung der TGA2.1-Menge zurückzuführen. Somit hat im Gegensatz zu den Daten, dass eine Überexpression des bZIP-Transkriptionsfaktors TGA2.1 in Tabakpflanzen nach Salicylsäureinduktion zu einer signifikant erhöhten Expression (Faktor 5) des Zielgens NT103 führt (KEGLER, 2001), eine Reduzierung der TGA2.1-Menge keinen Einfluss auf die Expression dieses Gens. Die konstitutive Expression des PRla-Gens für die Linie \#2 konnte in einem unabhängigen Experiment reproduziert werden. Für die transgenen RNAi-Pflanzen im SNN2.2UE-Hintergrund hatte die veränderte Transkriptmenge von tga2.1 weder einen Einfluss auf die Expression des frühen noch des späten Gens. Interessanterweise zeigen die Pflanzen 3-I und 3-II, die aus der transgenen Linie \#3 generiert worden sind, wieder eine reduzierte tga2.1mRNA-Menge (Abbildung 5-31). 


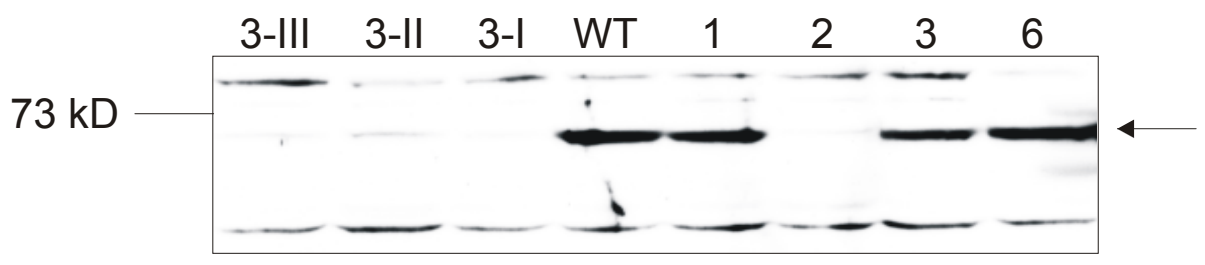

\begin{abstract}
Abbildung 5-31: Western-Blot-Analyse mit denaturierten Gesamtzellextrakten der transgenen Tabakpflanzen im SNN-Hintergrund zum Nachweis von TGA2.1. Normalisierte Proteinmengen wurden mittels SDS-PAGE aufgetrennt und auf PVDF-Membranen geblottet. Die Proteine wurden im Immunoblot mittels des affinitätsaufgereinigten Antiserums gegen TGA2.1 detektiert. Die spezifische TGA2.1-Bande ist mit einem Pfeil gekennzeichnet.
\end{abstract}

$\mathrm{Zu}$ unterschiedlichen Zeitpunkten wurden von diesen Linien Blattproben geerntet und in Bezug auf die PRIa-Expression analysiert. Diese Analyse ergab, dass PRla in der Linie 3-I nach längerer Zeit unter Klimakammerbedingungen im Vergleich zu der Linie \#2 schwach exprimiert wird. Bei der Linie 3-II ist zunächst PRla schwach detektierbar und nimmt im weiteren Verlauf ab (Abbildung 5-32). Für die Wildtyppflanze und die transgene tga2.1RNAi-Pflanze \#11 (Kapitel 5.2.1.1) konnte eine PRla-Expression nicht detektiert werden.

\begin{tabular}{|c|c|c|c|c|c|c|c|c|c|c|c|c|c|c|}
\hline \multicolumn{3}{|c|}{ WT } & \multicolumn{3}{|c|}{ I-3 } & \multicolumn{4}{|c|}{$3-11$} & \multicolumn{4}{|c|}{ \#11 } & \#2 \\
\hline 1 & 2 & 3 & 1 & 2 & 0 & & & 2 & 3 & & & 2 & 3 & \\
\hline 45 & & & & & & & & & & & & & & \\
\hline & & & & $=$ & & & & & & & & & - & I \\
\hline
\end{tabular}

\begin{abstract}
Abbildung 5-32: Einfluss der Nttga2.1-Expression auf die PRla-Expression (Northern-Blot-Analyse). Blattscheiben von RNAi-Pflanzen im SNN-Hintergrund wurden zu unterschiedlichen Zeitpunkten $(1,2,3)$ in Abstand von einer Woche geerntet und in Bezug auf die PRIa-Expression untersucht. Die Pflanze \#11 stammt aus dem ersten Transformationsansatz mit dem Konstrukt pMSK5 (Kapitel 5.2.1.1). Für jeden Schritt wurden $10 \mu \mathrm{g}$ Gesamt-RNA analysiert. Für die Beladungskontrolle ist unten die Ethidiumbromidfärbung der geblotteten RNA dargestellt (EtBr).
\end{abstract}




\subsubsection{Analyse der Abwehrreaktion der tga2.1RNAi-Pflanze \#2 nach einer TMV- Infektion}

Im Anschluss wurde nun die Reaktion der RNAi-Pflanzen \#2 auf eine TMV-Infektion untersucht. Die Infektion mit dem Tabak-Mosaik-Virus (TMV) führt über die $N$-Gen vermittelte Resistenz zur Auslösung einer ,hypersensitive response“ (HR) und in diesem Zusammenhang u. a. auch zur Expression von $P R$-Genen. Nachdem die Analyse salicylsäureinduzierbarer Gene gezeigt hatte, dass in der RNAi-Linie \#2 PR la sehr stark konstitutiv exprimiert wurde, war es interessant $\mathrm{zu}$ untersuchen, ob die Linie \#2 resistenter gegenüber einer TMV-Infektion als eine Wildtyppflanze ist. Dazu wurden sechs Wochen alte in Erde kultivierte Tabakpflanzen verwendet. Pro Blatt wurden $5 \mathrm{mg}$ TMV, suspendiert in $50 \mathrm{mM}$ Kaliumphosphatpuffer $\mathrm{pH}$ 7,0 mit Carborundum und Wattepads auf die Blattoberseite gerieben. Die infizierten Tabakpflanzen wurden in der Klimakammer weiterkultiviert (Kapitel 4.4). Nach neun Tagen wurden die Pflanzen erneut mit dem Tabak-Mosaik-Virus infiziert. Die Ergebnisse sind in Abbildung 5-33 dargestellt.
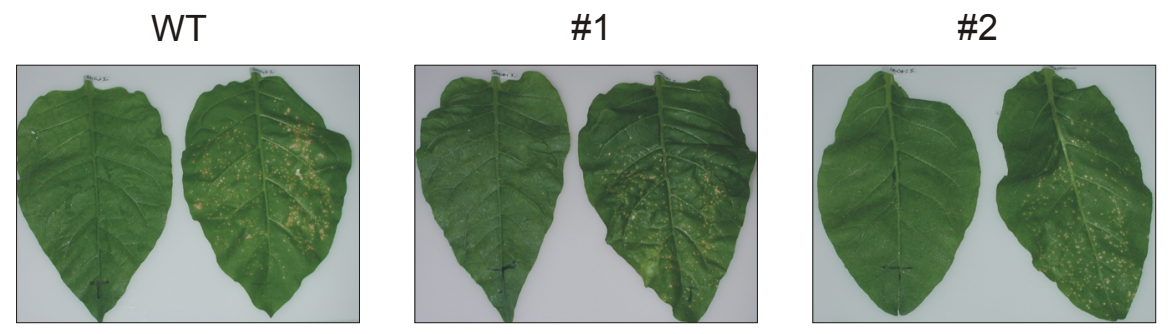

Abbildung 5-33: Untersuchung der Abwehrreaktion der RNAi-Linie \#2 nach einer TMV-Infektion. Es wurden 6 Wochen alte in Erde kultivierte Tabakpflanzen verwendet. Pro Blatt wurden $5 \mathrm{mg}$ TMV, suspendiert in $50 \mathrm{mM}$ Kaliumphosphatpuffer $\mathrm{pH}$ 7,0 mit Carborundum und Wattepads auf die Blattoberseite gerieben. Die infizierten Tabakpflanzen wurden in der Klimakammer weiterkultiviert. Linke ist die Primärinfektion, rechts die Sekundärinfektion dargestellt.

Zwischen der RNAi-Linie \#2 und den verwendeten Kontrollpflanzen (Linie \#1 und Wildtyp) konnte kein Unterschied in Bezug auf die Größe der Läsionen, entstanden durch das Absterben virusbefallener Zellen, und den Zustand der Pflanzen beobachtet werden. Eine Sekundärinfektion mit dem TMV-Virus nach neun Tagen machte auch keine Unterschiede sichtbar. Somit ist die RNAi-Linie \#2 gegenüber einer TMVInfektion nicht resistenter als eine Wildtyppflanze. 


\section{Diskussion}

\subsection{Verwendung des „Ubiquitin-based split-protein sensor systems“ zur Durchmusterung einer cDNA-Bank}

Um Proteine zu identifizieren, die mit den Komponenten des ASF-1-Komplexes interagieren und somit potentielle Regulatoren der as-1-vermittelten, salicylsäureinduzierbaren Genexpression sein könnten, wurde im Rahmen dieser Arbeit eine cDNA-Bank aus Tabakblättern hergestellt und durchgemustert. Als Köder diente der bZIP-Transkriptionsfaktor TGA2.1 aus Nicotiana tabacum, der im ASF-1-Komplex enthalten ist. Dieser zeichnet sich durch einen langen N-Terminus aus, der möglicherweise Interaktionsdomänen enthält. Da der bZIP-Transkriptionsfaktor TGA2.1 in Hefe als Aktivator fungiert (THUROW et al., 2001), konnte das HefeZweihybridsystem nicht verwendet werden. Deswegen wurde zur Identifizierung von Interaktionspartnern das „Ubiquitin-based split-protein sensor system“ (USPS) (JOHNSSON und VARSHAVSKY, 1994) für TGA2.1 etabliert. Dieses stellt eine gute Möglichkeit dar, um die Interaktion von transkriptionellen Regulatoren zu untersuchen, da die Identifizierung von potentiellen Interaktionspartnern nicht wie im HefeZweihybridsystem durch eine direkte Transkriptionsaktivierung von Reportergenen im Zellkern, sondern durch das Abspalten eines an das Ubiquitin fusioniertes Reporterprotein im Cytoplasma reguliert wird. Aus der Literatur sind viele Beispiele bekannt, wo dieses Hefesystem bereits erfolgreich zur Untersuchung bekannter Wechselwirkungen verwendet worden ist (STAGLJAR et al., 1998; DüNNWALD et al., 1999; Rojo-NiERSBACH et al., 2000; RAQUeT et al., 2001; REINDERS et al., 2002; SchUlZE et al., 2003). Zudem wurde dieses System auch bereits zur Durchmusterung einer cDNA-Bank verwendet (LASER et al., 2000).

Im „USPS-Screen“ wurde das Köderfusionsprotein TGA2.1L-Cub-Rura3 verwendet, welches aus dem bZIP-Transkriptionsfaktor TGA2.1, dem carboxyterminalen Teil des Ubiquitins ( $\mathrm{Cub}$ ) und dem Reporterprotein Rura3 besteht. Die Expressionsrate dieses 
Proteins wird über den $\mathrm{Cu}^{2+}$-induzierbaren Promotor Cup1 reguliert. Wird das Reporterprotein Rura3 ausreichend stark exprimiert, so sind die Hefezellen uracilprototroph und 5-FOA-sensitiv. Es ist bekannt, dass für die Expression einiger Fusionsproteine die Basalaktivität des $\mathrm{Cu}^{2+}$-induzierbaren Promotors ausreicht, um Uracilprototrophie und 5-FOA-Sensivität $\mathrm{zu}$ vermitteln (JOHNSSON, persönliche Mitteilung). Für andere Proteine dagegen ist es notwendig, die Expressionsrate durch die Zugabe von 0,1 mM bzw. 0,2 $\mathrm{mM} \mathrm{CuSO}_{4}$ zu steigern (STAGLJAR et al., 1998; LASER et al., 2000). Die indirekte Bestimmung der Expressionsrate des TGAL-Cub-Rura3Proteins durch das Wachstum der transformierten Hefezellen auf analytischem Medium (SD-URA) zeigte, dass erst bei sehr hohen $\mathrm{Cu}^{2+}$-Konzentrationen $(0,75 \mathrm{mM})$ die Uracilauxotrophie ausgeglichen werden kann (Kapitel 5.1.1.2). In diesen Vortests erwies sich, dass die Hefezellen trotz dieser hohen Kupferkonzentration wachsen konnten. Um den Stressfaktor Kupfer $\mathrm{zu}$ minimieren, wäre es sinnvoll, eine verbesserte Expressionsrate z. B. durch die Verwendung einzelner Domänen von TGA2.1 als Köder zu erreichen.

Um eine repräsentative Menge von cDNAs $\mathrm{zu}$ analysieren, sollte eine Transformationseffizienz von $5 \times 10^{5}$ erreicht werden. Dadurch wird gewährleistet, dass eine hohe Anzahl der vorhandenen cDNAs des Tabakgenoms analysiert wird. Im „USPS-Screen“ wurden allerdings insgesamt nur 1 x $10^{5}$ Transformanden getestet. Von diesen Transformanden konnten 238 Hefeklone unter den entsprechenden Selektionsbedingungen wachsen, d. h. sie waren 5-FOA-resistent. Von diesen Klonen zeigten jedoch nur 23 Klone (9,7 \%) zusätzlich einen uracilauxotrophen Phänotyp. Aus einigen dieser verbliebenen Klone konnten mehrere Bankplasmide isoliert werden, die sich durch die Größe des cDNA-Inserts unterscheiden. Die Sequenzanalyse (Kapitel 5.1.3) der cDNA-Insertionen (insgesamt 29) ergab, dass hauptsächlich kodierende cDNAs inseriert worden waren. Allerdings wurden auch fünfmal Poly(A)Sequenzabschnitte inseriert. Unter den kodierenden cDNAs waren zudem einige dabei, deren abgeleitete Proteine offensichtlich nicht als Interaktionspartner des pflanzlichen bZIP-Transkriptionsfaktors TGA2.1 in Frage kamen. Kriterien dafür waren die Lokalisierung und die in vivo-Funktion des homologen Proteins. Dazu gehörten u. a. die Malonyl-CoA-Decarboxylase (Mensch), das Keratin-assoziierte Protein 6-2 (Maus), der Translationsinitiationsfaktor IF-2 (Erbse) und das PSI-D2-Protein (Tabak). 
Anschließend wurde die Interaktion der verbliebenen Klone mit TGA2.1 verifiziert. Dazu wurden die Klone zusammen mit dem Köder in den Hefezellen exprimiert. Mit Hilfe eines „Growth Assays“ wurden die Transformanden auf Uracilauxotrophie getestet. Anhand dieses Experimentes konnten drei weitere Klone als „falsch“ positiv identifiziert werden. Mit den verbliebenen Klonen wurde im Anschluss ein „Growth Assay“ durchgeführt, bei dem das unspezifische Köderprotein Ssh1, ein ERMembranprotein aus Hefe, verwendet wurde. Dadurch konnten sechs weitere „falsch“ positve Klone identifiziert werden (zur Übersicht siehe Kapitel 5.1.3, Abbildung 5-9). Somit blieben von den ursprünglichen 238 Klonen nur vier Klone übrig. Die cDNAs dieser Klone kodieren für Proteine, die eine Homologie zu einer „Metal-transporting P-type ATPase“ aus Arabidopsis thaliana, einer DEAD-Box-RNA-Helicase aus Arabidopsis thaliana und zum „Ubiquitin carrier protein 4“ aus Glycine max aufweisen. Die DEAD-Box-RNA-Helicase wurde zweimal identifiziert.

Die Charakterisierung der Bankklone, 238 Klone aus 1 x $10^{5}$ Transformanden, hat gezeigt, dass das USPS als effizienter Ansatz für einen „Bankscreen“ nicht so gut geeignet war, da der Hintergrund, d. h. das Wachstum „falsch“ positiver Hefeklone, sehr hoch gewesen ist. Eine Möglichkeit den Hintergrund zu drücken, wäre die Verwendung anderer Nub-Varianten. Im Rahmen dieser Arbeit wurde NubI verwendet, welches an Position 13 ein Isoleucin besitzt. Diese Variante hat eine größere Affinität zum carboxyterminalen Teil des Ubiquitins als NubA oder NubG, die ein Alanin bzw. Glycin an Position 13 besitzen (Johnsson und VARShavsKy, 1994). Die Verwendung einer dieser beiden Varianten könnte dazu führen, dass die Wiederherstellung des Ubiquitins und das damit verbundene Abspalten des Reporterproteins vom carboxyterminalen Teil nur durch die Assoziation von zwei interagierenden Proteinen vermittelt wird und nicht unspezifisch durch eine vorhandene Affinität zwischen NubI und Cub. Zuvor konnte gezeigt werden, dass die Affinität zwischen dem unfusionierten NubI und Cub zu gering ist, um den Interaktionsphänotyp zu vermitteln (Kapitel 5.1.4). Jedoch kam es durch die Fusion von NubI an bestimmte cDNA-Sequenzen, z. B. an einen Poly(A)-Schwanz, zum Wachstum auf 5-FOA-Platten bzw. zu Uracilauxotrophie. Diese Fusion könnte die 34 aa große Domäne NubI stabilisieren, wodurch die Wahrscheinlichkeit einer Interaktion mit Cub höher wird. Eine andere Möglichkeit den Hintergrund des „Bankscreens“ zu reduzieren, wäre die Verwendung eines anderen Reporterproteins. In dieser Arbeit wurde URA3 (Kapitel 5.1.1.1) als Reportergen verwendet. Wird es in den Hefezellen 
exprimiert, so zeichnen sich die Zellen durch einen uracilprototrophen und 5-FOAsensitiven Phänotyp aus. Vortests hatten gezeigt, dass die 5-FOA-Selektion nicht so stringent ist wie die Uracilselektion (Kapitel 5.1.1.2). Da jedoch eine Proteininteraktion in den Hefezellen Uracilauxotrophie vermittelt, kann dieser Marker in einem „Screen“ nicht verwendet werden. Er eignet sich nur zum Nachtesten der Hefeklone. Ein Beispiel für ein alternatives Reporterprotein ist das Fusionsprotein PLV, bestehend aus ProteinA, LexA und der konstitutiven Aktivierungsdomäne des viralen Proteins 16 (VP16). Das Fusionsprotein diffundiert nach Abspaltung vom carboxyterminalen Teil des Ubiquitins in den Zellkern und bindet dort an einen LexA-abhängigen Promotor, wodurch die Expression von Reportergenen (HIS3, lacZ) induziert wird (STAGLJAR et al., 1998).

Ein weiterer Nachteil des USPS mit Rura3 als Reporterprotein bestand darin, dass zur Überprüfung 5-FOA-resistenter Klone diese nicht direkt auf Medium ohne Zusatz von Uracil überführt werden konnten. Es musste stets ein „Growth Assay“ (Kapitel 4.8.6.1) durchgeführt werden, um einen eindeutigen Phänotyp zu bekommen. Dazu wurden die Zellen über Nacht in Plasmidselektionsmedium angezogen, die Zellzahl der Kultur bestimmt und unterschiedliche Verdünnungsstufen $\left(10^{5}\right.$ bis $\left.10^{2}\right)$ auf analytisches Medium aufgetropft. Diese Methode hat den Nachteil, dass sehr viel Zeit erforderlich ist, um die Hefezellen zu charakterisieren. Könnte man die Hefezellen nach der Transformation direkt auf Interaktionsmedium ausplattieren, oder bereits transformierte Zellen direkt auf Interaktionsmedium überführen, könnten in derselben Zeit sehr viel mehr Hefezellen charakterisiert werden.

In der Literatur ist bis heute nur ein Beispiel bekannt, bei dem das USPS zum Durchmustern einer cDNA-Bank verwendet worden ist. LASER et al. (2000) hatten ebenfalls mit dem „Ubiquitin-based split-protein sensor system“ und Rura3 als Reporterprotein „Bankscreens“ durchgeführt. Bei ihnen diente als Köderprotein GAL4, ein Transkriptionsaktivator, bzw. TUP1, ein Repressor der Transkription aus Hefe. Insgesamt wurden $5 \times 10^{4}$ bzw. 1 × $10^{5}$ Transformanden analysiert. Neben positiven Klonen (NHP6B für GAL4 und CDC73 für TUP1) wurden Klone, 16 von insgesamt 20 Klonen, identifiziert, die noch auf ihre biologische Relevanz hin getestet werden müssen. Zudem führte die Verwendung des USPS zur Identifizierung von „falsch“ positiven Klonen. Dazu gehören u. a. GOG5 und YMD8, kleine Molekültransporter, die eine Resistenz gegenüber 5-FOA vermitteln. Im „Screen“ konnten Proteine, wie z. B. 
GAL80, von dem bekannt ist, dass es im USPS mit GAL4 interagiert (LASER et al., 2000), nicht identifiziert werden.

Zusammenfassend lässt sich sagen, dass das „Ubiquitin-based split-protein sensor system“ eine Alternative zum Hefe-Zweihybridsystem darstellt. Es eignet sich gut, um potentielle Interaktionen von Proteinen zu verifizieren. Allerdings stellte es unter den gewählten Bedingungen keinen effizienten Ansatz für die Durchmusterung einer cDNABank dar.

\subsection{Identifizierung einer DEAD-Box-RNA-Helicase und einer E2- Ligase als potentielle Interaktionspartner des bZIP-Transkrip- tionsfaktors TGA2.1 mit Hilfe des „Ubiquitin-based split-protein sensor system"}

Mit Hilfe des USPS konnten vier Klone als potentielle Interaktionspartner des bZIPTranskriptionsfaktors TGA2.1 identifiziert werden. Dabei handelt es sich um Klon 117-1, Klon 172-16, Klon 175-1 und Klon 184-1.

Der Klon 117-1 kodiert für ein Protein, das eine 78 \%-ige Homologie zu einer „Metaltransporting P-type ATPase" aus Arabidopsis thaliana aufweist. Die Homologie erstreckt sich über die konservierte, 30 aa lange HMA-Domäne, die für den Transport von Schwermetallionen wichtig ist. P-Typ-ATPasen sind für den Transport von Ionen $\left(\mathrm{H}^{+}, \mathrm{Na}^{+} / \mathrm{K}^{+}, \mathrm{H}^{+} / \mathrm{K}^{+}, \mathrm{Ca}^{2+}\right)$, Schwermetallen und Lipiden in der Zelle zuständig. Die P-Typ-ATPasen-Familie zeichnet sich dadurch aus, dass für den Transport durch die Membran die Hydrolyse von ATP notwendig ist (BAXTER et al., 2003). Für die „Metaltransporting P-type ATPase“ aus Arabidopsis thaliana konnte gezeigt werden, dass diese ein aminoterminales, chloroplastidäres Transitpeptid aufweist. Wird das Gen, welches für dieses Protein kodiert, mutiert, führt das dazu, dass der pflanzliche Elektronentransport beeinträchtigt ist und die Kupferkonzentration in den Chloroplasten reduziert ist. Somit scheint dieses Protein eine wichtige Komponente des Kupfertransportsystems in Chloroplasten zu sein (SHIKANAI et al., 2003). Aufgrund 
dieser Funktion und der Lokalisierung im Chloroplasten kommt Klon 117-1 als Interaktionspartner des Transkriptionsfaktors TGA2.1 nicht in Frage.

Von Enzymen ist bekannt, dass diese als Cofaktoren Metallionen besitzen, die entweder für die katalytischen Funktion erforderlich sind, oder das Substrat an das Enzym binden. Die Expression des Köderproteins TGA2.1 wurde durch die Zugabe von $\mathrm{Cu}^{2+}$-Ionen induziert. Es ist vorstellbar, dass TGA2.1 über eine $\mathrm{Cu}^{2+}$-Brücke mit dem Klon 117-1, der eine HMA-Domäne besitzt, interagiert haben könnte. In bereits durchgeführten „Bankscreens“ mit TGA2.1 bzw. TGA2.2 als Köderprotein wurden sehr oft Proteine als Interaktionspartner identifiziert, die Metallionen binden (THUROW, 2001; HÜLPER, 2003). Allerdings erfüllten diese Proteine in der Zelle u. a. enzymatische Aufgaben und kamen so als Interaktionspartner von TGA2.1 ebenfalls nicht in Betracht.

Die Klone 172-16 und 175-1 wiesen identische cDNA-Insertionen auf, welche für ein 209 aa langes Protein kodieren. Dieses Ergebnis legt die Vermutung nahe, dass diese Klone aus einem einzigen Ursprungsklon entstanden sein müssen. Da sich beide Klone während der Nachtests stets identisch verhalten haben, spricht dies für die Spezifität der Interaktion mit TGA2.1. Das abgeleitete Protein weist eine 76 \%-ige Homologie zu dem carboxyterminalen Teil einer DEAD-Box-RNA-Helicase aus Arabidopsis thaliana auf. Mitglieder der DEAD-Box-Familie, die sich durch die charakteristische Sequenz AspGlu-Ala-Asp auszeichnen, kommen sowohl in Pro- und Eukaryoten vor. Sie spielen eine Rolle bei vielen Prozessen in der Zelle: Rekombination, Reparatur, Transkription, RNAProzessierung, Translation und posttranslationale Regulation (YAN et al., 2003). Ein Beispiel für die Regulation der Genexpression durch RNA-Helicasen, ist die Aktivierung der $C B F$-Genexpression. In Arabidopsis thaliana wird die Kältetoleranz der Pflanze mit Hilfe der CBF-Transkriptionsfaktoren reguliert. Die CBF-Proteine werden durch Kälteinduktion in der pflanzlichen Zelle exprimiert und binden anschließend an DRE/CRT-cis-Elemente in den Promotoren der COR/RD-Gene und aktivieren so deren Expression, was bei der Pflanze zu Kältetoleranz führt. Die Analyse der kältesensitiven Mutante los4-1, bei der die kälteinduzierte Expression der $C B F$-Gene unterbleibt, hat ergeben, dass die DEAD-Box-RNA-Helicase LOS4 ein positiver Regulator der CBFGenexpression ist (GoNG et al., 2002). Für den Transkriptionsfaktor c-Jun aus Säugetierzellen konnte gezeigt werden, dass eine direkte Interaktion zwischen einer DEAD-Box-RNA-Helicase und dem Transkriptionsfaktor zu einer Genaktivierung führt. 
Die DEAD-Box-RNA-Helicase RHII/Gu wurde als Interaktionspartner von c-Jun mit Hilfe der ,tandem affinity purification (TAP)-Methode (RIGAUT et al., 1999) isoliert (WestermarK et al., 2002). Nach Stimulus löst sich die Helicase aus den Nukleoli und liegt im Nukleoplasma vor, wo sie mit der aminoterminalen Aktivierungsdomäne von cJun interagiert, was zu einer c-Jun-abhängigen Genaktivierung führt. $\mathrm{Da}$ der Transkriptionsfaktor TGA2.1 dem Transkriptionsfaktor c-Jun sehr ähnlich ist und zusätzlich zumindest auch in Hefe eine aminoterminale Aktivierungsdomäne besitzt, wäre es denkbar, dass der Regulationsmechanismus aus Säugetierzellen auch auf pflanzliche Zellen übertragbar ist. Somit scheint Klon 175-1 ein interessanter Kandidat für die Regulation as-1-abhängiger Promotoraktivität zu sein.

Der Klon 184-1 wies eine 733 bp große cDNA-Insertion auf, die für ein 146 aa langes Protein kodiert. Dieses zeichnet sich durch eine 97 \%-ige Homologie zu dem „Ubiquitin carrier protein 4“, einer E2-Ligase, aus Glycine max aus. Die Homologie ist in diesem Fall sehr ausgeprägt und erstreckt sich fast über das gesamte Protein aus Glycine max und schließt das aktive Zentrum des Enzyms mit ein. Weitere Homologievergleiche zeigten, dass die E2-Ligase aus Glycine max den Klasse 2 E2-Ligasen UBC4, UBC5 und UBC6 aus Arabidopsis thaliana zuzuordnen ist. Diese Klasse zeichnet sich durch eine carboxyterminale Extension aus (BACHMAIR et al., 2001). E2-Ligasen katalysieren die kovalente Verknüpfung von Ubiquitin an Zielproteine. Eine aktivierte Ubiquitineinheit wird von einem Ubiquitin-aktivierenden Enzym (E1) zu einer E2-Ligase transferiert. Diese ligiert die Ubiquitineinheit dann direkt an das Zielprotein mit oder ohne Hilfe von spezifischen E3-Ligasen (SulLIVAN et al., 1994). Die Aufgabe von E3-Ligasen besteht darin, die Zielproteine zu den E2-Ligasen zu rekrutieren. Diese Ubiquitinylinierung kann entweder zum proteasomvermittelten Abbau des markierten Proteins, oder zur Aktivierung von Kinasen, zur Bestimmung eines Lokalisierungssignals und zur ,protein lipidation“ führen (PICKERT, 2001; ICHIMURA et al., 2000). Unter „protein lipidation“ versteht man einen Prozess, bei dem lösliche Proteine durch eine reversible Verknüpfung mit Lipiden membrangängig gemacht werden. Der proteasomvermittelte Abbau von Proteinen spielt eine wichtige Rolle bei einer großen Anzahl von Signalwegen in der Pflanze. Dazu gehört u. a. die Antwort der Pflanze auf Hormone, Licht und Pathogene. Bei der Abwehr von Pathogenen spielt u. a. das Signalosom SCF eine wichtige Rolle. Der SCF-Komplex gehört zur Familie der RING-Typ E3-Ligasen, die durch eine RING-Finger-Domäne charakterisiert sind. Diese dient als Andockstelle 
für E2-Ligasen (WEISSMANN, 2002). Das RING-Finger-Protein RBX1 ist die zentrale Komponente des SCF-Komplexes und interagiert direkt mit CULLIN1. SKP1 ermöglicht die Interaktion von CULLIN1 mit einem F-Box-Protein, welches das Zielprotein für die Ubiquitinylinierung zum SCF-Komplex rekrutiert. Die Funktion der beiden F-Box Proteine COI1 (,coronatine insensitive 1“) (XIE et al., 1998) und SON1 (,suppressor of nim1-1“) (KIM et al., 2002) bei der Abwehrreaktion der Pflanze ist gut untersucht. COI1 kontrolliert Abwehrreaktionen, die über Jasmonsäure reguliert werden. Jasmonsäure ist ein Signalmolekül, das bei der Reaktion der Pflanze auf abiotischen und biotischen Stress eine Rolle spielt (TURNER et al., 2002). Das F-Box-Protein SON1 reguliert dagegen eine induzierte Abwehrreaktion der Pflanze, die unabhängig von Salicylsäure und SAR ist (KIM et al., 2002). SON1 scheint im Gegensatz zu COI1 ein negativer Regulator der pflanzlichen Abwehrreaktion zu sein. Es konnte somit gezeigt werden, dass E3-Ligasen eine wichtige Rolle bei der Pathogenabwehr übernehmen (Devoto et al., 2003).

Der Transkriptionsfaktor TGA2.1, dem wahrscheinlich eine Aufgabe bei der Pathogenabwehr zukommt, interagiert im USPS ebenfalls mit einer Komponente des Ubiquitinylinierungsweges, einer E2-Ligase. Man kann sich vorstellen, dass die Ubiquitinylinierung des bZIP-Transkriptionsfaktors TGA2.1 einen wichtigen Regulationsmechanismus darstellt. PONTIER et al. (2002). konnten z. B. zeigen, dass die Proteinmengen von Klasse I TGA-Faktoren aus Arabidopsis thaliana in Blattzellen über den proteasomvermittelten Abbau reguliert werden. Für den Klasse II TGA-Faktor TGA2.1 konnte bis jetzt nach Salicylsäureinduktion kein Abbau des Proteins nachgewiesen werden (KEGLER, 2001).

Für den Repressor der Transkription TUP1 aus Hefe konnte mit Hilfe des „Ubiquitinbased split-protein sensor systems“ (JOHNSSON und VARSHAVSKY, 1994) ebenfalls die Interaktion mit der Klasse 2 E2-Ligase UBC1 detektiert werden (KERKMANN et al., 2001). KOYAMA et al. (2003) konnten für den pflanzlichen Transkriptionsfaktor ERF3 aus Nicotiana tabacum, der an der ethylenabhängigen Antwort der Pflanze beteiligt ist, im Hefe-Zweihybridsystem ebenfalls eine Interaktion mit einer Klasse 2 E2-Ligase, $N t \mathrm{UBC} 2$, nachweisen. Allerdings muss für diese beiden Interaktionen von transkriptionellen Regulationsproteinen mit E2-Ligasen die biologische Relevanz noch getestet werden. Aus der Literatur sind sehr viele Beispiele bekannt, bei denen die 
Ubiquitinylinierung von Proteinen über E3-Ligasen vermittelt wird. Somit müsste die Signifikanz der Interaktion zwischen der E2-Ligase und TGA2.1 noch überprüft werden.

Der nächste Schritt bestand nun darin, die Interaktion zwischen dem pflanzlichen bZIPTranskriptionsfaktor und seinen potentiellen Interaktionspartnern, der DEAD-BoxRNA-Helicase und der E2-Ligase, zu verifizieren. Im Rahmen dieser Arbeit wurde dazu bereits das Hefe-Zweihybridsystem verwendet. Für Klon 184-1, der für eine E2-Ligase kodiert, konnte beobachtet werden, dass eine Wechselwirkung mit TGA2.1 eine Reduktion der Reportergenexpression verursacht, was wiederum in einem verlangsamten Wachstum der Hefezellen resultiert. Weitere Tests im Hefezweihybridsystem haben zudem gezeigt, dass 184-1 ein spezifischer Partner von TGA-Faktoren mit Aktivierungsdomäne sein könnte (Kapitel 5.1.6), da für die TGAFaktoren TGA1a und TGA10 derselbe Effekt beobachtet werden konnte. Die Beobachtung, dass eine Koexpression von Klon 184-1 zusammen mit aktivierenden TGA-Faktoren in einer Reduzierung der Reportergenexpression resultiert, kann zum einen damit begründet werden, dass die Proteinwechselwirkung die Bindung der Proteine an die Promotoren der Reportergene negativ beeinflusst oder zum anderen dadurch, dass der durch die Proteinwechselwirkung entstandene Komplex nicht stabil ist. Diese Hypothesen wurden mit Hilfe des modifizierten „One-Hybrid“-Systems (SIEMSEN, 2002) überprüft (Kapitel 5.1.7). Ein Reportergenkonstrukt, bestehend aus drei as-1 Elementen und dem HIS3-Gen, wurde in das Hefegenom des Stammes YTSH1 integriert (Kapitel 3.7.1). Wird in diesem Stamm der TGA-Faktor TGA2.1 exprimiert, kann dieser an die as-1 Elemente binden und die HIS3-Expression induzieren. Bindet TGA2.1 nicht mehr an den Minimalpromotor, so sind die Hefezellen nicht in der Lage auf Medium ohne Histidin zu wachsen. Allerdings konnte in diesem Experiment eine Verminderung der Reportergenexpression nicht nachgewiesen werden, wodurch die aufgestellten Hypothesen nicht bestätigt werden konnten. Eine Erklärung der Reduzierung der Reportergenexpression im Hefe-Zweihybridsystem ist somit mit den vorliegenden experimentellen Daten leider nicht möglich.

Aufgrund der ermittelten Daten des Hefe-Zweihybridsystems und des modifizierten „One-Hybrid-Systems“, die teilweise im Widerspruch zu den USPS-Daten stehen, ist es sehr wichtig, die Signifikanz der Interaktion weiter $\mathrm{zu}$ untersuchen. Eine wichtige Möglichkeit die Interaktion zwischen der RNA-Helicase und der E2-Ligase mit TGA2.1 
zu verifizieren, stellt das „Pull-Down-Assay“ (KHOLOD und Mustelin, 2001) dar. Für diesen experimentellen Ansatz wird einer der beiden Interaktionspartner an GST fusioniert, der andere an einen „HIS-tag“. Beide Fusionsproteine werden anschließend in E. coli koexprimiert. Findet eine Interaktion zwischen diesen beiden Fusionsproteinen statt, dann werden diese gleichzeitig über GST mit Hilfe der Affinitätschromatographie aus dem E. coli-Extrakt isoliert. Die Interaktion kann im Anschluss mit Hilfe der Western-Blot-Analyse mit dem anti-HIS-Antikörper überprüft werden. Zudem wäre es interessant zu untersuchen, ob die DEAD-Box-RNA-Helicase wie die RHII/Gu-Helicase aus Säugetierzellen ebenfalls über eine induzierte Translokalisation aus dem Nukleolus in das Nukleoplasma reguliert wird. Dazu könnte man GFP-Fusionen herstellen und deren Lokalisierung im uninduzierten Zustand bzw. im induzierten Zustand mit Hilfe von Tabak-Mesophyllprotoplasten analysieren. Die Analyse transgener Tabakpflanzen, in denen die Expression des RNA-Helicase-Gens bzw. des E2-Ligase-Gens über den Mechanismus des „post transcriptional gene silencings“" vermindert ist (Kapitel 5.2.1), kann Hinweise über die Funktion dieser beiden potentiellen Interaktionspartner von TGA2.1 im Rahmen der as-1-abhängigen Promotoraktivität geben. Ein anderer Weg wäre die Analyse von Mutanten. Für viele Arabidopsis thaliana-Gene sind bereits „knock-out“-Mutanten identifiziert worden. Die „knock-out“-Mutante (SALK 062599) für das homologe At-Gen (At1g20920) der DEAD-Box-RNA-Helicase zeichnet sich durch eine T-DNA-Insertion im 3'-UTR aus. Bevor man jedoch von dem Tabaksystem in das Arabidopsis thaliana-System wechseln kann, müsste die Interaktion von der RNA-Helicase bzw. der E2-Ligase mit den homologen TGA-Faktoren, z. B. TGA3 (MiAO et al., 1994) aus Arabidopsis thaliana, der ebenfalls einen langen N-Terminus aufweist, verifiziert werden.

Zudem wäre es wichtig, noch weiter nach potentiellen Interaktionspartnern der TGAFaktoren zu suchen. Eine Alternative zu den Hefesystemen stellt die „tandem affinity purification“-(TAP)-Methode dar (RIGAUT et al., 1999). Der Vorteil dieser Methode im Vergleich zu den Hefesystemen besteht darin, dass die Proteine in ihrer natürlichen Umgebung der pflanzlichen Zelle miteinander interagieren. Das Protein von Interesse, z. B. TGA2.1, wird an zwei Ligandenbindedomänen, das Calmodulinbindepeptid und ProteinA, fusioniert. Das resultierende Fusionsprotein zeichnet sich durch eine hohe Affinität gegenüber Calmodulin und IgG-Antikörpern aus. Das Calmodulinbindepeptid und das ProteinA sind separiert durch eine Erkennungssequenz der TEV-(,,tobacco etch 
virus“)-Protease. Diese dient dazu, das Fusionsprotein durch proteolytische Elution von dem IgG-Antikörper, der an eine Matrix gebunden ist, abzukoppeln. Das markierte Protein, welches in einem Komplex mit interagierenden Faktoren vorliegt, kann somit aus Gesamtzellextrakten durch zwei aufeinander folgende Affinitätschromatographieschritte aufgereinigt werden.

\subsection{Stabilität des RNAi-Effektes in transgenen Pflanzen}

Da die Klasse II TGA-Faktoren TGA2.1 und TGA2.2 aus Nicotiana tabacum als Bestandteile von ASF-1 identifiziert werden konnten (NIGGEWEG et al., 2000b), sollte die in vivo-Funktion des Transkriptionsfaktors TGA2.1 untersucht werden.

Zur Analyse sollten transgene Pflanzen hergestellt werden, in denen die Expression des Nttga2.1-Gens vermindert ist. Dazu wurden spezielle DNA-Konstrukte in die Pflanzen eingebracht, die durch doppelsträngige RNA-Interferenz (RNAi; CHUANG et al., 2000) zu posttranskriptionellem Abschalten (PTGS, ,post transcriptional gene silencing“) des Nttga2.1-Gens führen sollten. Im Rahmen dieser Arbeit wurden zwei verschiedene Konstrukte verwendet. Basierend auf der Arbeit von WATERHOUSE et al. (1998) wurde ein RNAi-Konstrukt hergestellt, bei dem die konstitutive Expression der vollständigen Kodierregion der tga2.1-cDNA in korrekter und entgegengesetzter Orientierung unabhängig voneinander stattfindet (Kapitel 5.2.1.1). Mit Hilfe dieses Ansatzes konnten nur zwei transgene Linien identifiziert werden, bei denen sowohl die Transkriptmenge als auch die Proteinmenge von TGA2.1 deutlich reduziert waren. Um weitere unanhängige transgene RNAi-Pflanzen zu bekommen, wurde ein anderes Konstrukt verwendet, welches einen 257 bp-großen Teilbereich der Kodierregion der tga2.1-cDNA sowohl in entgegengesetzter als auch in korrekter Orientierung unter Kontrolle eines konstitutiven Promotors enthält (WATERHOUSE et al., 2000). Zwischen den beiden Orientierungen ist ein Intron lokalisiert. Konstrukte mit einem Intron zwischen den beiden gegenläufigen Sequenzabschnitten sind nach SMITH et al. (2000) besonders wirksam. Dieser Ansatz erwies sich als sehr erfolgreich. Es konnten Transformanden isoliert werden, die eindeutig eine Reduzierung der tga2.1-Transkriptmenge und der TGA2.1-Proteinmenge aufwiesen (Kapitel 5.2.1.2). Zudem konnte auch nachgewiesen 
werden, dass durch die Verwendung des RNAi-Konstruktes die Transkriptmenge des verwandten TGA-Faktors TGA2.2 nicht beeinflusst war.

Im Rahmen der Analysen der transgenen Pflanzen konnte zum einen beobachtet werden, dass sich der RNAi-Effekt auch erst nach längerer Zeit ausprägen kann, und zum anderen, dass in Pflanzen, die zunächst eindeutig eine Reduzierung der TGA2.1-Menge aufwiesen, wieder die WT-TGA2.1-Menge detektiert werden konnte.

Ein Beispiel dafür, dass sich der RNAi-Effekt erst nach längerer Zeit ausprägen kann, sind die Linien im SNN.2UE-Hintergrund \#29 und \#30. Diese zeigten in der Primäranalyse, d. h. bei der Bestimmung der Nttga2.1-Transkriptmenge mit Hilfe der Northern-Blot-Analyse, keine Reduzierung der Nttga2.1mRNA-Menge (Kapitel 5.2.1.2; Abbildung 5-20). Somit wurden diese als transgene Kontrollpflanzen für weitere Analysen verwendet. Die Bestimmung der TGA2.1-Proteinmenge mit Hilfe der Western-Blot-Analyse und Gelretardationsexperimenten zeigte, dass mittlerweile auch diese Pflanzen eine reduzierte TGA2.1-Proteinmenge aufwiesen. Nach dem Modell von WATERHOUSE et al. (1998) ist ein Schwellenwert von ds RNA in den Zellen notwendig, um PTGS zu induzieren. Somit wäre eine mögliche Erklärung, dass in diesen Pflanzen zum Zeitpunkt der ersten Analyse noch nicht ausreichende Mengen an ds RNA, hervorgerufen durch die Expression des eingebrachten Konstruktes, vorhanden gewesen sind, um PTGS zu induzieren.

Eine andere Beobachtung war, dass in transgenen Pflanzen, die zunächst eine Reduzierung der tga2.1-Transkriptmenge zeigten, später wieder WT-Mengen von TGA2.1 detektierbar waren. Ein Beispiel dafür ist die transgene Linie \#12 im SNN2.2UE-Hintergrund. Diese zeigte bei der Primäranalyse (Kapitel 5.2.1.2; Abbildung 5-20) eine Verminderung der Nttga2.1mRNA-Menge. Jedoch konnte für diese Linie in allen weiteren Experimenten stets TGA2.1 nachgewiesen werden (Kapitel 5.2.1.2; Abbildung 5-22 und 5-23). Dieser Effekt war auch für die Linie \#11 im SNNHintergrund, die aus dem ersten Transformationsansatz mit dem Konstrukt pMSK5 resultiert (Kapitel 5.2.1.1) zu beobachten. Es wäre vorstellbar, dass unter bestimmten Umweltbedingungen, denen die transgenen Pflanzen ausgesetzt sind, der RNAi-Effekt reprimiert wird. Dieses könnte dadurch ermöglicht werden, dass die Expression des Transgens unterdrückt wird. Dieser Mechanismus könnte dazu führen, dass das durch das RNAi-Konstrukt hervorgerufene ,post transcriptional gene silencing“ unterbleibt. 
Für die Linie \#3 im SNN-Hintergrund war zudem noch eine andere Besonderheit zu beobachten. Zunächst war der RNAi-Effekt stark und konstant ausgeprägt (Kapitel 5.2.1.2). Jedoch zeigte diese Pflanze nach längerer Zeit wieder die WT-TGA2.1-Menge (Kapitel 5.4.5; Abbildung 5-30). Wurden jedoch aus Blattstücken dieser transgenen Linie neue Pflanzen generiert, dann zeigten diese (Linien \#3-I, \#3-II und \#3-III) wieder eine stark reduzierte TGA2.1-Menge (Kapitel 5.2.5; Abbildung 5-31). Dieses zeigt, dass die Generation der neuen Pflanzen, welche genetisch identisch zu der Ausgangspflanze sind, dazu beigetragen hat, dass der RNAi-Effekt sich wieder ausprägen konnte.

Interessanterweise konnte die Instabilität des RNAi-Effektes nur in den transgenen SNN-Pflanzen und nicht in den transgenen SNN2.2UE-Pflanzen beobachtet werden. Es ist $\mathrm{zu}$ vermuten, dass das ,post transcriptional gene silencing“ von TGA2.1 durch die Überexpression des Transkriptionsfaktors TGA2.2 stabilisiert werden kann.

Für den bZIP-Transkriptionsfaktor TGA5 aus Arabidopsis thaliana wurde ebenfalls versucht, transgene Pflanzen herzustellen, in denen die Menge von TGA5 reduziert ist (Kim und Delaney, 2002). Für diesen Ansatz wurde im Gegensatz zu dieser Arbeit die tga5-cDNA nur in entgegengesetzter Orientierung in den Pflanzen exprimiert. Interessanterweise zeigten die transgenen Pflanzen eine sehr starke Erhöhung der tga5Transkriptmenge. Eine Akkumulierung von tga5-,,antisense“-RNA konnte nicht nachgewiesen werden. Dieses Beispiel verdeutlicht ebenfalls, dass es schwierig ist, transgene Pflanzen herzustellen, in denen die Transkriptmenge eines Gens stabil reduziert ist. Im Rahmen der Arbeiten unsere Arbeitsgruppe wurde der Ansatz von WATERHOUSE et al. (2000) erfolgreich verwendet, um die Expression anderer Tabakgene posttranskriptionell zu reduzieren. Leider liegen noch keine weiteren Daten zu diesen RNAi-Pflanzen vor, die etwas über die Stabilität des RNAi-Effektes aussagen könnten. 


\subsection{Auswirkung der reduzierter TGA2.1-Mengen auf die Expression von Nt103 und PRIa}

Das Wissen über pflanzliche Gene, deren Expression von TGA-Faktoren reguliert werden könnte, ist begrenzt. As-1-ähnliche Elemente vermitteln Genexpression bevorzugt in Wurzeln und als Antwort auf Hormone und xenobiotischen Stress (LIU und LAM, 1994; XIANG et al., 1996). Viele Arbeiten haben gezeigt, dass TGA-Faktoren die Expression von einigen Glutathion-S-Transferase-Genen regulieren können (DROOG et al., 1995; LIU und LAM, 1994; XIANG et al., 1996). Somit war es interessant zu untersuchen, ob auch die Klasse II TGA-Faktoren TGA2.1 und TGA2.2 an der Regulation des Nt103-Gens beteiligt sein könnten. In früheren Arbeiten konnte gezeigt werden, dass eine Überexpression der Klasse II TGA-Faktoren TGA2.1 und TGA2.2 eine verstärkte Nt103-Expression nach Auxin- und Salicylsäurebehandlung (KEGLER, 2001) vermittelt. Pflanzen, die ein Fusionsprotein, bestehend aus der konstitutiven Aktivierungsdomäne des viralen Proteins 16 und dem TGA-Faktor, überexprimieren, zeigten ebenfalls eine verstärkte Expression dieses Gens nach Salicylsäurebehandlung (LENK, 2001). Wird eine dominant negative TGA-Variante, die nicht mehr an die DNA binden kann, in den Zellen exprimiert, so wird die salicylsäureabhängige Expression von Nt103 reduziert (Niggeweg, 2000b; Kegler, 2001). Die Analysen der Überexpressionspflanzen sowie der transgenen Pflanzen, die eine dominant negative TGA-Variante exprimieren, deuten darauf hin, dass die beiden Klasse II TGA-Faktoren TGA2.1 und TGA2.2 in ihrer Funktion in Bezug auf die Regulation des NT103-Gens redundant sind. Im Rahmen dieser Arbeit wurden die Nt103-Expression nach Auxinund Salicylsäurebehandlung in den tga2.1RNAi-Pflanzen im Vergleich zu Kontrollpflanzen untersucht.

Es konnte gezeigt werden, dass eine Reduzierung der TGA2.1-Menge keinen Einfluss auf die auxin- und salicylsäureinduzierte NT103-Genexpression hat (Kapitel 5.2.3 und Kapitel 5.2.5). Ein Grund dafür könnte die vermutete Redundanz der TGA-Faktoren sein. Es ist vorstellbar, dass die Funktion von TGA2.1 in transgenen RNAi-Linien von TGA2.2 übernommen werden könnte. Im Gegensatz zu den RNAi-Linien kommt es in den Suppressorpflanzen zu einer Reduzierung der Nt103-Expression. Da KEgLER (2001) 
zudem zeigen konnte, dass in diesen Pflanzen die ASF-1-Bindeaktivität reduziert ist, könnte man postulieren, dass durch die Interaktion mit der dominant negativen Variante von TGA2.1 bindeaktive TGA-Faktoren, z. B. TGA2.2, an der DNA-Bindung inhibiert werden. Zusammenfassend lässt sich somit sagen, dass TGA2.1 anscheinend für die auxin- und salicylsäureabhängige Regulation des as-1-abhängigen Promotors des Nt103Gens nicht essentiell ist.

Ein anderes Set von Genen, deren Expression von TGA-Faktoren reguliert werden kann, sind die Gene, die für PR-Proteine kodieren, wie z. B. PRI aus Arabidopsis thaliana und PRla aus Nicotiana tabacum. Bei PR-Proteinen handelt es sich um saure, extrazelluläre bzw. basische, vakuoläre Proteine. Einige zeigen antimikrobielle Aktivität, bei anderen handelt es sich um hydrolytische Enzyme. Der PRl-Promotor besitzt zwei TGACGElemente (LEBEL et al., 1998), an die der Klasse II TGA-Faktor TGA2 aus Arabidopsis thaliana binden kann (DEPRÉS et al., 2000). STROMPEN et al. (1998) konnten im PRlaPromotor ein salicylsäureresponsives Element, welches zwei TGACG-Motive aufweist, detektieren. Promotoranalysen haben nachgewiesen, dass die $T G A C G$-Motive für die Salicylsäureinduzierbarkeit der PR-Gene aus Arabidopsis und Tabak, PRI und PRla, essentiell sind (LeBel et al., 1998; Strompen et al., 1998). Niggeweg (1999) und KEGLER (2001) konnten zeigen, dass die Überexpression der beiden Klasse II TGAFaktoren TGA2.2 und TGA2.1 keinen Einfluss auf die PR1a-Genexpression hat. Zudem führt nur die Expression der dominant negativen Variante von TGA2.2 zu einer Reduzierung der ASF-1-Bindeaktivität und somit zu einer Verringerung der PRlaGenexpression. PONTIER et al. (2001) konnten dagegen zeigen, dass die Expression einer dominant negativen Variante von TGA2 zum vollständigen Verlust der ASF-1-Aktivität führt, was eine erhöhte PRl-Genexpression zur Folge hat. Aufgrund dieser Daten kann postuliert werden, dass es in der pflanzlichen Zelle negativ und positiv wirkende TGAFaktoren gibt. Die erhöhte PRla-Expression ist auf die vollständige Reduzierung des negativen TGA-Pools zurückzuführen, wodurch der positiv wirkende TGA-Pool sehr stark begünstigt wird. Die Reduzierung der PRla-Genexpression kommt dadurch zustande, dass aktivierende TGA-Faktoren mit der dominant negativen Variante von TGA2.2 Heterodimere bilden können und so an der DNA-Bindung gehindert werden. Hinweise darauf, dass Klasse II TGA-Faktoren negativ auf die PRl-Expression wirken können, geben die Experimente von KIM und DELANEY (2002) in Arabidopsis thaliana. 
Eine Erhöhung der tga2- und tga5-Transkriptmenge führt zu einer Reduzierung der PR1-Expression.

Im Rahmen dieser Arbeit wurde untersucht, welchen Einfluss die Reduzierung der Menge des Klasse II TGA-Faktors TGA2.1 auf die salicylsäureabhängige PRlaExpression hat.

Interessanterweise zeigten die transgenen RNAi-Pflanzen im Gegensatz zu den Kontrollpflanzen eine PRla-Expression im uninduzierten Zustand. Bei der Linie \#2 ist dieser Effekt sehr stark ausgeprägt, bei der Linie \#3 deutlich schwächer. Die transgenen RNAi-Pflanzen im SNN2.2UE-Hintergrund zeigten diese uninduzierte PR Ia-Expression nicht (Kapitel 5.2.3 und Kapitel 5.2.5).

Ein Grund für die konstitutive PRla-Genexpression könnte sein, dass die Reduzierung des Klasse II-Pools von TGA-Faktoren die PRIa-Expression ermöglicht. Wird durch eine Überexpression von TGA2.2 die Reduzierung der TGA2.1-Menge ausgeglichen, kann dadurch die PRla-Expression unterbunden werden. Somit könnten die Klasse II TGA-Faktoren TGA2.1 und TGA2.2 negative Regulatoren darstellen, deren funktionelle Bedeutung für die Regulation des PRla-Gens ebenfalls redundant ist. Da die RNAiPflanzen im SNN-Hintergrund bereits ohne Zugabe von Salicylsäure eine Expression des PRIa-Gens aufwiesen, muss ein anderer Stimulus die Expressionsinduktion bewirkt haben. Eine Möglichkeit stellt die Lichtqualität bzw. die Lichtstärke dar. Die Beleuchtungsstärke in der Klimakammer, in der die Pflanzen für die Analysen herangezogen worden sind, war um den Faktor vier höher als in vergleichbaren Klimakammern. Wurden die transgenen Pflanzen in diesen herangezogen, so war der PRla-Effekt nicht zu beobachten. Anhand dieser Daten lässt sich nun folgendes Modell postulieren, dass mit den oben genannten Daten in Einklang zu bringen ist. In der pflanzlichen Zellen gibt es negativ wirkende TGA-Faktoren, z. B. TGA2.1 und TGA2.2, und bislang nicht eindeutig identifizierte, positiv wirkende TGA-Faktoren. Beide Pools liegen in einer Konkurrenzsituation um die Bindung an den PRIa-Promotor vor. Der Stressfaktor Licht begünstigt in WT-Pflanzen die Bindung des negativen Pools an die DNA. Ist die Menge dieses Pools nicht reduziert, so ist die PRla-Expression reprimiert. Die Zugabe von Salicylsäure bedingt, dass sich der positiv wirkende TGA-Pool durchsetzt. Im Laufe der Zeit werden dadurch die negativ wirkenden TGA-Faktoren von dem PRla-Promotor verdrängt, die positiv wirkenden TGA-Faktoren können binden und 
so die Expression induzieren. Ein potentieller Kandidat des positiven TGA-Pools könnte der Klasse I TGA-Faktor TGA1a sein. Für diesen TGA-Faktor aus Nicotiana tabacum konnte gezeigt werden, dass die Reduzierung der Nttgala-Transkriptmenge zu einer verringerten PRla-Expression führt (STROMPEN, 1997). Zudem konnte für den homologen TGA-Faktor aus Arabidopsis thaliana TGA1 gezeigt werden, dass dieser in reduzierter Form mit NPR1, einem Schlüsselregulator der systemisch erworbenen Resistenz (SAR), interagieren kann (DEPRÉS et al., 2003). Im Rahmen der SAR wird NPR1 reduziert und als Monomer im Zellkern akkumuliert (MoU et al., 2003), wo es mit der reduzierten Form von TGA1 interagieren und so die Expression der $P R$-Gene induzieren könnte. Da mit Hilfe der Chromatin-Immunopräzipitation (ChIP) für die Klasse II TGA-Faktoren aus Nicotiana tabacum und aus Arabidopsis thaliana eine salicylsäureinduzierbare Bindung an den PRla- bzw. PRl-Promotor bereits nachgewiesen werden konnte (BUTTERBRODT, persönliche Mitteilung, JOHNSON et al., 2003), wäre es nun interessant zu untersuchen, ob die Klasse II TGA-Faktoren auch lichtinduziert binden können. Zudem sollte ebenfalls untersucht werden, ob der potentielle Aktivator TGAla aus Nicotiana tabacum ebenfalls salicylsäureinduziert direkt an den PRla-Promotor binden kann. 


\section{Literaturverzeichnis}

- Altschul, S.F., Madden, T.L., Schäffer, A.A., Zhang, J., Zhang, Z., Miller, W., and Lipman, D.J. (1997): Gapped BLAST and PSI-BLAST: a new generation of protein database search programs. Nucl. Acids Res. 25, 3389-3402.

- Bachmair, A., Novatchkova, M., Potuschak, T., and Eisenhaber, F. (2001): Ubiquitylation in plants: a post-genomic look at a post- translational modification. Trends Plant Sci. 6, 463-470.

- Barnes, W.M., (1994): PCR amplification of up to $35 \mathrm{~kb}$ DNA with high fidelity and high yield from lambda bacteriophage templates. Proc. Natl. Acad. Sci. USA 91, 2216-2220.

- Baxter, I., Tchieu, J., Sussmann, M.R., Boutry, M., Palmgren, M.G., Gribskov, M., Harper, J.F., and Axelsen, K.B. (2003): Genomic comparision of P-type ATPase ion pump in Arabidopsis and rice. Plant Phys. 132, 618-628.

- Benfey, P.N., and Chua, N.-H. (1990): The cauliflower mosaic virus 35S promoter: Combinatorial regulation of transcription in plants. Science 250, 959-966.

- Benfey, P.N., Ren, L., and Chua, N.-H. (1989): The CaMV 35S enhancer contains at least two domains which can confer different developmental and tissue-specific expression patterns. EMBO J. 8, 2195-2202.

- Bernard, P., and Couturier, M. (1992): Cell killing by the F plasmid ccdB protein involves poisoning of DNA-topoisomerase II complex. J. Mol. Biol. 226, 735-745.

- Boeke, J.D., La Croute, F., and Fink, G.R. (1984). Mol. Gen. Genet. 197, 345.

- Bonas, U., and van den Ackerveken, G. (1999): Gene-for-gene interaction: bacterial avirulence proteins specify plant disease resistance. Curr. Opin. Microbiol. 2, 94-98

- Boot, K.J.M., van der Zaal, B.J., Velterop, J., Quint, A., Mennes, A.M., Hooykaas, P.J.J., and Libbenga, K.R. (1993): Further characterization of expression of auxin-induced genes in tobacco (Nicotiana tabacum) cell-suspension cultures. Plant Physiol. 102, 513-520.

- Bouche, N., and Bouchez, D. (2001): Arabidopsis gene knockout: phenotypes wanted. Curr. Opin. Plant Biol. 4, 111-117.

- Bouchez, D., Tokuhisa, J.G., Llewellyn, D.J., Dennis, E.S., and Ellis, J.G. (1989): The ocselement is a component of the promoters of several T-DNA and plant viral genes. EMBO J. 8, 4197-4204.

- Bradford, M.M. (1979): A rapid and sensitive method for the quantification of microgram quantities of protein utilizing the principle of protein dye binding. Anal. Biochem. 72, 248-254. 
- Cao, H., Glazebrook, J., Clarke, J.D., Volko, S., and Dong, X. (1997): The Arabidopsis NPR1 gene that controls systemic acquired resistance encodes a novel protein containing ankyrin repeats. Cell 88, 57-63.

- Chatfield, S.P., Stirnberg, P., Forde, B.G., and Leyser, O. (2000): The hormonal regulation of axillary bud growth in Arabidopsis. Plant J. 24, 159-169.

- Chen, W., Provart, N.J., Glazebrook, J., Katagiri, F., Chang, H.-S., Eulgem, T., Mauch, F., Luan, S., Zou, G., Whitham, S.A., Budworth, P.R., Tao, Y., Xie, Z., Chen, X., Lam, S., Kreps, J.A., Harper, J.F., Si-Ammour, S., Mauch-Mani, B., Heinlein, M., Kobayashi, K., Hohn, T., Dangl, JL., Wang, X., and Zhu, T. (2002): Expression profile matrix of Arabidopsis transcription factor genes suggests their putative functions in response to enviromental stresses. Plant Cell 14, 559574.

- Cheong, Y.H., Park, J.M., Yoo, C.M., Bahk, J.D., Cho, M.J., and Hong, J.C. (1994): Isolation and characterization of STGA1, a member of the TGA1 familiy of bZIP transcription factors from soybean. Mol. Cells 4, 405-412.

- Chern, M.-S., Fitzgerald, H.A., Yadav, R.C., Canlas, P.E., Dong, X., and Ronald, P.C. (2001): Evidence for a disease-resistance pathway in rice similar to the NPR1-mediated signaling pathway in Arabidopsis. Plant J. 27, 101-113.

- Chuang, C.-F., and Meyerowitz, E.M. (2000): Specific and heritable genetic interference by double-stranded RNA in Arabidopsis thaliana. Proc. Natl. Acad. Sci. USA 97, 4985-4990.

- Chuang, C.-F., Running, M.P., Williams, R.W., and Meyerowitz, E.M. (1999): The PERIANTHIA gene encodes a bZIP protein involved in the determination of floral organ number in Arabidopsis thaliana. Genes Dev. 13, 334-344.

- $\quad$ Church, G.M., Gilbert, W. (1984): Genomic Sequencing. Proc. Natl. Acad. Sci. 81, 1991-1995.

- Colicelli, J., Birchmeier, C., Michaeli, T., O’Neill, K., Riggs, M., and Wigler, M. (1989): Isolation and characzerization of a mammalian gene encoding a high-affinity cAMP phosphodiesterase. Proc. Natl. Acad. Sci. 86, 3599-3603.

- Cooke, R. (1990): The figwort mosaic virus gene VI promoter region contains a sequence highly homologous to the octopine synthase (ocs) enhancer element. Plant Mol. Biol. 15, 181-187.

- Cutt, J.R., Dixon, D.C., Carr, J.P., and Klessig, D.F. (1988): Isolation and nucleotide sequence of cDNA clones for the pathogenesis-related proteins PR1a, PR1b and PR1c of Nicotiana tabacum cv. Xanthi nc induced by TMV infection. Nucl. Acids Res. 16, 9861.

- Daniel, V. (1993): Glutathion S-transferases: gene structure and regulation of expression. Crit. Rev. Biochem. Mol. Biol. 24, 337-384. 
- De Pater, S., Pham, K., Memelink, J., and Kijne, J. (1996): Binding specificity and tissue-specific expression pattern of the Arabidopsis bZIP transcription factor TGA2. Mol. Gen.Genet. 250, 237239.

- Deblaere, R., Bytebier, B., de Greve, H., Deboeck, F., Schell, J., van Montagu, M., and Leemans, J. (1985): Efficient octopine Ti-plasmid derived for Agrobacterium-mediated gene transfer. Nucl. Acids Res. 13, 4777-4788.

- Després, C., Chubak, C., Rochon, A., Clark, R., Bethune, T., Desveaux, D., and Fobert, P.R. (2003): The Arabidopsis NPR1 disease resistance protein is a novel cofactor that confers redox regulation of DNA binding activity to the basic domain/leucin zipper transcription factor TGA1. Plant Cell 15, 2181-2191.

- Després, C., DeLong, C., Glaze, S., Liu, E., and Fobert, P.R. (2000): The Arabidopsis NPR1/NIM1 protein enhances the DNA binding activity of a subgroup of the TGA familiy of bZIP transcription factors. Plant Cell 12, 279-290.

- Devoto, A., Muskett, P.R., and Shirasu, K. (2003): Role of ubiquitination in the regulation of plant defence against pathogens. Curr. Opin. Plant Biol. 6, 307-311.

- Dong, X. (1998): SA, JA, ethylene, and disease resistance in plants. Curr. Opin. Plant Biol. 1, 316-323.

- Dower, W.J., Miller J.F., and Ragsdale, C.W. (1988): High effiency transformation of E. coli with high voltage electroporation. Nucl. Acids Res. 16, 6127-6145.

- Droog, F., Spek, A., van der Kooy, A., de Ruyter, A., Hoge, H., Libbenga, K., Hooykaas, P., and van der Zaal B. (1995): Promoter analysis of the auxin-regulated tobacco glutathione Stransferase genes Nt103-1 and Nt103-35. Plant Mol. Biol. 29, 413-429.

- Dünnwald, M., Varshavsky, A., and Johnsson, N. (1999): Detection of transient in vivo interactions between substrate and transporter during protein translocation into the endoplasmatic reticulum. Mol. Biol. Cell 10, 329-344.

- Durner, J., Shah, J., and Klessig, D.F. (1997): Salicylic acid and disease resistance in plants. Trends Plant Sci. 2, 266-274.

- Ellis, J.G., Tokuhisa, J.G., Llewellyn, D.J., Bouchez, D., Singh, K., Dennis, E.S., and Peacock, W.J. (1993): Does the ocs-element occur as a functional component of the promoters of plant genes? Plant J. 4, 433-443.

- Fan, W., and Dong, X. (2002): In vivo interaction between NPR1 and transcription factor TGA2 leads to salicylic acid-mediated gene activation in Arabidopsis. Plant Cell, 14, 1-13.

- Feinberg, A.P., and Vogelstein, B. (1983): A technique for radiolabelling DNA restriction endonuclease fragments to high specific activity. Anal. Biochem. 132, 6-13. 
- Feltkamp, D., Masterson, R., Starke, J., and Rosahl, S. (1994): Analysis of the involvement of ocs-like bZip-binding elements in the differential strenght of the bidirectional mas1'2'promoter. Plant Physiol. 105, 259-268.

- Fields, S., and Song, O. (1989): A novel genetic system to detect protein-protein interactions. Nature 340, 245-247.

- Fitzgerald, K., Wilkinson, H.A., and Greenwald, I. (1993): glp-1 can substitute for lin-12 in specifying cell fate decisions in Caenorhabditis elegans. Dev. 119, 1019-1027.

- Foley, R.C., Grossmann, C., Ellis, J.G., Llewellyn, D.J., Dennis, E.S., Peacock, W.J., and Singh, K.B. (1993): Isolation of a maize bZIP protein subfamily: Candidates for the ocs-element transcription factor. Plant J. 3, 669-679.

- $\quad$ Fromm, H., Katagiri, F., and Chua, N.-H. (1989): An octopine synthase enhancer element directs tissue-specific expression and binds ASF-1, a factor from tobacco nuclear extracts. Plant Cell 1, 977-984.

- Fromm, H., Katagiri, F., and Chua, N.-H. (1991): The tobacco transcription activator TGA1a binds to a sequence in the $5^{\prime}$-upstream region of a gene encoding a TGA1a related protein. Mol. Gen. Genet. 229, 181-188.

- Fromm, H., Taylor, L.P., and Walbot, V. (1985): Expression of genes transferred into monocot and dicot plant cells by electroporation. Proc. Natl. Acad. Sci. USA 82 (9), 5824-5828.

- $\quad$ Fusco, C., Guidotti, E., and Zervos, A.S. (1999): In vivo construction of cDNA libraries for use in the yeas two-hybrid system. Yeast 15, 715-720.

- Gatz, C., Kaiser, A., and Wendenburg, R. (1992): Regulation of a modified CaMV 35S promoter by the Tn10-encoded Tet repressor in transgenic tobacco. Mol. Gen. Genet. 227, 229-237.

- Gish, W., and States, D.J. (1993): Identification of protein coding regions by database similarity search. Nat. Genet. 3, 266-272.

- $\quad$ Gong, Z., Lee, H., Xiong, L., Jagendorf, A., Stevenson, B., and Zhu, J.-K. (2002): RNA helicaselike protein as an early regulator of transcription factors for plant chilling and freezing tolerance. Proc. Natl. Acad. Sci. 99, 11507-11512.

- Hammond-Kosack, K.E., and Jones, J.D.G. (1996): Resistance gene-dependent plant defense responses. Plant Cell 8, 1773-1791.

- Hanahan, D. (1983): Studies on transformation of Escherichia coli with plasmids. J. Mol. Biol. $166,557-580$. 
- Heinekamp, T., Kuhlmann, M., Lenk., A., Strathmann, A., Dröge-Laser, W. (2002): The tobacco bZIP transcription factor BZI-1 bind to G-box promoter cis-elements of phenylpropanoid pathway genens in vitro, but is not involved in their regulation in vivo. Mol Gen. Genom. 267, $16-26$.

- Herrmann, I., (2003): Funktionelle Analyse der Transkriptionsfaktoren TGA2.1 und TGA2.2 aus Nicotiana tabacum. Diplomarbeit, Georg-August-Universität Göttingen, Göttingen.

- Horsch, R.B., Fry, J.E., Hoffmann, N.L., Eichholtz, D., Rogers, S.G., and Fraley, R.T. (1985): A simple and general method for transferring genes into plants. Science 227, 1229-1231.

- Horvath, D.M., and Chua, N.-H. (1996): Identification of an immediate-early salicylic acidinducible tobacco gene and characterization of induction by other compounds. Plant Mol. Biol. 31, 1061-1072.

- Hülper, P. (2003): Identifizierung von Protein-Interaktionspartnern des bZIPTranskriptionsfaktors TGA2.2 aus Nicotiana tabacum. Diplomarbeit, Georg-August-Universität Göttingen, Göttingen.

- Ichimura, Y., Kirisako, T., Takao, T., Satomi, Y., Shimonishi, Y., Ishihara, N., Mizushima, N., Tanida, I., Kominami, E., Ohsumi, M. (2000): A ubiquitin-like system mediates protein lipidation. Nature 408, 488-492.

- Inoue, H. Nojima, H., and Okayama, H. (1990): High efficiency transformation of Escherichia coli with plasmids. Gene 96, 23-28.

- James, P., Halladay, J., and Craig, E.A. (1996): Genomic libraries and a host strain designed for highly efficient two-hybrid selection in yeast. Genetics 144, 1425-1436.

- Jia, Y., McAdams, S.A., Bryan, G.T., Hershey, H.P., and Valent, B. (2000): Direct interactions of resistance gene and avirulence gene products confers rice blast resistance. EMBO 19, 4004-4014.

- Johnson, C., Boden, E., and Arias, J. (2003): Salicylic acid and NPR1 induce the recruitment of trans-activating TGA factors to a defense gene promoter in Arabidopsis. Plant Cell. 15, 18461858.

- Johnson, C., Boden, E., Desai, M., Pascuzzi, P., and Arias, J. (2001b): In vivo target promoter binding activities of a xenobiotic stress-activated TGA factor. Plant J.,28, 237-243.

- Johnson, C., Glover, G., and Arias, J. (2001a): Regulation of DNA binding and trans-activation by a xenobiotic stress-activated plant transcription factor. J. Biol. Chem. 276, 172-178.

- Johnsson, N., and Varshavsky, A. (1994): Split ubiquitin as a sensor of protein interactions in vivo. Proc. Natl. Acad. Aci. USA 91, 10340-10344.

- Jupin, I., and Chua, N.-H. (1996): Activation of the CaMV as-1 cis-element by salicylic acid: differential DNA-binding of a factor related to TGA1a. EMBO J. 15, 5679-5689. 
- Katagiri, F., Lam, E., and Chua, N.-H. (1989): Two tobacco DNA-binding proteins with homology to nuclear factor CREB. Nature 340, 727-730.

- $\quad$ Kawata, T., Imada, T., Shiraishi, H., Okada, K., Shimura, Y., and Ivabuchi, M. (1992): A cDNA clone encoding a HBP-1b homologue in Arabidopsis thaliana. Nucl. Acids Res. 20, 1141-1147.

- Kegler, C. (2001): Analyse des Transkriptionsfaktors TGA2.1 aus Nicotiana tabacum. Dissertation, Georg-August-Universität Göttingen, Göttingen.

- $\quad$ Keller, C.P., and van Volkenburg, E. (1997): Auxin-induced Epinasty of tobacco leaf tissues. Plant Physiol. 113, 603-610.

- Kellogg, D.E., Rybylkin, I., Chen, S., Mukhamedova, N., Vlasik, T., Siebert, P.D., and Chenchik, A. (1994): TaqStart Antibody: "hot start" PCR facilitated by a monoclonal antibody directed against Taq DNA Polymerase. Biotechniques 16, 1134-1137.

- Kholod, N., and Mustelin, T. (2001): Novel vectors for co-expression of two proteins in E. coli. Biotechniques 31, 322-328.

- Kim, H.S., and Delaney, T.P. (2002): Over-expression of TGA5, which encodes a bZIP transcription factor that interacts with NIM/NPR1, confers SAR-independent resistance in Arabidopsis thaliana to Peronospora parasitica. Plant J. 32, 151-163.

- Kim, T.S., and Delaney, T.P. (2002): Arabidopsis SON1 is an F-box protein that regulates a novel induced defense response independent of both salicylic acid and systemic acquired resistance. Plant Cell 14, 1469-1482.

- Kinkema, M., Fan, W., and Dong, X. (2000): Nuclear localisation of NPR1 is required for activation of $P R$ gene expression. Plant Cell 12, 2339-2350.

- Klessig, D.F., and Malamy, J. (1994): The salicylic acid signal in plants. Plant Mol. Biol. 26, 1439-1458.

- Klinedinst, S., Pascuzzi, P., Redman, J., Desai, M., and Arias, J. (2000): A xenobiotic-stressactivated transcription factor and its cognate target genes are preferentially expressed in root tip meristems. Plant Mol. Biol. 42, 679-688.

- Kombrink, E., and Somssich, I.E. (1997): Pathogenesis-related proteins and plant defense. In: The Mycota (Part A, Plant Relationships, Carroll, G., and Tudzynski, P., eds), pp. 107-128, Springer-Verlag, Berlin.

- Koncz, C., and Schell, J. (1986): The promoter of TL-DNA gene 5 controls the tissue-specific expression of chimaeric genes carries by a novel type of Agrobacterium binary vector. Mol. Gen. Genet. 204, 383-396. 
- Koyama T., Okada, T., Kitajima, S., Ohme-Takagi, M., Shinshi, H., and Sato, F. (2003): Isolation of tobacco ubiquitin-conjugating enzyme cDNA in a yeast two-hybrid system with tobacco ERF3 as bait and its characterization of specific interaction. J. Exp. Bot. 54, 1175-1181.

- Krawczyk, S. (1999): Charakterisierung der DNA-Bindungseigenschaften des pflanzlichen bZIPTranskriptionsfaktors TGA2.1 aus Nicotiana tabacum. Diplomarbeit, Georg-August-Universität Göttingen, Göttingen.

- Krawczyk, S., Thurow, C., Niggeweg, R., and Gatz, C. (2002): Analysis of the spacing between the two palindromes of activation sequence-1 with respect to binding to different TGA factors and transcriptional activation. Nucl. Acids Res. 30, 775-781.

- Kyhse-Andersen, J. (1984): Electroblotting of multiple gels: a simple apparatus without buffer tank for rapid transfer of proteins from polyacrylamide to nitrocellulose. J. Biochem. Biophys. Meth. 10, 203-209.

- Laemmli, U.K. (1970): Cleavage of structural proteins during the assembly of the head of bacteriophage T4. Nature 227, 680-685.

- Lam, E., and Lam, Y.K.-P. (1995): Binding site requirements and differential representation of TGA factors in nuclear ASF-1 activity. Nucl. Acids Res. 23, 3778-3785.

- Lam, E., Benfey, P.N., Gilmartin, P.M., Fang, R.-X., and Chua, N.-H. (1989): Site specific mutations alter in vitro factor binding and change promoter expression pattern in transgenic plants. Proc. Natl. Acad. Sci. USA 86, 7890-7894.

- Lam, E., Katagiri, F., and Chua, N.-H. (1990): Plant nuclear factor ASF-1 binds to an essential region of the nopaline synthase promoter. J. Biol. Chem. 265, 9909-9913.

- Laser, H., Bongards, C., Schüller, J., Hech, S., Johnsson, N., and Lehming, N. (2000): A new screen for protein interactions reveals that the Saccharomyces cerevisiae high mobility group proteins Nhp6A/B are involved in the regulation of the GAL1 promoter. Proc. Natl. Acad. Sci. 97, 13732-13737.

- Le Gouill, C., Parent, J.-L., Rola-Pleszczynski, M., and Stankova, J. (1994): Analysis of recombinant plasmids by a modified alkaline lysis method. Anal. Biochem. 219, 164.

- Lebel, E., Heifetz, P., Thorne, L., Uknes, S., Ryals, J., and Ward, E. (1998): Functional analysis of regulatory sequences controlling PR-1 gene expression in Arabidopsis. Plant J. 16, 223-233.

- Lenk, I. (2001): Analyse der in-vivo Funktion der Transkriptionsfaktoren TGA2.1 und TGA2.2 aus Tabak nach Fusion mit einer konstitutiven Aktivierungsdomäne. Dissertation, Georg-AugustUniversität Göttingen, Göttingen.

- Levine, A., Tenhaken, R., Dixon, R., and Lamb, C. (1994): $\mathrm{H}_{2} \mathrm{O}_{2}$ from the oxidative burst orchestrates the plant hypersensitive disease resistance response. Cell 79, 583-593. 
- Lewin, B. (1994): Genes V, Oxford, New York, Tokyo: Oxford University Press.

- Li, X., Zhang, Y., Clarke, J.D., Li, Y., and Dong, X. (1999): Identification and cloning of a negative regulator of systemic acquired resistance, SNI1, through a screen for suppressors of npr1-1. Cell 98, 329-339.

- Liu, X., and Lam, E. (1994): Two binding sites for the plant transcription factor ASF-1 can respond to auxin treatments in transgenic tobacco. J. Biol. Chem. 269, 668-675.

- Madden, T.L., Tatusov, R.L., and Zhang, J. (1996): Applications of network BLAST server. Meth. Enzymol. 266, 131-141.

- Maddox, D., Ahl-Goy, P., Luntz, T., and Ward, E. (1993): Increased tolerance to oomycete pathogens in transgenic tobacco expressing pathogenesis-related protein 1a. Proc. Natl. Acad. Sci. USA 90, 7327-7331.

- Malamy, J., Carr, J.P., Klessig, D.F., and Raskin, I. (1990): Salicylic acid: a likely endogenous signal in the resistance response of tobacco to viral infection. Science 250, 1002-1004.

- Maleck, K., Levine, A., Eulgem, T., Morgan, A., Schmid, J., Lawton, K.A., Dangl, J.L., and Dietrich, R.A. (2000): The transcriptome of Arabidopsis thaliana during systemic acquired resistance. Nat. Genet. 25, 403-410.

- Marchuk, D., Drumm, M., Saulino, A., and Collins, F.S. (1991): Construction of T-vectors, a rapid and general system for direct cloning of unmodified PCR products. Nucl. Acids Res. 19, 1154.

- Mauch, F., Mauch-Mani, B., Gaille, C., Kull, B., Haas, D., and Reimmann, C. (2001): Manipulation of salicylate content in Arabidopsis thaliana by the expression of an engineered bacterial salicylate synthase. Plant J. 25, 67-77.

- Mead, D.A., Pey, K., Herrnstadt, C., Marcil, R.A., and Smith, L.M. (1991): A universal method for the direct cloning of PCR amplified nucleic acid. Biotechnology 9, 657-662.

- Medberry, S.L., Lockhart, B.E.L., and Olszewski, N.E. (1992): The commelina yellow mottle virus promoter is a strong promoter in vascular and reproductive tissues. Plant Cell 4, 185-192.

- Miao, Z.-H., and Lam, E. (1995): Construction of a trans-dominant inhibitor for members of the TGA family of transcription factors conserved in higher plants. Plant J. 7, 887-896.

- Miao, Z.-H., Liu, X., and Lam, E. (1994): TGA3 is a distinct member of the TGA family of bZIP transcription factors in Arabidopsis thaliana. Plant Mol. Biol. 25, 1-11.

- Mou, Z., Fan, W., and Dong, X. (2003): Inducers of plant systemic acquired resistance regulate NPR1 function through redox changes. Cell 113, 935-944.

- Mullis, K.B., and Faloona, F.A. (1987): Specific synthesis of DNA in vitro via a polymerasecatalyzed chain reaction. Methods Enzymol. 155, 335-350. 
- Murashige, T., and Skoog, F. (1962): A revised medium for rapid growth and bioassays with tobacco tissue culture. Plant Physiol. 15, 473-497.

- Neuhaus, G., Neuhaus-Url, G., Katagiri, F., Seipel, K., and Chua, N.-H. (1994): Tissue-specific expression of as-1 in transgenic tobacco. Plant Cell 6, 827-834.

- Nickolov, K. (2002): Subcellular Localization of Nicotiana tabacum TGA transcription factors. Dissertation, Georg-August-Universität Göttingen, Göttingen.

- Niggeweg, R. (1999): Salizylsäure- und Auxin-induzierte Genexpression in Nicotiana tabacum: Funktionelle Bedeutung der TGA-Faktoren der Subklasse II. Dissertation, Universität Bielefeld.

- Niggeweg, R., and Gatz, C. (1997): Isolation of TGA2.1 (Accession No U90214), a member of a new subclass of the TGA-family of bZIP-transcription-factors in Nicotiana tabacum. Plant Physiol. 113, 1464.

- Niggeweg, R., Thurow, C., Kegler, C., and Gatz, C. (2000b): Tobacco transcription factor TGA2.2 is the main component of as-1-binding factor ASF-1 and is involved in salicylic acidand auxin-inducible expression of as-1-containing target promoters. J. Biol. Chem. 275, 1989719905.

- Niggeweg, R., Thurow, C., Weigel, R., Pfitzner, U., and Gatz, C. (2000a): Tobacco TGA factors differ with respect to interaction with NPR1, activation potential and DNA-binding properties. Plant Mol. Biol. 42, 775-788.

- Odell, G.T., Nagy, F., and Chua, N.-H. (1985): Identification of DNA sequences required for activity of the cauliflower mosaic virus $35 \mathrm{~S}$ promoter. Nature $313,810-812$.

- Ow, D.W., Jacobs, J.D., and Howell, S.H. (1987): Funtional regions of the cauliflower mosaic virus 35S truncated promotor. Mol. Gen.Genet. 217, 209-214.

- Pascuzzi, P., Hamilton, D., Bodily, K., and Arias, J. (1998): Auxin-induced stress potentiates trans-activation by a conserved plant basic/leucine-zipper factor. J. Biol. Chem. 273, 2663126637.

- Pastink, A., Eeken, J.C., and Lohmann p.H. (2001): Genomic integrity and the repair of doublestrand DNA breaks. Mutat. Res. 480-481, 37-50.

- Payne, G., Parks, T.D., Burkhart, W., Dincher, S., Ahl, P., Metraux, J.P., and Ryals, J. (1988): Isolation of the genomic clone for pathogenesis-related protein 1a from Nicotiana tabacum cv. Xanthi-nc. Plant Mol. Biol. 11, 247-254.

- Perlman, D.C., and Halvorson, H.O. (1987): Improved resolution of DNA fragments in polysaccharid-supplemented agarose gels. Anal. Biochem. 163, 247-256.

- Pickert, C.M. (2001): Ubiquitin enters the new millenium. Mol. Cell 8, 499-504. 
- Pickett, F.B., and Meeks-Wagner, D.R. (1995): Seeing double: appreciating genetic redundancy. Plant Cell 7, 1347-1356.

- Pontier, D., Miao, Z.-H., and Lam, E. (2001): Trans-dominant suppression of plant TGA factors reveals their negative and positive roles in plant defense responses. Plant J. 27, 529-538.

- Pontier, D., Privat, I., Trifa, Y., Zhou, J.-M., Klessig, D.F., Lam, E. (2002): Differential regulation of TGA transcription factors by post-transcriptional control. Plant J. 32, 641-653.

- Prat, S., Willmitzer, L., and Sanchez-Serrano, J.J. (1989): Nuclear proteins binding to a cauliflower mosaic virus 35S truncated promotor. Mol. Gen. Genet. 217, 209-214.

- Qin, X.-F., Holuigue, L., Horvath, D.M., and Chua, N.-H. (1994): Immediate early transcription activation by salicylic acid via the cauliflower mosaic virus as-1 element. Plant Cell 6, 863-874.

- Raquet, X., Eckert, J.H., Müller, S., and Johnsson, N. (2001): Detection of altered protein conformations in living cells. J. Mol. Biol. 305, 927-938.

- Rate, D.N., Cuenca, J.V., Bowman, G.R., Guttman, D.S., and Greenberg, J.T. (1999): The gainof-function Arabidopsis acd6 mutant reveals novel regulation and function of the salicylic acid signaling pathway in controlling cell death, defenses, and cell growth. Plant Cell 11, 1695-1708.

- Reinders, A., Schulze, W., Kühn, C., Barker, L., Schulz, A., Ward, J.M., and Frommer, W.B. (2002): Protein-protein interactions of different affinities colocalized in the same endonucleate sieve element. Plant Cell 14, 1567-1577.

- Rieping, M., Fritz, M., Prat, S., and Gatz, C. (1994): A dominant negative mutant of PG13 suppresses transcription from a cauliflower mosaic virus $35 \mathrm{~S}$ truncated promoter in transgenic tobacco plants. Plant Cell 6, 1087-1098.

- Rigaut, G., Shevchenko, A., Rutz, B., Wilm, M., Mann, M., and Seraphin, B. (1999): A generic protein purification method for protein complex characterization and proteome exploration. Nature Biotechnol. 17, 1030-1032.

- Rojo-Niersbach, E., Morley, D., Heck, S., and Lehming, N. (2000): A new method for the selection of protein interactions in mammalian cells. Biochem. J. 348, 585-590.

- Roux, C., and Perrot-Rechenmann, C. (1997): Isolation by differential display and characterization of a tobacco auxin-responsive cDNA Nt-gh3, related to GH3. FEBS Lett. 419, 131-136.

- Runne, H. (2001): Herstellung einer cDNA-Bank unter Verwendung von mRNA aus Salicylsäure-induzierten Tabakblättern. Diplomarbeit, Georg-August-Universität Göttingen, Göttingen. 
- Ryals, J.A., Weymann, K., Lawton, K., Friedrich, L., Ellis, D., Steiner, H.-Y., Johnson, J., Delaney, T.P., Jesse, T., Vos, P., and Uknes, S. (1997): The Arabidopsis NIM1 protein shows homology to the mammalian transcription factor inhibitor IкB. Plant Cell 9, 425-439.

- Sambrook, J., Fritsch, E.F., and Maniatis, T. (1989): Molecular cloning: A Labatory Manual $2^{\text {nd }}$ edition. Cold Spring Harbour Laboratory Press.

- Sanger, F., Nickler, S., and Coulson, A.R. (1977): DNA-sequencing with chain-terminating inhibitors. Proc. Natl. Acad. Sci: USA 74, 5463-5467.

- Schenk, P.M., Kazan, K., Wilson, I., Anderson, J.P., Richmond, T., Somerville, S.C., and Manners, J.M. (2000): Coordinated plant defense response in Arabidopsis revealed by microarray analysis. Proc. Natl. Acad. Sci. USA 97, 11655-11660.

- Schiermeyer, A., Thurow, C., and Gatz, C. (2003): Tobacco bZIP factor TGA10 is a novel member of the TGA family of transcription factors. Plant Mol. Biol. 51, 817-829.

- Schindler, U., Beckmann, H., and Cashmore, A.R. (1992): TGA1 and G-box binding factors: Two distinct classes of Arabidopsis leucine zipper proteins compete for the G-box-like element TGACGTGG. Plant Cell 4, 1309-1319.

- Schulze, W.X., Reinders, A., Ward, J., Lalonde, S., and Frommer, W.B. (2003): Interactions between co-expressed Arabidopsis sucrose transporters in the split-ubiquitin system. BMC Biochem. 4, 3

- Shah, J., Kachroo, P., and Klessig, D.F (1999): The Arabidopsis ssi mutation restores pathogenesis-related gene expression in npr1 plants and renders defensin gene expression salicylic acid dependent. Plant Cell 11, 191-206.

- Shikanai, T., Muller-Moule, P., Munekage, Y., Niyogi, K.K., and Pilon, M. (2003): PAA1, a Ptype ATPase of Arabidopsis, functions in copper transport in chloroplasts. Plant Cell 15, 13331346.

- Siemsen, T. (2002): Identifizierung von Protein-Interaktionspartnern des bZIPTranskriptionsfaktors TGA2 mit Hilfe des modifizierten Hefe-“One-Hybrid”-Systems. Diplomarbeit, Georg-August-Universität Göttingen, Göttingen.

- $\quad$ Sikorski, R.S., and Hieter, P. (1989): A system of shuttle vectors and yeast host strains designed for efficient manipulation of DNA in Saccharomyces cerevisiae. Genet. 122, 19-27.

- Singh, K., Dennis, E.S., Ellis, J.G., Llewellyn, D.J., Tokuhisa, J.G., Wahleithner, J.A., and Peacock, W.J. (1990): OCSBF-1, a maize Ocs enhancer binding factor: Isolation and expression during development. Plant Cell 2, 891-903.

- $\quad$ Singh, K., Tokuhisa, J.G., Dennis, E.S., and Peacock, W.J. (1989): Saturation mutagenesis of the octopine synthase enhancer: Correlation of mutant phenotypes with binding of a nuclear protein factor. Proc. Natl. Acad. Sci. USA 86, 3733-3737. 
- $\quad$ Smith, N.A., Singh, S.P., Wang, M.-B., Stoutjesdijk, P.A., Green, A.G., and Waterhouse, P.M. (2000): Total silencing by intron-spliced hairpin RNAs. Nature 407, 319-320.

- Stagljar, I., Korostensky, C., Johnsson, N., and Te Heesen, S. (1998): A genetic system based on split-ubiquitin for the analysis of interactions between membrane proteins in vivo. Proc. Natl. Acad. Sci. 95, 5187-5192.

- Stange, C., Ramirez, I., Gómez, I., Jordana, X., and Holuigue, L. (1997): Phosphorylation of nuclear proteins directs binding to salicylic acid-responsive elements. Plant J. 11, 1315-1324.

- Strathmann, A. (2003): Charakterisierung der Nicotiana tabacum bZIP-Transkriptionsfaktoren BZI-2, BZI-3 und BZI-4 als Heterodimerisierungspartner von BZI-1. Dissertation, GeorgAugust-Universität Göttingen, Göttingen

- Strompen, G. (1997): Identifizierung von DNA-Bindemotiven und Transkriptionsfaktoren, die an der Regulation der Expression des ,pathogenesis-related“ Proteins 1a (PR1a) aus Nicotiana tabacum L. beteiligt sind. Dissertation, Universität Hohenheim.

- Strompen, G., Grüner, R., and Pfitzner, M. (1998): An as-1-like motif controls the level of expression of the gene for the pathogenesis-related protein 1a from tobacco. Plant Mol. Biol. 37, $871-883$.

- Subramaniam, R., Desveaux, D., Spickler, C., Michnick, S.W., and Brisson, N. (2001): Direct visualization of protein interactions in plant cells. Nat. Biotechnol. 19, 769-772.

- Sullivan, M.L., Carpenter, T.B., and Vierstra, R.D. (1994): Homologues of wheat ubiquitinconjugating enzymes--TaUBC1 and TaUBC4 are encoded by small multigene families in Arabiopsis thaliana. Plant Mol. Biol. 24, 651-661.

- Tabata, T., Nakayama, T., Mikami, K., and Iwabuchi, M. (1991): HBP-1a and HBP-1b: Leucine zipper type transcription factors of wheat. Embo J. 10, 1459-1467.

- $\quad$ Takahashi, Y., Kuroda, H., Tanaka, R., Machida, T., and Nagata, T. (1989): Isolation of an auxinregulated gene cDNA expressed during the transition from $\mathrm{G}_{0}$ to $\mathrm{S}$ phase in tobacco mesophyll protoplasts. Proc. Natl. Acad. Sci. USA 86, 9279-9283.

- Thurow, C. (2001): Biochemische Aufreinigung, funktionelle Analyse und Identifikation eines Interaktionspartners des an der Salicysäure-induzierbaren Genexpression beteiligten SARPKomplexes aus Tabak. Dissertation, Georg-August-Universität Göttingen, Göttingen.

- $\quad$ Turner, J.G., Ellis, D., and Devoto, A. (2002): the jasmonate signal pathway. Plant Cell 14, S153S164.

- $\quad$ Uknes, S., Dincher, S., Friedrich, L., Negrotto, D., Williams, S., Thompson-Taylor, H., Potter, S., Ward, E., and Ryals, J. (1993b): Regulation of pathogenesis-related protein-1a gene expression in tobacco. Plant Cell 5, 159-169. 
- $\quad$ Uknes, S., Winter, A.M., Delaney, T., Vernooij, B., Morse, A., Friedrich, L., Nye, G., Potter, S., Ward, E., and Ryals, J. (1993a): Biological induction of systemic acquired resistance in Arabidopsis. Mol. Plant Microbe Interact. 6, 692-698.

- Ulmasov, R., Hagen, G., and Guilfoyle, T. (1994): The ocs element in the soybean GH2/4 promoter is activated by both active and inactive auxin and salicylic acid analogues. Plant Mol. Biol. 26, 1055-1064.

- $\quad$ van der Zaal, E.J., Droog, F.N.J., Boot, C.J.M., Hensgens, L.A.M., Hoge, J.H.C., Schilperoort, R.A., and Libbenga, K.R. (1991): Promoters of auxin-induced genes from tobacco can lead to auxin-inducible and root tip-specific expression. Plant Mol. Biol. 10, 145-157.

- Van Loon, L.C., and Antoniw, J.F. (1982): Comparison of the effects of salicylic acid and etephon with virus-induced hypersensitivity and aquired resistance in tobacco. Neth. J. Plant Pathol. 88, 237-256.

- Varshavsky, A. (1997): The N-end rule pathway of protein degradation. Genes to Cell 2, 13-28.

- Verberne, M.C., Verpoorte, R., Bol, J.F., Mercado-Blanco, J., and Linthorst, H.J. (2000): Overproduction of salicylic acid in plants by bacterial transgenes enhances pathogen resistance. Nat. Biotechnol. 18, 779-783.

- Walsh, J., Waters, C.A., and Freeling, M. (1997): The maize gene liguleless2 encodes a basic leucine zipper protein involved in the establishment of the leaf blade-sheath boundary. Genes Dev. 11, 208-218.

- Ward, E.R., Uknes, S.J., Williams, S.C., Dincher, S.S., Wiederhold, D.L., Alexander, D.C., Ahl-Goy, P., Métraux, J.-P., and Ryals, J.A. (1991): Coordinate gene activity in response to agents that induce systemic acquired resistance. Plant Cell 3, 1085-1094.

- Waterhouse, P.M., Graham, M.W., and Wang, M.-B. (1998): Virus resistance and gene silencing in plants can be induced by simultaneous expression of sense and antisense RNA. Proc. Natl. Acad. Sci. USA 95, 13959-13964.

- Weigel, R.R., Bäuscher, C., Pfitzner, A.J.P., and Pfitzner, U.M. (2001): NIMIN-1, NIMIN-2 and NIMIN-3, members of a novel family of proteins from Arabidopsis that interact with NPR1/NIM1, a key regulator of systemic acquired resistance in plants. Plant Mol. Biol. 46, 143160 .

- Weissmann, A.M. (2001): Themes and variations on ubiquitylation. Nat. Rev. Mol. Cell Biol. 2, 169-178.

- Westermarck, J., Weiss, C., Saffrich, R., Kast, J., Musti, A.-M., Wessely, M., Ansorge, W., Séraphin, B., Wilm, M., Valdez, B.C., and Bohmann, D. (2002): The DEAD/H-box RNA helicase RHII/Gu is a co-factor for c-Jun-activated transcription. EMBO 21, 451-460. 
- Wittke, S., Lewke, N., Müller, S., and Johnsson, N. (1999): Probing the molecular enviroment of membrane proteins in vivo. Mol. Biol. Cell 10, 2519-2530.

- Xiang, C., Miao, Z., and Lam E. (1997): DNA-binding properties, genomic organization and expression pattern of TGA6, a new member of the TGA familiy of bZIP transcription factors in Arabidopsis thaliana. Plant Mol. Biol. 34, 403-415.

- Xiang, C., Miao, Z.-H., and Lam, E. (1996): Coordinated activation of as-1-type elements and a tobacco glutathione S-transferase gene by auxins, salicylic acid, methyl-jasmonate and hydrogen peroxide. Plant Mol. Biol. 32, 415-426.

- Xie, D.X., Feys, B.F., James, S., NietoRostro, M., Turner, J.G. (1998): COI1: an Arabidopsis gene required for jasmonate-regulated defense and fertility. Science 280, 1091-1094.

- Yalpani, N., Silverman, P., Wilson, T.M., Kleir, D.A., Raskin, I. (1991): Salicylic acid is a systemic signal and an inducer of pathogensis-related proteins in virus-infected tobacco. Plant Cell 3, 809-818.

- Yan, X., Mouillet, J.F., Ou, Q., and Sadovsky, Y. (2003): A novel domain within the DEAD-box protein DP103 is essential for transcriptional repression and helicase activity. Mol. Cell Biol. 23, 414-423.

- Zhang, B., and Singh, K.B. (1994): Ocs element promoter sequences are activated by auxin and salicylic acid in Arabidopsis. Proc. Natl. Acad. Sci. USA 91, 2507-2511.

- Zhang, B., Foley, R.C., and Singh, K.B. (1993): Isolation and characterization of two related Arabidopsis ocs-element bZIP binding proteins. Plant J. 4, 711-716.

- Zhang, Y., Fan, W., Kinkema, M., Li, X., and Dong, X. (1999): Interaction of NPR1 with basic leucine zipper protein transcription factors that bind sequences required for salicylic acid induction of the PR-1 gene. Proc. Natl. Acad. Sci. USA 96, 6523-6528.

- Zhou, J.-M., Trifa, Y., Silva, H., Pontier, D., Lam, E., Shah, J., and Klessig, D.F. (2000): NPR1 differentially interacts with members of the TGA/OBF familiy of transcription factors that bind an element of the PR-1 gene required for induction by salicylic acid. Mol. Plant Microbe Interact. 13 (2), 191-202.

- Zhu, Y.Y., Machleder, E.M., Chenchik, A., Li, R., and Siebert, P.D. (2001): Reverse transcriptase template switching: a SMART approach for full-length cDNA library construction. Biotechniques 30, 892-897. 


\section{Anhang}

\subsection{Abkürzungen}

\begin{tabular}{|c|c|}
\hline A & Adenosin \\
\hline$A$. & Agrobacterium \\
\hline aa & Aminosäure \\
\hline abs. & absolut \\
\hline Ac & Acetat \\
\hline $\mathrm{AD}$ & Aktivierungsdomäne \\
\hline $\mathrm{ADE}$ & Adenin \\
\hline ADE2 & Aminoimidazolribonukleotid-Carboxylase aus $S$ cerevisiae \\
\hline ADH1 & Alkoholdehydrogenase 1 aus $S$ cerevisiae \\
\hline Amp & Ampicillin \\
\hline$a m p^{r}$ & Ampicillin-Resistenzgen \\
\hline APS & Ammoniumpersulfat \\
\hline$a s-1$ & activating sequence-1 \\
\hline ASF-1 & activating sequence factor-1 \\
\hline 3-AT & 3-amino-1,2,4-triazol \\
\hline A.t & Arabidopsis thaliana \\
\hline ATP & Adenosin-5'-Triphosphat \\
\hline BAP & 6-Benzylaminopurin \\
\hline $\mathrm{BD}$ & Bindedomäne \\
\hline bidest & bidestilliertes Wasser \\
\hline bp & Basenpaar \\
\hline BSA & Rinderserumalbumin \\
\hline $\mathrm{BTB} / \mathrm{POZ}$ & broad-complex, tramtrack, bric-à-brac/poxvirus, zinc finger \\
\hline BY -2 & Bright Yellow-2 Nicotiana tabacum Suspensionskultur \\
\hline bZIP & basische Region / Leucin-Zipper-Domäne \\
\hline bzw. & beziehungsweise \\
\hline $\mathrm{C}$ & Cytosin \\
\hline${ }^{\circ} \mathrm{C}$ & Grad Celsius \\
\hline ca. & cirka \\
\hline CaMV & Blumenkohlmosaikvirus „Cauliflower Mosaic Virus“ \\
\hline cDNA & Kopie-DNA von RNA-Sequenzen \\
\hline cfu & colony forming units \\
\hline ChIP & Chromatin-Immunopräzipitation \\
\hline $\mathrm{Ci}$ & Curie \\
\hline $\mathrm{cm}^{r}$ & Chloramphenicol-Resistenzgen \\
\hline cpm & Zählimpulse pro Minute \\
\hline $\mathrm{Cu}^{2+}$ & Kupfer-Ionen \\
\hline $\mathrm{Cub}$ & carboxyterminale Einheit (35-76 aa) vom Ubiquitin \\
\hline Cup1 & „Copper-inducible promotor ${ }^{“ “}$ \\
\hline $\mathrm{d}$ & $\operatorname{Tag}(\mathrm{e})$ \\
\hline 2,4-D & 2,4-Dichlorphenoxyessigsäure \\
\hline $\mathrm{dA}$ & Desoxyadenosin \\
\hline dATP & $2^{\prime}$-Desoxyadenosin- $5^{\prime}$-Triphosphat \\
\hline ddT & Didesoxythymidin \\
\hline dCTP & $2^{\prime}$-Desoxycytidin-5'-Triphosphat \\
\hline DEPC & Diethylpyrocarbonat \\
\hline dGTP & $2^{\prime}$-Desoxyguanosin-5'-Triphosphat \\
\hline d.h. & das heißt \\
\hline DMF & N,N-Dimethylformamid \\
\hline DMSO & Dimethylsulfoxid \\
\hline
\end{tabular}




\begin{tabular}{|c|c|}
\hline DNA & Desoxyribonukleinsäure \\
\hline dNTP & Desoxynukleosidtriphosphat \\
\hline dsDNA & doppelsträngige DNA \\
\hline dsRNA & doppelsträngige RNA \\
\hline $\mathrm{dT}$ & Desoxythymidin \\
\hline DTT & Dithiothreitol \\
\hline dTTP & $2^{\prime}$-Desoxythymidin-5'-Triphosphat \\
\hline dYT & double yeast extract and tryptone \\
\hline$E$. & Escherichia \\
\hline ECL & Enhanced Chemiluminescence \\
\hline EDTA & Ethylendiamintetraessigsäure \\
\hline ER & Endoplasmatisches Reticulum \\
\hline et al. & und andere \\
\hline EtBr & Ethidiumbromid \\
\hline $\mathrm{EtOH}$ & Ethanol \\
\hline $\mathrm{f}$ & femto $\left(\mathrm{x} 10^{-15}\right)$ \\
\hline $\mathrm{F}$ & Farad \\
\hline $\mathrm{fl}$ & full length (= volle Länge) \\
\hline 5-FOA & "5-Fluoro orotic acid" \\
\hline g & Gramm \\
\hline G & Guanosin \\
\hline GAD & GAL4-Aktivierungsdomäne \\
\hline$\beta-G a l$ & $\beta$-Galactosidase \\
\hline GBD & GAL4-DNA-Bindedomäne \\
\hline GFP & green flourescent protein (-Grün-floureszierendes Protein) \\
\hline$G m^{r}$ & Gentamycin-Resistenzgen \\
\hline GTP & Guanosin 5'-Triphosphat \\
\hline Gus & $\beta$-Glucoronidase \\
\hline h & Stunde(n) \\
\hline HEPES & N-[2-Hydroxyethyl]-piperazin-N'-[2-Ethansulfonsäure] \\
\hline HIS & Histidin \\
\hline HIS3 & Imidazolglycerinphosphat-Dehydratase aus $S$. cerevisiae \\
\hline HR & hypersensitive response (= hypersensitive Reaktion) \\
\hline$h_{y g}{ }^{r}$ & Hygromycin-Resistenzgen \\
\hline IPTG & Isopropyl-1-thio- $\beta$-D-galactosid \\
\hline $\mathrm{k}$ & kilo $\left(\mathrm{x} 10^{3}\right)$ \\
\hline $\mathrm{kan}^{r}$ & Kanamycin-Resistenzgen \\
\hline $\mathrm{kb}$ & Kilobasen \\
\hline $\mathrm{kDa}$ & Kilo-Dalton \\
\hline $\mathrm{Km}$ & Kanamycin \\
\hline 1 & Liter \\
\hline lacZ & $\beta$-Galactosidase-Gen \\
\hline LB & Luria/Bertani-Medium \\
\hline LEU & Leucin \\
\hline LEU2 & $\beta$-Isopropylmalat-Dehydrogenase aus $S$. cerevisiae \\
\hline Lsg. & Lösung \\
\hline $\mathrm{m}$ & milli $\left(\mathrm{x} 10^{-3}\right)$ \\
\hline M & molar \\
\hline mas & Mannopin-Synthase \\
\hline mes & multiple cloning site, Polylinker \\
\hline MET25 & Methionin-reprimierbarer Promotor \\
\hline $\min$ & Minute(n) \\
\hline mind. & Mindestens \\
\hline $\mathrm{mm}$ & Millimeter \\
\hline MOPS & 3-(N-Morpholino)-propansulfonsäure \\
\hline mRNA & messenger RNA \\
\hline MS & Murashige und Skoog Medium \\
\hline MTX & Methotrexat \\
\hline
\end{tabular}




\begin{tabular}{|c|c|}
\hline MW & Molekulargewicht \\
\hline $\mathrm{n}$ & nano $\left(\times 10^{-9}\right)$ \\
\hline $\mathrm{N}$ & Normalität, normal \\
\hline$N$. & Nicotiana \\
\hline NAA & $\alpha$-Naphtalinessigsäure \\
\hline nim1, NIM1 & noninducible immunity (= nichtinduzierbare Immunität) \\
\hline nos & Nopalin-Synthase \\
\hline nprl, NPR1 & nonexpresser of PR genes 1 (= Nichtexprimierer der PR-Gene) \\
\hline$N t$ & Nicotiana tabacum \\
\hline Nub & aminoterminale Einheit (1-34 aa) vom Ubiquitin \\
\hline$O$. & Oryza \\
\hline ocs & Octopin-Synthase \\
\hline OD & optische Dichte \\
\hline $\mathrm{OD}_{260}$ & optische Dichte bei $260 \mathrm{~nm}$ \\
\hline $\mathrm{OD}_{280}$ & optische Dichte bei $280 \mathrm{~nm}$ \\
\hline $\mathrm{OD}_{420}$ & optische Dichte bei $420 \mathrm{~nm}$ \\
\hline $\mathrm{OD}_{600}$ & optische Dichte bei $600 \mathrm{~nm}$ \\
\hline ORF & open reading frame ( $=$ offenes Leseraster) \\
\hline $\mathrm{p}$ & $\operatorname{pico}\left(\times 10^{-12}\right)$ \\
\hline${ }^{1} 2 \mathrm{P}$ & Phosphorisotop der relativen Masse 32 \\
\hline$P$. & Pisum \\
\hline $\mathrm{pA}$ & Polyadenylierungssignal \\
\hline PAA & Polyacrylamid \\
\hline PCR & polymerase chain reaction (= Polymerasekettenreaktion) \\
\hline PEG & Polyethylenglycol \\
\hline $\mathrm{pH}$ & $\begin{array}{l}\text { negativ dekadischer Logarithmus der } \text { Wasserstoff- } \\
\text { ionenkonzentration }\end{array}$ \\
\hline PMSF & Phenylmethylsulfonylfluorid \\
\hline polydI/dC & Polydesoxyinosin-desoxycytidylsäure \\
\hline$P P T^{\mathrm{r}}$ & Phosphinotricin-Resistenzgen \\
\hline PR & pathogenesis-related (= mit der Pathogenese zusammen-hängend) \\
\hline PTGS & $\begin{array}{l}\text { post-transcriptional gene silencing (= posttranskriptionelle } \\
\text { Stillegung von Genexpression) }\end{array}$ \\
\hline PVDF & Polyvinylendifluorid \\
\hline rek. & rekombinant exprimiert \\
\hline Rif & Rifampicin \\
\hline rif $^{r}$ & Rifampicin-Resistenzgen \\
\hline RNA & Ribonukleinsäure \\
\hline RNAi & RNA-Interferenz \\
\hline RNAse A & Ribonuklease A \\
\hline rpm & Umdrehungen pro Minute \\
\hline RR-Mix & Ready Reaction Mix von Perkin-Elmer \\
\hline rRNA & ribosomale RNA \\
\hline RT & Raumtemperatur \\
\hline Rura3 & $\begin{array}{l}\text { Orotidin-5'-Phosphat-Decarboxylase, die aminoterminal ein } \\
\text { Arginin aufweist }\end{array}$ \\
\hline $35 \mathrm{~S}$ & 35S-Promotor des CaMV \\
\hline $\mathrm{S}$ & Sekunde(n) \\
\hline$S$. & Solanum \\
\hline SA & Salicylsäure \\
\hline SAI & SA-inhibitor \\
\hline sail, SAI1 & salicylic acid-insensitiv (= Salicylsäure-insensitiv) \\
\hline SAR & systemic acquired resistance ( $=$ systemisch erworbene Resistenz) \\
\hline SARP & salicylic acid response protein \\
\hline SD & synthetic drop out (Selektionsmedium für Hefe) \\
\hline SDS & Natriumdodecylsulfat \\
\hline SDS-DISKPAGE & diskontinuierliche SDS-Polyacrylamid-Gelelektrophorese \\
\hline SMART & „Switching Mechanism at 5'-End of RNA-Transcript” \\
\hline
\end{tabular}


snil, SNI1

SNN

s.o.

ssDNA

$\mathrm{T}$

Term

TEMED

TF

TMV

Tris

TRP

TRP1

TSR

Tx

U

u.a.

UBC

UBP

UE

ü.N.

ÜNK

UORF

URA3

USPS

UTR

u.U.

UV

V

Vol.

$\%(\mathrm{v} / \mathrm{v})$

WT

$\%(\mathrm{w} / \mathrm{v})$

$\mathrm{X}$-Gal

z.B.

ZIP

$\lambda$

$\mu$

$\Omega$ suppressor of npr1-1, inducible (= induzierbarer Suppressor der nprl-Mutante)

Tabakkultivar Samsun NN

siehe oben

Einzelstrang-DNA

Thymin

Terminator

$\mathrm{N}, \mathrm{N}, \mathrm{N}^{\prime}, \mathrm{N}^{\prime}$-Tetramethylethylendiamin

Transkriptionsfaktor

Tabakmosaikvirus

Tris(hydroxymethyl)aminomethan

Tryptophan

Phosphoribosylanthranilat-Isomerase aus $S$. cerevisiae

Template Suppression Reagent von Perkin-Elmer

Tetracyclin-induzierbarer Promotor

Unit (=Einheit) der Enzymaktivität

unter anderem

„Ubiquitin-conjugating enzyme“

Ubiquitin-spezifische Proteasen

Überexpression

über Nacht

Übernacht-Kultur

upstream open reading frame ( $=$ offenes Leseraster im $5{ }^{\prime}$-UTR)

Orotidin-5'-Phosphat-Decarboxylase aus $S$. cerevisiae

Ubiquitin-based split-protein sensor system

untranslated region (=nichttranslatierter Bereich der mRNA)

unter Umständen

Ultraviolettes Licht

Volt

Volumen

Volumenprozent

Wildtyp

Gewichtsprozent

5-Chlor-4-Brom-3-Indolyl- $\beta$-D-Galactopyranosid

zum Beispiel

Leucin-Zipper-Domäne

Bakteriophage Lambda

micro $\left(x 10^{-6}\right)$

$\mathrm{Ohm}$ 


\section{Aminosäuren:}

\begin{tabular}{ll}
\hline A & Alanin \\
C & Cystein \\
D & Asparaginsäure \\
E & Glutaminsäure \\
F & Phenylalanin \\
G & Glycin \\
H & Histidin \\
I & Isoleucin \\
K & Lysin \\
L & Leucin \\
M & Methionin \\
N & Asparagin \\
P & Prolin \\
Q & Glutamin \\
R & Arginin \\
S & Serin \\
T & Threonin \\
V & Valin \\
W & Tryptophan \\
Y & Tyrosin
\end{tabular}




\subsection{Sequenzen}

Im folgenden sind Sequenzen und Sequenzübergänge wichtiger verwendeter Nukleinsäuren mit relevanten Restriktionsschnittstellen aufgeführt.

\subsubsection{PADNX-NubI-Rec}

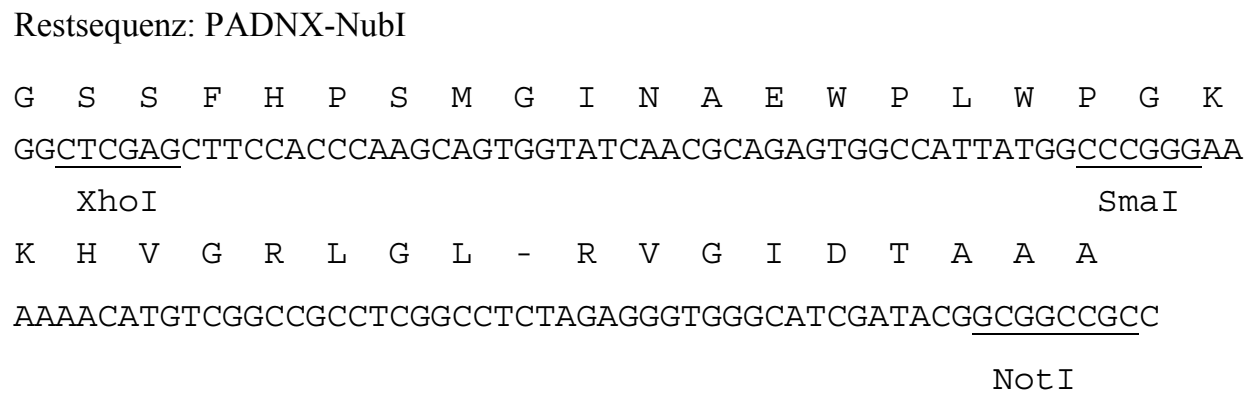

Der Vektor wurde für die in vivo-Klonierung der cDNA in Hefe über die SmaI-Schnittstelle linearisiert.

\subsection{2 pDONRTGA2.1}

Restsequenz: $\mathrm{pDONR}^{\mathrm{TM}} 207$

Zwischen Nukleotid 111 und 2351 wurde folgendes DNA-Stück von TGA2.1 inseriert:

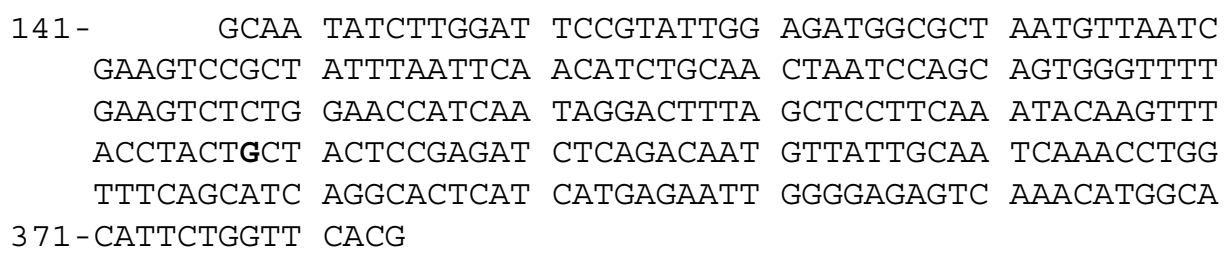

„fett“ gedruckt ist eine Punktmutation in der Nukleotidsequenz. In der ursprünglichen Sequenz befindet sich ein Adenin anstelle des Guanins.

\subsection{3 pFGC2.1}

Restsequenz: pFGC5941 gateway RNAi

Zwischen die attR-Sequenzen wurde folgendes DNA-Stück von TGA2.1 inseriert:

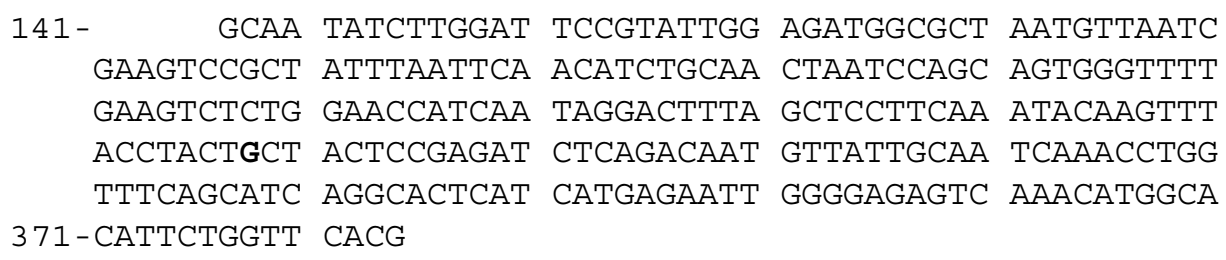

„fett" gedruckt ist eine Punktmutation in der Nukleotidsequenz. In der ursprünglichen Sequenz befindet sich ein Adenin anstelle des Guanins. 


\subsection{4 pGAD117 und pGBT117}

Restsequenz: pGAD424 oder pGBT9

E $\quad F \quad G \quad K$

--Gal4-AD oder -BD--//GAATTCGGGAAG//--117--//TCTTGTCGACCTGC

\subsection{5 pGAD175 und pGBT175}

Restsequenz: pGAD424 oder pGBT9

E $\quad F \quad E \quad D$

--Gal4-AD oder -BD--//GAATTCGAAGAT//--175--//CAAAGTCGACCTGC

ECORI

SalI

\subsection{6 pGAD184 und pGBT184}

Restsequenz: pGAD424 oder pGBT9

$\begin{array}{llllllllllllllll}E & \mathrm{~F} & \mathrm{H} & \mathrm{P} & \mathrm{S} & \mathrm{M} & \mathrm{G} & \mathrm{I} & \mathrm{N} & \mathrm{A} & \mathrm{E} & \mathrm{W} & \mathrm{P} & \mathrm{L} & \mathrm{W}\end{array}$

--Gal4-AD oder -BD--//GAATTCCACCCAAGCAGTGGTATCAACGCAGAGTGGCCATTATGG ECORI

$\begin{array}{lll}P & \mathrm{G} & \mathrm{R}\end{array}$

CCGGGCCGT / / - - 184 - - / / AAAGGGAAAAAACATGTCGGCCGCCTCGGCCTCTAGAGGGTGGGCATC GATACGGGATTCATCGAGCTCGAGCTG

XbaI

BamHI XhoI

\subsection{7 pGADT7-Rec/184}

Restsequenz: pGADT7-Rec

--Gal4-AD oder -BD--//GAATTCCACCCAAGCAGTGGTATCAACGCAGAGTGGCCATTATGG ECORI

$\begin{array}{lll}P & \mathrm{G}\end{array}$

CCGGGCCGT / / - - 184 - - / / AAAGGGAAAAAACATGTCGGCCGCCTCGGCCTCTAGAGGGTGGGCATC GATACGGGATTCATCGAGCTCGAGCTG

XbaI

$$
\text { BamHI } \frac{\text { XhoI }}{\text { Bat }}
$$




\subsection{8 pGEM/GH3}

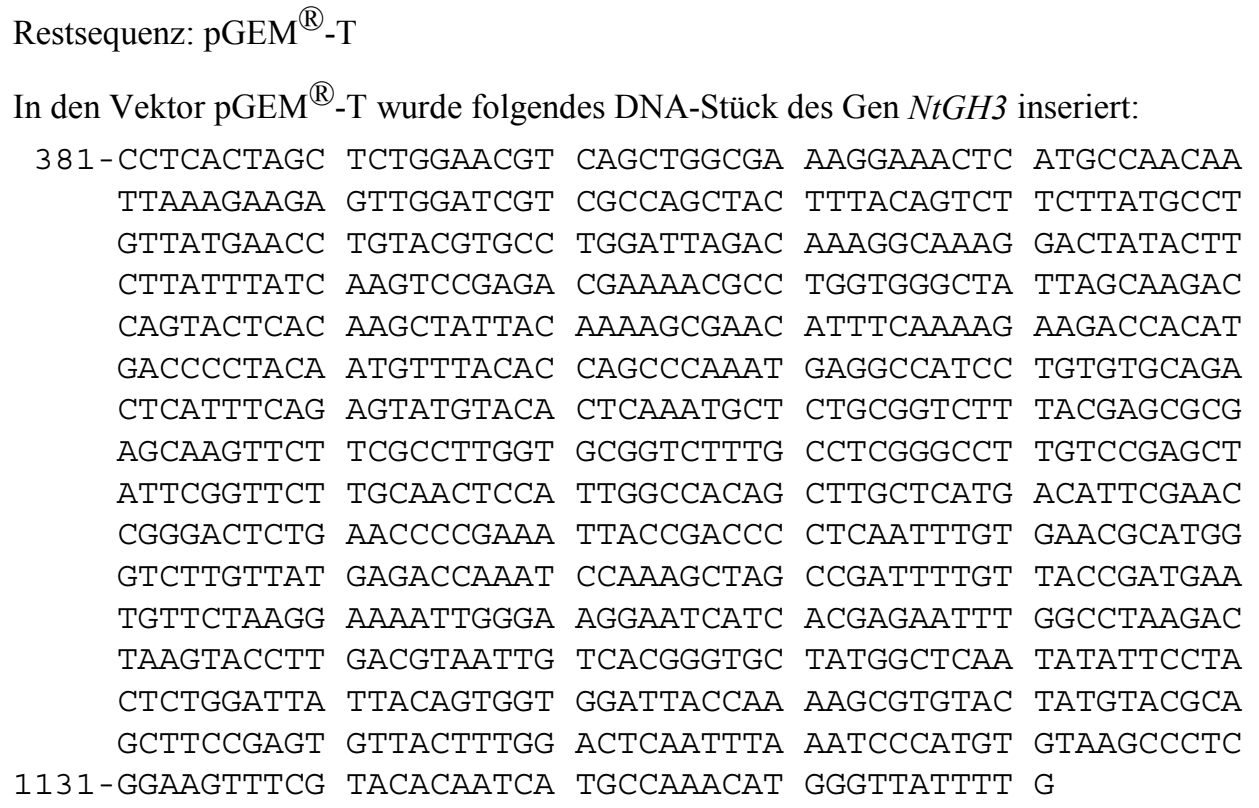

Angegeben ist nur der kodierende Teil der Nukleotidsequenz (790 bp). Da die PCR zur Isolierung von $N t G H 3$ auf genomischer DNA gemacht wurde, sind zusätzlich noch „Introns“ vorhanden. Somit ist das PCR-Produkt $\sim 1000$ bp groß.

\subsection{9 pMSK1}

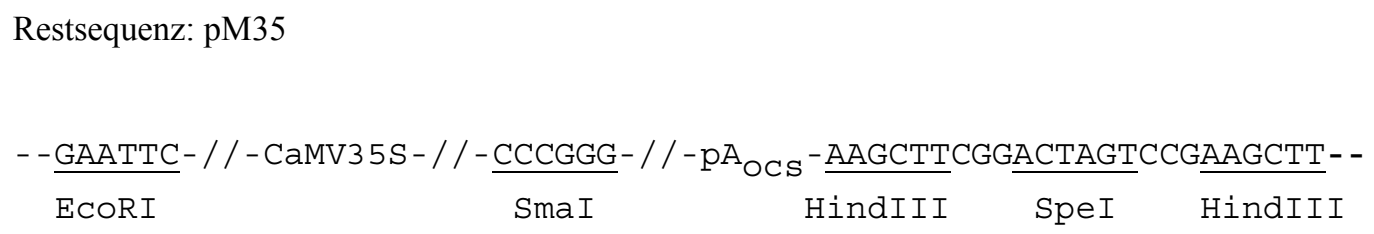

\subsubsection{0 pMSK2}

Restsequenz: pMSK1
- - $\frac{\text { GAATTCCGGACTAGTCCGGAATTC- }}{\text { ECORI }} \frac{\text { SpeI / - CaMV35S- }}{\text { ECORI }}$
AAGCTTCGGACTAGTCCGAAGCTT-- 


\subsubsection{1 pMSK3}

Restsequenz: pMSK1

- - CaMV3 5S- - // - - CCCGGG-tga2 . 1 (sense) - CCCGGG- - // - -pA ocs ${ }^{-}$-AAGCTTCGG SmaI SmaI

ACTAGTCCGAAGCTT - -

SpeI

\subsubsection{2 pMSK4}

Restsequenz: pMSK2

-GAATTCCGGACTAGTCCGGAATTC- / / - - CaMV35S- - / / - CCCGGG-tga2 . 1 (antisense) SpeI SmaI

- CCCGGG - - // - -pAOCs ${ }^{-}$-AAGCTTCGGACTAGTCCGAAGCTT- -

SmaI SpeI

\subsubsection{3 pMSK5}

Restsequenz: pMSK3

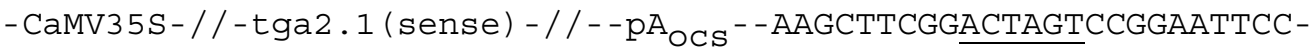

SpeI

// - CaMv35S-//-tga2. 1 (antisense) - //-pAoCs-AGCTTGGACTAGTCCGAAGCTT-

SpeI

\subsubsection{4 pSK7}

Restsequenz: PADNX-NubI

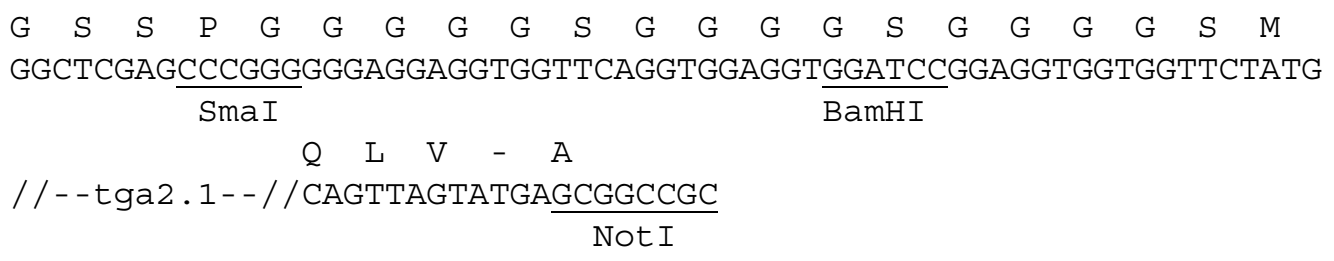




\subsubsection{5 pSKL6}

Restsequenz: Pcup1-Cub-Rura314

$\mathrm{M}$

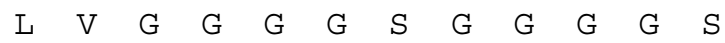

GAATTCAAAAAAAATG / / - - tga2 . 1 - - / / TTAGTAGGAGGAGGTGGTTCAGGTGGAGGTGGATCC ECORI

BamHI

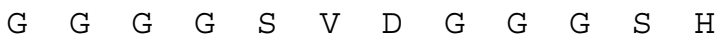

GGAGGTGGTGGTTCAGTCGACGGTGGTGGGTCGACC- - / / - - Cub-Rura3

SalI SalI 


\section{Danksagung}

Am Ende dieser Arbeit möchte ich mich bei denjenigen bedanken, die mich während meiner Promotionszeit unterstützt haben.

Frau Prof. Dr. C. Gatz danke ich dafür, dass ich in ihrer Arbeitsgruppe meine Dissertation anfertigen durfte. Sie hat mir die Möglichkeit gegeben, im Bereich Forschung und Lehre sehr viel zu lernen. Besonders bedanken möchte ich mich für die konstruktive Zusammenarbeit beim Schreiben dieser Arbeit.

Herrn PD Dr. Giselbert Hinz danke ich für die freundliche Übernahme des Korreferats. Ich danke allen jetzigen und ehemaligen Mitarbeitern der Arbeitsgruppe für ihre Hilfsbereitschaft, Unterstützung und die tolle Arbeitsatmosphäre. Besonders bedanken möchte ich mich bei Corinna, Wolfram und Ronny für die gemeinsamen Laborjahre, die durch eine ausgezeichnete Zusammenarbeit, Verlässlichkeit, Hilfs- und Diskussionsbereitschaft sowie jede Menge Spaß geprägt waren :-). Meinem Praktikanten Benjamin danke ich für die selbstlose Hilfe bei der Charakterisierung der Hefeklone. Ein großes Dankeschön an Thorsten für die langjährige Unterstützung.

Mein Dank geht auch an die Gärtner Uwe Wedemeyer und Felicitas Glasenapp für die sorgsame Pflege meiner Pflanzen.

Zum Schluss möchte ich meinen Eltern, meiner Familie und meinen Freunden ein riesengroßes Dankeschön für die liebevolle Unterstützung während meiner Promotionszeit aussprechen. Sie haben stets für Ausgleich zum „harten“ Laboralltag gesorgt. Ein liebesvolles Dankeschön geht an meinen Freund Thomas, der mich während der letzten $1 \frac{1}{2}$ Jahre in allen Belangen meines Lebens begleitet und unterstützt hat, wodurch mein Leben unendlich bereichert worden ist. 


\section{Lebenslauf}

Persönliche Angaben

Hochschulausbildung

$11 / 99-11 / 2003$

$02 / 00-01 / 02$

$10 / 94-09 / 99$
Stefanie Krawczyk

Diplom-Biologin

geboren m 12.10.1973 in Bielefeld

deutsche Staatsangehörigkeit

Anfertigung der vorliegenden Dissertation am Lehrstuhl für ,Allgemeine und Entwicklungsphysiologie der Pflanze“ des Albrecht-von-Haller-Instituts für Pflanzenwissenschaften der Georg-August-Universität Göttingen bei Prof. Dr. C. Gatz

Stipendium der Stiftung Stipendien-Fonds des Verbandes der Chemischen Industrie

Studium der Biologie an der Universität Bielefeld und an der Georg-August-Universität Göttingen

Diplomarbeit in der Abteilung „Allgemeine und Entwicklungsphysiologie der Pflanze" des Albrecht-vonHaller-Instituts für Pflanzenwissenschaften der GeorgAugust-Universität Göttingen bei Prof. Dr. C. Gatz

„Charakterisierung der DNA-Bindungseigenschaften des pflanzlichen bZIP-Transkriptionsfaktors TGA2.1 aus Nicotiana tabacum"

Abschluss: Diplom (Note 1,0 „mit Auszeichnung“)

Schule

$08 / 84-05 / 94$

Städt. Gymnasium im Schulzentrum Aspe Abschluss: Allgemeine Hochschulreife (Note 1,9) 